\title{
Formation of 2-halomethylene-4-cyclopentene-1,3-diones and/or 2-halo-1,4-benzoquinones, total synthesis of methyl linderone and Wacker-type oxidation of aryl-substituted alkenes
}

Hong Yin

West Virginia University

Follow this and additional works at: https://researchrepository.wvu.edu/etd

\section{Recommended Citation}

Yin, Hong, "Formation of 2-halomethylene-4-cyclopentene-1,3-diones and/or 2-halo-1,4-benzoquinones, total synthesis of methyl linderone and Wacker-type oxidation of aryl-substituted alkenes" (2014).

Graduate Theses, Dissertations, and Problem Reports. 389.

https://researchrepository.wvu.edu/etd/389

This Dissertation is protected by copyright and/or related rights. It has been brought to you by the The Research Repository @ WVU with permission from the rights-holder(s). You are free to use this Dissertation in any way that is permitted by the copyright and related rights legislation that applies to your use. For other uses you must obtain permission from the rights-holder(s) directly, unless additional rights are indicated by a Creative Commons license in the record and/ or on the work itself. This Dissertation has been accepted for inclusion in WVU Graduate Theses, Dissertations, and Problem Reports collection by an authorized administrator of The Research Repository @ WVU.

For more information, please contact researchrepository@mail.wvu.edu. 


\title{
Formation of 2-halomethylene-4-cyclopentene-1,3-diones and/or 2-halo-1,4-benzoquinones, total synthesis of methyl linderone and Wacker-type oxidation of aryl-substituted alkenes
}

\author{
Hong Yin \\ Dissertation submitted \\ to the Eberly College of Arts and Sciences \\ at West Virginia University \\ in partial fulfillment of the requirement for the degree of \\ Doctor of Philosophy in \\ Chemistry
}

Björn C. G. Söderberg, Ph. D., Chair

Kung K. Wang, Ph. D.

Alan M. Stolzenberg, Ph. D.

John H. Penn, Ph. D.

Patrick S. Callery, Ph. D.

C. Eugene Bennett Department of Chemistry

Morgantown, West Virginia

2014

Keywords: alkynylcyclobutenones, rearrangement, 2-alkylidene-1,3-cyclopentendiones, $N$-halosuccinimide, methyl linderone, aryl-substituted alkene, Wacker oxidation, $\alpha$-arylated ketone

Copyright 2014 Hong Yin 


\begin{abstract}
Formation of 2-halomethylene-4-cyclopentene-1,3-diones and/or 2-halo-1,4-benzoquinones, total synthesis of methyl linderone and Wacker-type oxidation of aryl-substituted alkenes

\section{Hong Yin}

We have discovered a practical general method for the preparation of diverse 2-halomethylene-4-cyclopentene-1,3-diones and/or 2-halo-1,4-benzoquinones. An in-depth study of the reactions of 4-(ethynyl)-4-hydroxy-2,3-substituted-2-cyclobuten-1-ones with $\mathrm{N}$-bromo- or $\mathrm{N}$-iodosuccinimide is described. This reaction was used in a short total synthesis of methyl linderone. Also, a series of facile, palladium catalyzed, direct, and regiospecific Wacker-type oxidations has been developed to yield various $\alpha$-arylated ketones from aryl-substituted internal alkenes. 


\section{Acknowledgments}

This work is dedicated to my parents, Lingxiang Yin and Yuying Hong. I am glad that they are here today to witness my accomplishments.

I would like to thank my advisor, Dr. Björn C. G. Söderberg, for his constant advising, patience, and encouragement during my graduate studies. I would also like to thank all faculty members in the C. Eugene Bennett Department of Chemistry for their assistance over the years, especially my doctoral defense committee members.

Finally, thanks to all my research group members, past and present, for all of their help and friendship. 


\section{Table of Contents}

Title Page $\quad$ i

Abstract $\quad$ ii

Acknowledgment $\quad$ iii

Table of Contents $\quad$ iv

Appendix vii

List of Figures $\quad$ viii

List of Schemes $\quad$ xvi

List of Tables $\quad$ xix

\section{Chapter 1}

\section{Formation of 2-halomethylene-4-cyclopentene-1,3-diones and/or}

2-halo-1,4-benzoquinones via ring-expansion of

\section{4-ethynyl-4-hydroxy-2,3-substituted-2-cyclobuten-1-ones}

1.1 Rearrangement of 4-alkynylcyclobutenones 2

1.1.1 Thermally induced ring expansions of 4-alkynylcyclobutenones 3

1.1.2 Electrophilic reagents induced ring expansions of 4-alkynylcyclobutenones 15

1.2 Ring expansion of 4-alkynyl-4-hydroxycyclo-2-buten-1-ones in the presence of an

$\begin{array}{ll}N \text {-halosuccinimide } & 20\end{array}$

1.3 Results and discussion 23

1.4 Conclusions 31 


\section{Chapter 2}

\section{Total synthesis of methyl linderone}

2.1 Introduction to linderone and methyl linderone

2.2 Previous synthesis of linderone and methyl linderone

2.3 Methyl linderone via ring expansion of 4-ene-yne-substituted cyclo-2-buten-1-

one and $\mathrm{N}$-iodosuccinimide

2.3.1 Retrosynthetic analysis

2.3.2 Results and discussion

2.3.3 Conclusions

\section{Chapter 3}

\section{Synthesis of $\alpha$-arylated ketone via Wacker-type oxidation of aryl-substituted alkenes}

$3.1 \alpha$-Arylated ketone background

3.2 Wacker-type oxidation

3.3 Wacker-type oxidation of aryl-substituted alkenes

3.4 Results and discussion 


\section{Chapter 4}

\section{Supporting information: experimental procedures}

4.1 Supporting information Chapter 1: Ring-expansion of 4-ethynyl-4-hydroxy-2,3-

substituted-2-cyclobuten-1-ones

4.2 Supporting information Chapter 2: Total synthesis of methyl linderone

4.3 Supporting information Chapter 3: Wacker-type oxidation of aryl-substituted alkenes 107 


\section{Appendix}

\section{${ }^{1} \mathrm{H}$ and ${ }^{13} \mathrm{C}$ NMR Spectra}

- ${ }^{1} \mathrm{H}$ and ${ }^{13} \mathrm{C}$ NMR for Chapter 1: Ring-expansion of 4-ethynyl-4-hydroxy-2,3-

substituted-2-cyclobuten-1-ones

- $\quad{ }^{1} \mathrm{H}$ and ${ }^{13} \mathrm{C}$ NMR for Chapter 2: Total synthesis of methyl linderone

- $\quad{ }^{1} \mathrm{H}$ and ${ }^{13} \mathrm{C}$ NMR for Chapter 3: Wacker-type oxidation of aryl-substituted alkenes

208 


\section{List of Figures}

Figure1: Structures of arnebifuranone, isoarnebifuranone, nanaomycin D, and deoxyfrenolicin

Figure 2: Structures of $( \pm)$-terreic acid and $( \pm)$-isoperezone

Figure 3: Eicosanoid core and naturally occurring eicosanoids

Figure 4: Postulated reaction path for palladium catalyzed ring expansion reaction

Figure 5: Hydrolysis products $\mathbf{8 5}$ and $\mathbf{8 6}$

Figure 6: Structures of linderone, methyl linderone, lucidone, methyl lucidone isolated from Lindera species

Figure 7: Structures of Stigmahamones I-II

Figure 8: Structure of kanakugiol

Figure 9: Structure of calythrone

Figure 10: Structures of coumestan, phenylbenzofurans, and isoflavones

Figure 11: Chemical structures of various palladium-complex catalysts

Figure 12: Typical apparatus for Wacker-type oxidation

Figure 13: Palladium complex accounts for the deactivation

Figure 14: Structures of substrates 238, 240, 241, and 242

Figure 15: Wacker-type oxidation of 1-aryl-1-propene

Figure 17: ${ }^{1} \mathrm{H}$ NMR of 2,3-bis(1-methylethoxy)-5-trimethylsilyl-2,5-cyclohexadiene- 
Figure 18: ${ }^{13} \mathrm{C}$ NMR of 2,3-bis(1-methylethoxy)-5-trimethylsilyl-2,5-cyclohexadiene1,4-dione (70)

Figure 19: ${ }^{1} \mathrm{H}$ NMR of 2-(1-iodo-1-trimethylsilylmethylene)-4,5-bis(1-methylethoxy)-

4-cyclopentene-1,3-dione (71)

Figure 20: ${ }^{13} \mathrm{C}$ NMR of 2-(1-iodo-1-trimethylsilylmethylene)-4,5-bis(1-methylethoxy)-

4-cyclopentene-1,3-dione (71)

Figure 21: ${ }^{1} \mathrm{H}$ NMR of 2-(1-bromo-1-trimethylsilylmethylene)-4,5-bis(1-methylethoxy)-

4-cyclopentene-1,3-dione (72)

Figure $22:{ }^{13} \mathrm{C}$ NMR of 2-(1-bromo-1-trimethylsilylmethylene)-4,5-bis(1-methylethoxy)-

4-cyclopentene-1,3-dione (72)

Figure 23: ${ }^{1} \mathrm{H}$ NMR of 2,3-bis(1-methylethoxy)-2,5-cyclohexadiene-1,4-dione (74)

Figure $24:{ }^{13} \mathrm{C}$ NMR of 2,3-bis(1-methylethoxy)-2,5-cyclohexadiene-1,4-dione (74)

Figure 25: ${ }^{1} \mathrm{H}$ NMR of 2-(iodomethylene)-4,5-bis(1-methylethoxy)-4-cyclopentene-

1,3-dione (75)

Figure 26: ${ }^{13} \mathrm{C}$ NMR of 2-(iodomethylene)-4,5-bis(1-methylethoxy)-4-cyclopentene-

1,3-dione (75)

Figure 27: ${ }^{1} \mathrm{H}$ NMR of 2-(bromomethylene)-4,5-bis(1-methylethoxy)-4-cyclopentene1,3-dione (76)

Figure $28:{ }^{13} \mathrm{C}$ NMR of 2-(bromomethylene)-4,5-bis(1-methylethoxy)-4-cyclopentene-

Figure 29: ${ }^{1} \mathrm{H}$ NMR of 5-chloro-2,3-bis(1-methylethoxy)-2,5-cyclohexadiene-1,4-dione 
Figure 30: ${ }^{13} \mathrm{C}$ NMR of 5-chloro-2,3-bis(1-methylethoxy)-2,5-cyclohexadiene-1,4-dione

Figure 31: ${ }^{1} \mathrm{H}$ NMR of 4-hydroxy-2,3-bis(1-methylethoxy)-4-(2-iodoethynyl)-2-

cyclobutene-1-one (78)

Figure $32:{ }^{13} \mathrm{C}$ NMR of 4-hydroxy-2,3-bis(1-methylethoxy)-4-(2-iodoethynyl)-2-

cyclobutene-1-one (78)

Figure 33: ${ }^{1} \mathrm{H}$ NMR of 5-iodo-2,3-bis(1-methylethoxy)-2,5-cyclohexadiene-1,4-dione

Figure 34: ${ }^{13} \mathrm{C}$ NMR of 5-iodo-2,3-bis(1-methylethoxy)-2,5-cyclohexadiene-1,4-dione

Figure 35: ${ }^{1} \mathrm{H}$ NMR of 2-(diiodomethylene)-4,5-bis(1-methylethoxy)-4-cyclopentene-

1,3-dione (80)

Figure $36:{ }^{13} \mathrm{C}$ NMR of 2-(diiodomethylene)-4,5-bis(1-methylethoxy)-4-cyclopentene-

Figure 37: ${ }^{1} \mathrm{H}$ NMR of 4-hydroxy-2,3-bis(1-methylethoxy)-4-(2-bromoethynyl)-2-

cyclobutene-1-one $(\mathbf{8 1})$

Figure 38: ${ }^{13} \mathrm{C}$ NMR of 4-hydroxy-2,3-bis(1-methylethoxy)-4-(2-bromoethynyl)-2-

cyclobutene-1-one (81)

Figure 39: ${ }^{1} \mathrm{H}$ NMR of 5-bromo-2,3-bis(1-methylethoxy)-2,5-cyclohexadiene-1,4-dione

Figure 40: ${ }^{13} \mathrm{C}$ NMR of 5-bromo-2,3-bis(1-methylethoxy)-2,5-cyclohexadiene-1,4-dione 
Figure 41: ${ }^{1} \mathrm{H}$ NMR of 2-(1-bromo-1-iodomethylene)-4,5-bis(1-methylethoxy)-4cyclopentene-1,3-dione $(\mathbf{8 3})$

Figure 42: ${ }^{13} \mathrm{C}$ NMR of 2-(1-bromo-1-iodomethylene)-4,5-bis(1-methylethoxy)-4cyclopentene-1,3-dione $(\mathbf{8 3})$

Figure 43: ${ }^{1} \mathrm{H}$ NMR of 2-(dibromomethylene)-4,5-bis(1-methylethoxy)-4-cyclopentene-

Figure 44: ${ }^{13} \mathrm{C}$ NMR of 2-(dibromomethylene)-4,5-bis(1-methylethoxy)-4-cyclopentene-

Figure 45: ${ }^{1} \mathrm{H}$ NMR of 4-hydroxy-2-methyl-3-(1-methylethoxy)-4-

(2-trimethylsilylethynyl)-2-cyclobutene-1-one (89)

Figure 46: ${ }^{13} \mathrm{C}$ NMR of 4-hydroxy-2-methyl-3-(1-methylethoxy)-4-

(2-trimethylsilylethynyl)-2-cyclobutene-1-one (89)

Figure 47: ${ }^{1} \mathrm{H}$ NMR of 2-trimethylsilylmethylene-4-(1-methylethoxy)-5-methyl-4cyclopentene-1,3-dione (90) and 5-trimethylsily-3-methyl-2-(1-methylethoxy)-2,5cyclohexadiene-1,4-dione (91)

Figure $48:{ }^{13} \mathrm{C}$ NMR of 2-trimethylsilylmethylene-4-(1-methylethoxy)-5-methyl-4cyclopentene-1,3-dione (90) and 5-trimethylsily-3-methyl-2-(1-methylethoxy)-2,5cyclohexadiene-1,4-dione (91)

Figure 49: ${ }^{1} \mathrm{H}$ NMR of 2-(1-iodo-1-trimethylsilylmethylene)-4-(1-methylethoxy)-

5-methyl-4-cyclopentene-1,3-dione (92)

Figure 50: ${ }^{13} \mathrm{C}$ NMR of 2-(1-iodo-1-trimethylsilylmethylene)-4-(1-methylethoxy)- 
Figure 51: ${ }^{1} \mathrm{H}$ NMR of 6-iodo-5-trimethylsilyl-3-methyl-2-(1-methylethoxy)-2,5cyclohexadiene-1,4-dione (93)

Figure 52: ${ }^{13} \mathrm{C}$ NMR of 6-iodo-5-trimethylsilyl-3-methyl-2-(1-methylethoxy)-2,5-

cyclohexadiene-1,4-dione (93)

Figure 53: ${ }^{1} \mathrm{H}$ NMR of 2-(1-bromo-1-trimethylsilylmethylene)-4-(1-methylethoxy)-5methyl-4-cyclopentene-1,3-dione (94)

Figure 54: ${ }^{13} \mathrm{C}$ NMR of 2-(1-bromo-1-trimethylsilylmethylene)-4-(1-methylethoxy)-5methyl-4-cyclopentene-1,3-dione (94)

Figure 55: ${ }^{1} \mathrm{H}$ NMR of 6-bromo-5-trimethylsily-3-methyl-2-(1-methylethoxy)-2,5cyclohexadiene-1,4-dione (95)

Figure 56: ${ }^{13} \mathrm{C}$ NMR of 6-bromo-5-trimethylsily-3-methyl-2-(1-methylethoxy)-2,5cyclohexadiene-1,4-dione (95)

Figure 57: ${ }^{1} \mathrm{H}$ NMR of 3-methyl-2-(1-methylethoxy)-2,5-cyclohexadiene-1,4-dione (97)

Figure 59: ${ }^{1} \mathrm{H}$ NMR of 2-(1-iodomethylene)-4-methyl-5-(1-methylethoxy)-4cyclopentene-1,3-dione (98)

Figure $60:{ }^{13} \mathrm{C}$ NMR of 2-(1-iodomethylene)-4-methyl-5-(1-methylethoxy)-4cyclopentene-1,3-dione (98)

Figure 61: ${ }^{1} \mathrm{H}$ NMR of 2-(1-bromomethylene)-4-(1-methylethoxy)-5-methyl-4cyclopentene-1,3-dione (99)

Figure $62:{ }^{13} \mathrm{C}$ NMR of 2-(1-bromomethylene)-4-(1-methylethoxy)-5-methyl-4cyclopentene-1,3-dione (99) 
Figure 63: ${ }^{1} \mathrm{H}$ NMR of 2-(diiodomethylene)-4-(1-methylethoxy)-5-methyl4-cyclopentene-1,3-dione (101)

Figure $64:{ }^{13} \mathrm{C}$ NMR of 2-(diiodomethylene)-4-(1-methylethoxy)-5-methyl-

4-cyclopentene-1,3-dione (101)

Figure 65: ${ }^{1} \mathrm{H}$ NMR of ethyl 2-(3,4-dimethoxy-2,5-dioxo-3-cyclopenten-1-ylene)-2iodoethanoate (104)

Figure $66:{ }^{13} \mathrm{C}$ NMR of ethyl 2-(3,4-dimethoxy-2,5-dioxo-3-cyclopenten-1-ylene)-2iodoethanoate (104)

Figure 67: ${ }^{1} \mathrm{H}$ NMR of ethyl 2-(3,4-dimethoxy-2,5-dioxo-3-cyclopenten-1-ylene)-2bromoethanoate (105)

Figure $68:{ }^{13} \mathrm{C}$ NMR of ethyl 2-(3,4-dimethoxy-2,5-dioxo-3-cyclopenten-1-ylene)-2bromoethanoate (105)

Figure 69: ${ }^{1} \mathrm{H}$ NMR of 2,3-dimethoxy-4-hydroxy-4-[(E)-4-phenyl-3-buten-1-yn-1-yl]-2cyclobuten-1-one (137)

Figure 70: ${ }^{13} \mathrm{C}$ NMR of 2,3-dimethoxy-4-hydroxy-4-[(E)-4-phenyl-3-buten-1-yn-1-yl]2-cyclobuten-1-one (137)

Figure 71: ${ }^{1} \mathrm{H}$ NMR of 4,5-dimethoxy-[(E)-2-(1-iodo-3-phenyl-2-propen-1-ylidene)]-4cyclopentene-1,3-dione (138)

Figure $72:{ }^{13} \mathrm{C}$ NMR of 4,5-dimethoxy-[(E)-2-(1-iodo-3-phenyl-2-propen-1-ylidene)]-4cyclopentene-1,3-dione (138)

Figure 73: ${ }^{1} \mathrm{H}$ NMR of 4,5-dimethoxy-2-[(E)-3-phenyl-2-propen-1-ylidene]-4- 
Figure 74: ${ }^{13} \mathrm{C}$ NMR of 4,5-dimethoxy-2-[(E)-3-phenyl-2-propen-1-ylidene]-4cyclopente-1,3-dione (139)

Figure 75: ${ }^{1} \mathrm{H}$ NMR of 4,5-dimethoxy-2-[(E)-1-(N,N-dimethylamino)-3-phenyl-2propen-1-ylidene]-4-cyclopente-1,3-dione (140)

Figure 76: ${ }^{1} \mathrm{H}$ NMR of 4-fluoro-2-nitro-1-(1-propen-1-yl)benzene (233)

Figure 77: ${ }^{13} \mathrm{C}$ NMR of 4-fluoro-2-nitro-1-(1-propen-1-yl)benzene (233)

Figure 78: ${ }^{1} \mathrm{H}$ NMR of 2,4-dinitro-1-(1-propen-1-yl)benzene (234)

Figure 79: ${ }^{1} \mathrm{H}$ NMR of 4-carbomethoxy-2-nitro-1-(1-propen-1-yl)benzene (235)

Figure 80: ${ }^{1} \mathrm{H}$ NMR of 4-methoxy-2-nitro-1-(1-propen-1-yl)benzene (236)

Figure 81: ${ }^{13} \mathrm{C}$ NMR of 4-methoxy-2-nitro-1-(1-propen-1-yl)benzene (236)

Figure 82: ${ }^{1} \mathrm{H}$ NMR of 5-methoxy-2-nitro-1-(1-propen-1-yl)-benzene (237)

Figure 83: ${ }^{1} \mathrm{H}$ NMR of 3-nitrobenzaldehyde (250) and 1-(3-nitrophenyl)-1,2-

propanedione (251)

Figure $84:{ }^{13} \mathrm{C}$ NMR of 3-nitrobenzaldehyde (250) and 1-(3-nitrophenyl)-1,2propanedione (251)

Figure 85: ${ }^{1} \mathrm{H}$ NMR of 1-(4-fluoro-2-nitrophenyl)-2-propanone (257)

Figure 86: ${ }^{13} \mathrm{C}$ NMR of 1-(4-fluoro-2-nitrophenyl)-2-propanone (257)

Figure 87: ${ }^{1} \mathrm{H}$ NMR of 4-fluoro-1-(1,1-dimethoxymethyl)-2-nitrobenzene (258)

Figure 88: ${ }^{13} \mathrm{C}$ NMR of 4-fluoro-1-(1,1-dimethoxymethyl)-2-nitrobenzene (258)

Figure 89: ${ }^{1} \mathrm{H}$ NMR of 4-fluoro-2-nitrobenzaldehyde (259) and 1-(4-fluoro-2-

nitrophenyl)-1,2-propanedione (260) 
Figure 90: ${ }^{13} \mathrm{C}$ NMR of 4-fluoro-2-nitrobenzaldehyde (259) and 1-(4-fluoro-2nitrophenyl)-1,2-propanedione (260)

Figure 91: ${ }^{1} \mathrm{H}$ NMR of 4-fluoro-1-(1,1-dimethoxymethyl)-2-nitrobenzene (263)

Figure 92: ${ }^{13} \mathrm{C}$ NMR of 4-fluoro-1-(1,1-dimethoxymethyl)-2-nitrobenzene (263)

Figure 93: ${ }^{1} \mathrm{H}$ NMR of 4-carbomethoxy-2-nitrobenzaldehyde (266) and 1-(4-carbomethoxy-2-nitrophenyl)-1,2-propanedione (267)

Figure 94: ${ }^{1} \mathrm{H}$ NMR of 1-(5-methoxy-2-nitrophenyl)-2-propanone (269)

Figure $95:{ }^{13} \mathrm{C}$ NMR of 1-(5-methoxy-2-nitrophenyl)-2-propanone (269)

Figure 96: ${ }^{1} \mathrm{H}$ NMR of 5-methoxy-2-nitro-benzaldehyde (270) and 1-(5-methoxy-2nitrophenyl)-1,2-propanedione (271)

Figure 97: ${ }^{13} \mathrm{C}$ NMR of 5-methoxy-2-nitro-benzaldehyde (270) and 1-(5-methoxy-2nitrophenyl)-1,2-propanedione (271)

Figure 98: ${ }^{1} \mathrm{H}$ NMR of 4-(2-nitrophenyl)-3-methoxy-2-methyl-1-butene (277)

Figure 99: ${ }^{13} \mathrm{C}$ NMR of 4-(2-nitrophenyl)-3-methoxy-2-methyl-1-butene (277)

Figure 100: ${ }^{1} \mathrm{H}$ NMR of 1-(2-bromophenyl)-1,2-propanedione (282)

Figure 101: ${ }^{13} \mathrm{C}$ NMR of 1-(2-bromophenyl)-1,2-propanedione (282) 


\section{List of Schemes}

Scheme 1: Rearrangement of 4-alkynylcyclobutenones

Scheme 2: Preparation of 4-alkynyl-4-hydroxycyclobutenones from squaric acid

Scheme 3: Thermally ring expansion to form substituted 1,4-benzoquinones

Scheme 4: Thermally ring expansion to form substituted 1,4-benzoquinones and

2-alkylidene-1,3-cyclopentenediones

Scheme 5: Plausible mechanisms for thermal ring expansion of 4-hydroxy-2-

cyclobuteneones

Scheme 6: Thermally ring expansion to form 2-alkylidene-1,3-cyclopentenediones

Scheme 7. Synthesis of isoarnebifuranone

Scheme 8. Synthesis of nanaomycin D

Scheme 9: Synthesis of deoxyfrenolicin

Scheme 10: Thermal ring expansion of 4-alkynyl-tert-butoxycyclobutenones

Scheme 11: Synthesis of the natural product, $( \pm)$-terreic acid

Scheme 12: Synthesis of the natural product, $( \pm)$-isoperezone

Scheme 13: Palladium(II) catalyzed ring expansion of 4-alkynyl-4-hydroxy-

cyclobutenones

Scheme 14: Palladium catalyzed ring expansion-coupling reaction

Scheme 15: Iodine mediated ring expansion of 4-alkynyl-4-hydroxycyclobutenones

Scheme 16: Conversion of iodomethylenecyclopentene-1,3-dione to

aminomethylenecyclopentene-1,3-dione 
Scheme 18: Synthesis of ring expansion substrates 89 and 96

Scheme 20: Thermal ring expansion of tert-butoxy analog

Scheme 21: Ring expansion of an electron deficient substrate

Scheme 22: Proposed mechanism for inhibition of human chymase by compound 112

Scheme 23: Lee's synthesis route of methyl linderone in 1967

Scheme 24: Lee's synthesis route of methyl linderone in 1986

Scheme 25: Aoyama's synthesis route of methyl linderone

Scheme 26: Langer's synthesis route of linderone

Scheme 27: Retrosynthetic analysis of methyl linderone

Scheme 28: Synthesis of methyl linderone

Scheme 29: Transition metal-catalyzed arylation reactions of ketone enolates

Scheme 30: Synthesis of 2,3-diarylbenzofurans by means of a palladium catalyst system

Scheme 31: Plausible reaction mechanism for the synthesis of 2,3-diarylbenzofurans

Scheme 32: Synthesis of the benzomorphan derivatives

Scheme 33: Asymmetric $\alpha$-arylation of 2-methyl- $\alpha$-tetralones

Scheme 34: Nickel-catalyzed enantioselective $\alpha$-arylation of cycloalkanones

Scheme 35: $\alpha$-Arylation of $N$-tosyl-2'-aminoacetophenone with $o$-dibromobenzene 
Scheme 37: Pd-catalyzed synthesis of 1,2,2-triarylethanones from acetophenones

Scheme 38: Pd-catalyzed synthesis of the acetonylpurine

Scheme 39: Pd-catalyzed synthesis of benzyl methyl ketone

Scheme 40: Individual reactions of the Wacker process

Scheme 41: Wacker process of terminal alkenes

Scheme 42: Overall catalytic cycle of the Wacker process

Scheme 43. Modified Wacker oxidation using $\mathrm{H}_{2} \mathrm{O}_{2}$ as the terminal oxidant

Scheme 44: Mimoun et al.'s mechanism for peroxide-mediated Wacker oxidation

Scheme 45: Formation of biogenetic intermediate 190 and 191

Scheme 46: Synthesis of (+)-dihydropinidine and (-)-epidihydropinidine

Scheme 47: Synthesis of (-)-pinidinone

Scheme 48: Synthesis of tetracycle $(+)-203$

Scheme 49: Synthesis towards key hexahydronaphthalene 206

Scheme 50: The synthesis of 1,2,5-trisubstituted pyrrole

Scheme 51: $\mathrm{C}_{3}$ Symmetric tripyrrolyl benzene synthesis

Scheme 52: Synthesis of 1,3-cyclooctanedione 219 from cyclooctanone 217

Scheme 53: TBHP-mediated Wacker-type oxidation

Scheme 54: TBHP-mediated Wacker-type oxidation to form $\beta$-hydroxy ketone

Scheme 55: TBHP-mediated Wacker-type oxidation to form methyl ketone

Scheme 56: Benzoquinone-reoxidant Wacker-type oxidation to acetophenone 


\section{List of Tables}

Table 1: Ring-expansion of $\mathbf{6 8}, \mathbf{7 3}, \mathbf{7 8}$, and $\mathbf{8 1}$ in the absence or presence of NXS

Table 2: Ring-expansion of $\mathbf{8 9}$ and $\mathbf{9 6}$ in the absence or presence of NIS or NBS

Table 3: Synthesis of 1-aryl-1-propenes

Table 4: Ratios of products for crude reaction mixtures from oxidation of

2-ethenyl-1-nitrobenzene

Table 5: Wacker-type oxidation of aryl-substituted alkenes 


\section{Chapter 1}

Formation of 2-halomethylene-4-cyclopentene-1,3-diones and/or 2halo-1,4-benzoquinones via ring-expansion of 4-ethynyl-4-hydroxy-

\section{2,3-substituted-2-cyclobuten-1-ones}

1.1 Rearrangement of 4-alkynylcyclobutenones

1.1.1 Thermally induced ring expansions of 4-alkynylcyclobutenones

1.1.2 Electrophilic reagents induced ring expansions of 4-alkynylcyclobutenones

1.2 Ring expansion of 4-alkynyl-4-hydroxycyclo-2-buten-1-ones in the presence of an

$N$-halosuccinimide

1.3 Results and discussion

1.4 Conclusions 


\subsection{Rearrangement of 4-alkynylcyclobutenones}

The rearrangement of 4-alkynylcyclobutenones $\mathbf{1}$ is an extremely useful method for the synthesis of substituted 1,4-benzoquinones $\mathbf{3}$ and 2-alkylidene-1,3-cyclopentenediones 2 (Scheme 1). ${ }^{1,2}$ Substituted 1,4-benzoquinones constitute members of compounds which are reasonable precursors to electrophilic alkylating agents ${ }^{3,4}$ while 2-alkylidene-4-cyclopentene1,3-diones are attractive building blocks for synthesis of cyclopentanoids. ${ }^{5-7}$

\section{Scheme 1: Rearrangement of 4-alkynylcyclobutenones}

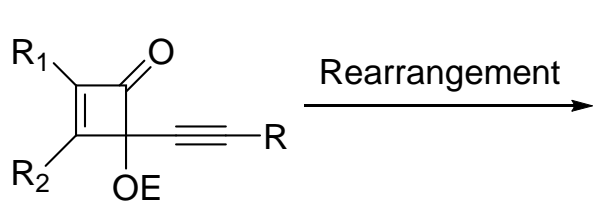

1<smiles>[R]C(F)=C1C(=O)C([R])=C([R2])C1=O</smiles>

2<smiles>[R]C1=C([R])C(=O)C(F)=C([R])C1=O</smiles>

3

E=proton, trimethysilyl, or allyl

Moore et al. provided a simple method for the transformation of 4alkynylcyclobutenones into benzoquinones and/or 2-alkylidene-4-cyclopentenediones, starting with cyclobutenediones $\mathbf{5}$, a class of compounds which are easily prepared in a variety of substitution patterns from commercially available squaric acid (4). ${ }^{8}$ Alkynyl anions add in high yield to cyclobutenediones $5^{9}$ to give 4-alkynyl-4-hydroxycyclobutenones 6 (Scheme 2), and the reaction occurs with good regioselectivity with a number of unsymmetrically substituted substrates. ${ }^{10,11}$

Scheme 2: Preparation of 4-alkynyl-4-hydroxycyclobutenones from squaric acid<smiles>Cc1ccccc1</smiles>

4

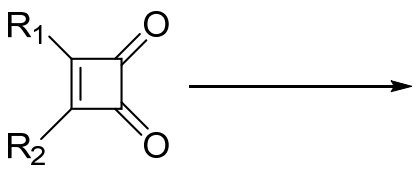

5<smiles>[R3]C#CC1(O)C(=O)C([R])=C1[R]</smiles>

6 


\subsubsection{Thermally induced ring expansions of 4-alkynylcyclobutenones}

In 1989, Moore and co-workers developed a limited thermal rearrangement route involving a (2-alkynylethenyl)ketene ${ }^{12}$ for the synthesis of benzoquinones and/or 2alkylidene-4-cyclopentenediones. The synthetic scope and specific examples illustrating the synthetic utility of this method are given in Schemes 3. The syntheses in Scheme 3 began with the conversion of dimethyl squarate (7) to the 4-alkynyl-2,3-dimethoxy-4-hydroxyl cyclobutenones 8 in 50-90\% yield using the corresponding lithium acetylides (THF, $-78{ }^{\circ} \mathrm{C}$ ) followed by quenching of the reaction mixture with ammonium chloride. Thermolyses of the realized cyclobutenones ( $p$-xylene, $138{ }^{\circ} \mathrm{C}$ ) provided the 1,4-benzoquinones 9 as the only isolable products.

\section{Scheme 3: Thermally ring expansion to form substituted 1,4-benzoquinones}

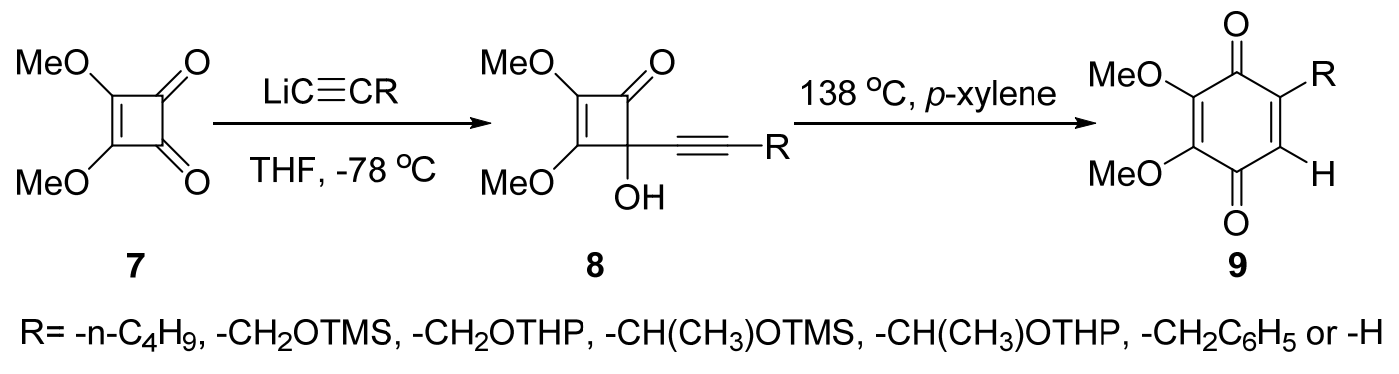

The thermal ring expansion of 4-alkynyl-2,3-dimethoxy-4-hydroxyl cyclobutenones 8 is an extremely useful method for the synthesis of benzoquinones, which have a variety of substitution patterns for further study. ${ }^{13,14}$ It is also important to note that this reaction is apparent an ideal and highly regioselective generality for the synthesis of trimethylsilylsubstituted 1,4-benzoquinones, which are particularly regarded as potential bioreductive alkylating agents or reasonable precursors to electrophilic quinone methides subsequent to an in vivo reduction.

Recognizing that only the corresponding benzoquinones were detected as products of 
the thermolyses of all of the above examples, in which the alkyne moiety is substituted with an alkyl group or a proton, Moore et al. decided to implement the same condition in cases when the substituent R of $\mathbf{1 0}$ (Scheme 4) is an alkoxy, phenyl, or trimethylsilyl group. Interestingly, a mixture of the benzoquinones 11 and 2-alkylidene-1,3-cyclopentenediones 12 resulted.

Scheme 4: Thermally ring expansion to form substituted 1,4-benzoquinones and 2alkylidene-1,3-cyclopentenediones<smiles>[R]C=C1C(=O)C(OC)=C(OC)C1=O</smiles>

$\mathrm{R}=-\mathrm{C}_{6} \mathrm{H}_{5},-\mathrm{OC}_{2} \mathrm{H}_{5}$, or $-\mathrm{TMS}$

In order to explain the observed results, Moore et al. proposed the mechanisms of thermal ring expansion of 4-hydroxy-2-cyclobutenones 13 as shown in Scheme 5, beginning with a remarkably selective electrocyclic ring opening upon mild thermolysis to form a1kynylethenyl)ketenes 14. Next, a ring closure of ketene $\mathbf{1 4}$ occurs to give the unique diradicals (or zwitterions) 15 and 17. Finally, an intramolecular transfer of the proton substituent from oxygen to carbon of diradicals gives products $\mathbf{1 6}$ and $\mathbf{1 8} .^{12}$

With knowledge that this rearrangement selectivity to give either benzoquinones or cyclopentenediones is significantly influenced by the R substituent of the alkyne moiety, an effort was made by Moore et al. to drive the rearrangement completely to the cyclopentenediones 20 when the cyclobutenones 19 are employed (Scheme 6). This came to fruition. 
Scheme 5: Plausible mechanisms for thermal ring expansion of 4-hydroxy-2-

cyclobuteneones<smiles>[R]C#CC1(O)C(=O)C([R20])=C1[R2]</smiles>

13

$\triangle$<smiles>[R]C#Cc1c(O)c([R20])c([R])c2c1OC2</smiles>

14<smiles>[R]C#CC(O)=C([R2])C([R])=C1CC1</smiles>

14<smiles>[R]Oc1c(O)cc([R])c([O])c1[O]</smiles>

15<smiles>[R]OC1=C([R20])C(=O)C=C([R])C1=O</smiles>

16<smiles>[R]C=C1C(=O)C([R20])=C([R])C1=O</smiles>

Scheme 6: Thermally ring expansion to form 2-alkylidene-1,3-cyclopentenediones<smiles>[R]C=C1C(=O)C(OC)=C(OC)C1=O</smiles>

19

$\mathrm{R}=-\mathrm{CO}_{2} \mathrm{C}_{2} \mathrm{H}_{5}$, or $-\mathrm{CH}=\mathrm{CHOCH}_{3}$

Stabilization of the carbon centered radical in $\mathbf{1 7}$ by the adjacent $\mathrm{R}$ group has been used as an argument for the formation of 2-alkylidene-4-cyclopentene-1,3-diones. ${ }^{12}$ The intermediate $\mathbf{1 7}$ becomes favored over $\mathbf{1 5}$ when the substituent $\mathrm{R}$ becomes more and more capable of stabilizing an adjacent radical site (Scheme 5). In contrast, the presumed aromatic stabilization associated with six-membered ring formation $\mathbf{1 5}$ is overcome by direct stabilization of one of the radical centers by the adjacent $\mathrm{R}$ substituent when five-membered ring formation $\mathbf{1 7}$ takes place. 
In general, alkynes having an ester or a carbon-carbon double bond in conjugation give only 2-alkylidene-4-cyclopentene-1,3-diones while terminal alkynes, alkyl, and trimethylsilyl substituted alkynes produce predominantly or only 1,4-benzoquinones. Mixtures of both products are usually encountered from substrates having an aryl or an alkoxy group attached to the alkyne.

Later, in the same year, Moore et al. ${ }^{15}$ utilized their methodology described in the preceding paper, the rearrangement of 4-alkynylcyclobutenones to 1,4-benzoquinones, in the preparation of selected naturally occurring products arnebifuranone (21), isoarnebifuranone (22), nanaomycin D (23), and deoxyfrenolicin (24) to further illustrate its wide utility and synthetic scope.

Figure1: Structures of arnebifuranone, isoarnebifuranone, nanaomycin $D$, and deoxyfrenolicin<smiles>COC1=C(OC)C(=O)C(C/C(C)=C/CCc2ccoc2)=CC1=O</smiles>

21<smiles>CC1OC2CC(=O)OC2C2=C1C(=O)c1cccc(O)c1C2=O</smiles><smiles>COC1=C(OC)C(=O)C(C/C(C)=C/CCc2ccoc2)=CC1=O</smiles>

22<smiles>[R4]C1C(=O)c2c(O)cccc2C(=O)C2=C1C(CCC)OC1CC(=O)OC21</smiles>

Arnebifuranone (21) is a naturally occurring 2,3-dimethoxy-l,4-benzoquinone ${ }^{16,17}$ which possesses $Z$ stereochemistry at the stereogenic alkene site. ${ }^{18}$ Arnebifuranone, along with des-O-methyllasiodiplodin, shikonofuran, arnebinol, and arnebinone have been isolated 
from the roots of Arnebia euchroma (Royle) Johnst., which has been used as a pain killer in the Chinese culture. ${ }^{19}$ These compounds are of high interest because of their various pharmacological assay systems and they are able to function as inhibitors of prostaglandin biosynthesis. ${ }^{20,21}$ The attempted synthesis of arnebifuranone (21), was outlined in Scheme 7.

The synthesis of 22 initiated from 3-(2-bromoethyl)furan (25), which was converted to the corresponding Grignard reagent using magnesium in ether, and was further transformed into 26 in 75\% yield upon the treatment with 2-methylpropenal. When $\mathrm{SOCl}_{2}$ was added in hexane to 26, the allylic chloride 27 was obtained in $65 \%$ isolated yield and excellent regioselectivity. 27 was the major isomer of a 7:1 mixture of regioisomers. Exposure of 27 to the Grignard reagent obtained from (trimethylsi1yl)ethyne under copper-catalyzed conditions and subsequently deprotection provided the previously unknown alkyne $\mathbf{2 8}$ in $\mathbf{7 6 \%}$ yield as a colorless liquid. Alkyne $\mathbf{2 8}$ was then underwent deprotonation using butyl lithium and was reacted with dimethyl squarate (7) in THF at $-78{ }^{\circ} \mathrm{C}$ to give the adduct $\mathbf{2 9}$ as a colorless oil. Finally, the developed methodology was applied as a key step in the construction of arnebifuranone (21). ${ }^{1,10}$ However, thermolysis of 29 in refluxing $p$-xylene $\left(138^{\circ} \mathrm{C}\right)$ for $2 \mathrm{~h}$ only gave isoarnebifuranone (22) as an orange oil in 86\% isolated yield. Isoarnebifuranone is actually stereoisomeric with the natural product arnebifuranone (21) and is another benzoquinone with the thermodynamically more stable $E$ configuration, which is consistent with the fact that the naturally occurring quinone is quite unstable. 


\section{Scheme 7: Synthesis of isoarnebifuranone}

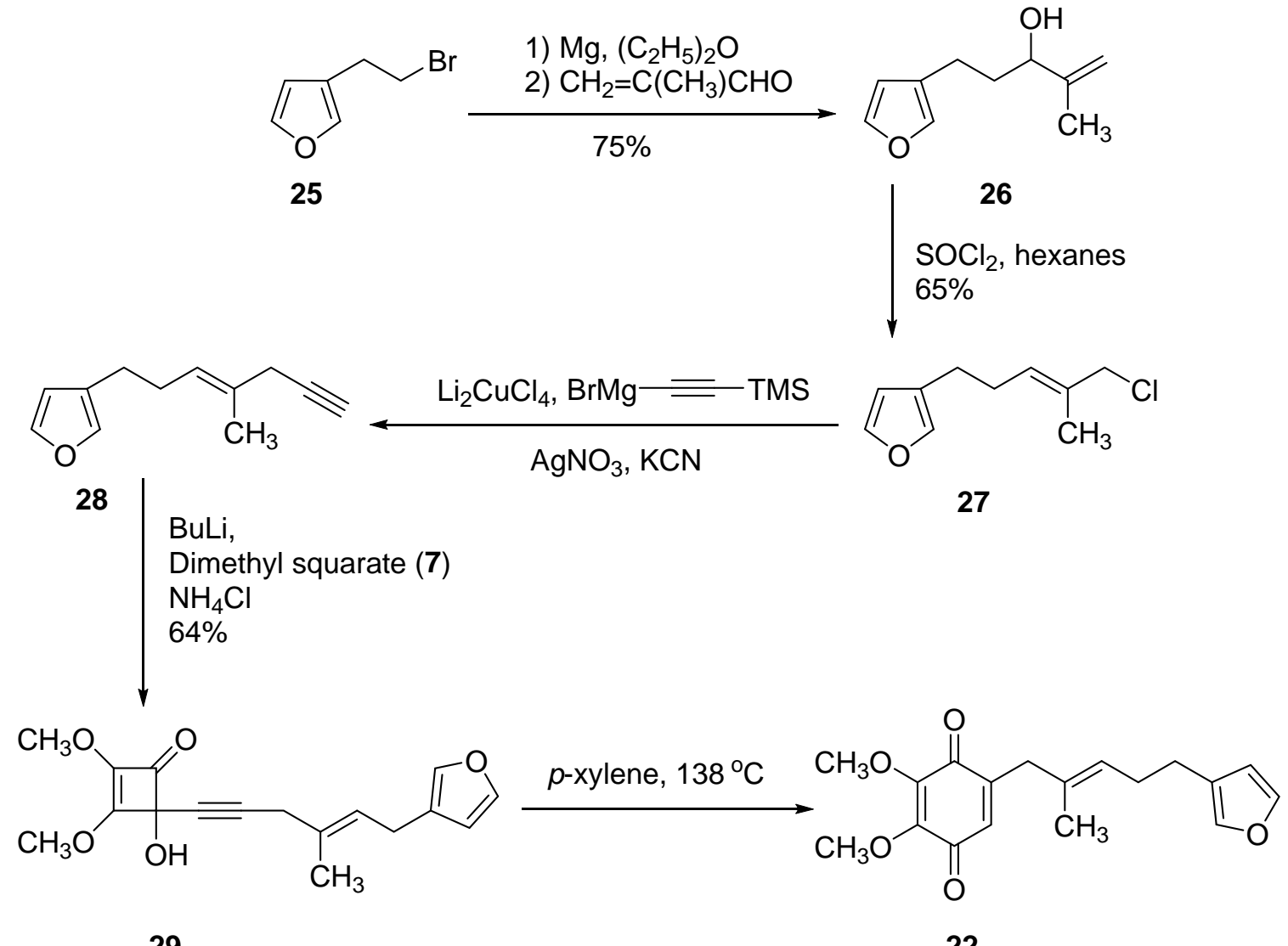

Another reported example that further illustrates the synthetic utility of the quinonecyclobutenone rearrangement is the regiospecific syntheses of the naphthoquinones $\mathbf{3 4}$ and 36, which are key synthetic precursors to the biologically important quinones nanaomycin D (23) and deoxyfrenolicin (24).

Nanaomycin D (23) and deoxyfrenolicin (24) are members of an important family of naturally occurring isochroman-1,4-naphthoquinones (approximately 45) which are of great importance due to the significant biological activity that they have elicited in antibiotics, antimycotics and antineoplastic assays. ${ }^{22-24}$ The definite and concrete biological action mechanism of these compounds remains elusive. The proposed mode of their biological action involves bioreductive alkylation due to their structural features, which was regarded 
necessary to allow them to be employed as precursors to electrophilic quinone methides subsequent to an in vivo reduction. . $^{3,4}$

Starting from 30, treatment with the lithium salt of 3-(tetrahydropyrany1oxy) propyne (2:1 mixture of diastereomers) at $-78{ }^{\circ} \mathrm{C}$ in THF gave 31 and its regioisomer in a respective ratio of 3:1 as a yellow oil in 58\% yield (Scheme 8). Moreover, each regioisomer was obtained as a 2:1 mixture of diastereomers. Further experimentation with $\mathbf{3 0}$ and other lithium acetylides revealed that the reaction regioselectivities could be improved to approximately 95:5 at $-100{ }^{\circ} \mathrm{C}$ in a mixed solvent of THF/diethyl ether (l:l) while yields might be lowered as a result. ${ }^{25}$ Reaction of $\mathbf{3 1}$ with an excess of allyl iodide followed by the addition of $\mathrm{Ag}_{2} \mathrm{CO}_{3}$ in dioxane gave the allyl ether 32 in $>95 \%$ yield as a yellow oil. ${ }^{19}$ Allyl ether 32 was then converted to naphthoquinone 33 as a yellow oil in $71 \%$ yield upon thermolysis in refluxing $p$ xylene $\left(138{ }^{\circ} \mathrm{C}\right)$. The reaction proceeded by removal of THP protecting group using 4:2:1 $\mathrm{CH}_{3} \mathrm{COOH} / \mathrm{THF} / \mathrm{H}_{2} \mathrm{O}$, resulted in the synthetic precursor naphthoquinone 34 in $73 \%$ yield. Finally, nanaomycin D (23) was prepared from 34 according to the published methods. ${ }^{27}$

The last example to demonstrate the synthetic utility of the quinone-cyclobutenone rearrangement is the synthesis of $\mathbf{3 6}$, the precursor of deoxyfrenolicin, which was accomplished by performing a procedure analogous to that described above (Scheme 9). That is, once the major regioisomer product of the alkynylation of $\mathbf{3 0}$ with the lithium salt of 3(tetrahydropyrany10xy)hexyne in hand, which is actually a mixture of two diastereomeric benzocyclobutenones with only $2 \%$ of the corresponding regioisomers. The major product was conveniently purified by flash chromatography and the allylation of the major product was carried out to give 35, which was further converted to synthetic precursor 
naphthoquinone 36 by the method reported above. Finally, deoxyfrenolicin (24) was prepared from 36 according to the published methods. ${ }^{27}$

Scheme 8: Synthesis of nanaomycin D<smiles>COc1cccc2c(=O)c(=O)c12</smiles>

30<smiles>C=CCC1=C(C(C)[OH+])C(=O)c2c(OC)cccc2C1=O</smiles>

33

$\mathrm{CH}_{3} \mathrm{COOH}:$ THF: $\mathrm{H}_{2} \mathrm{O}(4: 2 ; 1)$

$$
72 \%
$$<smiles>C=CCC1=C(C(C)O)C(=O)c2c(OC)cccc2C1=O</smiles>

34<smiles>COc1cccc2c1C(=O)C2(O)C#CC(C)[OH+]P</smiles>

31

$\overbrace{\mathrm{Ag}_{2} \mathrm{CO}_{3}, 99 \%}$<smiles>C=CCOC1(C#CC(C)[OH+]P)C(=O)c2c(OC)cccc21</smiles>

32<smiles>CC1OC2CC(=O)OC2C2=C1C(=O)c1cccc(O)c1C2=O</smiles>

\section{Scheme 9: Synthesis of deoxyfrenolicin}

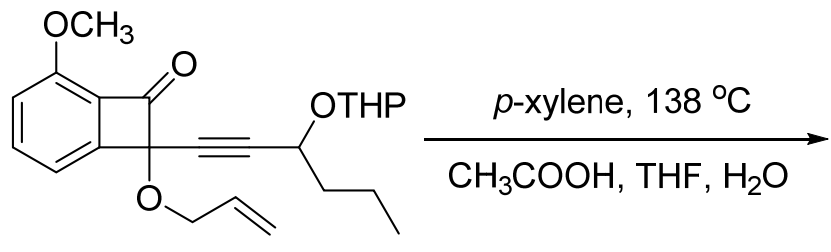<smiles>C=CCC1=C(C(O)CCC)C(=O)c2c(OC)cccc2C1=O</smiles>

35<smiles>[Z4]CC1OC2CC(=O)OC2C2=C1C(=O)c1cccc(O)c1C2=O</smiles>

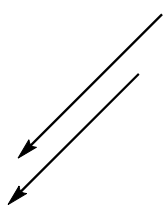

36 
The methodology provided successful syntheses of naphthoquinones $\mathbf{3 4}$ and $\mathbf{3 6}$, constituting a formal synthesis of the natural isochroman-1,4-naphthoquinones nanaomycin D (23), and deoxyfrenolicin (24). ${ }^{29,30}$ Quinones 34 and 36 were obtained in 28\% and 22\% yield from 30 respectively. Therefore, the quinone-cyclobutenone rearrangement methodology is not only efficient, brief, and simple, but also is a potentially general route to naphthoquinones of specific substitution patterns.

In 1990, Moore et al. further developed their methodology where 2,3-di-tertbutoxycyclobutenedione (37) (Scheme 10) was a useful synthon for hydroxyquinones. Besides the synthetic scope of this methodology, they also described its specific utilization in successful preparation of natural products, $( \pm$ )-terreic acid (43), and $( \pm)$-isoperezone (44) based on the thermal ring expansion of 4-alkynyl-tert-butoxycyclobutenones. ${ }^{31}$

Scheme 10: Thermal ring expansion of 4-alkynyl-tert-butoxycyclobutenones<smiles>CC1(C)C(=O)C(O)=C1O</smiles>

4

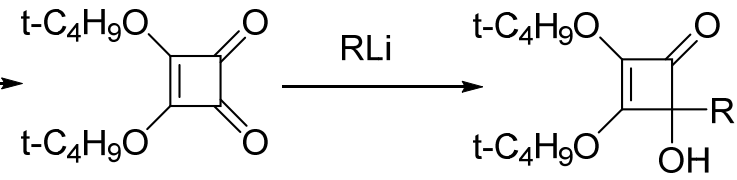

37

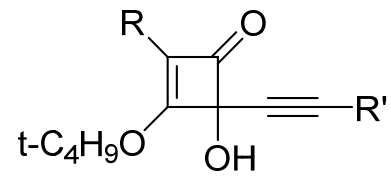

40

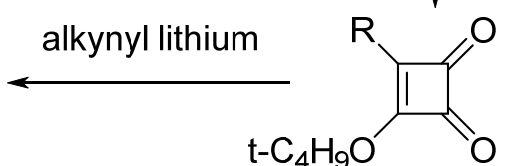

39 $p$-xylene, $138^{\circ} \mathrm{C}$<smiles>[R]C1=C([R])C(=O)C(OCCCC)=CC1=O</smiles>

41<smiles>[R]C1=C(O)C(=O)C([R])C(=O)C1</smiles>

42

$\mathrm{R}=$ Alkyl, Aryl, Alkenyl, Alkynyl, Allyl $\mathrm{R}^{\prime}=$ Alkyl 
Moore et al. reported the synthesis of tert-butoxyquinones $\mathbf{4 1}$ from the thermal ring expansion of 4-alkynyl-butoxycyclobutenones $\mathbf{4 0}$ in $p$-xylene at $138{ }^{\circ} \mathrm{C}$ and subsequently transformed to hydroxyquinones $\mathbf{4 2}$ upon treatment with trifluoroacetic acid at low temperature (Scheme 10).

In a typical procedure, squaric acid (4) was first converted to 2,3-di-tertbutoxycyclobutenedione (37) without any difficulty. ${ }^{12}$ Next, cyclobutenedione 37 was treated with an alkynyl organolithium reagent to give the cyclobutenones $\mathbf{3 8}$ which were then readily hydrolyzed to the cyclobutenediones 39 upon treatment with trifluoroacetic anhydride (TFAA). ${ }^{32}$ After regiospecific addition of an alkynyllithium reagent to the more electrophilic (nonvinylogous ester) carbonyl group in 39, cyclobutenones $\mathbf{4 0}$ were furnished. As mentioned above, thermolysis of $\mathbf{4 0}$ gave the tert-butoxyquinones $\mathbf{4 1}$, which are members of a rare class of quinones. Finally, a variety of hydroxyquinones $\mathbf{4 2}$ were provided via deprotection of $\mathbf{4 1}$ upon treatment with trifluoroacetic acid at $0{ }^{\circ} \mathrm{C} .{ }^{33}$

Two real complex examples of the specific synthetic utility of this methodology are given below. The first example is the total synthesis of the natural antibiotic $( \pm)$-terreic acid (43), and the second one is total synthesis of naturally occurring ( \pm )-isoperezone (44).

Figure 2: Structures of $( \pm)$-terreic acid and $( \pm)$-isoperezone<smiles>CC1=C(O)C(=O)C2OC2C1=O</smiles>

43<smiles>CC(C)=CCCC(C)C1=C(O)C(=O)C=C(C)C1=O</smiles>

44

The efficient synthesis of $\left( \pm\right.$ )-terreic acid (43), a naturally occurring antibiotic ${ }^{34,35}$ was outlined in Scheme 11. 
Preparation of ( \pm )-terreic acid (43) via thermal ring expansion of 4-alkynyl-tertbutoxycyclobutenones began with the alkynylation of 3-tert-butoxy-4methylcyclobutenedione (45) with lithium acetylides followed by ammonium chloride, yielding the cyclobutenones $\mathbf{4 6}$ in good yield. These transformations were carried out at -78 ${ }^{\circ} \mathrm{C}$ in THF and the reactions were efficient. Cyclobutenones 46 were then converted to benzoquinones $\mathbf{4 7}$ in respective yields of $79 \%$ and $69 \%$ in refluxing acetonitrile or benzene. Reactions of these quinones $\mathbf{4 7}$ with tert-butyl hydroperoxide or Triton $\mathrm{B}^{36}$ gave epoxide $\mathbf{4 8}$ in yields $59 \%$ and $68 \%$. De-tert-butylation of 48 under previous used condition $\left(0{ }^{\circ} \mathrm{C}\right.$, trifluoroacetic acid ) gave ( \pm )-terreic acid (43) in 84\% yield. The syntheses had an overall yields of $22 \%$ and $26 \%$, starting with the cyclobutenedione 45 which was readily available from squaric acid (4). Compared with the previously reported work, these syntheses are superior to the other two routes to $( \pm)$-terreic acid. ${ }^{37,38}$

Scheme 11: Synthesis of the natural product, $( \pm)$-terreic acid

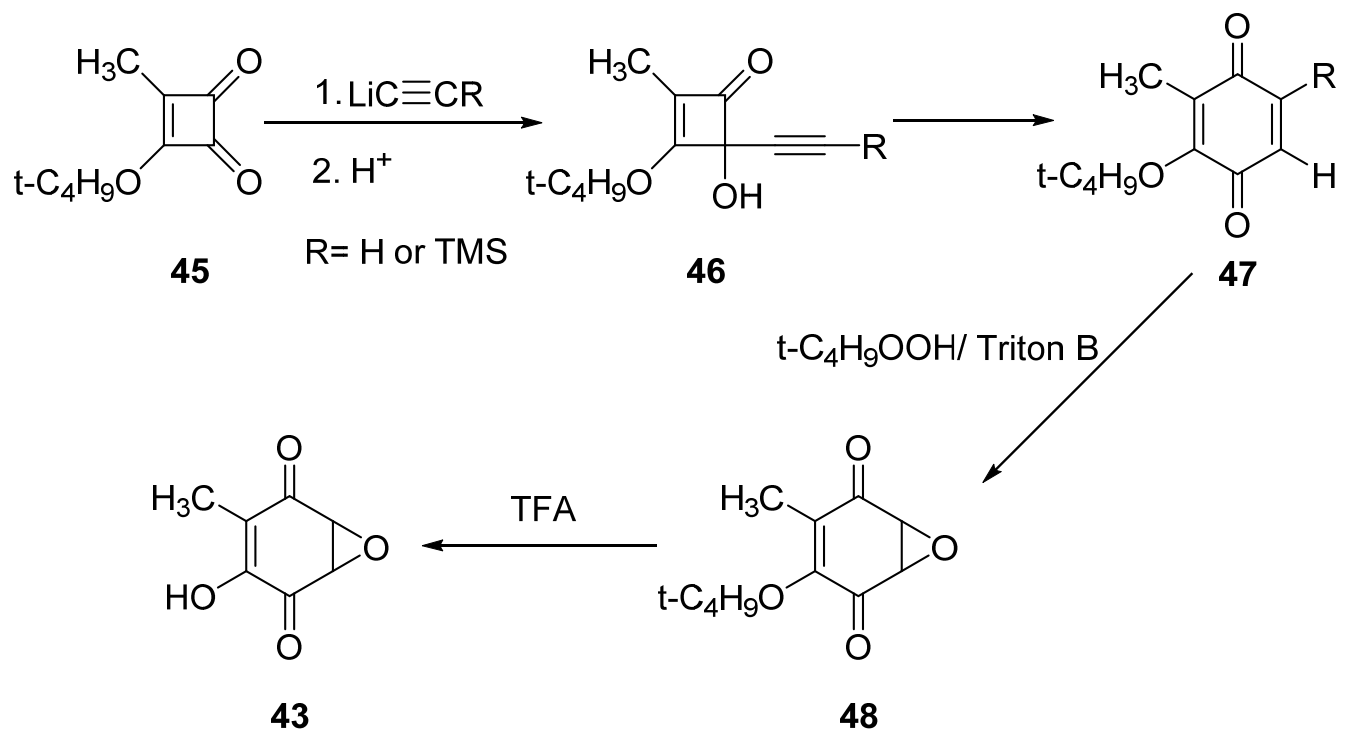

Final illustration of the specific synthetic utility of the thermal rearrangement of 4alkynyl-tert-butoxycyclobutenones methodology was described as follows, that is, total 
synthesis of the naturally occurring ( \pm )-isoperezone (44) (Scheme 12). The synthesis began via an alkylation of squarate 37 with 2-lithio-6-methyl-hept-5-ene, resulting in cyclobutenone 49, ${ }^{39}$ which was then dissolved in pyridine in the presence of trifluoroacetic anhydride to give the cyclobutenedione $\mathbf{5 0}$ in 52\% yield. Cyclobutenone $\mathbf{5 1}$ was then obtained by the regiospecific addition of 1-lithiopropyne to the more electrophilic carbonyl group of $\mathbf{5 0}$ and thermolysis of $\mathbf{5 1}$ in refluxing benzene furnished quinone $\mathbf{5 2}$ in $\mathbf{7 0 \%}$ yield. The last step to complete this total synthesis of $( \pm)$-isoperezone was deprotection of 52 with $4 \mathrm{~N} \mathrm{HCl}$ in refluxing dioxane, which directly provided 44 in $72 \%$ yield. The overall yield is $26 \%$ while the previous synthesis, reported in 1987, proceeded in 38\% overall yield from parvifolene, a natural product isolated from Pereziae spp. ${ }^{40}$

Scheme 12: Synthesis of the natural product, $( \pm)$-isoperezone

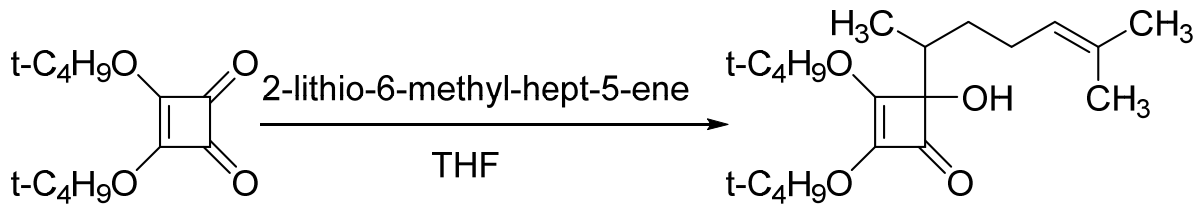

37

49

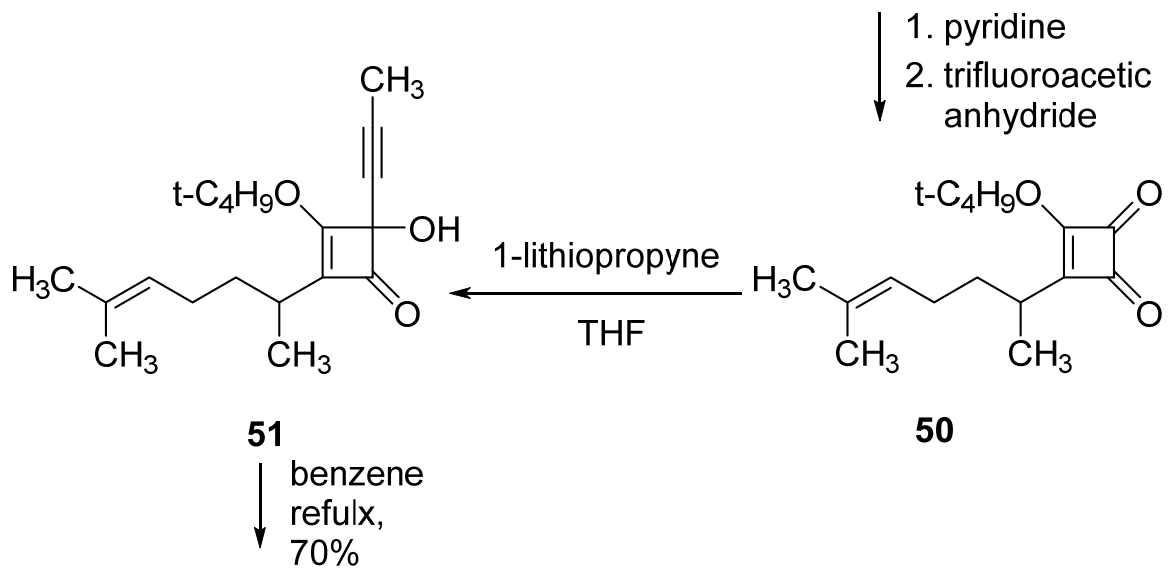<smiles>CC(C)=CCCC(C)C1=C(O)C(=O)C=C(C)C1=O</smiles> 


\subsubsection{Electrophilic reagents induced ring expansions of 4-alkynylcyclobutenones}

In addition to thermally induced ring expansion, some electrophilic reagents have also been shown to induce ring expansions of 4-alkynyl-4-hydroxy-2-cyclobuten-1-ones. For example, Liebeskind et al. proposed that the 4-alkynyl-4-hydroxy-cyclobutenone ring system 6, was transformed to an alkylidenecyclopentenedione 53 possessing a vinyl-palladium bond via ring expansion reaction with an electrophilic source of $\operatorname{Pd}(\mathrm{II}){ }^{41,42} 53$ could be subsequently activated toward protonation by using the $\mathrm{HX}$ generated in the ring expansion step to provide access to synthetically useful alkylidenecyclopentenediones 54. Meanwhile, the electrophilic $\mathrm{Pd}(\mathrm{II})$ reagent source rendering the reaction catalytic in Pd was regenerated (Scheme 13).

\section{Scheme 13: Palladium(II) catalyzed ring expansion of 4-alkynyl-4-hydroxy-}

\section{cyclobutenones}

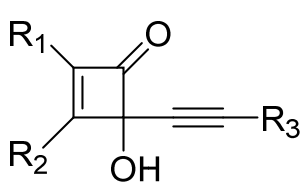

6

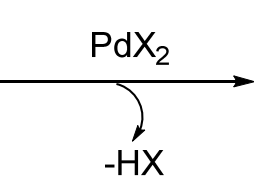

$-H X$<smiles>[R][R](CC)=C1C(=O)C([R])=C([R])C1=O</smiles>

53<smiles>[R]C=C1C(=O)C([R])=C([R])C1=O</smiles>

54

In 1987, Liebeskind et al. ${ }^{43}$ successfully demonstrated a new, highly stereoselective and practical synthesis of highly functionalized 4-oxygenated 5-alkylidenecyclopentenones and 3-oxygenated 2-alkylideneindanones based on the palladium-catalyzed reactions. As shown in Scheme 14, Palladium(II) catalyzed reactions afford exclusively 2-alkylidene-4cyclopentene-1,3-diones. Exposing 4-(l-hexynyl)-4-hydroxy-3-methoxy-2-methyl-cyclobut2-enone (55a) to the condition $\left(10 \mathrm{~mol} \% \mathrm{Pd}\left(\mathrm{OCOCF}_{3}\right)_{2}\right.$ in THF at $60{ }^{\circ} \mathrm{C}$ for $1 \mathrm{~h}$,) afforded (E)-alkylidene cyclopentenedione 56a, which was isolated together with the Z-stereoisomer 
in a $12: 1$ ratio in $45 \%$ yield. Two other 4 -alkynyl-4-hydroxycyclobutenones $5 \mathbf{5 b}$, 55c were exposed to the similar conditions discussed above $\left(10 \mathrm{~mol} \% \mathrm{Pd}\left(\mathrm{OCOCF}_{3}\right)_{2}\right.$ in THF at $40{ }^{\circ} \mathrm{C}$ for $5 \mathrm{~h}$ ) and resulted in the formation of 56b in 49\% yield (11 : 1 ratio) and 56c in $40 \%$ yield (15: 1 ratio).

Scheme 14: Palladium catalyzed ring expansion-coupling reaction<smiles>[R]C#CC1(O)C(=O)C(C)=C1OC</smiles>

55 a $\mathrm{R}=\mathrm{n}-\mathrm{Bu}$

55 b $R=T M S$

$55 \mathrm{c} \mathrm{R}=\mathrm{Ph}$<smiles>[R]C=C1C(=O)C(C)=C(OC)C1=O</smiles>

56 a: $45 \%$

56 b: $49 \%$

56 c: $40 \%$

The reaction is of interest because of its potential application in the synthetic field of the naturally occurring eicosanoids as well as simpler analogues of the natural products.

\section{Figure 3: Eicosanoid core and naturally occurring eicosanoids}<smiles>[R]C=C1C(=O)C([R])=C([R])C1([R3])O</smiles>

57<smiles>[X]C1=CC(O)(CC=CCCCCC)C(=CC=CCCCC(C)=O)C1=O</smiles>

$\mathrm{X}=\mathrm{Cl}, \mathrm{Br}$ or I 59

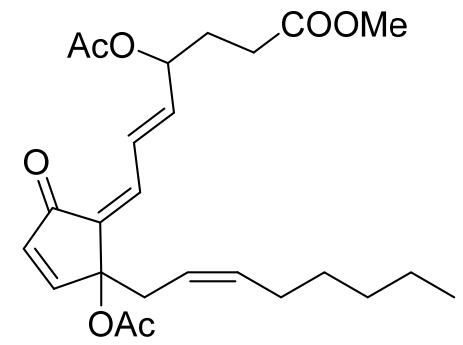

58<smiles>CC/C=C/CCCC(OC(C)=O)C(/C=C1/C(=O)C(Cl)=CC1(O)CCCC(C)=O)OC(C)=O</smiles>

60

Marine organisms produce an unprecedented molecular diversity by the incorporation of elements like halogen that are not readily available to terrestrial species. ${ }^{44}$ Naturally 
occurring marine eicosanoids, such as the clavulone $\mathbf{5 8}^{45}$ (claviridenones ${ }^{45,46}$ ), chloro, ${ }^{6,48}$ bromo, and iodovulones (59), ${ }^{49}$ and the punaglandin $\mathbf{6 0},{ }^{50}$ containing a 4-oxygenated 5alkylidenecyclopentenone core 57 (Figure 3), are often produced and of great importance due to their remarkable bioactivity that they possess in both vitro and vivo cytotoxicity studies. ${ }^{51}$ There has been numerous reported syntheses for the 4-oxygenated 5alkylidenecyclopentenone core $57,{ }^{52-54}$ however, the remarkable stereoselectivity challenges associated with the construction of these complex alkylidene systems are reflected in the many distinct approaches that have been reported for their racemic and enantioselective total syntheses. ${ }^{55-58}$

The observed exceptional stereoselectivity in the palladium-induced ring expansions of 4-alkynyl-4-hydroxycyclobutenones was rationalized by the author. ${ }^{43}$ It was postulated that non-vinyl bond "a” in $\mathbf{6 1}$ (Figure 4) was migrating to the adjacent sp hybridized carbon, resulting in a cationic intermediate with the ability to best stabilize the positive charge. The reaction proceeded through the most stable cationic intermediate and the ability of the migrating group to stabilize positive charge might play an important role in controlling the selectivity of the reaction. Therefore, a plausible reaction pathway might be the trans addition of bond "a" across the alkyne bond to furnish the desired alkylidene cyclopentenedione in a stereospecific fashion.

\section{Figure 4: Postulated reaction path for palladium catalyzed ring expansion reaction}

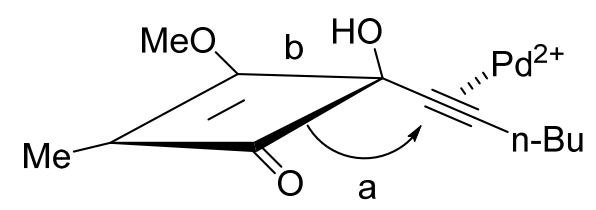

61

In 1995, Eguchi et al. ${ }^{59}$ demonstrated the ring expansion in Scheme 15 was probably 
cationic in nature, and the result of coordination of an electron deficient species [Pd(II) and $\left.\mathrm{H}^{+}\right]$to the alkyne followed by acyl migration. ${ }^{60,61}$ Those transformations in Scheme 15 employed diethyl squarate (62) as a starting material, which was easily converted to the 4alkynyl-4-hydroxycyclobutenone ring system 63 upon treatment with the corresponding lithium acetylides (THF, $-78{ }^{\circ} \mathrm{C}$ ) followed by quenching of the reaction mixture with ammonium chloride. ${ }^{9,32}$ The realized cyclobutenones $\mathbf{6 3}$ were converted to the corresponding cyclopentene-1,3-diones 64 via the ring expansion employing reagents which were believed to form hypoiodite. Specifically, conversion of cyclobutenones 63a, 63b, 63c to the corresponding cationic intermediate using $\mathrm{I}_{2} / \mathrm{PhI}(\mathrm{OAc})_{2}$ at $-15{ }^{\circ} \mathrm{C}$, followed by deprotonation afforded cyclopentene-l,3-diones 64a, 64b, 64c in 68\%, 63\%, 57\% yields respectively.

The mechanism of the reaction was thought to begin with the transfer of positive iodine atom from a hypoiodite moiety to alkyne the terminus and concomitantly, 1,2-acyl migration happened to form cyclopentene-1,3-diones 64. One of the driving force for this reaction was the ring strain relief which would facilitate the 1,2-acyl migration, and hence ring expansion.

Scheme 15: Iodine mediated ring expansion of 4-alkynyl-4-hydroxycyclobutenones<smiles>CCOc1c(OCC)c(=O)c1=O</smiles>

62<smiles>[R]C#CC1(O)C(=O)C(OCC)=C1OCC</smiles>

63

63a: $R=T M S$

63b: $R=H$ 63c: $\mathrm{R}=\mathrm{Ph}$<smiles>[R]C(I)=C1C(=O)C(OCC)=C(OCC)C1=O</smiles><smiles>[R]C#CC1(O)OC(=O)C(OCC)=C1OCC</smiles> 
Electrophilic reagent induced ring expansions of 4-alkynylcyclobutenones provide an alternative practical route to cyclopentene-1,3-diones from squaric acid, switching the rearrangement of 4-alkynyl-4-hydroxycyclobutenones from radical to ionic via electron deficient species. Overall, both thermally induced ring expansions and electrophilic reagent induced ring expansions of 4-alkynylcyclobutenones have significant synthetic utility in preparing substituted 1,4-benzoquinones and 2-alkylidene-1,3-cyclopentenediones. 


\subsection{Ring expansion of 4-alkynyl-4-hydroxycyclo-2-buten-1-ones in the presence of an $\mathrm{N}$ -}

\section{$\underline{\text { halosuccinimide }}$}

Although the ring expansion of 4-alkynylcyclobutenones has been well investigated, very little research has been examined the thermal ring expansion of 4-alkynyl-4hydroxycyclo-2-buten-1-ones in the presence of an $N$-halosuccinimide or thermal ring expansion of haloalkynylcyclobutenones. Herein, we paid an effort to prepare chloro-, bromo- or iodo-substituted methylenecyclopentene-1,3-diones and benzoquinones from squaric acid, which also may be useful for further conversion or employed in palladium catalyzed cross coupling reactions and ultimately in the synthesis of functionalized carbazoles. A simple case is demonstrated below (Scheme 16). ${ }^{59}$

\section{Scheme 16: Conversion of iodomethylenecyclopentene-l,3-dione to aminomethylene}

\section{cyclopentene-1,3-dione}<smiles>CCOC1=C(OCC)C(=O)C(=C(Br)I)C1=O</smiles>

65

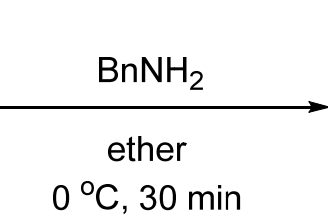

$78 \%$<smiles>CCOC1=C(OCC)C(=O)C(=C(Br)NCc2ccccc2)C1=O</smiles>

66

We examined the thermal ring expansion of 4-alkynyl-4-hydroxycyclo-2-buten-1-ones in the presence of an $\mathrm{N}$-halosuccinimide. If the cationic pathway is sufficiently slow, at the elevated temperatures required for a thermal rearrangement, it may be possible to halogenate the diradical 15 (Scheme 5$)^{62}$ in the presence of an $N$-halosuccinimide. The results of reactions of 4-alkynyl-4-hydroxycyclo-2-buten-1-ones with or without an $N$-halosuccinimide will be presented in this chapter.

Four 2,3-di(1-methylethoxy)-4-alkynyl-4-hydroxy-2-cyclobuten-1-ones having 
different alkynyl groups including ethynyl (73), 2-trimethylsilylethynyl (68), 2-iodoethynyl (78), and 2-bromoethynyl (81) groups were initially examined. Compound 68 and 73 were prepared according to literature procedures ${ }^{63}$ and compound $\mathbf{7 8}$ and $\mathbf{8 1}$ were prepared from 68 using NIS or NBS, respectively, in the presence of a catalytic amount of $\mathrm{AgNO}_{3}$ (Scheme 17). Compound 68 was prepared from diisopropyl squarate (67).

Scheme 17: Synthesis of ring expansion substrates 73, 78, and 81

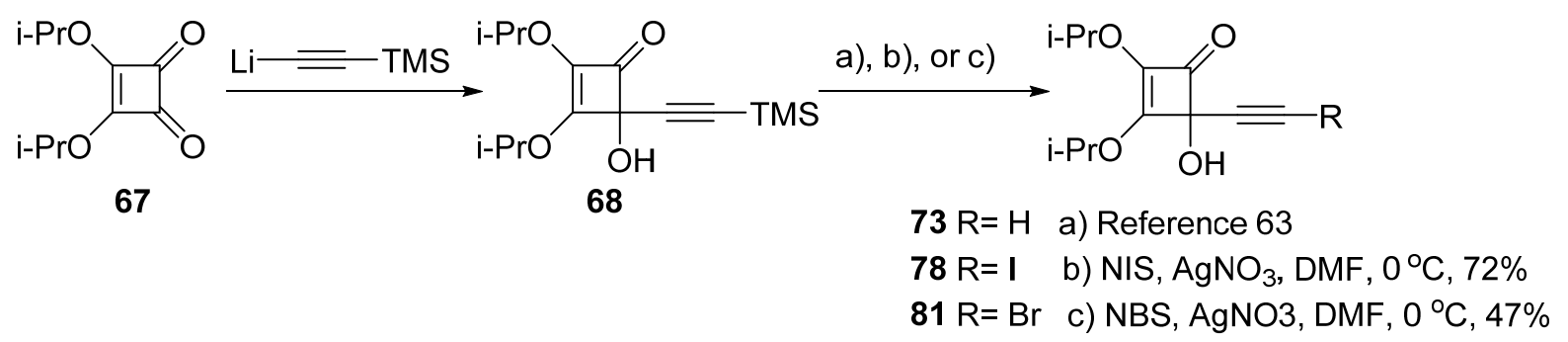

In addition to the reactions discussed above, cyclobutenones $\mathbf{8 9}$, readily available from diisopropyl squarate (67) as well, was converted to 2-methyl-3-(1-methylethoxy)-4ethynyl-2-cyclobuten-1-one (96) as outlined in Scheme 18. This was accomplished by its initial treatment with an alkynyl organolithium reagent to give cyclobutenone 87, which are readily hydrolyzed to $\mathbf{8 8}$ upon treatment with hydrochloric acid in dichloromethane $\left(\mathrm{CH}_{2} \mathrm{Cl}_{2}\right)$. Cyclobutenedione $\mathbf{8 8}$ was then converted to $\mathbf{8 9}$ by the regiospecific addition of an alkynyllithium reagent to the more electrophilic carbonyl group. Subsequently, cyclobutenone $\mathbf{8 9}$ was transformed to $\mathbf{9 6}$ using potassium fluoride in methanol and water. Cyclobutenone 96 was then subjected to reactions with or without NIS or NBS. 
Scheme 18: Synthesis of ring expansion substrates 89 and 96<smiles>O=c1c(O)c(O)c1=O</smiles>

67

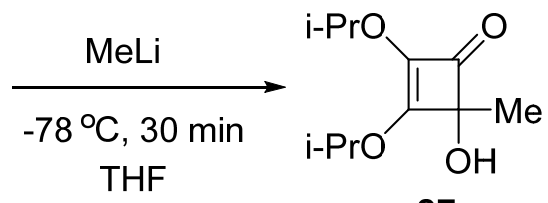

87

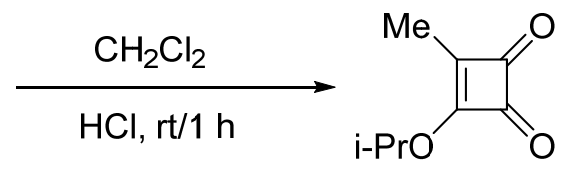

88

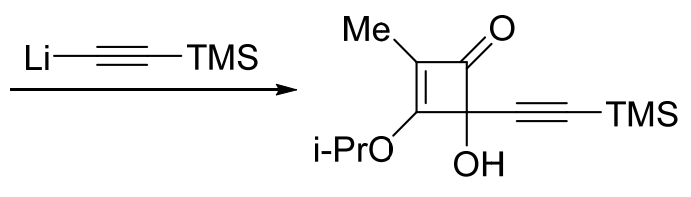

89

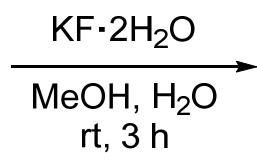

rt, $3 \mathrm{~h}$

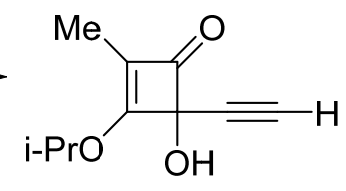

96

It is noteworthy that in an attempt to prepare iodoalkynyl derivative $\mathbf{1 0 0}$ by reaction of 89 with NIS, only diiodomethylene cyclopentenedione 101 was obtained in a low isolated yield (Scheme 19). It is plausible that $\mathbf{1 0 0}$ was formed in the reaction but immediately underwent NIS induced ring expansion under the reaction conditions.

Scheme 19: Attempted synthesis of 100<smiles>CC1=C(O[In])C(O)(C#CC(C)(C)C)C1=O</smiles>

89

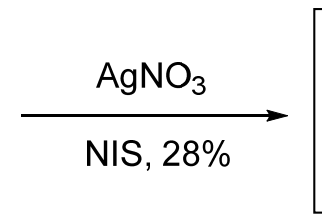

$\mathrm{NIS}, 28 \%$

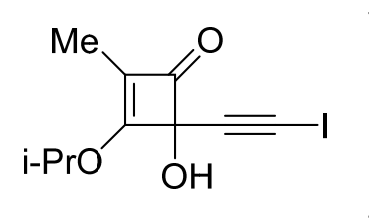

100 not observed

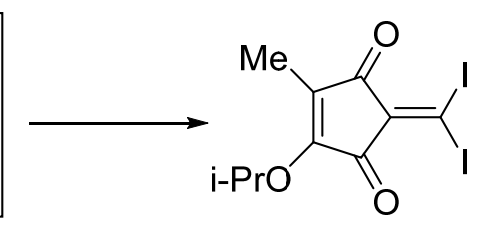

101 


\subsection{Result and discussion}

As described above, we first attempted to examine four 2,3-di(1-methylethoxy)-4alkynyl-4-hydroxy-2-cyclobuten-1-ones having different alkynyl groups including ethynyl (73), 2-trimethylsilylethynyl (68), 2-iodoethynyl (78), and 2-bromoethynyl (81).

Each compound was subjected to thermolysis either in the absence or in the presence of an $\mathrm{N}$-halosuccinimide at selected temperatures. The results of these reactions are summarized in Table 1.

Table 1: Ring-expansion of 68, 73, 78, and 81 in the absence or presence of NXS

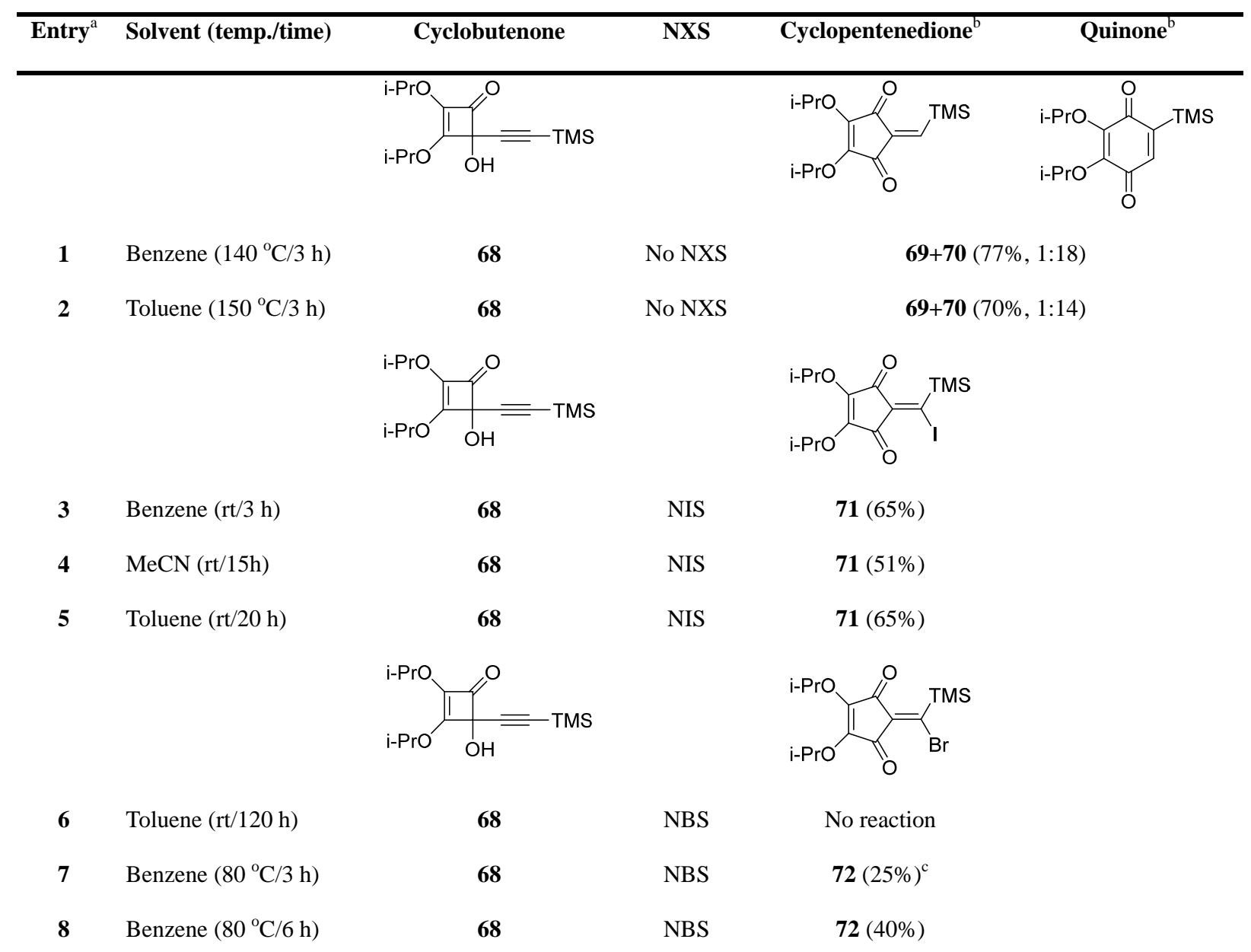


Table 1 (continued)

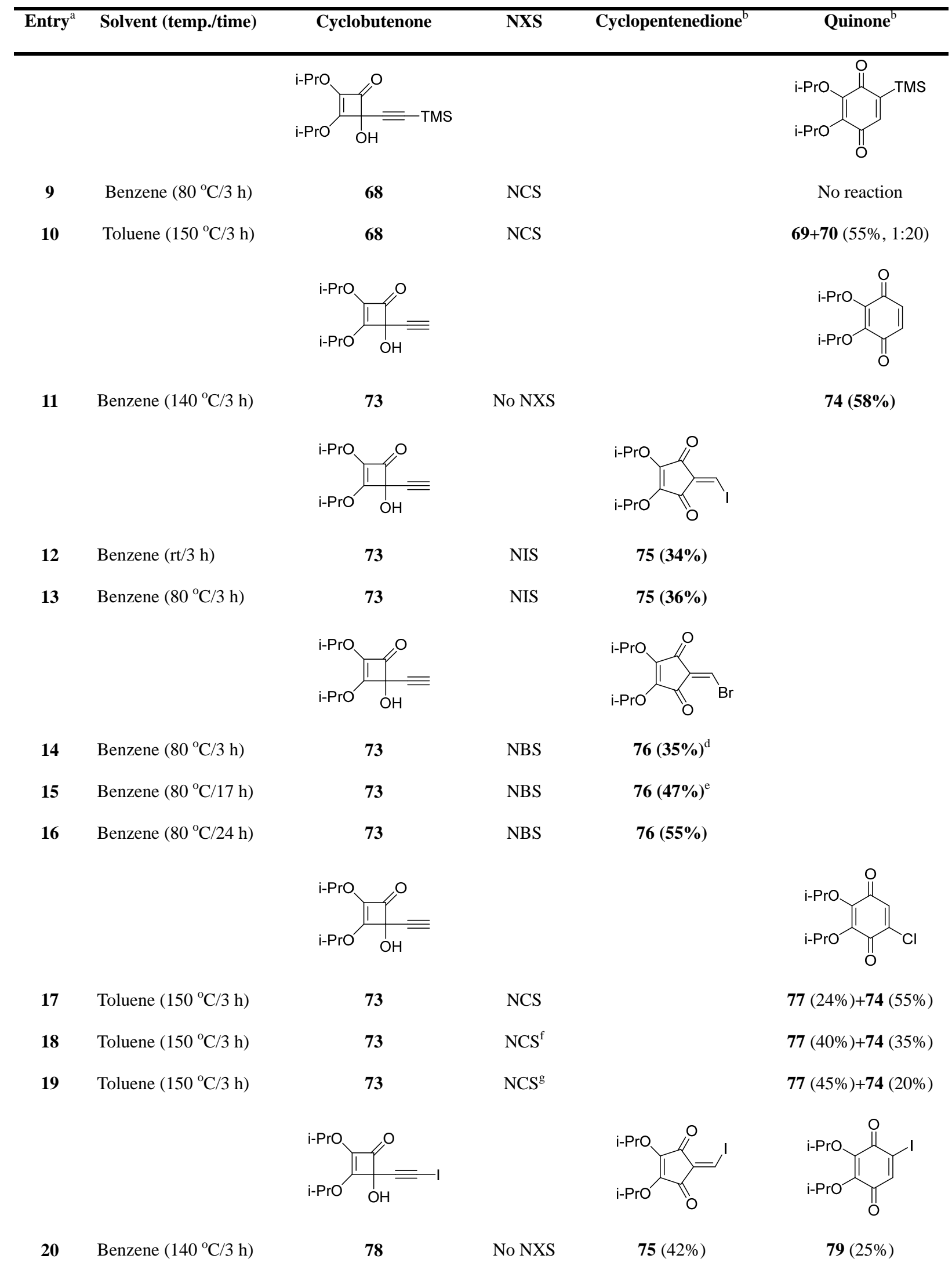


Table 1 (continued)

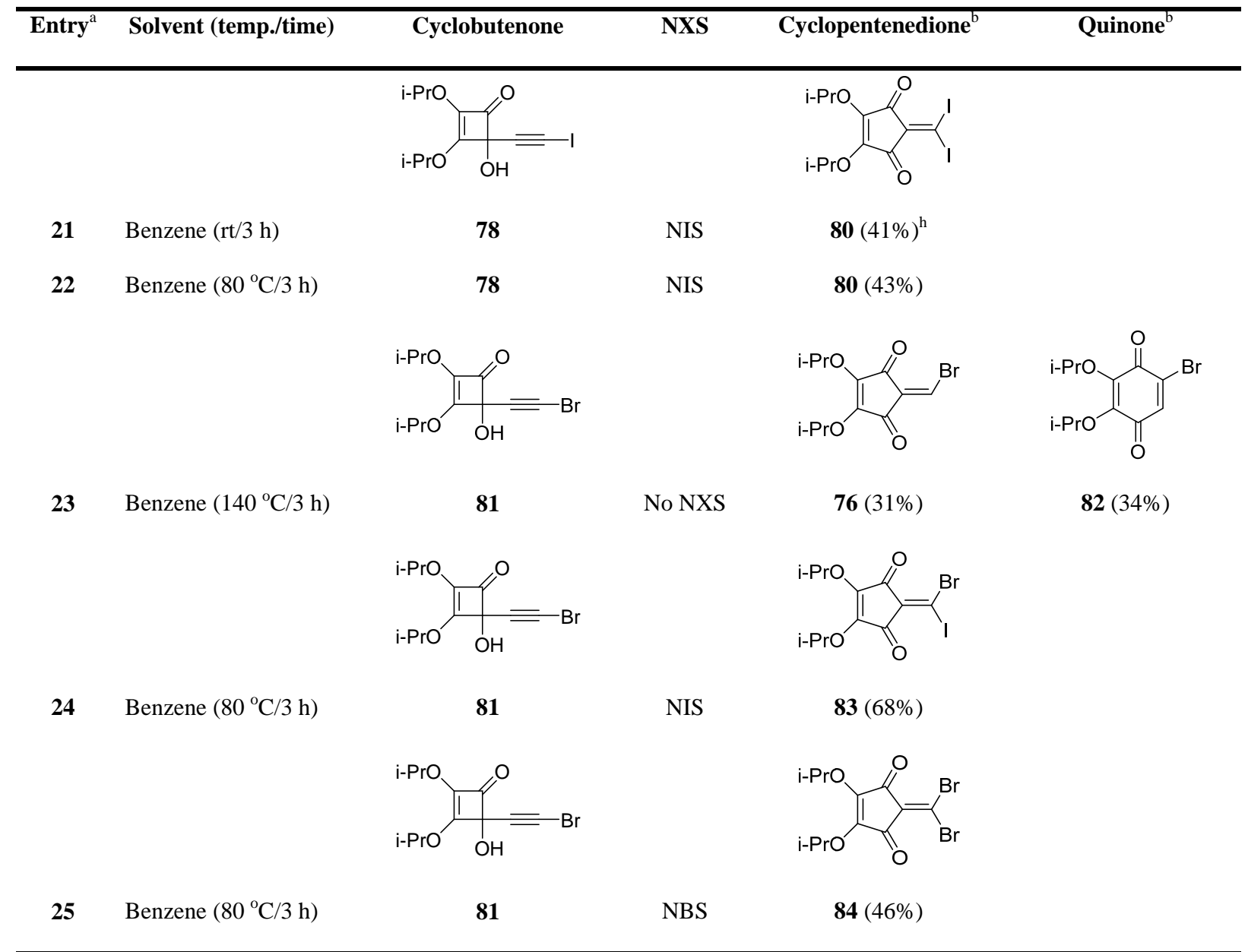

${ }^{\mathrm{a}}$ See Experimental section for detailed reaction conditions.

${ }^{\mathrm{b}}$ Yield of product after chromatographic separation on silica gel.

${ }^{\mathrm{c}}$ Hydrolysis product 85 (8\%) and starting material $(\mathbf{6 8}, 24 \%)$ were also obtained.

${ }^{\mathrm{d}}$ Hydrolysis product 86 (12\%) and starting material (32\%) were also obtained.

e Hydrolysis product 86 (11\%) and starting material (73, 10\%) were also obtained.

${ }^{\mathrm{f}}$ Three equivalents of NCS were used.

${ }^{\text {g }}$ Six equivalents of NCS were used.

${ }^{\mathrm{h}}$ Starting material (78, 29\%) was obtained.

All thermolysis reactions were performed in an ACE-Glass pressure tube capped with a Teflon screw cap. Thermolysis of $\mathbf{6 8}$ at $140{ }^{\circ} \mathrm{C}$ in benzene gave an inseparable mixture of 1,4-benzoquinone 70 and the corresponding cyclopentene-1,3-dione $\mathbf{6 9}$ in an 18:1 ratio in 77\% yield as evidenced by ${ }^{1} \mathrm{H}$ NMR (entry 1 ). The reaction of $\mathbf{6 8}$ is somewhat more selective and 
higher yielding compared to the previously reported rearrangement of the analogous 2,3dimethoxy-substituted compound wherein an 8:1 ratio was observed in a $46 \%$ yield. ${ }^{12}$ Toluene was also used as the solvent with a slightly lower ratio of products in a comparable yield (entry 2).

The benzoquinone and cyclopentenedione products reported herein are easily differentiated by ${ }^{1} \mathrm{H}$ NMR analysis. For example, the methine protons of the two methylethyl groups of 4-cyclopentene-1,3-dione 69 resonate at 5.59 and $5.54 \mathrm{ppm}$, respectively. In contrast, the corresponding 1,4-benzoquinone methine protons of compound $\mathbf{7 0}$ resonate upfield at 4.81 and $4.80 \mathrm{ppm}$. A similar difference in chemical shifts for methoxy groups of related 4-cyclopentene-1,3-diones and 1,4-benzoquinones has previously been reported by Moore et al. ${ }^{1,12}$ In addition, the color of the pure products are different, the 1,4benzoquinones are red while the 4-cyclopentene-1,3-diones are orange.

Reaction of $\mathbf{6 8}$ with $\mathrm{N}$-iodosuccinimide (NIS) proceeded much faster and gave even at ambient temperature in benzene only 2-iodomethylene-4-cyclopentene-1,3-dione $\mathbf{7 1}$ (entry 3). The same product was observed using acetonitrile or toluene as the solvent, the former gave a somewhat lower yield of product 71 (entries 4 and 5). Reaction of 68 with $N$ bromosuccinimide (NBS) did not afford any appreciable amount of product at ambient temperature even after prolonged reaction time (entry 6). However, 2-bromomethylene-4cyclopentene-1,3-dione $\mathbf{7 2}$ was isolated as the only ring expansion product after heating for 6 h at $80{ }^{\circ} \mathrm{C}$ (entry 8). A small amount of the hydrolysis product cyclobutenedione $\mathbf{8 5}$ was also isolated (Figure 5). Although the solvents were carefully dried before use, adventitious water present may still be present in the solution. 


\section{Figure 5: Hydrolysis products 85 and $86^{1}$}

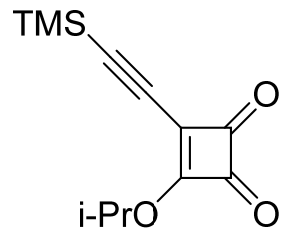

85

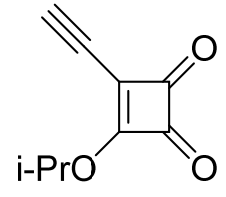

86

The reaction of $\mathbf{6 8}$ in the presence of $\mathrm{N}$-chlorosuccinimide (NCS) was even slower and did not proceed at all at $80{ }^{\circ} \mathrm{C}$. Increasing the temperature of the reaction to $150{ }^{\circ} \mathrm{C}$ did not furnish any chlorinated product but gave instead 1,4-benzoquinone $\mathbf{7 0}$ as the only product (entries 9 and 10). The results obtained from the reactions of $\mathbf{6 8}$ are interpreted as a change from a rapid cationic process seen for NIS to a slower cationic process using NBS to a radical process not involving NCS. It should be noted that no reaction was observed at temperatures below $100{ }^{\circ} \mathrm{C}$ for $\mathbf{6 8}$ in the absence of NBS or NIS.

Thermal reactions of 73 were examined next. Heating 73 in benzene at $140{ }^{\circ} \mathrm{C}$ gave 1,4-benzoquinone $\mathbf{7 4}$ as the sole product (entry 11). As was observed for $\mathbf{6 8}$, reactions using either NIS or NBS produced 2-iodo- and 2-bromo-methylene-4-cyclopentene-1,3-diones, respectively (entries 12-16). Substrate 73 appeared to react somewhat slower with NBS compared to 68 since a longer reaction time was required for complete consumption of the starting material. A small amount of the hydrolysis product 86 (Figure 5) was isolated in some cases (entries 14 and 15). Thermolysis of 73 in the presence of NCS gave the chlorinated 1,4-benzoquinone $\mathbf{7 7}$ and 1,4-benzoquinone $\mathbf{7 4}$ in a 1:2 ratio (entry 17). The yield of 77 was improved by addition of an excess of NCS however, a significant amount of 1,4benzoquinone 74 was isolated even using 6 equiv of NCS (entries 18 and 19). The latter three reactions indicate that it is possible to obtain chlorinated 1,4-benzoquinones via this 
methodology although, in low to moderate yields using a large excess of NCS. Due to the absence of chlorinated product using $\mathbf{6 8}$ and the mediocre yield isolated from 73, NCS was not further examined.

Thermal ring expansions of haloalkynylcyclobutenones have not previously been reported. Heating 78 at $140{ }^{\circ} \mathrm{C}$ in benzene in the absence of NXS gave a mixture of the fiveand six-membered products 75 and 79 (entry 20). A similar reactivity was observed using 81 affording 76 and 82 (entry 23). Reaction of $\mathbf{7 8}$ with NIS proved to be somewhat slower compared to $\mathbf{6 8}$ and 73. A significant amount of starting material was isolated after $3 \mathrm{~h}$ at ambient temperature but a complete conversion to $\mathbf{8 0}$ was observed at $80{ }^{\circ} \mathrm{C}$ (entries 21 and 22). Finally, $\mathbf{8 1}$ was transformed to the iodobromomethylene and dibromomethylene derivatives 83 and 84 in moderate yields using NIS and NBS, respectively (entries 24 and 25).

In addition to the reactions discussed above, two 2-methyl-3-(1-methylethoxy)-4alkynyl-2-cyclobuten-1-ones (89 and 96) were prepared and subjected to reactions with or without NIS or NBS. The results are summarized in Table 2.

Table 2: Ring-expansion of 89 and 96 in the absence or presence of NIS or NBS

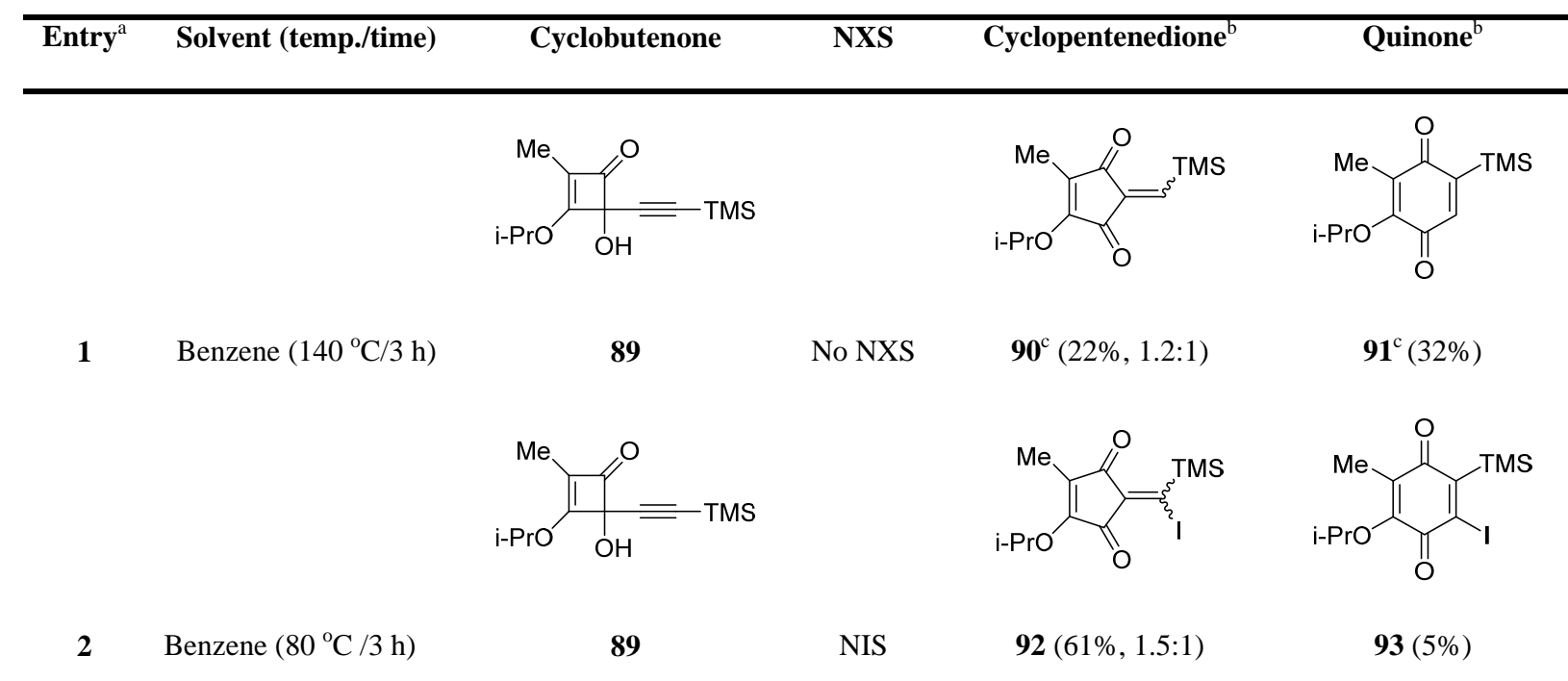


Table 2 (continued)

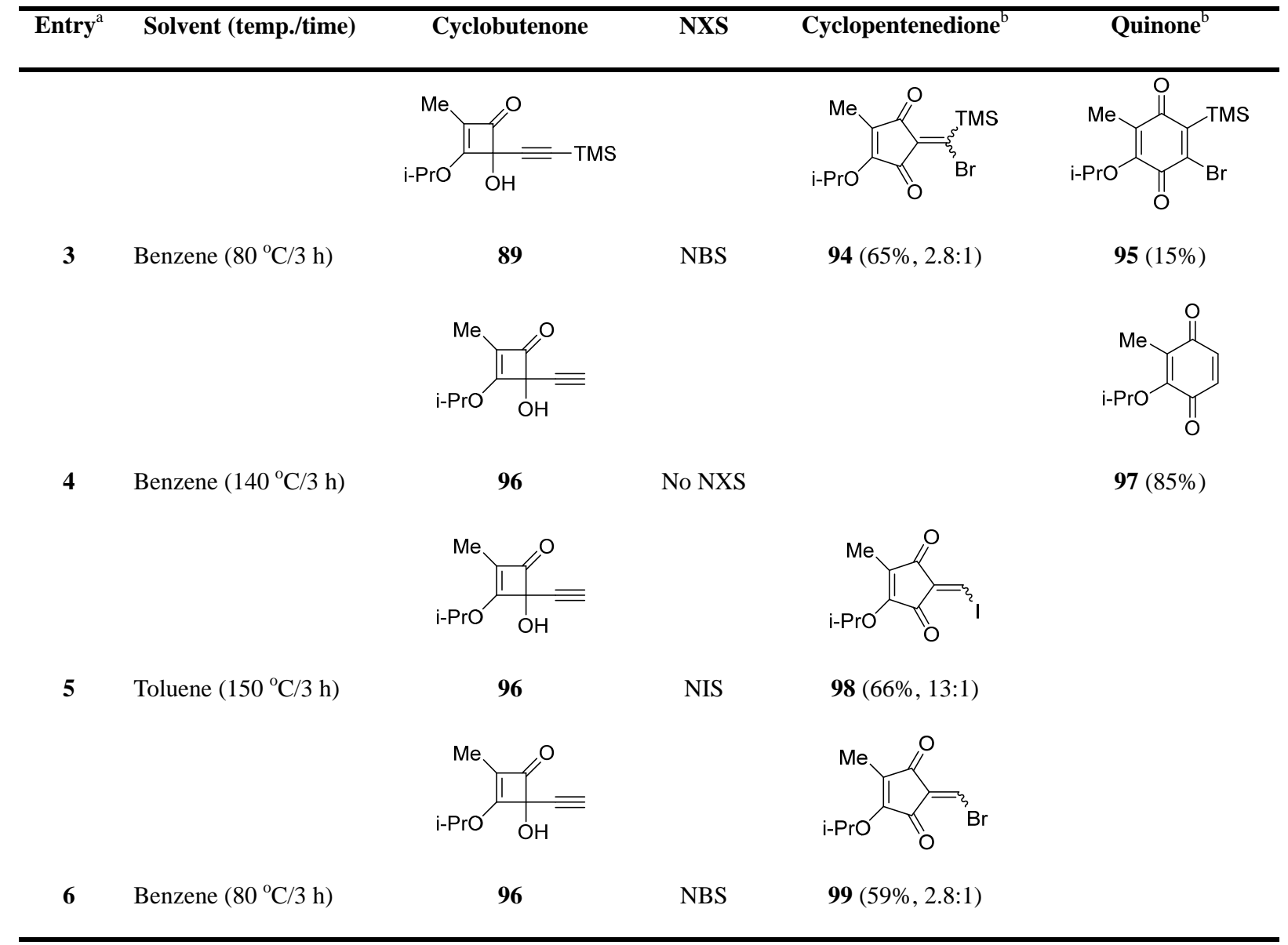

\footnotetext{
${ }^{\mathrm{a}}$ For detailed reaction conditions, see Chapter 4 experimental procedures.

${ }^{\mathrm{b}}$ Yield of product after chromatography.

${ }^{\mathrm{c}}$ The products could not be separated by chromatorgraphy.
}

Thermal ring expansion of $\mathbf{8 9}$ gave an inseparable 2:3 mixture of five- and sixmembered cyclic products (entry 1). The cyclopentenedione $\mathbf{9 0}$ was obtained as a 1.2:1 mixture of double bond isomers. ${ }^{12}$ A mixture of products was obtained from reactions of $\mathbf{8 9}$ with either NIS or NBS at elevated temperatures (entries 2 and 3). The result is surprising since we have not observed the formation of a quinone in any previous reaction using NIS or NBS. It is also interesting to note that Moore et al. did not report the formation of a fivemembered cyclic product upon thermolysis of the tert-butoxy analog of $\mathbf{4 6}$ (Scheme 20). ${ }^{2}$ 
Scheme 20: Thermal ring expansion of tert-butoxy analog

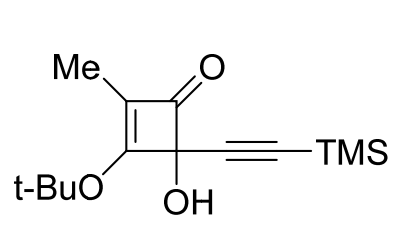

46

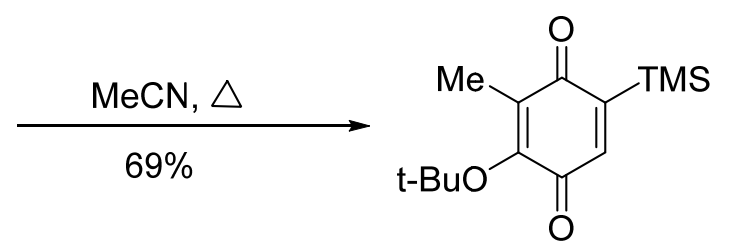

47

Heating a solution of $\mathbf{9 6}$ either in the absence or presence of NIS or NBS gave the more predictable result. That is, quinone $\mathbf{9 7}$ was formed upon thermolysis of $\mathbf{9 6}$ in the absence of an NXS, while reactions with NIS or NBS gave cyclopentenediones $\mathbf{9 8}$ and $\mathbf{9 9}$, respectively (entries 4-6).

As the final example, the electron deficient alkyne 102 was examined. This substrate has previously been shown by Moore et al. to exclusively afford 2-alkylidene-4cyclopentene-1,3-dione 103 upon thermolysis in xylenes (Scheme 21). ${ }^{12}$ This selectivity for five-membered cyclic products was also observed upon reaction with either NIS or NBS where 104 and 105 were formed, respectively.

\section{Scheme 21: Ring expansion of an electron deficient substrate}

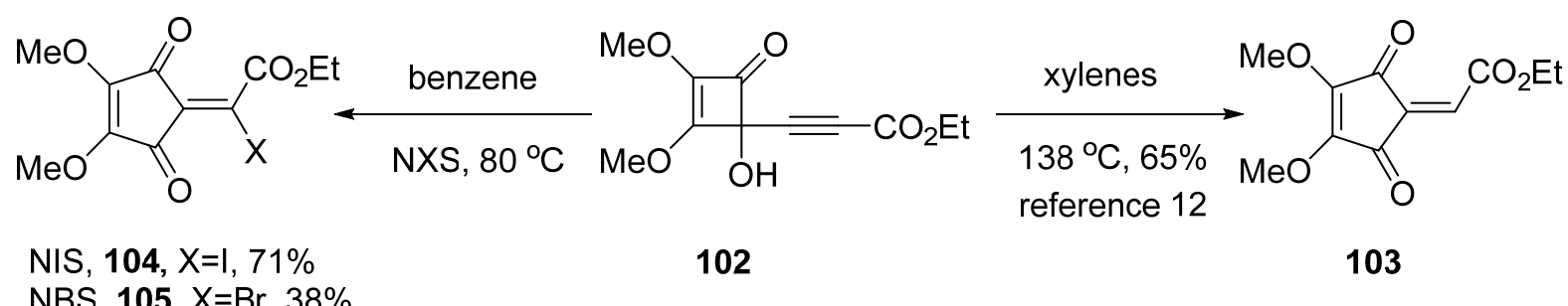




\subsection{Conclusions}

An in-depth study of the reactions of 4-(ethynyl)-4-hydroxy-2,3-substituted-2cyclobuten-1-ones with $N$-bromo- or $N$-iodosuccinimide, affording in most cases 2halomethylene-4-cyclopentene-1,3-dione, is described. In addition, the ring expansion of haloalkynylcyclobutenones with or without the presence $N$-halosuccinimide has been developed as well. The thermal ring expansion of 4-alkynyl-4-hydroxy cyclobutenones in the presence of $N$-halosuccinimide to form 2-halogenated methylene-4-cyclopentene-1,3-diones and/or 2-halo-1,4-benzoquinones selectively is a transformation of synthetic importance since no reliable general route to them has previously been reported.

The synthetic scope of this methodology has been investigated in this chapter and its specific utilization in the synthesis of a natural product, methyl linderone, will be described in next chapter. 


\section{Chapter 2}

\section{Total synthesis of methyl linderone}

2.1 Introduction to linderone and methyl linderone

2.2 Previous synthesis of linderone and methyl linderone

2.3 Methyl linderone via ring expansion of 4-ene-yne-substituted cyclo-2-buten-1-one and $N$-iodosuccinimide

2.3.1 Retrosynthetic analysis

2.3.2 Results and discussion

2.3.3 Conclusions 


\subsection{Introduction to linderone and methyl linderone}

A handful of 2-alkylidene-4-cyclopentene-1,3-diones have been isolated from natural sources (Figure 6). For example, linderone (106) and/or methyl linderone (107) were isolated from the root of Lindera pipericarpa ${ }^{64}$ and Lindera erythrocarpa. ${ }^{65}$ Lindera erythrocarpa Makino is one of the Lauraceae woody plants, which are distributed widely in Asia, including the People’s Republic of China, Korea, Japan. Lindera species, the large family Lauraceae that consists of mostly trees or shrub widely spread throughout the world, from the warmer regions of the earth, in both lowland and montane forests of Malaysia and Singapore ${ }^{66}$ and in the base of mountain forests of the Far East. They are found to be important medicinal plants including the Shiny Laurel, Lindera lucida (B1.) Boerl., L. strychnifolia, L. aggregate, and L. chunii. L. erythrocarpa (Lauraceae). Their fruits are used as a traditional medicine because of their analgesic, digestive, diuretic, antidote, and antibacterial properties. ${ }^{65,67}$

Plant secondary metabolites have provided an important source of drugs since ancient times and now around half of the practical drugs used are derived from natural sources. Many plants of Lauraceae have been applied in folk medicine for their interesting bioactivities. Previous studies of this species have afforded in addition to the cyclopentenedione derivatives linderone (106) and methyl lucidone (107), lucidone (108) and methyl lucidone (109) as lignans ${ }^{65}$ which were isolated from the bark of L. erythrocarpa. ${ }^{68}$ Methyl linderone (107), lucidone (108) and methyl lucidone (109) were also isolated from the fruits of Lindera lucida ${ }^{69,70}$ and methyl linderone has been reported from both $L$. erythrocarpa ${ }^{67}$ and $L$. pipericarpa. $^{71}$ 
Figure 6: Structures of linderone, methyl linderone, lucidone, methyl lucidone isolated from Lindera species<smiles>COC1=C(OC)C(=O)C(=C(O)C=Cc2ccccc2)C1=O</smiles>

106 Linderone<smiles>COC1=CC(=O)C(=C(O)C=Cc2ccccc2)C1=O</smiles>

108 Lucidone<smiles>COC(C=Cc1ccccc1)=C1C(=O)C(OC)=C(OC)C1=O</smiles>

107 Methyl linderone<smiles>COC1=CC(=O)/C(=C\C=C\c2ccccc2)C1=O</smiles>

109 Methyl lucidone

In 2000, Wu et al. ${ }^{72}$ reported two novel, closely related cyclopentenones, stigmahamone I (110) and stigmahamone II (111), had been isolated from the seeds of Fissistigma oldhamii. Fissistigma oldhamii (Hemsl.) Merr. (Annonaceae) is a perennial shrub, which is distributed mainly in southern China. As a folklore medicine, this plant is used for liver protection, anti-inflammatory and anti-arthritic effects, and anti-tumor action. ${ }^{73}$ These compounds are of high interest because of their significant activity in preliminary bioassay, such as in antiplatelet aggregation and so on.

Figure 7: Structures of Stigmahamones I-II<smiles>COC1=C(OC)C(OC)(C(C)OC)C(=C(O)C=Cc2ccccc2)C1=O</smiles>

110 Stigmahamone I<smiles>COC1=C(OC)C(O)(C(OC)OC)C(=C(O)C=Cc2ccccc2)C1=O</smiles>

111 Stigmahamone II 
Nowadays, more and more scientific study has been reported on the bioactivities of the cyclopentenedione derivatives, linderone (106), methyl lucidone (107), lucidone (108) and methyl lucidone (109). Methyl linderone is not only a human chymase inhibitor, ${ }^{74}$ but also exhibits cytotoxicity against a number of cell lines ${ }^{75}$ and the linderones are chitin synthase inhibitors. $^{76}$

Human chymase is a chymotrypsin-like serine protease that is stored in the secretory granules of mast cells. ${ }^{77}$ Although the precise physiological and pathological functions of human chymase have not been elucidated, several studies have suggested its involvement in cardiovascular diseases ${ }^{78}$ and chronic inflammation following fibrosis. ${ }^{79}$ In 2001, Aoyama et al. ${ }^{74}$ first reported the biological activity of methyl linderone as a human chymase inhibitor, which are thought to be potentially useful tools for elucidating the physiological function of chymase and therapeutic agents.

The postulated inhibition mechanism of the core struture 112 existing in methyl linderone against human chymase was as presented in Scheme 22. Mechanistically, the formation of serine hydroxy $O$-alkenyl enzyme occured through a process involving nucleophilic substitution of the active site serine residue (serine 195) in the enzyme at the $\beta$-olefinic carbon atom activated by two carbonyl groups, meanwhile, the phenyl group in $\mathbf{1 1 2}$ docks into the S1 pocket.

\section{Scheme 22: Proposed mechanism for inhibition of human chymase by compound 112}

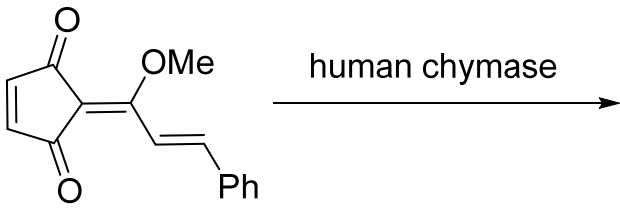

112

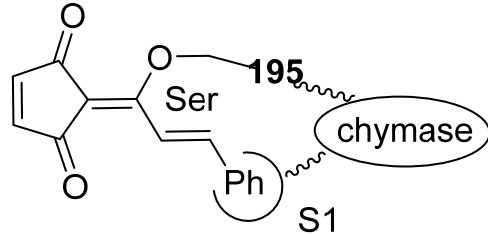

O-alkenyl enzyme 
In 2002, Kho et al. $^{75}$ suggested the important cytotoxic compound in lindera erythrocarpa was methyl linderone (107) based on evidence from the evaluating of three lignans, linderone (106), methyl linderone (107), and kanakugiol (113) in vitro cytotoxicity using three cancer cell line assay. Amongst the compounds, methyl linderone exhibited significant cytotoxicity against mouse melanoma (B16-F10), human acetabulum fibrosarcoma (HT 1080), and choronic myelogenous leukemia (K562) cancer cell lines, while linderone 106, and kanakugiol 113 showed weak inhibitory activity.

\section{Figure 8: Structure of kanakugiol}<smiles>COc1c(OC)c(OC)c(C(=O)/C=C/c2ccccc2)c(OC)c1OC</smiles>

113

All four linderones and lucidones are inhibitors of farnesyl transferase, ${ }^{80}$ having anti-inflammatory activity, ${ }^{81}$ and they are PPAR-g agonists. ${ }^{82}$ In 2005, Kwon et al. ${ }^{80}$ described the activity-guided isolation from the fruits of L. erythrocarpa and their inhibitory activities on FPTase. The results proved all four cyclopentenediones mentioned above were farnesyl protein transferase (FPTase) inhibitors and anti-tumor compounds by examining their inhibitory activity against H-ras-transformed rat-2 cells and a variety of human cancer cell lines. Especially, compounds methyl linderone and methyl lucidone showed strong inhibition for the growth of human cancer cells and colon tumor xenografted. From their bioassay results, a conclusion was drawn that methyl lucidone can be a potential anti-cancer agent against H-ras-transformed tumor and the cyclopentenediones will also be a good lead molecule for the development of a new class of anti-tumor drug and agents. 
After Kwon and his coworkers demonstrated that four cyclopentenediones from the methanol extract of the fruits of L. erythrocarpa exhibited farnesyl protein inhibitory activity, in 2007, Chang et al. ${ }^{81}$ reported their study of a bioactive investigation of the extract from $L$. erythrocarpa fruits presented a significant in vitro and in vivo anti-inflammatory activity in inhibiting significantly nitric oxide (NO) production in lipopolysaccharide induced NO in the murine macrophage cell line. Among the evaluated compounds, lucidone (108), cis/trans-methyl ludicone (109), methyl linderone (107) and linderone (106), lucidone possessed the strongest NO inhibitory activity. Furthermore, lucidone also provided anti-inflammatory activity in the croton oil-induced ear edema assay. It was indicated that lucidone has a good potential to be developed as an anti-inflammation agent.

In summary, L. erythrocarpa fruits possess potent anti-inflammatory activity, and according to the results obtained from large investigation, the cyclopentenedione skeleton compounds, are good candidates for development as anti-tumor and anti-inflammatory agent. This class of compounds is of great importance in further nutraceutical applications, pharmaceutical industries and epidemiological studies. 


\subsection{Previous synthesis of linderone and methyl linderone}

Linderone (106) and methyl linderone (107) are natural acylcyclopentenediones structurally similar to calythrone (114) ${ }^{83}$ (Figure 9) and methyl linderone belongs to a unique class of natural acylcyclopentenedione pigments. ${ }^{70,84}$ To our best knowlege, linderone and methyl linderone have been synthesized four times since first isolated. ${ }^{74,85-87}$

\section{Figure 9: Structure of calythrone}

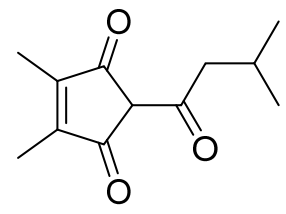

114

In 1967, Lee group described the first total synthesis of linderone and methyl linderone. ${ }^{85}$ It has been proposed these compounds might be derived from the appropriate precursor demethyldihydrolinderone (118), which could be readily generated through the alkaline rearrangement of the 1,4-quinone 117.

Preparation of linderone and methyl linderone from a six-membered ring precursor (Scheme 23) via well known reactions involving ring-contraction ${ }^{88}$ began with the oxidation of the chalcone $\mathbf{1 1 5}$ with nitric acid in acetic acid, indeed yielding the required quinochalcone precursor 116. Quinochalcone precursor 116 was then readily debenzylated via catalytic hydrogenation in methanol, with simultaneous saturation of the cinnamoyl side-chain. Subsequently, the hydroquinone intermediate was transformed to the 2,6-dihydroxy-quinone 117 by aerial oxidation in alkaline solution. A yellow product identified as demethyldihydrolinderone (118) was obtained after the quinone stood at room temperature in aqueous sodium hydroxide for 2-2.5 h either in the presence or absence of air. With the demethyldihydrolinderone (118) in hand, there remained only the introduction of unsaturation into the acyl side chain to complete the total 
synthesis of the natural product. Methylation of compound 118, followed by dehydrogenation gave methyl linderone (107) and hence linderone (106). This was accomplished by first converting demethyldihydrolinderone (118) with diazomethane into methyldihydrolinderone (119) and then dehydrogenating the latter with 2,3-dichloro-5,6-dicyanoquinone, thus giving methyl linderone (107) in 60\% yield. Finally, the partial hydrolysis of methyl linderone to linderone (106) completed the total synthesis of the desired naturally occruing compound. ${ }^{84}$

Scheme 23: Lee’s synthesis route of methyl linderone in 1967

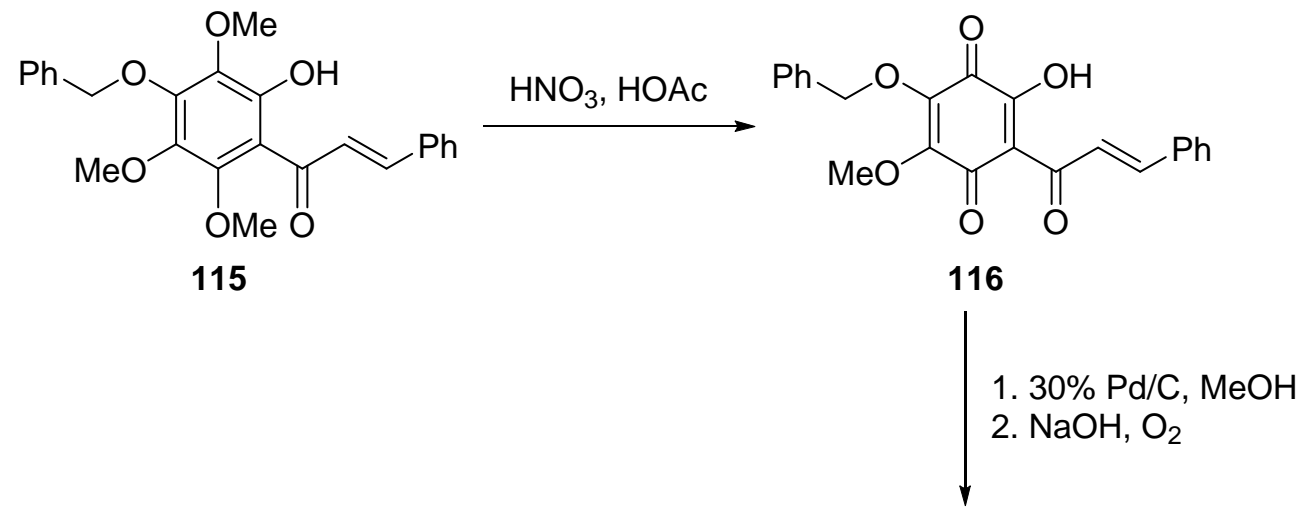<smiles>COC1=C(O)C(=O)C(C(=O)CCc2ccccc2)C1=O</smiles>

118
1. $2 \mathrm{~N} \mathrm{NaOH}, \mathrm{rt}, 2.5 \mathrm{~h}$ 2. con. $\mathrm{HCl}$<smiles>COC1=C(O)C(=O)C(O)=C(C(=O)CCc2ccccc2)C1=O</smiles>

117<smiles>COC(CCc1ccccc1)=C1C(=O)C(OC)=C(OC)C1=O</smiles>

119<smiles>N#Cc1c(O)c(Cl)c(Cl)c(Cl)c1C#N</smiles><smiles>COC1=C(OC)C(C)=C(C(C=Cc2ccccc2)OC)C1=O</smiles>

107<smiles>COC1=C(OC)C(=O)C(=C(O)/C=C/c2ccccc2)C1=O</smiles>

106 
In 1986, Lee et al. ${ }^{86}$ reported they have utilized another direct approach ${ }^{89}$ to synthesize linderone (106). That is converting methyl pedicinin (125) to 126 through the oxidative rearrangement by acetic anhydride-DMSO, which would be expected to undergo an acid-catalyzed conversion into linderone (106). The total synthesis employing this methodology is outlined in Scheme 24.

Methyl pedicinin (125), which could be isolated from the leaves of Didymocarpus pedicellata, was first synthesized in four steps from 2-hydroxy-3,4,6-trimethoxyacetophenone (121).$^{90}$ The synthesis started with a Friedel-Crafts acetylation of 1,2,3,5-tetramethoxy benzene (120) with acetyl chloride and aluminum chloride in dichloromethane at $30{ }^{\circ} \mathrm{C}$, resulting in 2-hydroxy-3,4,6-trimethoxyacetophenone (121) in 66\% yield. Treatment of $\mathbf{1 2 1}$ with benzaldehyde and potassium carbonate in alcohol for 3 days provided 2-hydroxy-3,4,6-trimethoxy-chalkone (122). The reaction of 122 with potassium carbonate and persulphate in pyridine at $10-15{ }^{\circ} \mathrm{C}$, followed by refluxing in benzene in the presence of sodium sulfite and chloric acid furnished pedicin (123), which was then subjected to oxidation using bromine in chloroform to give pedicinin (124). Exposing pedicinin (124) to the methylation condition (diazomethane prepared from nitrosomethyl urea, ice-chest, 48 h) afforded methyl pedicinin (125). Subsequent rearrangement of 125 by using acetic anhydride-DMSO at $75{ }^{\circ} \mathrm{C}$ for $1 \mathrm{~h}$ gave compound $\mathbf{1 2 6}$ as a yellow solid identified as linderone acetate in $42 \%$ yield. Mild acid hydrolysis of compound $\mathbf{1 2 6}$ upon refluxing in 10\% methanolic hydrochloric acid completed the synthesis of linderone (106). 
Scheme 24: Lee's synthesis route of methyl linderone in 1986<smiles>COc1cc(OC)c(OC)c(OC)c1</smiles>

120<smiles>COc1cc(OC)c(OC)c(C(=O)/C=C/c2ccccc2)c1O</smiles>

122
1. $\mathrm{K}_{2} \mathrm{CO}_{3}$, pyridine, persulphate, $10^{\circ} \mathrm{C}, 24 \mathrm{~h}$

2. $\mathrm{Na}_{2} \mathrm{SO}_{3}, \mathrm{HCl}$, benzene, reflux, $30 \mathrm{~min}$<smiles>COc1c(O)c(OC)c(C(=O)/C=C/c2ccccc2)c(O)c1OC</smiles>

123<smiles>CC(Cl)C(C)(C)[18OH]</smiles><smiles>COC1=C(O)C(=O)C(C(=O)/C=C/c2ccccc2)=C(O)C1=O</smiles>

$\mathrm{CH}_{2} \mathrm{~N}_{2}, 48 \mathrm{~h}, 0^{\circ} \mathrm{C}$

124<smiles>COC1=C(OC)C(=O)C(C(=O)/C=C/c2ccccc2)=C(O)C1=O</smiles>

125<smiles>COC1=C(OC)C(=O)C(=C(C=Cc2ccccc2)OC(C)=O)C1=O</smiles>

126

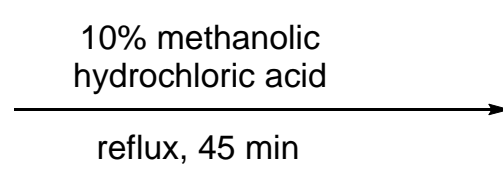<smiles>COC1=C(OC)C(=O)C(=C(O)/C=C/c2ccccc2)C1=O</smiles>

106

In 2001, Aoyama et al. ${ }^{74}$ performed a new and practical synthesis of methyl linderone (107). Methyl linderone was prepared using a palladium catalyzed rearrangement of $\mathbf{1 2 8}$ to $\mathbf{1 2 9}$ as the key step (Scheme 25). A DDQ mediated oxidation and a Michael-addition elimination sequence completed the synthesis. 
This synthesis of $\mathbf{1 0 7}$ initiated from alkyne $\mathbf{1 2 7}$ prepared from hydrocinnamaldehyde by the Corey-Fuchs method. ${ }^{91} \mathbf{1 2 7}$ was then converted to its lithium salt and added to dimethyl squarate (7) to give cyclobutenone 128. The palladium-catalyzed ring expansion of $\mathbf{1 2 8}$ with $5 \%$ $\mathrm{Pd}\left(\mathrm{OCOCF}_{3}\right)_{2}$ in the presence of $N$-bromosuccinimide (NBS) provided compound $\mathbf{1 2 9}$ in $77 \%$ yield. ${ }^{43}$ Dehydrogenation of 129 with 2,3-dichloro-5,6-dicyano-1,4-benzoquinone (DDQ) $)^{85,86}$ followed by nucleophilic substitution with NaOMe gave methyl linderone (107). Using this protocol, total synthesis of methyl linderone (107) was achieved in only four steps and the overall yield from dimethyl squarate was $21 \%$.

\section{Scheme 25: Aoyama's synthesis route of methyl linderone}
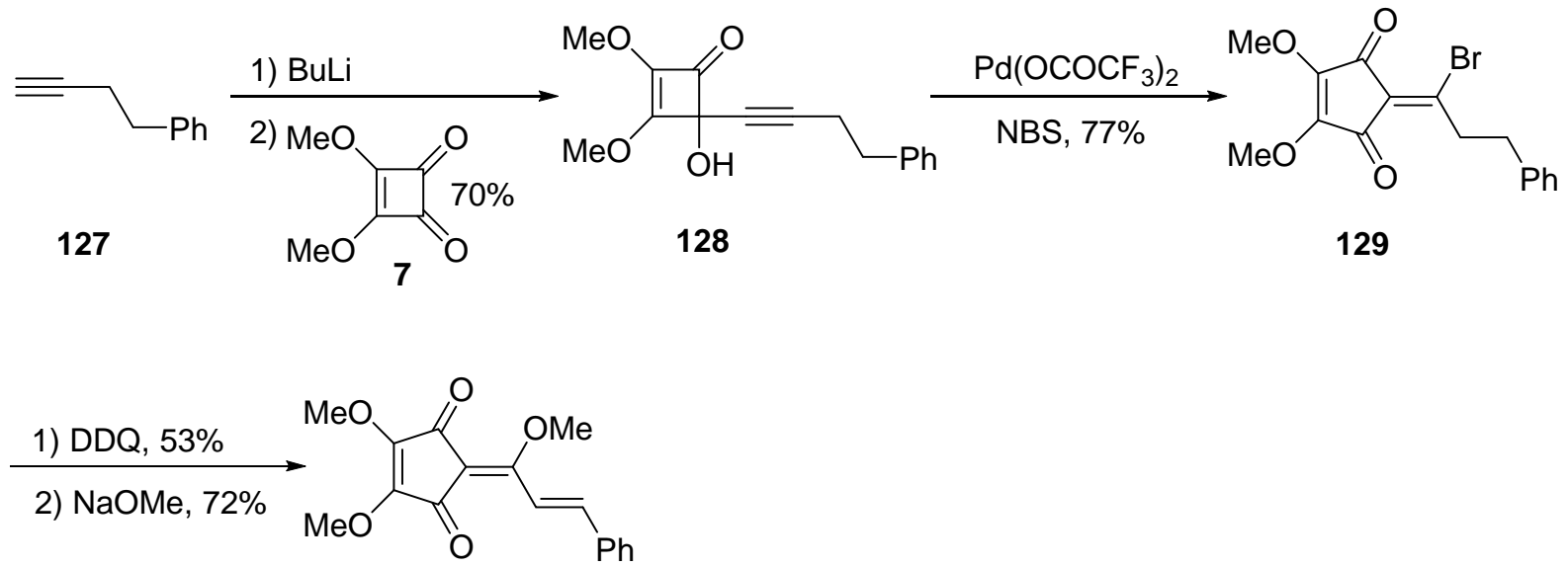

107

In 2004, Langer et al. ${ }^{87}$ developed an approach to linderone using synthetic precursor 135 prepared from 130 in 5 steps in 41\% overall yield (Scheme 26). When 2,4-bis-silyl enol ether 130 was treated with oxalyl chloride and trimethylsilyl triflate in dichloromethane at low temperature $\left(-78-20{ }^{\circ} \mathrm{C}\right)$, compound 131 was obtained in $82 \%$ yield. 
Scheme 26: Langer's synthesis route of linderone

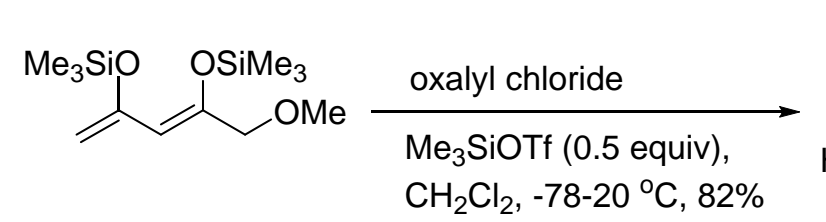

130

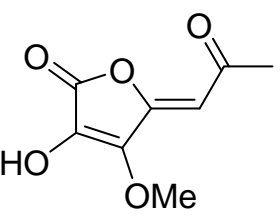

131

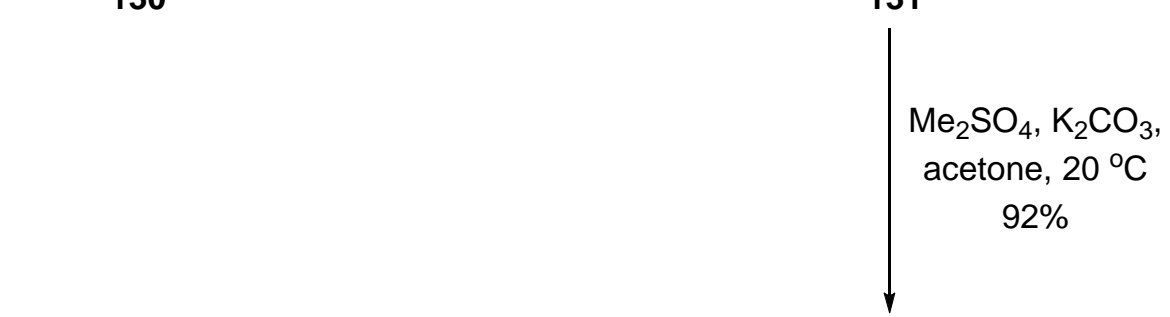<smiles>C=C(/C=C1\OC(=O)C(OC)=C1OC)O[SiH3]</smiles>

133
$\mathrm{Me}_{3} \mathrm{SiOTf}, \mathrm{Et}_{3} \mathrm{~N}$

$\mathrm{Et}_{2} \mathrm{O}, 0-20{ }^{\circ} \mathrm{C}, 93 \%$

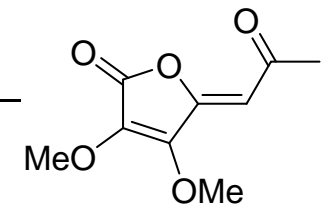

132

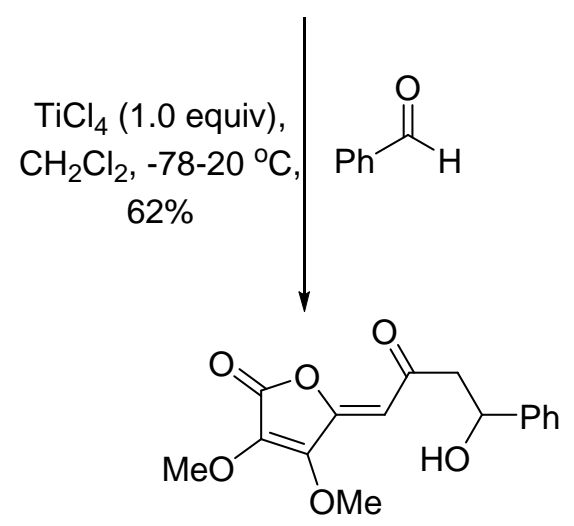

134

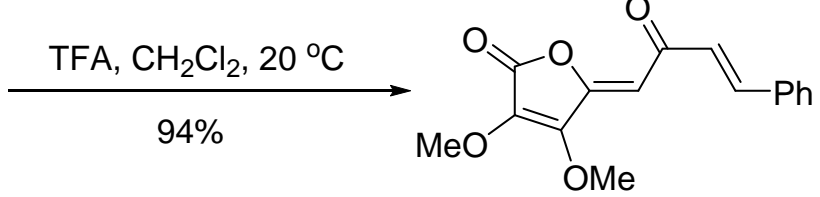

135

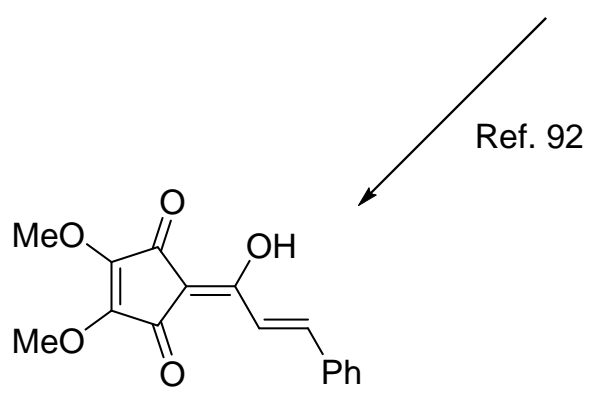

106

Furanone 132 was formed in excellent yield by treating 131 with dimethyl sulfate and potassium carbonate in acetone. Exposure of $\mathbf{1 3 2}$ to trimethylsilyl triflate in diethyl ether in the 
presence of triethyl amine generated the corresponding silyl enol ether $\mathbf{1 3 3}$ in 93\% yield. Subsequent reaction of 133 with benzaldehyde provided compound 134, which was then converted to 135 via dehydration. Finally, 135 was transformed to linderone (106), employing previously reported condition. ${ }^{92}$

The total syntheses of linderone (106) and methyl linderone (107) were achieved by Lee group via ring-contraction reaction and oxidative rearrangement. However, their total syntheses consist of many steps. Aoyama group successfully performed a much shorter total synthesis compared to Lee's method. With the inspiration of their research and our study in the reactions of 4-(ethynyl)-4-hydroxy-2,3-substituted-2-cyclobuten-1-ones with $N$-halosuccinimide, herein we report another synthetic route for the naturally occurring product methyl linderone (107). 


\subsection{Methyl linderone via ring expansion of 4-ene-yne-substituted cyclo-2-buten-1-one and}

\section{$\underline{N \text {-iodosuccinimide }}$}

As discussed in Chapter 1, a new convenient methodology to form the 2-halomethylene-4-cyclopentene-1,3-diones was developed. It is of interest to extend this type of ring expansion reactions and utilize it as a convenient method for the preparation of other natural cyclopentenediones, such as methyl linderone (107). The specific utilization of this methodology in the synthesis of methyl linderone is described in this chapter.

\subsubsection{Retrosynthetic analysis}

The proposed retrosynthetic route and a retrosynthetic analysis of methyl linderone (107), which takes advantage of the above rearrangement, is outlined in Scheme 27. It diagrams linderone and methyl linderone can be prepared from a general precursor cyclopentenedione $\mathbf{1 3 8 .}$ 138 can be seen as the product of the ring expansion of 4-ene-yne substituted cyclo-2-buten-1-one $\mathbf{1 3 7}$ in the presence of NIS. Compound $\mathbf{1 3 7}$ can be formed from deprotonation of 4-phenyl-3-butene-1-yne (136) ${ }^{93}$ followed by addition of dimethyl squarate (7). This came to fruition. 


\section{Scheme 27: Retrosynthetic analysis of methyl linderone}

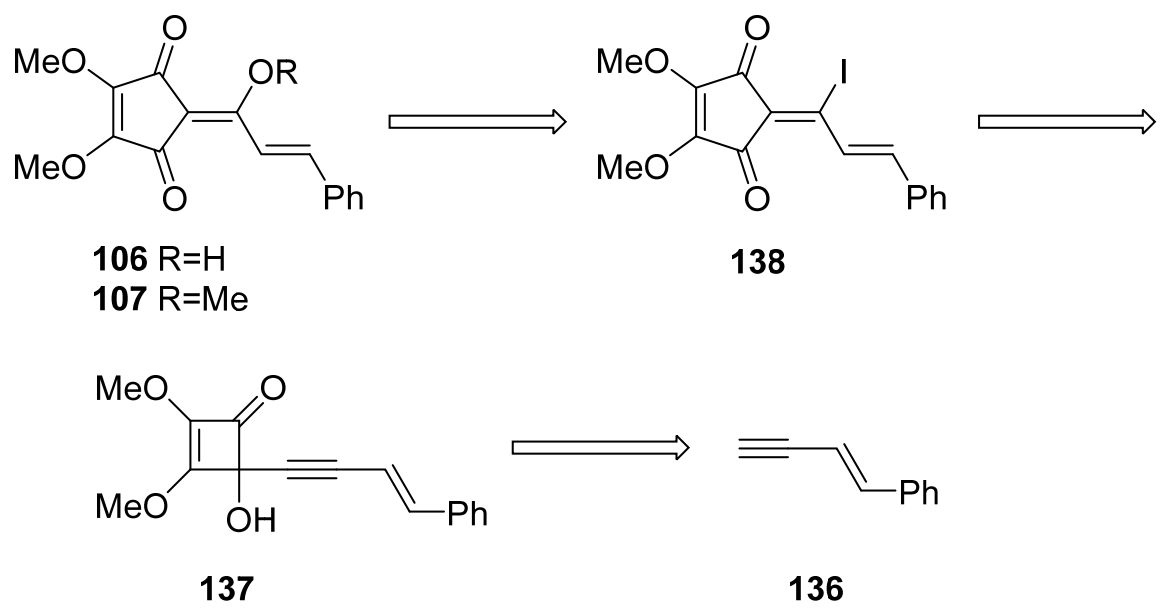

\subsubsection{Results and discussion}

The synthesis was performed using the 4-ene-yne substituted cyclo-2-buten-1-one 137 and NIS (Scheme 28). Deprotonation of 4-phenyl-3-butene-1-yne (136) with butyllithium followed by addition of dimethyl squarate (7) gave 2,3-dimethoxy-4-(5-phenyl-3-penten-1-ynyl)4-hydroxy-3-cyclobutene-1-one (137) in 47\% yield. To our knowledge, only three cases of thermal ring expansions of 4-ene-yne-substrates have previously been reported affording five-membered cyclic products. ${ }^{12}$ An intermolecular Diels-Alder dimerization of the diene system of the product has been reported and was initially a concern. Fortunately, thermolysis of 137 in the absence of NIS gave only 139 without a trace of Diels-Alder product. Reaction of 137 with $N$-iodosuccinimide gave the expected cyclopentenedione 138. The iodide in $\mathbf{1 3 8}$ was smoothly replaced with a methoxy group to give the natural product methyl linderone (107) in a comparable $15 \%$ overall yield to the synthesis seen in Scheme 28. While the substitution of an iodide for a methoxy group was facile, we were unable to introduce a hydroxy group under basic or acidic conditions. Even the small amount of dimethylamine formed or present in dimethylformamide (DMF) reacted preferentially to give the dimethylamino derivative 140 . 
Treatment of 138 using a number of other solvent systems including tetrahydrofuran- $\mathrm{H}_{2} \mathrm{O}$, 1,4-dioxane- $\mathrm{H}_{2} \mathrm{O}$, and $\mathrm{N}$-methylpyrroli-dinone- $\mathrm{H}_{2} \mathrm{O}$ under both basic and acidic conditions only resulted in no reaction or decomposition of the starting material.

\section{Scheme 28: Synthesis of methyl linderone}

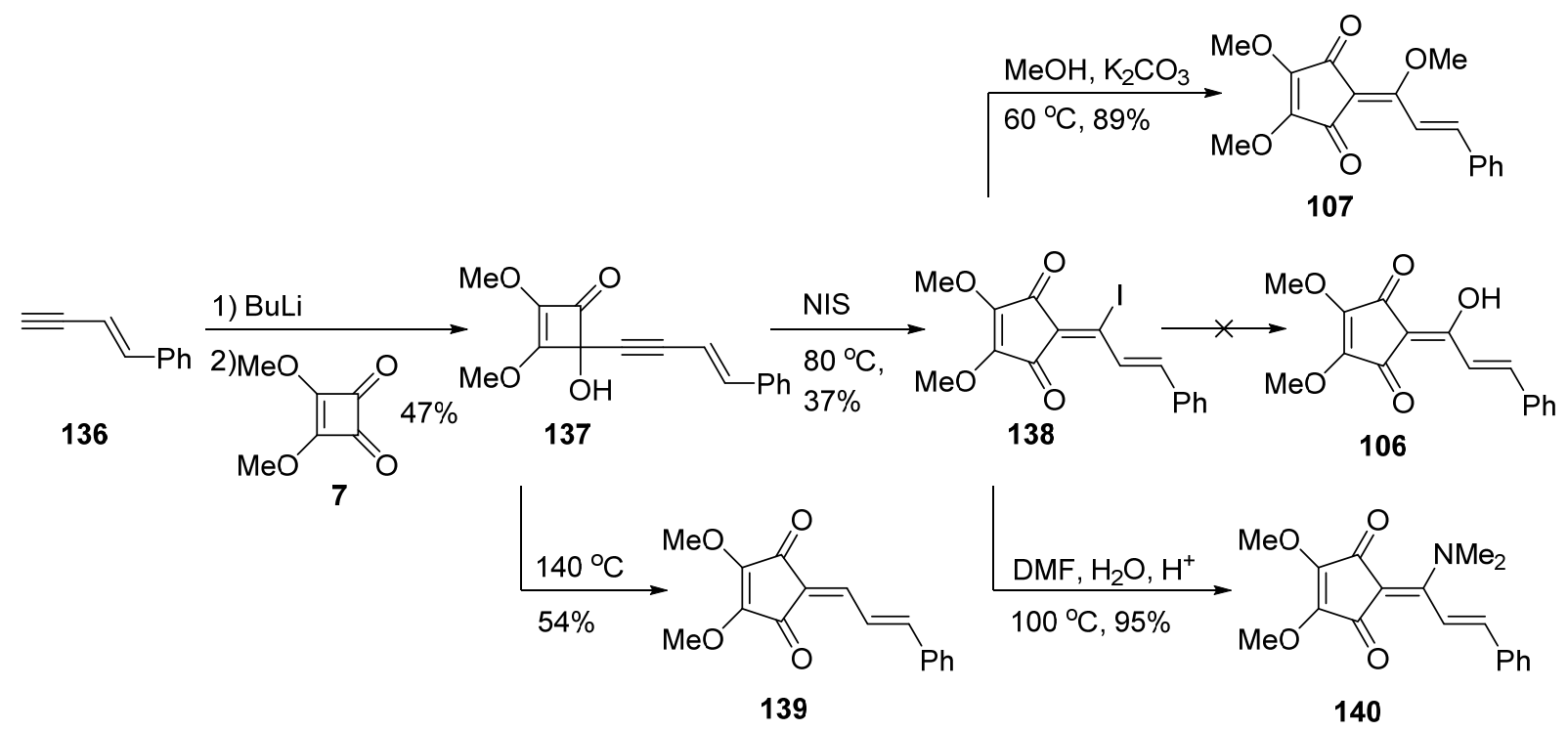

\subsubsection{Conclusions}

We have achieved an efficient short-step total synthesis of methyl linderone in only three steps with an overall yield of $15 \%$ from dimethyl squarate. The rearrangement of 4-ene-yne-substituted cyclo-2-buten-1-ones to halo-substituted cyclopentenediones in the presence of $N$-halosuccinimide can be utilized as key steps in the construction of cyclopentenedione derivatives having a variety of substitution patterns, which constitute members of a rare class of compounds with potential to be further developed to anti-cancer reagents and anti-tumor drugs in the future. 


\section{Chapter 3}

Synthesis of $\alpha$-arylated ketones via Wacker-type oxidation of aryl-

\section{substituted alkenes}

$3.1 \alpha$-Arylated ketone background

3.2 Wacker-type oxidation

3.3 Wacker-type oxidation of aryl-substituted alkenes

3.4 Results and discussion

3.5 Conclusions 


\section{1 $\underline{\alpha-a r y l a t e d ~ k e t o n e ~ b a c k g r o u n d ~}$}

The $\alpha$-arylated ketone structural skeleton can be seen in a variety of biologically active natural products and they are very useful synthetic intermediates of active pharmaceutical ingredients such as coumestan (141), ${ }^{94}$ phenylbenzofurans $\mathbf{1 4 2},{ }^{95}$ and isoflavones 143 (Figure 10). ${ }^{96}$ In organic synthesis, $\alpha$-arylated carbonyl compounds could be used as synthetic building blocks in constructing more complicated substituted heterocycles such as indoles, furans, imidazoles, oxazoles, and pyrazoles. ${ }^{97}$

Figure 10: Structures of coumestan, phenylbenzofurans, and isoflavones<smiles>O=c1oc2ccccc2c2oc3ccccc3c12</smiles>

coumestan 141<smiles>[R17]c1ccc2oc(-c3ccccc3)cc2c1</smiles>

phenylbenzofurans 142<smiles>O=c1c(-c2ccccc2)coc2cc[R]#cc12</smiles>

isoflavones 143

The selective installation of an aryl group in the $\alpha$-position of a carbonyl group has been an intense research subject over the past 40 years ${ }^{98}$ and many synthetic methods have been reported ${ }^{99-102}$ to construct these scaffolds, such as reaction of an enolate with a derivative of benzyne, ${ }^{99}$ aryl reagents, ${ }^{102}$ Grignard reaction of benzamides with benzylmagnesium halides, ${ }^{103}$ Friedel-Crafts reaction of phenols with various phenylacetic acids in $\mathrm{BF}_{3}-\mathrm{Et}_{2} \mathrm{O},{ }^{104}$ and so on.

However, due to their own limitation, the transition metal-catalyzed direct coupling of aryl halides 144 or pseudohalides with enolates 145 obtained in situ from the corresponding ketones under basic conditions to synthesize of $\alpha$-aryl substituted ketones 146 has emerged over the last three decades as a highly versatile method for the inter- and intramolecular construction of $\alpha$-arylated ketones (Scheme 29). ${ }^{105-107}$ The most commonly employed 
catalysts in the field of $\alpha$-arylation of ketones with aryl halides are the palladium catalysts.

Scheme 29: Transition metal-catalyzed arylation reactions of ketone enolates

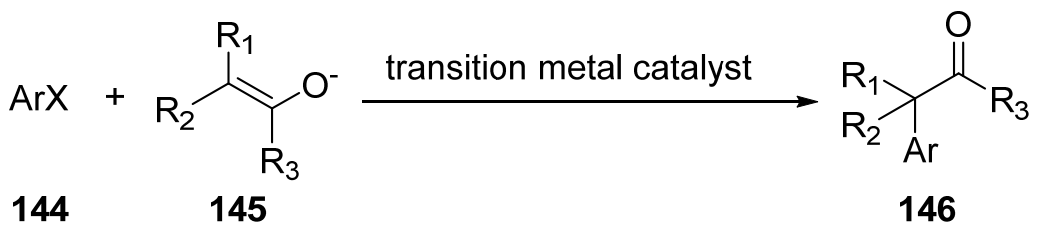

( $X=$ halogen or pseudohalogen)

The earliest examples of transitional metal-catalyzed $\alpha$-arylation of ketone enolates with aryl halides and pseudohalides was by Kuwajima, ${ }^{108}$ Buchwald, ${ }^{109}$ and Hartwig, ${ }^{110}$ in 1980 s and 1990s. The reactions were usually carried out with a base and a combination of $\mathrm{Pd}(\mathrm{OAc})_{2}$ or a $\operatorname{Pd}(0)$ compound such as $\operatorname{Pd}_{2}(\mathrm{dba})_{3}$ or $\operatorname{Pd}(\mathrm{dba})_{2}$ and a suitable phosphine ligand. One example of the synthetic utility of this methodology is Miura et al. ${ }^{111}$ in 1999 prepared a variety of 2,3-diarylbenzofurans 149 via reaction of aryl benzyl ketones 147 with $o$ dibromobenzenes 148 (Scheme 30).

Scheme 30: Synthesis of 2,3-diarylbenzofurans by means of a palladium catalyst system

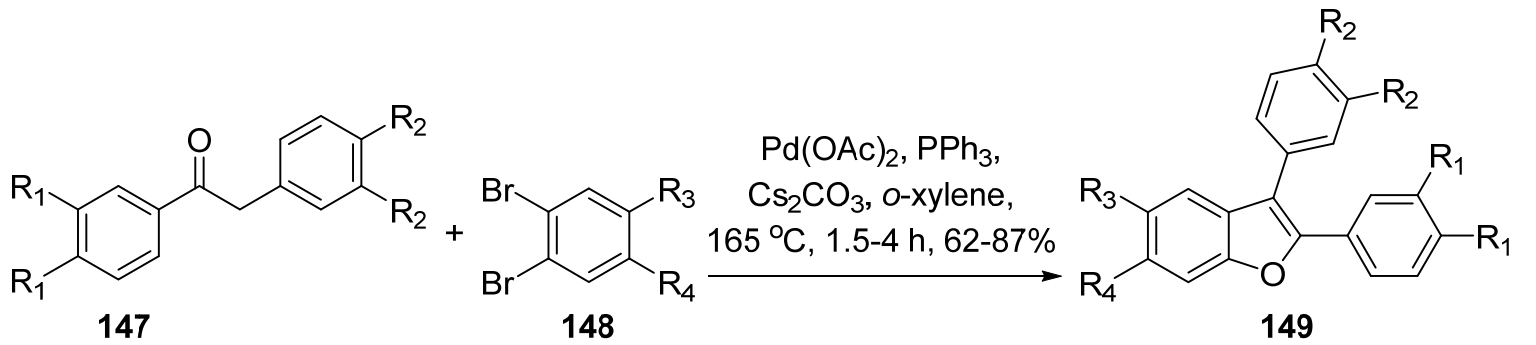

A plausible reaction sequence and key steps for these palladium-catalyzed reactions involves (i) the oxidative addition of the aryl halide to a $\operatorname{Pd}(0)$ species; (ii) arylation at the benzylic position of the aryl benzyl ketone in the presence of a base, (iii) C-O bond formation, as shown in Scheme 31, (iv) a reductive elimination reaction of Pd species resulting observed diarylbenzofurans 149. 
Scheme 31: Plausible reaction mechanism for the synthesis of 2,3-diarylbenzofurans<smiles>[R]c1cc2oc([Y10])c([Y16])c2cc1[R]</smiles>

In addition to tertiary phosphines, many excellent supporting ligands have been investigated in numerous palladium-catalyzed reactions and alternatives to the tertiary phosphines have been developed. ${ }^{112-114}$ A number of Pd-complexes catalysts show excellent activity in the $\alpha$-arylation of various ketone substrates with aryl halides, such as allylchloro[1,3-bis(2,6-di-i-propylphenyl)-4,5-dihydroimidazol-2-ylidene]palladium $[(\mathrm{SIPr}) \mathrm{Pd}(\mathrm{allyl}) \mathrm{Cl}] \quad \mathbf{1 5 0}^{112,113}, \quad$ complex $\quad(\mathrm{IPr}) \mathrm{Pd}(\mathrm{OAc})_{2} \quad \mathbf{1 5 1}^{114} \quad[\mathrm{IPr}=1,3-$ bis$(2,6-$ di-ipropylphenyl)imidazol-2-ylidene], (IPr)Pd(acac)Cl $152^{115}$, aminopalladacycle $153{ }^{78}$ complex $\mathbf{1 5 4},{ }^{79} \mathbf{1 5 5},{ }^{80} \mathbf{1 5 6},{ }^{81}$ and $157 .{ }^{116-120}$ 
Figure 11: Chemical structures of various palladium-complex catalysts<smiles>CCCc1cccc(C(C)C)c1N1CCN(c2c(C(C)C)cccc2C(C)C)C1=[PH](Cl)Cl</smiles>

$[(\mathrm{SIPr}) \operatorname{Pd}(\mathrm{allyl}) \mathrm{Cl}]$ 150<smiles>CC(C)c1cccc(C(C)C)c1N1C=CN(c2c(C(C)C)cccc2C(C)C)C1C</smiles><smiles></smiles>

$(\operatorname{IPr}) \operatorname{Pd}(\mathrm{OAc})_{2}$ 151

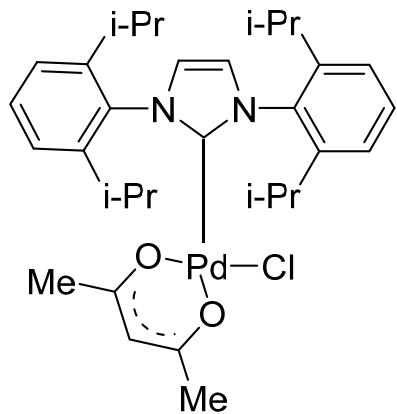

$(\mathrm{IPr}) \operatorname{Pd}(\mathrm{acac}) \mathrm{Cl}$ 152<smiles>COOCON1c2ccccc2-c2ccccc2[PH]1(O)Cl</smiles>

153<smiles>C=C[Te](Cl)C1N([Al])C(C)(C)C[C@@]12CCCC(C)C2</smiles>

154: $\mathrm{Ar}=2,6-\mathrm{di}-\mathrm{i}-\mathrm{PrC}_{6} \mathrm{H}_{3}$<smiles>[R20][R]([X])([H])c1c(OP)cc(C(=O)OCC)cc1OP</smiles>

156: $\mathrm{R}=\mathrm{i}-\mathrm{Pr} ; \mathrm{X}=\mathrm{Cl}$ 157: $\mathrm{R}=\mathrm{Ph} ; \mathrm{X}=\mathrm{OCOCF}_{3}$

Khartulyari and Maier in 2007 highlighted the synthetic utility of the palladiumcatalyzed intramolecular $\alpha$-arylations of ketones in an attempt to prepare benzomorphan analogues 159. ${ }^{121}$ Specifically, the cyclization of bromoketoesters $158 \mathbf{a}$ and $\mathbf{1 5 9 b}$ was carried out in refluxing toluene in the presence of $\mathrm{K}_{3} \mathrm{PO}_{4}$ as the base and a $\mathrm{Pd}(\mathrm{dba})_{2}$ and $\mathrm{P}(t-\mathrm{Bu})_{3}$ as the catalyst system to give tricyclic compounds $159 \mathrm{a}$ and $159 \mathrm{~b}$ in $35 \%$ and $36 \%$ yield, respectively (Scheme 32). 


\section{Scheme 32: Synthesis of the benzomorphan derivatives}

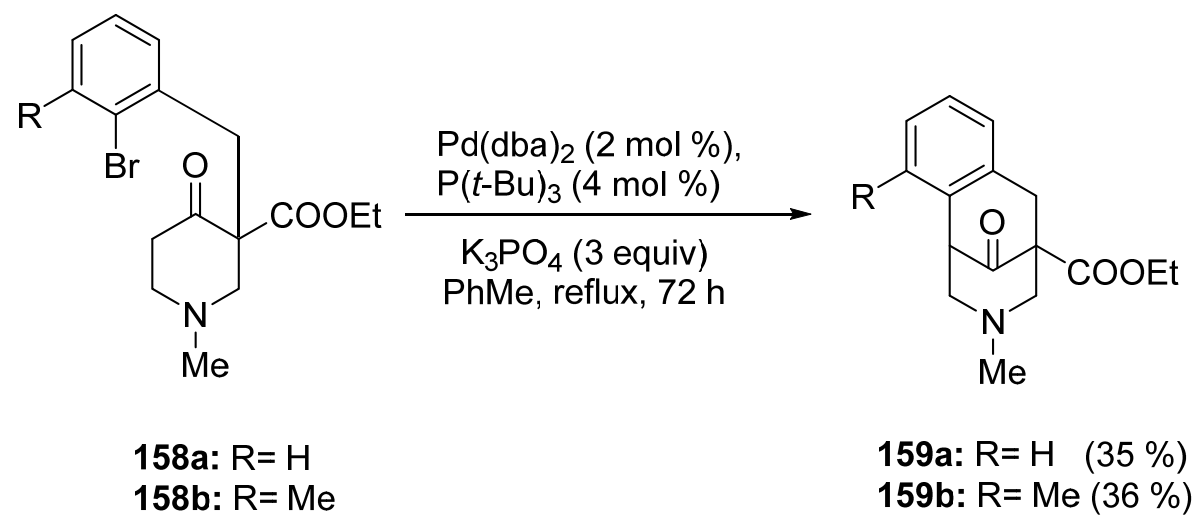

From 1998 until now, several asymmetric syntheses using the transition metalcatalyzed $\alpha$-arylation of ketone with aryl halides have been developed. ${ }^{95-98}$ For instance, in 1998, Buchwald et al. performed the intermolecular asymmetric arylation of 2-methyl- $\alpha-$ tetralones 160 with 5 equiv of aryl halide at $70{ }^{\circ} \mathrm{C}$, in the presence of 5 equiv of $\mathrm{NaOt}$-Bu and $\mathrm{Pd}_{2}(\mathrm{dba})_{3} /(S)$ - or $(R)$-BINAP catalyst system. ${ }^{122}$ The enantio-enriched products 161 were obtained with good levels of the yield and enantiomeric excess (ee) (Scheme 33).

\section{Scheme 33: Asymmetric a-arylation of 2-methyl-a-tetralones}

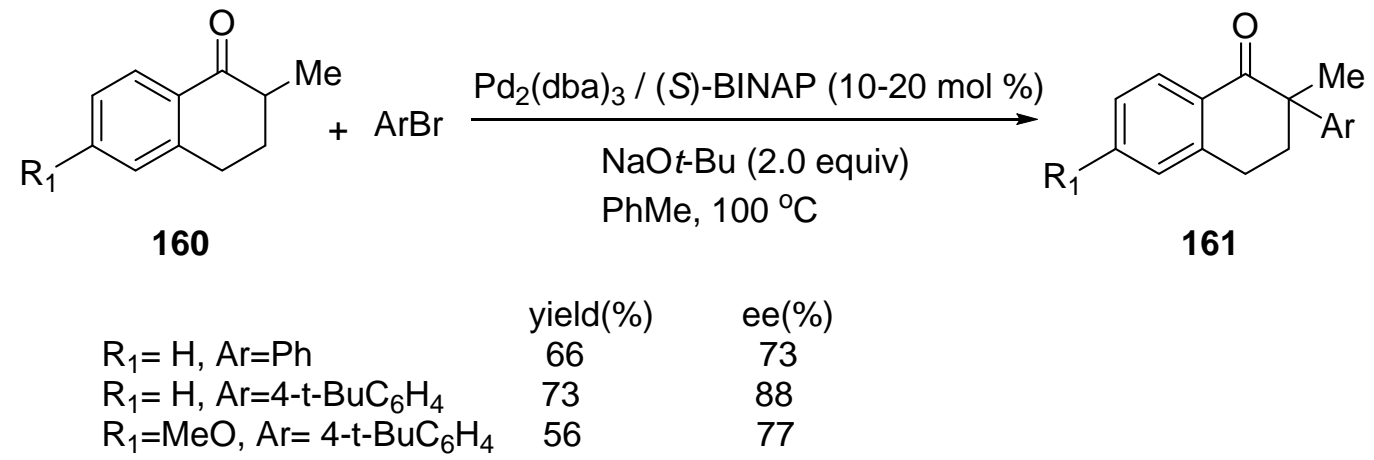

In addition to palladium catalyzed $\alpha$-arylation, nickel catalyzed asymmetric synthesis of ketones from organic halides and cycloalkanones was reported as well. In 2006, Kwong, Chan et al. used the atropoisomeric dipyridylphosphine $(R)-\mathrm{P}-\mathrm{Phos}^{123}$ to help pioneer $\mathbf{1 6 3}$ formation utilizing nickel-catalyzed $\alpha$-arylation of cycloalkanone 162 with aryl halides 144. Product 163 was enantio-selectively synthesized in excellent yields and ee (Scheme 34). 


\section{Scheme 34: Nickel-catalyzed enantioselective $\alpha$-arylation of cycloalkanones}

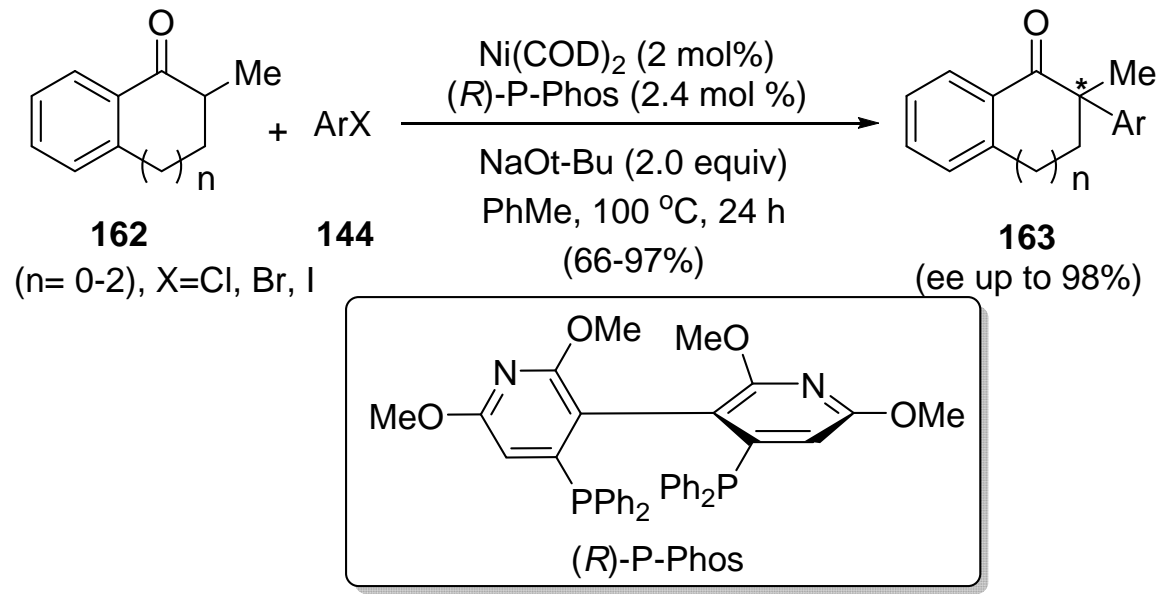

It is important to note that the synthesis of $\alpha$-aryl substituted ketones by $\alpha$-arylation of ketones with aryl halides or pseudohalides has been used extensively for the construction of key intermediates in pharmaceutically important compounds.

For example, $N$-tosyl-2'-aminoacetophenone (164) reacted with orthodibromobenzene (165) in toluene and water at $120{ }^{\circ} \mathrm{C}$ in the presence of $\mathrm{Cs}_{2} \mathrm{CO}_{3}$ and a combination of $\mathrm{Pd}(\mathrm{OAc})_{2}$ and XantPhos (Scheme 35) to provide intermediate 166 was a key step in a route to oxcarbazepine (167) (Trileptal). ${ }^{124}$ Trileptal is the most widely prescribed drug for the treatment of epilepsy both in children and adults.

Scheme 35: $\alpha$-Arylation of $N$-tosyl-2'-aminoacetophenone with $o$-dibromobenzene
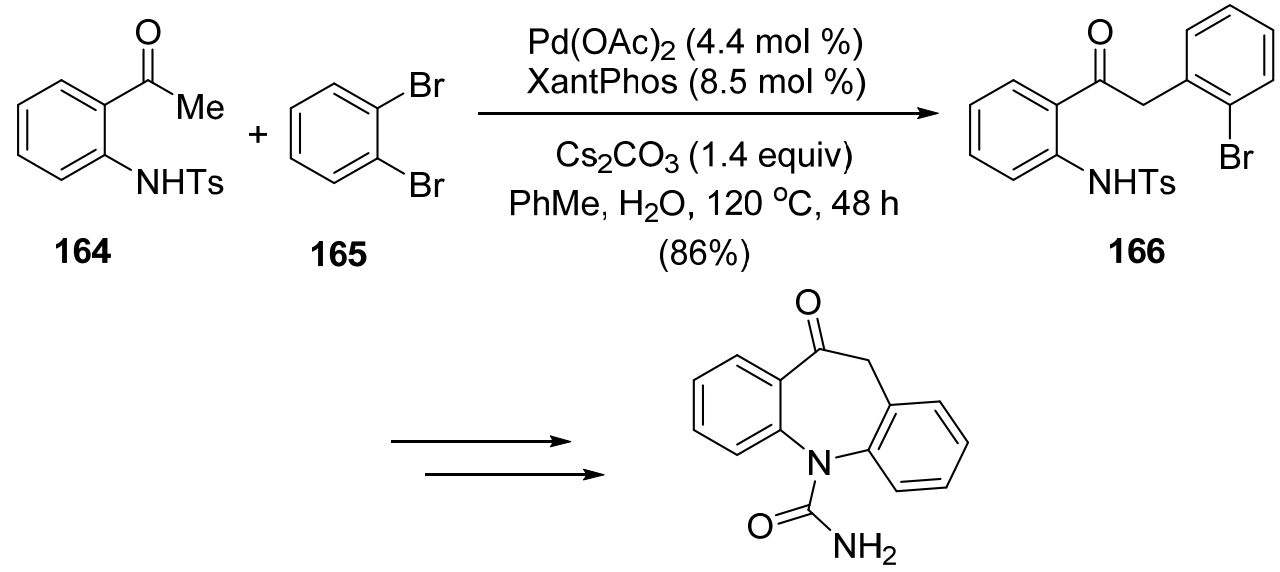

oxcarbazepine 167 
Another example is the synthesis of a wide variety of tamoxifen-related 1,2,2triarylethanones 170, which function as active selective estrogen receptor modulator in the treatment of breast cancer. ${ }^{125}$ SanMartin, Dominguez et al. in 2002 demonstrated that 170 were synthesized from the arylation reaction of aryl benzyl ketones $\mathbf{1 6 8}$ at the benzylic position with aryl bromides $\mathbf{1 6 9}$ (Scheme 36) with fair-to-good yield.

\section{Scheme 36: Pd-catalyzed synthesis of 1,2,2-triarylethanones from aryl benzyl ketones}<smiles>[R]c1ccc(CC(=O)c2ccc([R2])c([R2])c2)cc1[R]</smiles>

168<smiles>[R5]c1ccc(Br)c([R3])c1[R]</smiles>

169<smiles>[R2]c1ccc(C(=O)C(c2ccc([R])c([R])c2)c2ccc([R5])c([R])c2[R])cc1[R]</smiles>

170

$\mathrm{R}_{1}=\mathrm{H}, \mathrm{OMe} ; \mathrm{R}_{2}=\mathrm{H}, \mathrm{OMe} ; \mathrm{R}_{3}=\mathrm{H}, \mathrm{OMe}$

$\mathrm{R}_{4}=\mathrm{H}, \mathrm{OMe}, \mathrm{OCH}_{2} \mathrm{O} ; \mathrm{R}_{5}=\mathrm{H}, \mathrm{OMe}, \mathrm{NO}_{2}$

Later in 2004, 1,2,2-triarylethanones $\mathbf{1 7 0}$ were synthesized from acetophenones 171 and aryl bromides 172 in a better yield (Scheme 37). ${ }^{126}$ Specifically, method A focused on the use of the system $\mathrm{Pd}(\mathrm{OAc})_{2} / \mathrm{PPh}_{3} / \mathrm{Cs}_{2} \mathrm{CO}_{3}$, while method $\mathrm{B}$ entailed the use of the commercially available polymerbound catalyst FiberCat1026.

\section{Scheme 37: Pd-catalyzed synthesis of 1,2,2-triarylethanones from acetophenones}<smiles>[R]c1ccc(C(=O)C(c2ccc([R])c([R2])c2)c2ccc([R2])c([R2])c2)cc1[R2]</smiles>

Method A: $\mathrm{Pd}(\mathrm{OAc})_{2}, \mathrm{PPh}_{3}, \mathrm{Cs}_{2} \mathrm{O}_{3}$, DMF, $153^{\circ} \mathrm{C}, 1-7 \mathrm{~h}(35-91 \%)$

Method B: FibreCat 1026, $\mathrm{Cs}_{2} \mathrm{O}_{3}$, DMF, $153^{\circ} \mathrm{C}, 0.8-1 \mathrm{~h}(20-93 \%)$ 
Scheme 38: Pd-catalyzed synthesis of the acetonylpurine

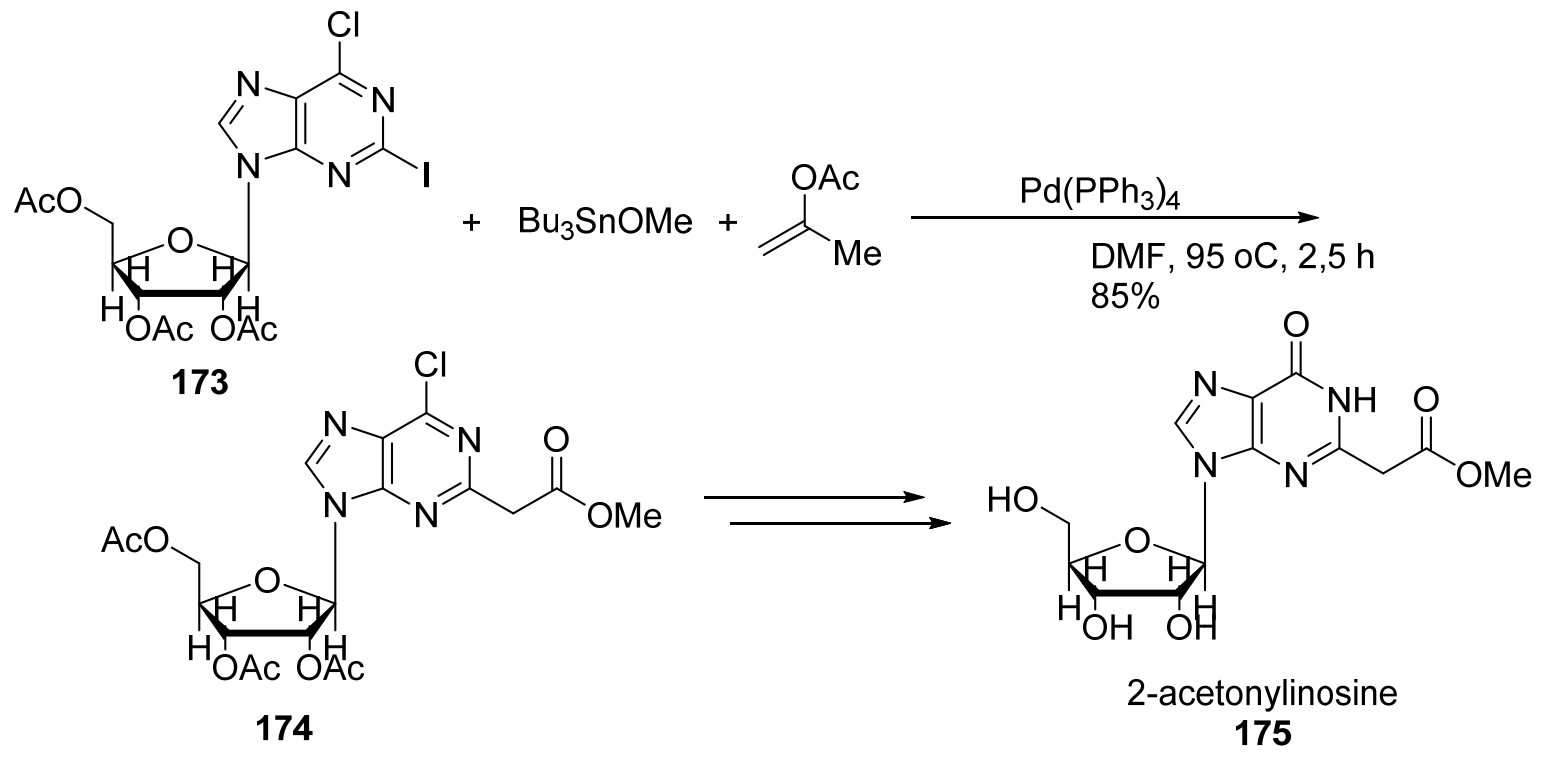

In 2005, Gupta and Nair ${ }^{127}$ applied the methodology in the synthesis of acetonylpurine (174), which is a important precursor in the synthesis of potent antiviral compound 2-acetonylinosine (175) via $\mathrm{Pd}\left(\mathrm{PPh}_{3}\right)_{4}$-catalyzed reaction of 6-chloro-2-iodopurine ribonucleoside (173), $\mathrm{Bu}_{3} \mathrm{SnOMe}$, and isopropenyl acetate (Scheme 38). Benzyl methyl ketone 177 was prepared using a similar protocol. Reaction of aryl bromide 176, isopropenyl acetate, and $\mathrm{Bu}_{3} \mathrm{SnOMe}$ in the presence of $\mathrm{Pd}_{2}(\mathrm{dba})_{3}$ and 2-diphenylphosphino-2'dimethylaminobinaphthyl catalyst system resulted the desired product in a good yield. ${ }^{128}$

Scheme 39: Pd-catalyzed synthesis of benzyl methyl ketone

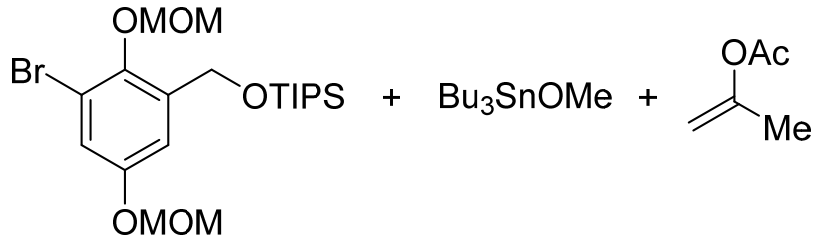

176<smiles>COc1cc(CO[SnH3])c(OC)c(CC(C)=O)c1</smiles><smiles>CN(C)c1ccccc1-c1ccccc1-c1ccccc1</smiles>

177 
Up to date, the transition metal-catalyzed synthesis of $\alpha$-aryl substituted ketones by $\alpha$ arylation of ketones with aryl halides or pseudohalides appears to be the most widely used as a very useful and powerful methodology for the formation of $\mathrm{Csp}^{3}-\mathrm{Csp}^{2}$ bonds. However, these reactions suffer from some drawbacks. For instance, some necessary ligands, catalysts, additives for the reactions are very expensive; some substrates do not tolerate the strongly basic reaction conditions or required harsh conditions such as elevated temperatures; sometimes multiple arylation might happen and specific protecting group need to be introduced to block one $\alpha$-position of the ketone.

Therefore, there is a need for the further development of direct installation of $\mathrm{C}(\mathrm{sp} 3)-\mathrm{C}(\mathrm{sp} 2)$ bonds. Recently, our research in Wacker-type oxidation of aryl-substituted alkenes to furnish diverse $\alpha$-aryl substituted ketones seems to be a promising alternative method for this goal. 


\subsection{Wacker-type oxidation}

The Wacker oxidation, olefin oxidation with $\mathrm{PdCl}_{2}$ catalysts, and related processes, has been a topic of research interest for well over a century. ${ }^{129}$ Smidt and co-workers were the first researchers to describe the overall process, and the transition metal promoted oxidation of ethylene to give acetaldehyde was realized in the late 1950 s by using palladium(II) chloride and copper(II) chloride as catalyst under an oxygen atmosphere (Scheme 40). ${ }^{130}$ This transformation was achieved by the oxidation of an olefin with an aerobic $\mathrm{PdCl}_{2}$-catalyzed, $\mathrm{Cu}$-mediated aqueous medium containing hydrochloric acid to a carbonyl.

The Wacker Process has remained one of the most important industrial process employing transition metal catalysts. Even though it was initially reported in 1962, it is still widely utilized for the industrial production of acetaldehyde from ethylene.

\section{Scheme 40: Individual reactions of the Wacker process}

$$
\begin{aligned}
& =+\mathrm{PdCl}_{2}+\mathrm{H}_{2} \mathrm{O} \longrightarrow \stackrel{\mathrm{O}}{\mathrm{H}}_{\mathrm{H}}+\mathrm{Pd}(0)+2 \mathrm{HCl} \quad \text { Eq. (1) } \\
& \mathrm{Pd}(0)+2 \mathrm{CuCl}_{2} \longrightarrow \mathrm{PdCl}_{2}+2 \mathrm{CuCl} \text { Eq. (2) } \\
& 2 \mathrm{CuCl}+2 \mathrm{HCl}+1 / 2 \mathrm{O} \longrightarrow 2 \mathrm{CuCl}_{2}+\mathrm{H}_{2} \mathrm{O} \\
& \angle+1 / 2 \mathrm{O} 2 \longrightarrow \stackrel{\mathrm{O}}{\mathrm{H}_{\mathrm{H}}}
\end{aligned}
$$

The Wacker oxidation reaction of ethylene involves three sequential stoichiometric oxidation and reduction reactions to constitute a catalytic cycle. Eq. (1) in Scheme 40 represents an oxidation reaction involving a $\mathrm{Pd}(\mathrm{II})$ catalyst which has been known for more than a century; ${ }^{131}$ Eq. (2) indicates the formed $\operatorname{Pd}(0)$ in eq. (1) could be regenerated by cupric chloride in situ; the final step [Eq. (3)] is the re-oxidation of $\mathrm{CuCl}$ to $\mathrm{CuCl}_{2}$. The net reaction 
of these three reactions leads to a simple air oxidation of ethene to ethanal.

In addition to ethylene, several synthesis have been developed by Smidt and coworkers specifically to produce other carbonyl compounds. ${ }^{130}$ These studies involve a wide variety of starting materials and reaction conditions, including both an acidic aqueous solution of palladium(II) chloride and organic media. ${ }^{132,133}$ In general, terminal olefins are transformed to methyl ketones rather than aldehydes through Wacker process as shown in Scheme 41.

\section{Scheme 41: Wacker process of terminal alkenes}

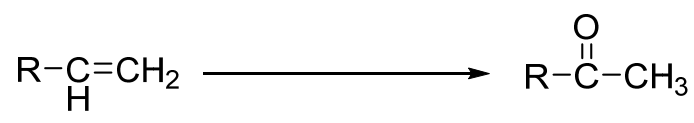

Although a lot of efforts have focused on the mechanism study of Wacker reaction, ${ }^{134-}$ 136 a textbook example of a homogeneous transition-metal-catalyzed reaction, no "true" pathway of the Wacker oxidation process was described so far due to its complicated kinetics. However an abbreviated scheme of the complete catalytic cycle of the Wacker process was proposed in Scheme 42, ${ }^{137}$ involving four key steps: the coordination of terminal alkene 179 to a palladium(II) species 178; nucleophilic attack of water to the palladium-alkene complex 180 results intermediate $\mathbf{1 8 1}$. Hydride shift in $\mathbf{1 8 1}$ followed by a reductive elimination furnish methyl ketone $\mathbf{1 8 2}$ and regenerate palladium(0) species, which could be reoxidized to palladium(II) catalyst. Extraordinary amount of research has provided strong evidence that subtle changes in experimental conditions, such as the structure of olefins, solvents and reoxidants, can result in substantially different reaction mechanisms, ${ }^{138,139}$ rates and yields. 
Scheme 42: Overall catalytic cycle of the Wacker process

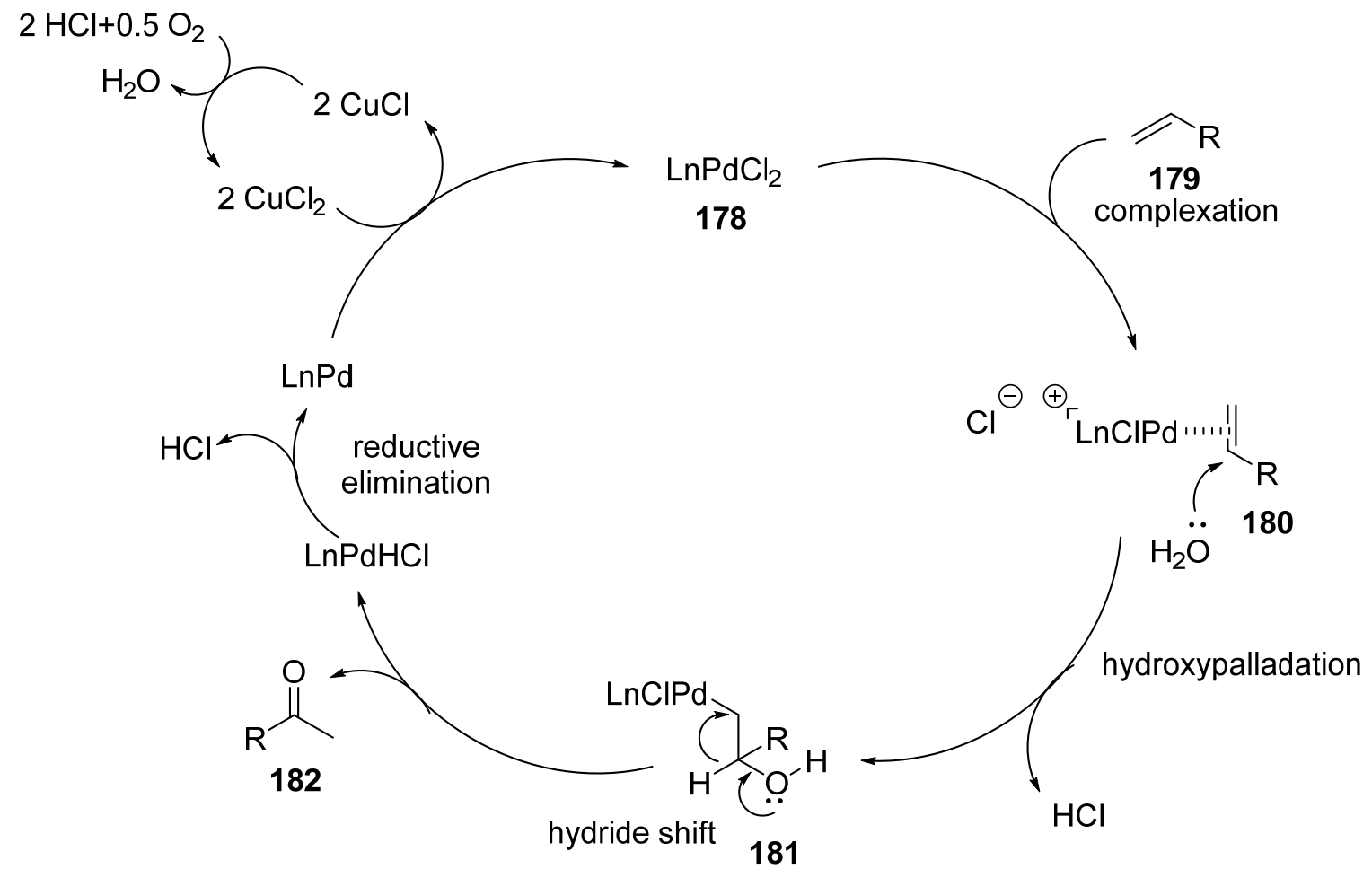

The oxidation on a laboratory scale can be carried out with palladium(II) catalyst and a copper salt under an oxygen atmosphere at room temperature using an apparatus as depicted in Figure 12.

\section{Figure 12: Typical apparatus for Wacker-type oxidation}

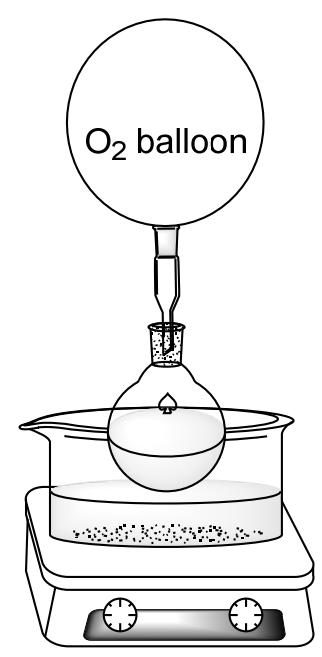

In order to apply this methodology to more complicated substrates, mixed-solvent systems have been developed and a lot of molecule-targeted syntheses were performed under 
various conditions. ${ }^{130,134,139}$ The Wacker oxidations of higher terminal olefins are slow but this problem can be partly solved by the addition of suitable organic solvents which can mix olefins with water. However, it is worth noticing that oxidation and isomerization of the double bond are competitive reactions, and the extents of the reactions are influenced by solvents. For instance, dimethylformamide is good for the oxidation, whereas use of acetic acid facilitate the isomerization. ${ }^{139}$ The double bond migration is facilitated by high temperatures. $^{140}$

A typical synthetic Wacker procedure, a mixed-solvent system of $N, N$ dimethylformamide and $\mathrm{H}_{2} \mathrm{O}$ with catalytic $\mathrm{PdCl}_{2}$ and stoichiometric $\mathrm{CuCl}$ under an aerobic atmosphere is referred to as Wacker-Tsuji oxidation. These classical conditions, using $N, N$ dimethylformamide (DMF)/ $\mathrm{H}_{2} \mathrm{O}$ mixture and stoichiometric $\mathrm{CuCl},{ }^{141}$ are developed by Tsuji based on modification and extension of the simple Wacker oxidation. Compared to other reported modified Wacker oxidation systems, these conditions are most common because of their convenience and simplicity. ${ }^{134}$

Many modifications for Wacker oxidation have been made. Other than $\mathrm{PdCl}_{2}$, palladium(II) trifluoroacetate, palladium(II) acetate, disodium tetrachloropalladate, palladium(II) sulfate, palladium(II) chloride-cobalt complexes, bis[acetonitrile]chloronitropalladium complex ${ }^{139}$ and so on were used as catalysts as well. Sometimes, palladium catalyst deactivation occurs during the reaction by the precipitation of black palladium metal, even when no precipitation is observed. The reason accounts for this issue is the formation of palladium(II) complex. For example, palladium(II) chloride bis-dimethylamine complex deactivates the catalyst when dimethylformamide is used as a solvent, ${ }^{133}$ and $\pi$-allyl 
palladium complexes $\mathbf{1 8 3}$ may retard the reaction when some olefin substrates were used as a reactants. $^{142}$

\section{Figure 13: Palladium complex accounts for the deactivation}

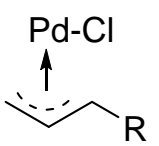

183

Therefore, the activation of the palladium catalyst is a common issue in the Wacker oxidation as well as other $\operatorname{Pd}(\mathrm{II})$-catalyzed oxidation reactions. Simple Wacker process adopts copper(II) chloride as a cocatalyst to efficiently regenerate the active $\mathrm{Pd}$ (II) catalyst. A number of other reoxidants have been introduced, ${ }^{139}$ such as copper(I) chloride, copper(II) nitrate, copper(II) acetate, benzoquinone, hydrogen peroxide and t-butyl hydroperoxide. Compared to copper(II) catalyst, copper(I) chloride, when pretreated with oxygen, is used no chlorination of ketones takes place and the rate of the reaction is high. Benzoquinone was another good reoxidant and was first used by Moiseev et al., ${ }^{143}$ but a stoichiometric amount is necessary. The ability of hydrogen peroxide and $t$-butyl hydroperoxide to reoxidize palladium $(0)$ as the terminal oxidant in the absence of $\mathrm{Cu}$ have been proved as well. ${ }^{144} \mathrm{In}$ 1980s, Mimoun and co-workers ${ }^{145}$ reported that high conversion and selectivity were obtained from terminal straight-chain olefins by using $0.067 \mathrm{~mol} \% \mathrm{Pd}(\mathrm{OAc})_{2}$ with 5 equiv of $\mathrm{H}_{2} \mathrm{O}_{2}(\mathrm{aq})$ in acetic acid (Scheme 43). The isotopic labeling studies using ${ }^{18} \mathrm{OH}_{2}$ indicated that the $\mathrm{O}$ atom incorporated into the ketone originated from hydrogen peroxide.

Scheme 43: Modified Wacker oxidation using $\mathrm{H}_{2} \mathrm{O}_{2}$ as the terminal oxidant

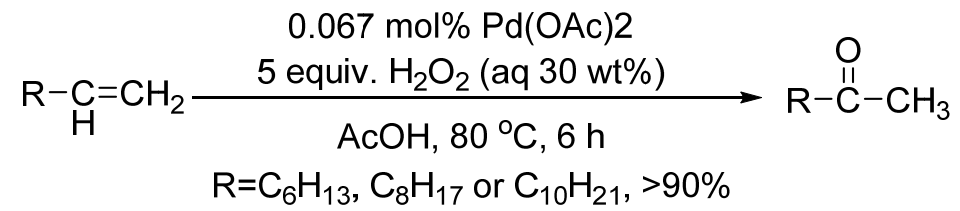


On the basis of this finding, a mechanism was proposed wherein a palladacyclic intermediate $\mathbf{1 8 4}$ is formed from peroxide insertion into the olefin, followed by an $\alpha$-hydride shift facilitated by O-O bond cleavage (Scheme 44). ${ }^{146}$ An exciting aspect of the proposed catalytic cycle is that $\mathrm{Pd}$ does not necessarily proceed through $\operatorname{Pd}(0)$ because catalyst regeneration can occur via a proton transfer from a peroxide to $\mathbf{1 8 5}$, regenerating active catalyst 186. This potentially alleviates the probability of $\operatorname{Pd}(0)$ aggregation and catalyst deactivation, which is a common problem in these oxidations.

\section{Scheme 44: Mimoun et al.'s mechanism for peroxide-mediated Wacker oxidation}

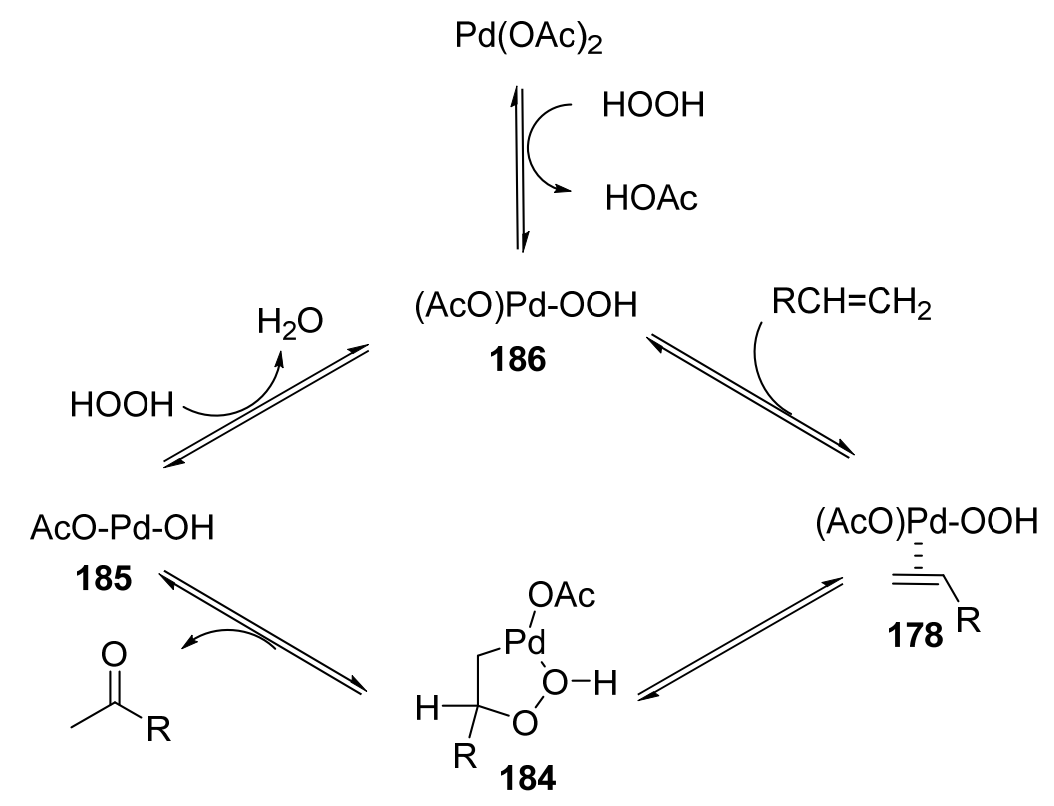

Methyl ketones are important functional groups and the palladium(II)-catalyzed oxidation of terminal olefins seems to be one of the best methods to methyl ketones because terminal olefins are easily available, stable under acidic, basic or nucleophilic conditions. ${ }^{139}$ Thus, synthetic organic chemists have paid great attention to the widespread use of the reaction as a synthetic method for ketones ${ }^{147}$ and carried out a considerable amount of work on the applications to organic synthesis. The reaction is an extremely useful method for the synthesis of a variety of natural product precursors and biologically active compound 
intermediates. Synthetic schemes from 45 to 52 are shown below as examples to demonstrate the usefulness of Wacker-type oxidation.

In 2006, Cook et al. ${ }^{148}$ successfully converted stable (+)-macroline equivalent $\mathbf{1 8 8}$ to (-)-alstonerine (189) in $12.6 \%$ overall yield, starting from tryptophan methyl ester 187, via an intramolecular Tsuji-Wacker oxidation (Scheme 45). The alkaloid 189 could be further converted into biogenetic intermediate (-)-talcarpine (190) and (-)anhydromacrosalhinemethine (191). The transformations constituted an improved total synthesis of the (-)-anhydromacrosalhine-methine (191) as well as (-)-talcarpine (190).

\section{Scheme 45: Formation of biogenetic intermediate 190 and 191}<smiles>COC(=O)C(N)Cc1c[nH]c2ccccc12</smiles>

187

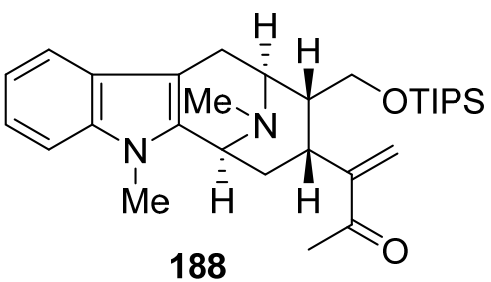

188

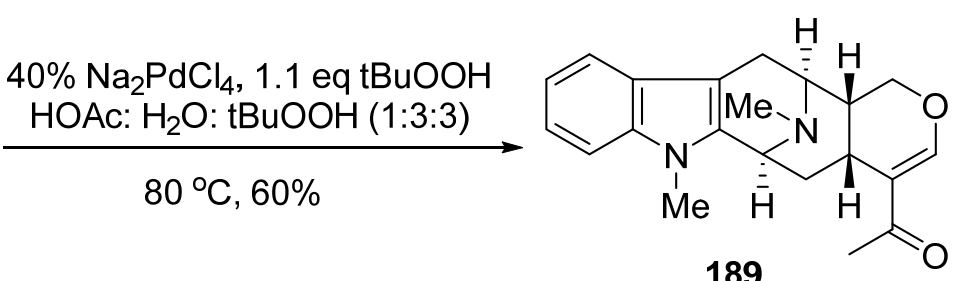

189<smiles>C[C@H]1OC[C@@H]2Cc3c(c4ccccc4n3C)C[C@H]2N1C</smiles>

(-)-talcarpine 190

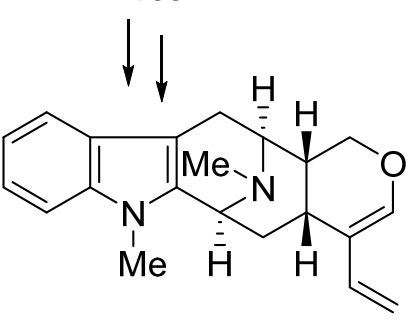

(-)-anhydromacrosalhine-methine 191

In 2011, Szolcsanyi et al. ${ }^{149}$ have reported up to date shortest routes with highest overall yields for three naturally occurring 2,6-disubstituted piperidine alkaloids, $(+)-$ dihydropinidine (196), (-)-epidihydropinidine (195) (as $\mathrm{HCl}$ salts), and (-)-pinidinone (199), which are naturally occurring defense chemicals, possessing antifeedant properties against 
budworm and usually isolated from many spruce and pinus species and various insects. The total syntheses began with (S)-epichlorohydrin (192) as common starting material, and regioselective copper-free Wacker-Tsuji oxidation of alkenylazides 193 and 197 as key steps to exclusively generate methyl ketones 194 and 198 (Scheme 46). 194 subsequently converted to (-)-epidihydropinidine (195) and (+)-dihydropinidine (196) with $34 \%$ and 54\% overall yield. The similar optimized Wacker-Tsuji transformation condition allowed the dialkenylazide 197 oxidized in good yield to the desired azidodiketone 198. The latter was finally converted to (-)-pinidinone (199) in high yield (Scheme 47) upon treatment with hydrogenation on Pearlman's catalyst in 35\% overall yield starting from 192.

Scheme 46: Synthesis of (+)-dihydropinidine and (-)-epidihydropinidine

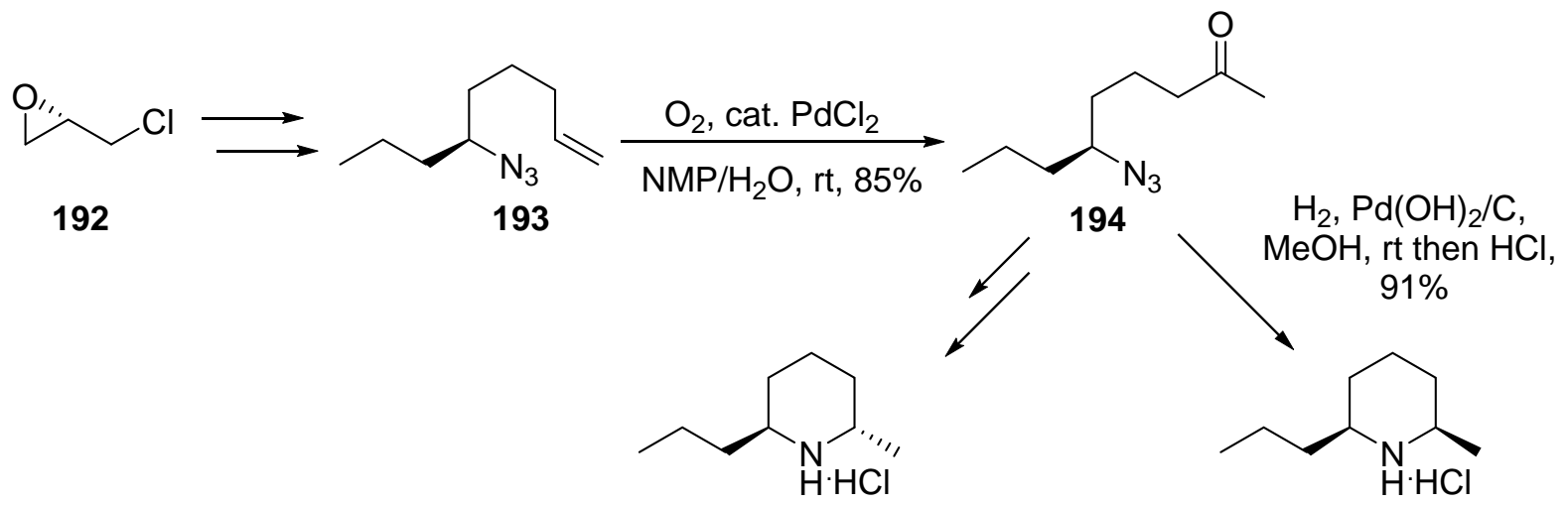

(-)-epiDHP

(+)-DHP

$195 \cdot \mathrm{HCl}$

$196 \cdot \mathrm{HCl}$

Scheme 47: Synthesis of (-)-pinidinone

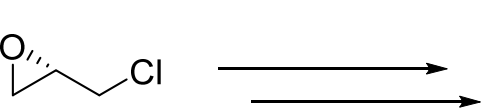

192<smiles>C=CCC(N)CCC/C=C\C(=O)OCC(C)CC(C)CC(N)CCCC(C)=O</smiles>

$\mathrm{H}_{2}, \mathrm{Pd}(\mathrm{OH})_{2} / \mathrm{C}, \mathrm{MeOH}, \mathrm{rt}, 70 \%$<smiles>CC(=O)C[C@@H]1CCC[C@H](C)N1</smiles>

(-)-pinidinone

199 
In 2013, Yaragorla et al. ${ }^{150}$ have demonstrated a concise approach toward the tetracycle 203, whose structural skeleton is contained in a diverse range of shiartane-type nortriterpenoids. They display a wide ranging bioactivity profile that includes anti-oxidant, anti-HIV, anti-cancer activities and possess great potential in modern drug discovery as well as in traditional medicine. The synthesis began with the conversion of synthon $(+)-\mathbf{2 0 0}$ to the epoxy-ketone 201 in six steps, followed by exposure of 201 to Wacker-Tsuji oxidation condition provided cleanly to the desired diketone $\mathbf{2 0 2}$ in $72 \%$ yield and set the stage for further four transformations to the tetracycle 203 (Scheme 48). The total synthesis was completed in 11 steps with $8 \%$ overall yield.

Scheme 48: Synthesis of tetracycle $(+)-203$

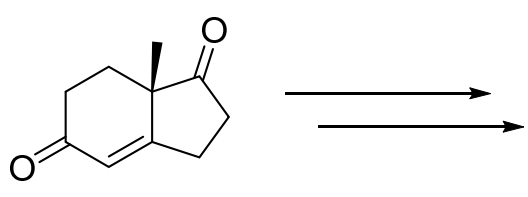

200<smiles>C=CCCC[C@]12O[C@]13CC[C@H](O[Sb])[C@@]3(C)CCC2=O</smiles>

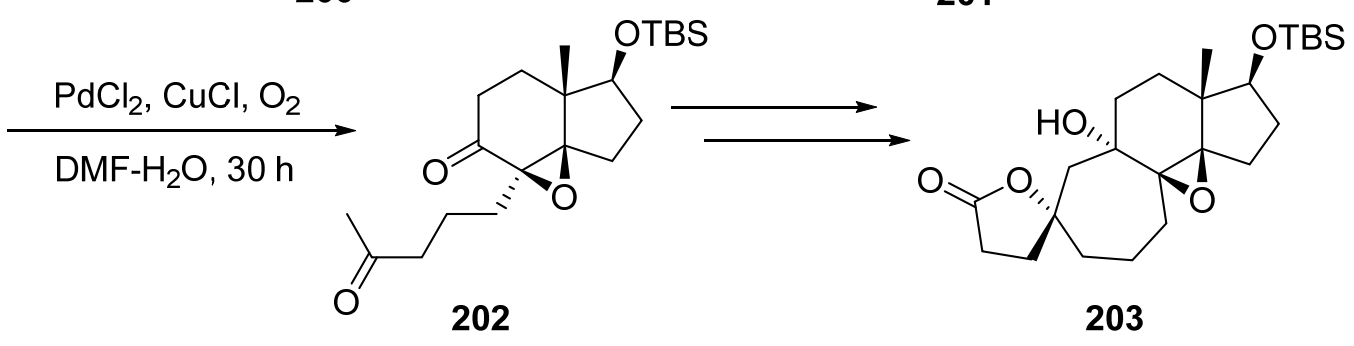

In 2013, Pipelier et al. ${ }^{151}$ utilized the Wacker-Tsuji oxidation in the stereoselective synthesis of a hexahydronaphthalene derivative $\mathbf{2 0 6}$, which was used as a building block or a suitable intermediate for the preparation of a variety of nardosinane-type compounds. Nardosinane sesquiterpene exhibits a wide biological activity spectrum and can be extracted from soft corals. They successful developed two synthetic strategies to realize this goal (Scheme 49). The first route was achieved by the Wacker-type oxidation of silyl ether 204 to 
give expected ketone $\mathbf{2 0 5}$ in $89 \%$ yield, which could be further transformed to bicyclic diene 206 in $60 \%$ yield $(\mathrm{dr}>95: 5)$ under acidic condition, (para-toluenesulfonic acid in acetone/water). Then they described their improvement in the access to diene $\mathbf{2 0 6}$ by a shorter synthesis. Same to the condition used in the first strategy, allylic enol 207 was oxidized to methyl ketone $\mathbf{2 0 8}$ in $65 \%$ yield, the tertiary hydroxy group in which was subsequently undergo dehydration under acidic conditions to afford diene 206 still with high diastereoselectivity $(\mathrm{dr}>95: 5)$ in $73 \%$ yield.

Scheme 49: Synthesis towards key hexahydronaphthalene 206

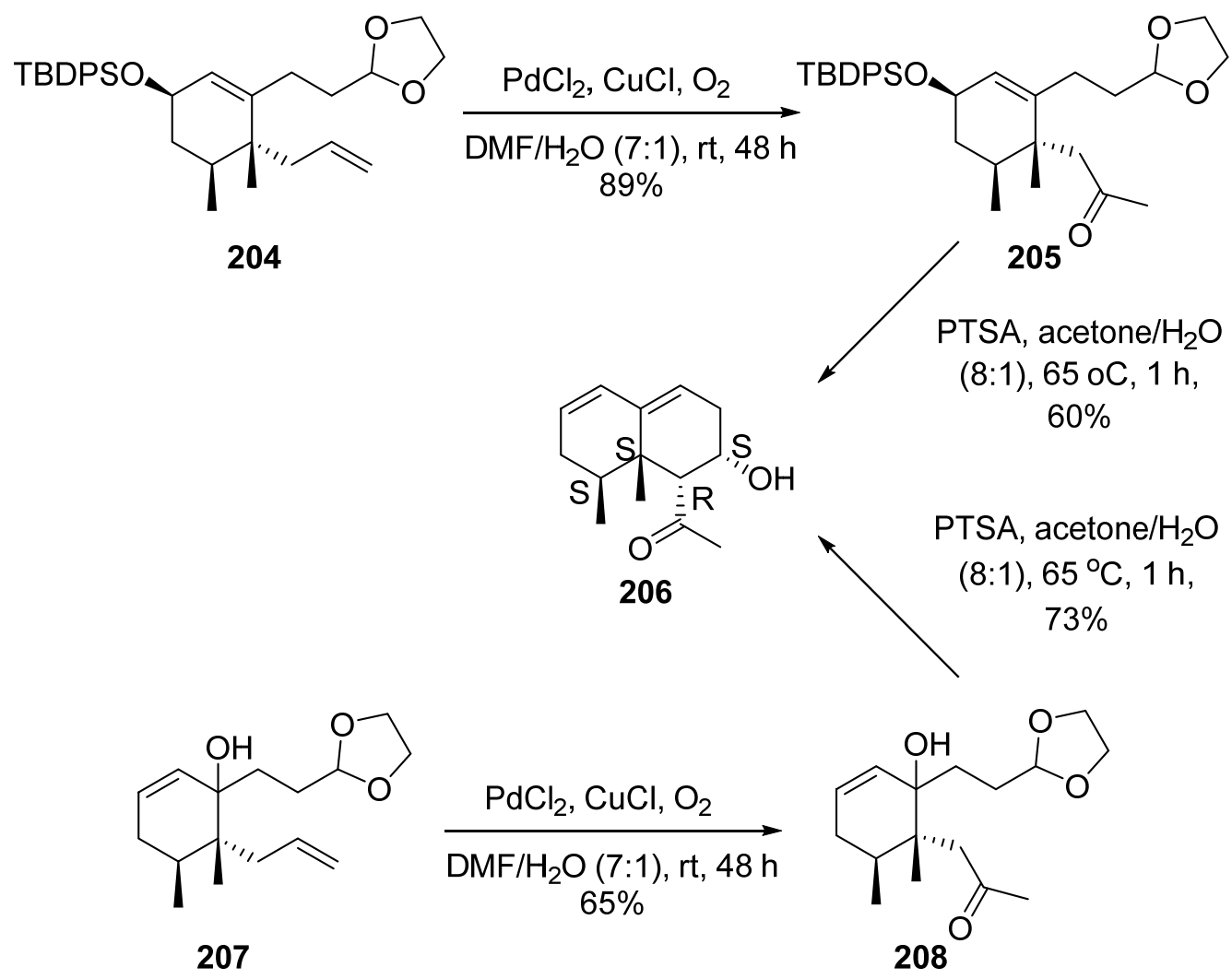

In 2004, Lubell et al. ${ }^{152}$ designed a convergent synthetic strategy from a series of structurally diverse aliphatic and aromatic esters 209 to give access to a range of pyrroles 212 by the three-step Grignard/Tsuji-Wacker/Paal-Knorr sequence in good yield and purity. Pyrroles are abundant as constituents of natural products ${ }^{5-8}$ and 1,2,5-trisubstitution pattern 
pyrroles display interesting biological properties, including antipsychotic, ${ }^{10-12}$ antiinflammatory, ${ }^{13,14}$ radioprotective, ${ }^{15}$ and spasmolytic ${ }^{16,17}$ activity. The oxidation of the olefin terminus was applied to ketone 210, generating the 1,4-dione 211, which could be used for next steps without further purification (Scheme 50).

Scheme 50: The synthesis of 1,2,5-trisubstituted pyrrole
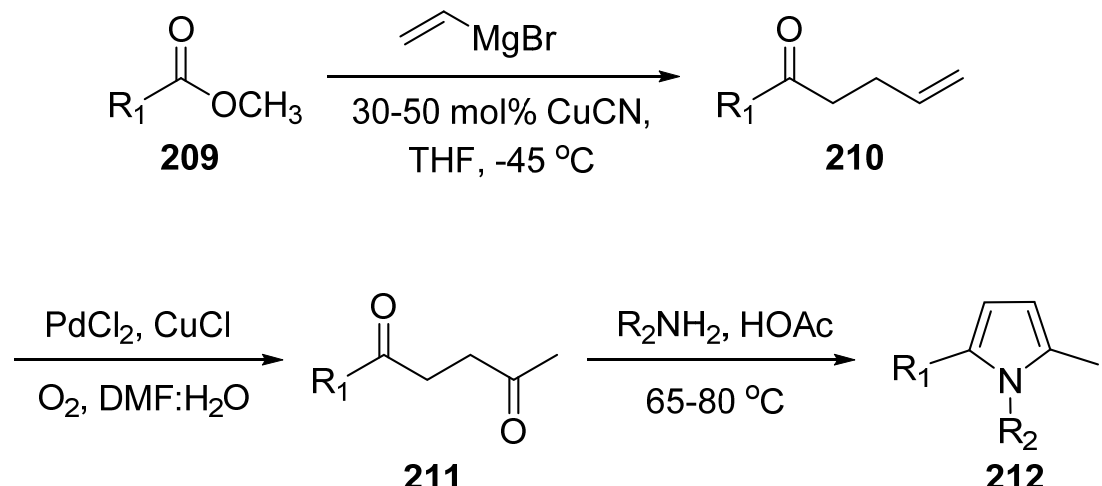

Scheme 51: $C_{3} \quad$ Symmetric tripyrrolyl benzene synthesis<smiles>C=CCCC(=O)c1cc(C(=O)CCC=C)cc(C(=O)CCC=C)c1</smiles><smiles>[Z16]c1cc(C(=O)CCC(C)=O)cc(C(=O)CCC(C)=O)c1</smiles>

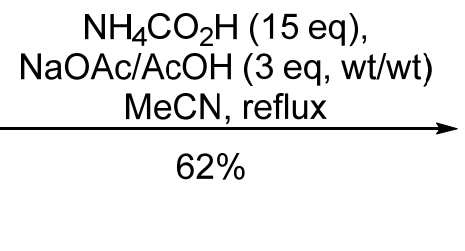<smiles>Cc1ccc(-c2cc(-c3ccc(C)[nH]3)cc(-c3ccc(C)[nH]3)c2)[nH]1</smiles>

10 Years later, Lubell group ${ }^{153}$ further extended the utilization of their synthetic methodology mention above in the preparation of conjugated $\mathrm{C}_{3}$ symmetric aryl tripyrroles, which may be promising materials for both electrochromic and fluorescence sensor applications. Three-step Grignard/Tsuji-Wacker/Paal-Knorr reaction sequence formed the 
final tripyrroles $\mathbf{2 1 6}$ in 9\% overall yields, starting from trimethyl 1,3,5-benzene tricarboxylate 213. Modified Wacker-Tsuji olefin oxidation of homoallylic ketone 214 gave tris(1,4-dione) 215 in $49 \%$ yields, featuring ultrasound agitation of the substrate in the presence of $\mathrm{PdCl}_{2}$ ( 0.6 equiv) and $\mathrm{CuCl}$ ( 3 equiv) in $\mathrm{THF} / \mathrm{H}_{2} \mathrm{O}$ (4:1) under oxygen atmosphere (Schemes 51).

Actually, a variety of terminal olefins can be oxidized to the corresponding methyl ketones via Wacker-type oxidation with functional groups remain intact, including aldehyde, carboxylic acid, ester, alcohol, ether, acetal, chloride, bromide, sulfonyl ester, sulfone and so on, ${ }^{139}$ since the Wacker-type oxidation proceeds under mild conditions.

In 2011, Anseth et al. ${ }^{154}$ first reported the successful application of the Wacker-type oxidation to a cyclic substrate to synthesis large-scale 1,3-cyclooctanedione (219) in five steps with $29 \%$ yield. The preparation started from converting the commercially available inexpensive starting material cyclooctanone (217) to enone 218 through 4 steps followed by a modified Wacker-Tsuji oxidation to gave the desired dione in a single step in $37 \%$ yield (Scheme 52). ${ }^{29,30}$ This synthesis was proved to be a good alternative method for the standard preparation of 1,3-cyclooctanedione. ${ }^{17}$ Moreover, this modified Wacker-Tsuji oxidation condition, which employed inexpensive oxidant, tert-butyl hydroperoxide was efficient for the oxidation of internal double bonds conjugated to carbonyl groups. ${ }^{41}$

Scheme 52: Synthesis of 1,3-cyclooctanedione 219 from cyclooctanone 217

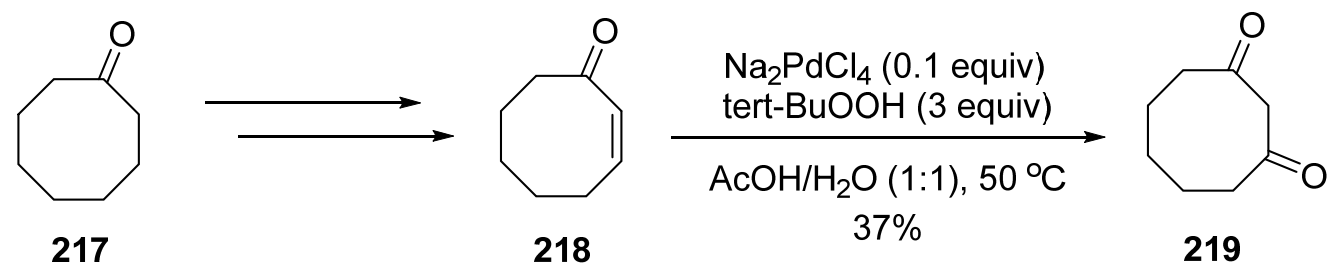


A definite mechanism explaining various modified Wacker-type oxidations remains elusive because of the utilization of added ions and co-oxidants. Recent advancements have been made toward the elimination of $\mathrm{Cu}$ additives resulting in the development of peroxidemediated and ligand modulation Wacker oxidations. Sigman et al. are among the researchers who paid great efforts in this area.

In 2009, Sigman et al. ${ }^{155}$ discovered a highly efficient Wacker-type oxidation system capable of converting classically challenging substrates to corresponding methyl ketones, for example, protected allylic alcohols 220 to acyloins 221, and homoallylic alcohol 222 to 223 in excellent yield (Scheme 53). In a typical reaction condition, low-loadings palladium(II)Quinox (bidentate ligand, quinoline-2-oxazoline) complex, aqueous $70 \mathrm{wt} \%$ TBHP (tert-butyl hydroperoxide) and $\mathrm{SbF}_{6}{ }^{-}$was used as catalyst, terminal oxidant and counterion, respectively. Various terminal alkenes were selectively converted to methyl ketones under these mild conditions with high selectivity.

\section{Scheme 53: TBHP-mediated Wacker-type oxidation}
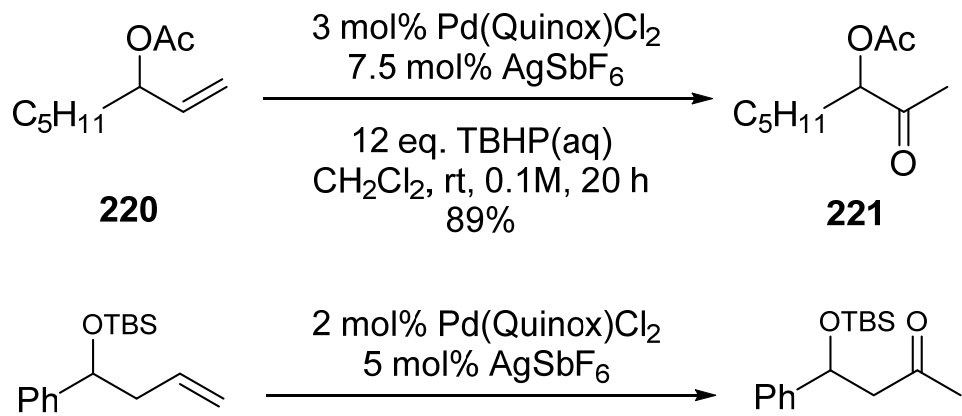

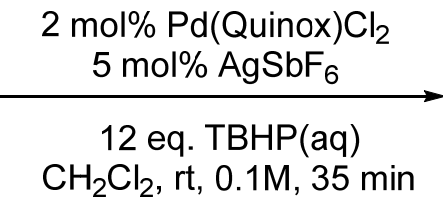

$92 \%$<smiles>c1ccc2nc(C3=NCCO3)ccc2c1</smiles>

Quinox<smiles>CC(=O)CC(O[GaH2])c1ccccc1</smiles>

223 
Two years later, in 2009, Sigman and co-workers ${ }^{156}$ further proved the methodology they discovered before could be used as a general synthetic route to oxidize olefin substrates bearing homoallylic alcohols to their corresponding methyl ketone, regardless of substitution on the substrates. Various homoallylic alcohols, such as $\mathbf{2 2 4}$ was transformed to $\beta$-hydroxy ketone 225 using a TBHP-mediated Pd(Quinox)-catalyzed Wacker-type system in good yields with significantly reduced reaction times (Scheme 54).

Scheme 54: TBHP-mediated Wacker-type oxidation to form $\beta$-hydroxy ketone

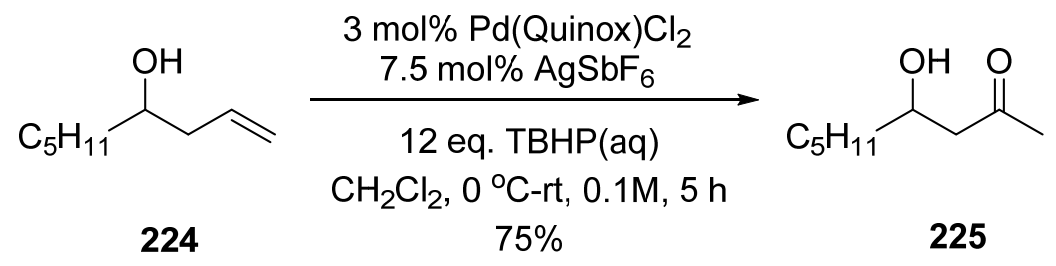

A number of styrene derivatives are another challenging substrate class for the Wacker-Tsuji oxidation. ${ }^{157}$ Therefore, more modified Wacker-type oxidations have been created for the purpose of enlarging its synthetic utility.

Exposing nitro-substituted styrene 226 to TBHP-mediated Wacker-type oxidation ${ }^{155}$ mentioned above resulted in methyl ketone 227 in $60 \%$ yield because of the highly electrondeficient system and a trace amount of $m$-nitro benzaldehyde was obtained (Scheme 55).

\section{Scheme 55: TBHP-mediated Wacker-type oxidation to form methyl ketone}

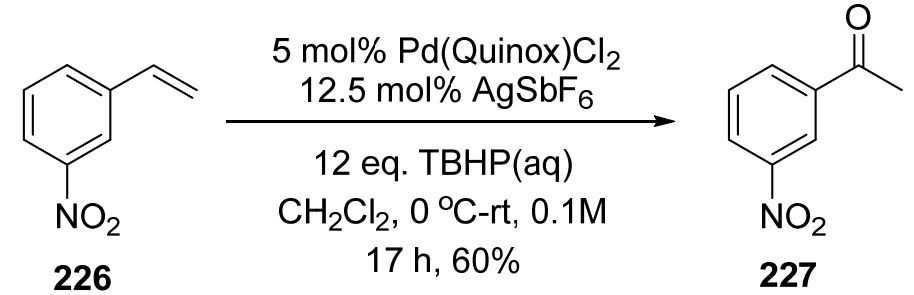

In 2012, Gröger, et al. ${ }^{158}$ converted styrene (228) to acetophenone (229) in excellent conversion and good selectivity of $99 \%$ and $90 \%$ respectively by using $\mathrm{PdCl}_{2}$ as a palladium catalyst, benzoquinone as oxidation and a mixture of methanol and water as solvent. However, 
side products $o$-methylphenylethan-1-ol (3\%), phenylacetaldehyde dimethyl acetal $(2 \%)$, methyl phenylacetate (3\%), and traces of racemic phenylethan-1-ol (1\%) were observed.

\section{Scheme 56: Benzoquinone-reoxidant Wacker-type oxidation to acetophenone}

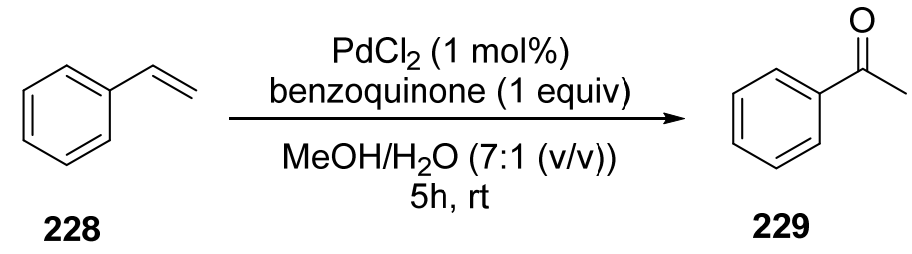

Compared with the facile oxidation of terminal olefins, the reaction of Wacker-type oxidation of internal alkenes is extremely slow and the selectivity for unsymmetrical alkenes is often poor unless substrates with some functional groups at suitable positions would be oxidized regioselectively by participation of the functional groups under proper conditions. For example, the selectivity can be substantially enhanced if the alkene substrate has a pendant group able to coordinate with palladium $\left(\mathrm{PdCl}_{2}, \mathrm{H}_{2} \mathrm{O}, \mathrm{O}_{2}(3 \mathrm{~atm})\right.$, DMA, $\left.80{ }^{\circ} \mathrm{C}\right) .{ }^{159}$ Thus, more improvement is necessary for the Wacker-type oxidation of internal olefins. The regioselective oxidation of functionalized internal olefins will be surveyed in this chapter because it would be a powerful and flexible method in the synthesis of $\alpha$-aryl substituted ketones, which are quite important synthons in pharmaceutical and biomedical chemistry. 


\subsection{Wacker-type oxidation of aryl-substituted alkenes}

Aryl-substituted alkenes are a substrate class that offers a unique set of challenges to Wacker-type oxidation. The 1-aryl-1-alkenes were prepared via a Kosugi-Migita-Stille cross coupling of an aryl-iodide or -bromide with tributyl 1-propen-1-yltin (Table 3) ${ }^{160-162}$. Since the impetus of the present study was the palladium catalyzed oxidation, no attempts were made to optimize the yields of the cross coupling reactions.

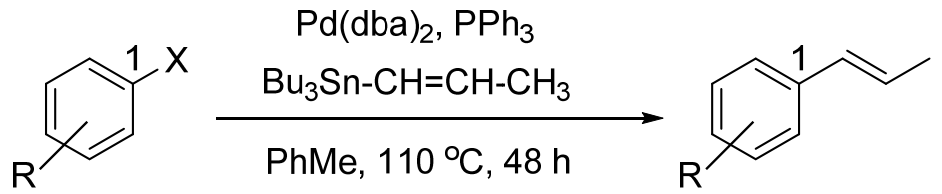

Table 3: Synthesis of 1-aryl-1-propenes

\begin{tabular}{|c|c|c|c|c|}
\hline Entry & $\bar{X}$ & $\mathbf{R}$ & & Yield (\%) \\
\hline 1 & $\mathrm{I}$ & $2-\mathrm{NO}_{2}$ & --- & $230(49 \%)$ \\
\hline 2 & $\mathrm{Br}$ & $3-\mathrm{NO}_{2}$ & --- & $231(49 \%)$ \\
\hline 3 & $\mathrm{Br}$ & 4- $\mathrm{NO}_{2}$ & --- & $232(57 \%)$ \\
\hline 4 & I & 2- $-\mathrm{NO}_{2}$ & 4-F & $233(73 \%)$ \\
\hline 5 & $\mathrm{Br}$ & 2- $-\mathrm{NO}_{2}$ & 4- $-\mathrm{NO}_{2}$ & $234(51 \%)$ \\
\hline 6 & I & 2- $-\mathrm{NO}_{2}$ & 4- $-\mathrm{CO}_{2} \mathrm{Me}$ & $235(56 \%)$ \\
\hline 7 & I & 2- $-\mathrm{NO}_{2}$ & 4-OMe & $236(32 \%)$ \\
\hline 8 & I & 2- $-\mathrm{NO}_{2}$ & 5-OMe & $237(37 \%)$ \\
\hline 9 & $\mathrm{Br}$ & $2-\mathrm{NO}_{2}$ & $6-\mathrm{Me}$ & $239(69 \%)$ \\
\hline 10 & I & $2-B r$ & --- & $243(40 \%)$ \\
\hline 11 & I & --- & --- & $244(13 \%)$ \\
\hline
\end{tabular}

Three other alkene substrates, 1-nitro-2-(1-penten-1-yl)-benzene (240), 1-(3-methyl1-butenyl)-2-nitrobenzene (241), and 1-nitro-2-(2-phenylethenyl)-benzene (242) (Figure 14) were synthesized using literature procedures. ${ }^{163,164}$ Coumpound (238), $\alpha$-asarone is commercially available. 
Figure 14: Structures of substrates 238, 240, 241, and 242<smiles>C/C=C/c1cc(OC)c(OC)cc1[N+](=O)[O-]</smiles>

238<smiles>CCC/C=C/c1ccccc1[N+](=O)[O-]</smiles>

240<smiles>CC(C)/C=C/c1ccccc1[N+](=O)[O-]</smiles>

241<smiles>O=[N+]([O-])c1ccccc1/C=C/c1ccccc1</smiles>

242

Our initial plan was to examine the possibility of generating $\alpha$-arylated ketones directly under the typical Wacker-Tsuji oxidation condition (Figure 15), $10 \mathrm{~mol} \%$ of $\mathrm{PdCl}_{2}$ as a palladium catalyst, 1 equiv of copper chloride as oxidation reagent, and $D M F / \mathrm{H}_{2} \mathrm{O}(10: 1$ (v/v) under an $\mathrm{O}_{2}$ atmosphere at $50{ }^{\circ} \mathrm{C}$ for $20 \mathrm{~h}$ (Condition 1). The 1-aryl-1-propene 230 was expected to be oxidized to form $\alpha$-arylated propanone 245 . But this condition yielded even no trace amounts of the expected 245; the starting materials were recovered unchanged. A thorough study of the literature on Wacker process made us realize that the oxidation of internal olefins is extremely slow under the usual conditions and the reactions are not regionselective. Rates and yields of the oxidation are heavily dependent on the structure of olefins. Also, the proper selection of solvents and reoxidants is crucial. Due to the traditional WackerTsuji oxidation condition seemed to be ineffective for this transformation, we chose first to change solvent by replacing DMF with $\mathrm{MeOH}$ (Condition 3). To our delight, a rapid reaction took place and $\alpha$-arylated ketone $\mathbf{2 4 5}$ was isolated in a decent yield of $73 \%$ with dimethyl acetal $246(4 \%)$ and an inseparable mixture of $o$-nitrobenzaldehyde $247(7 \%)$ and dione 248 (7\%) as side products. Subsequently, we decided to conduct an oxidant reagent screen by utilizing $\mathrm{H}_{2} \mathrm{O}_{2}$ with radical inhibitor (2,6-di-t-butyl-4-methylphenol) or tert-butyl hydroperoxide (TBHP) with radical inhibitor (Condition 4 and 5). $\alpha$-Arylated ketone 245 was isolated in $72 \%$ and $92 \%$ yields respectively. We were pleased to find that the oxidation of 230 was very clean under Condition 5 (only a single product spot on the TLC) and the 
desired methyl ketone was formed with a good $92 \%$ yield with no trace of any other byproducts. It is important to note that the yield of methyl ketone $\mathbf{2 4 5}$ dropped off from $72 \%$ to $18 \%$ when changing the reaction condition from Condition 4 to 2 . In fact, the addition of solvent (methanol and water) had a significant impact on the reaction yield (Conditions 2, 4).

Figure 15: Wacker-type oxidation of 1-aryl-1-propene
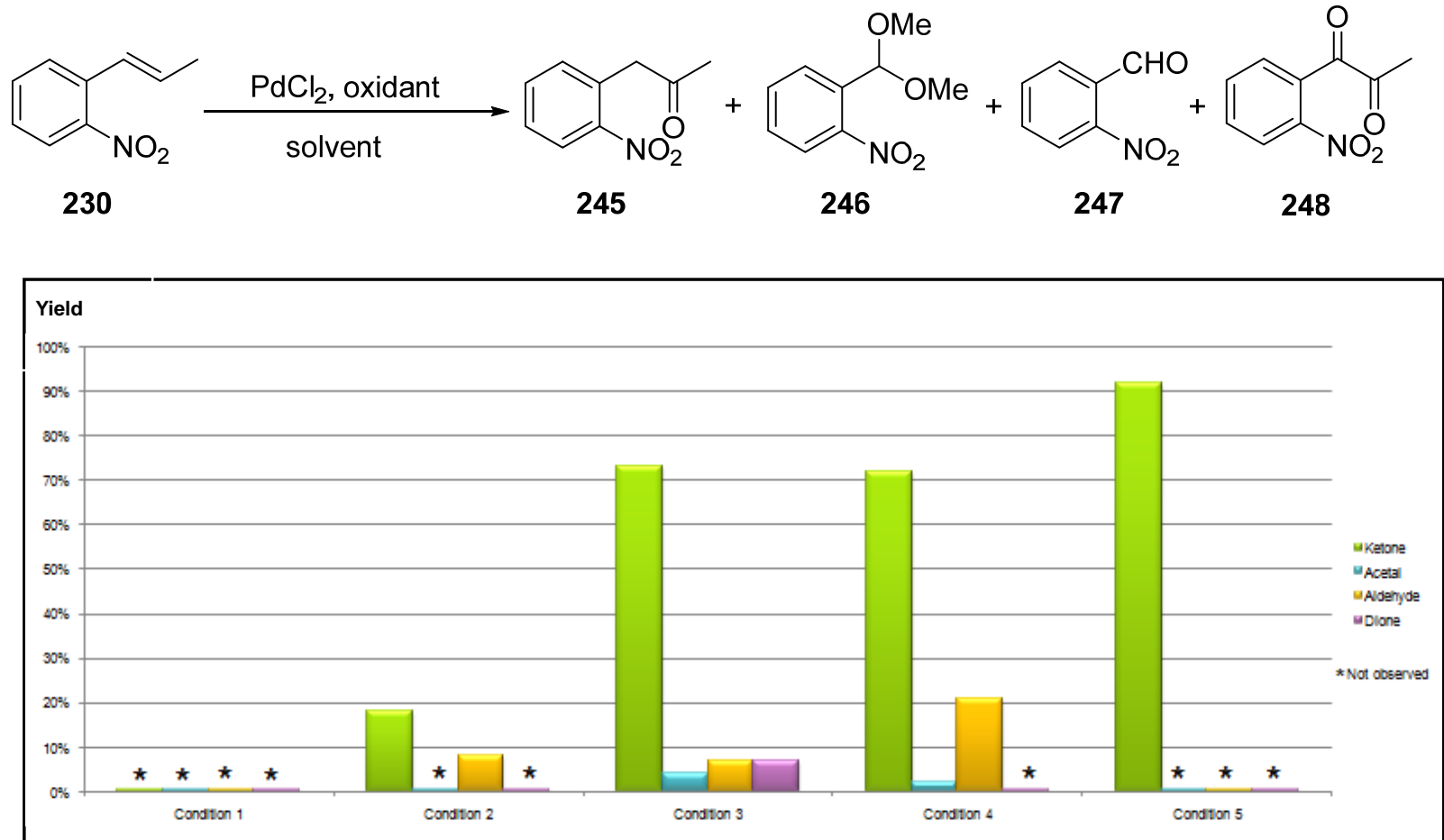

Reaction conditions:

1. Substrate $(0.2 \mathrm{mmol}), \mathrm{PdCl}_{2}(10 \mathrm{~mol} \%), \mathrm{CuCl}$ (1 equiv), $1.1 \mathrm{~mL}$ of $\mathrm{DMF}: \mathrm{H}_{2} \mathrm{O}(10: 1)$ at $50{ }^{\circ} \mathrm{C}, 20 \mathrm{~h}$.

2. Substrate $(0.2 \mathrm{mmol}), \mathrm{PdCl}_{2}(10 \mathrm{~mol} \%), \mathrm{H}_{2} \mathrm{O}_{2}$ (10 equiv) with $50 \%$ con. in aqueous solution, $50{ }^{\circ} \mathrm{C}, 48 \mathrm{~h}$.

3. Substrate $(0.2 \mathrm{mmol}), \mathrm{PdCl}_{2}(10 \mathrm{~mol} \%), \mathrm{CuCl}$ (1 equiv), $1.1 \mathrm{~mL}$ of $\mathrm{MeOH}: \mathrm{H}_{2} \mathrm{O}(10: 1)$ at $50{ }^{\circ} \mathrm{C}, 20 \mathrm{~h}$.

4. Substrate $(0.2 \mathrm{mmol}), \mathrm{PdCl}_{2}(10 \mathrm{~mol} \%), \mathrm{H}_{2} \mathrm{O}_{2}$ (10 equiv) with $50 \%$ con. in aqueous solution, 2,6-di-tbutyl-4-methylphenol (10 mol \%), $1.1 \mathrm{~mL}$ of $\mathrm{MeOH}: \mathrm{H}_{2} \mathrm{O}(10: 1), 50{ }^{\circ} \mathrm{C}, 48 \mathrm{~h}$.

5. Substrate $(0.2 \mathrm{mmol}), \mathrm{PdCl}_{2}(10 \mathrm{~mol} \%)$, tert-butyl hydroperoxide (10 equiv) with $90 \%$ con. in aqueous solution, 2,6-di-t-butyl-4-methylphenol (10 mol \%), $1.1 \mathrm{~mL}$ of $\mathrm{MeOH}: \mathrm{H}_{2} \mathrm{O}(10: 1), 50{ }^{\circ} \mathrm{C}, 48 \mathrm{~h}$.

Inspired by these results, we next conducted a thorough solvent ratio screen using the oxidation of 2-nitro styrene (285) as the model (Table 4). $\mathrm{MeOH} / \mathrm{H}_{2} \mathrm{O}(9: 1)$ was found to be the best solvent system (entry 2), giving methyl ketone product in $29 \%$ yeild. The reaction in $\mathrm{H}_{2} \mathrm{O}$ was significantly slower (entry 6); only 61\% of 2-nitro styrene was converted after $20 \mathrm{~h}$ 
and $22 \%$ yield of methyl ketone 286 was isolated. Reactions using $\mathrm{MeOH} / \mathrm{H}_{2} \mathrm{O}(3 / 7)$ or $\mathrm{DMF} / \mathrm{H}_{2} \mathrm{O}(10 / 1)$ did not complete either and large amount of starting material was recovered with low yield of desired ketone obtained (entries 5 and 7). Neither anhydrous methanol (entry 1) nor DMF/MeOH (1/1) (entry 8) led to any methyl ketone product. It seemed that the ratio of water to methanol had a significant impact on the product ratio under these reaction conditions (entries 1-6). Ratios of different products from oxidation of 2-nitro styrene (285) were summarized in Table 4.

Table 4: Ratios of products for crude reaction mixtures from oxidation of 2-ethenyl-1nitrobenzene

\begin{tabular}{|c|c|c|c|c|c|c|}
\hline \multirow[b]{2}{*}{285} & & & & \multirow[b]{2}{*}{246} & & \multirow[b]{2}{*}{288} \\
\hline & & 286 & 287 & & 247 & \\
\hline Entry & $\mathrm{MeOH} / \mathrm{H}_{2} \mathrm{O}$ & & & & & \\
\hline 1 & $1 /-(100 \%)$ & 0 & $17(73 \%)$ & 0 & 0 & 1 \\
\hline 2 & $9 / 1$ & $1(29 \%)$ & 2.3 & 0.15 & 0.25 & 0.16 \\
\hline 3 & $7 / 3$ & $1(26 \%)$ & 1.11 & 0.29 & 0.48 & 0.14 \\
\hline 4 & $1 / 1$ & $1(16 \%)$ & 0.60 & 0.73 & 1.28 & 0.26 \\
\hline 5 & $3 / 7^{\mathrm{a}}(21 \% \mathrm{sm})$ & $1(11 \%)$ & 0.23 & 0 & 1.75 & 0.26 \\
\hline 6 & $-/ 1^{b}(39 \% \mathrm{sm})$ & $1(22 \%)$ & 0 & 0 & 1.31 & 0 \\
\hline 7 & $10 / 1^{\mathrm{c}}(8 \% \mathrm{sm})$ & $1(7 \%)$ & 0 & 0 & $5.3(37 \%)$ & 0 \\
\hline 8 & $1 / 1^{\mathrm{d}}(36 \% \mathrm{sm})$ & 0 & $1.4(26 \%)$ & 0 & 0.07 & $1(19 \%)$ \\
\hline
\end{tabular}

The starting material was completely consumed in cases (1-4). $\mathrm{PdCl}_{2}(10 \mathrm{~mol} \%), \mathrm{CuCl}\left(1\right.$ equiv), $50{ }^{\circ} \mathrm{C}, 20 \mathrm{~h}$.

${ }^{\mathrm{a}} \mathrm{MeOH} / \mathrm{H}_{2} \mathrm{O}$ (3/7) was used as the solvents and starting material (21\%) was obtained after the reaction.

${ }^{\mathrm{b}} \mathrm{H}_{2} \mathrm{O}$ was used as the solvent and starting material (39\%) was obtained after the reaction.

${ }^{c} \mathrm{DMF} / \mathrm{H}_{2} \mathrm{O}(10 / 1)$ was used as the solvents and starting material (8\%) was obtained after the reaction.

${ }^{\mathrm{d}} \mathrm{DMF} / \mathrm{MeOH}(1 / 1)$ was used as the solvents and starting material (36\%) was obtained after the reaction. 


\subsection{Results and Discussion}

To ascertain the wide applicability of this Wacker-type oxidation methodology to target syntheses, the oxidations of a number of aryl-substituted internal alkene variants were investigated in an attempt to prepare structurally diverse $\alpha$-arylated ketones (Table 5).

Table 5: Wacker-type oxidation of aryl-substituted alkenes

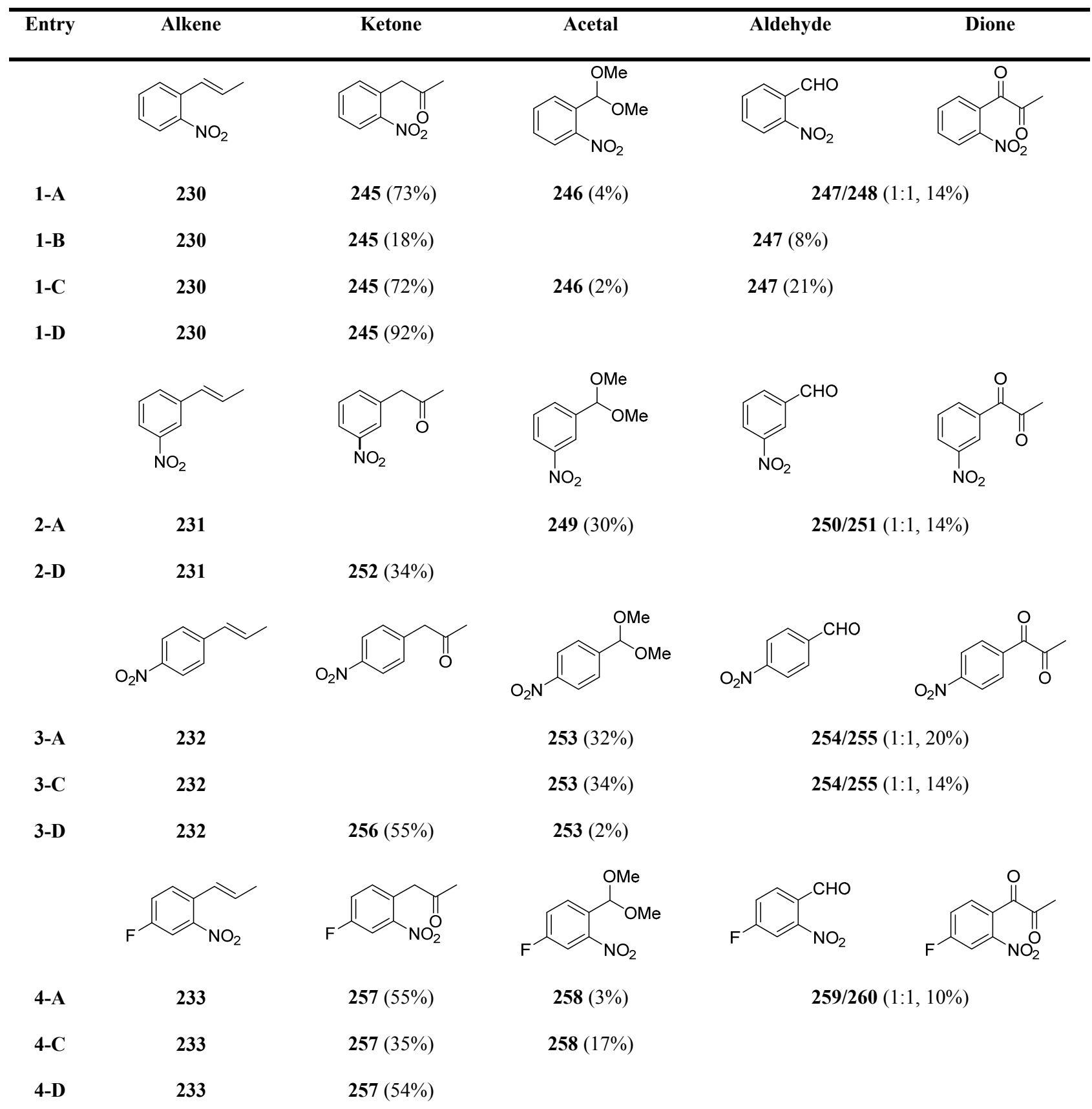


Table 5 (continued)

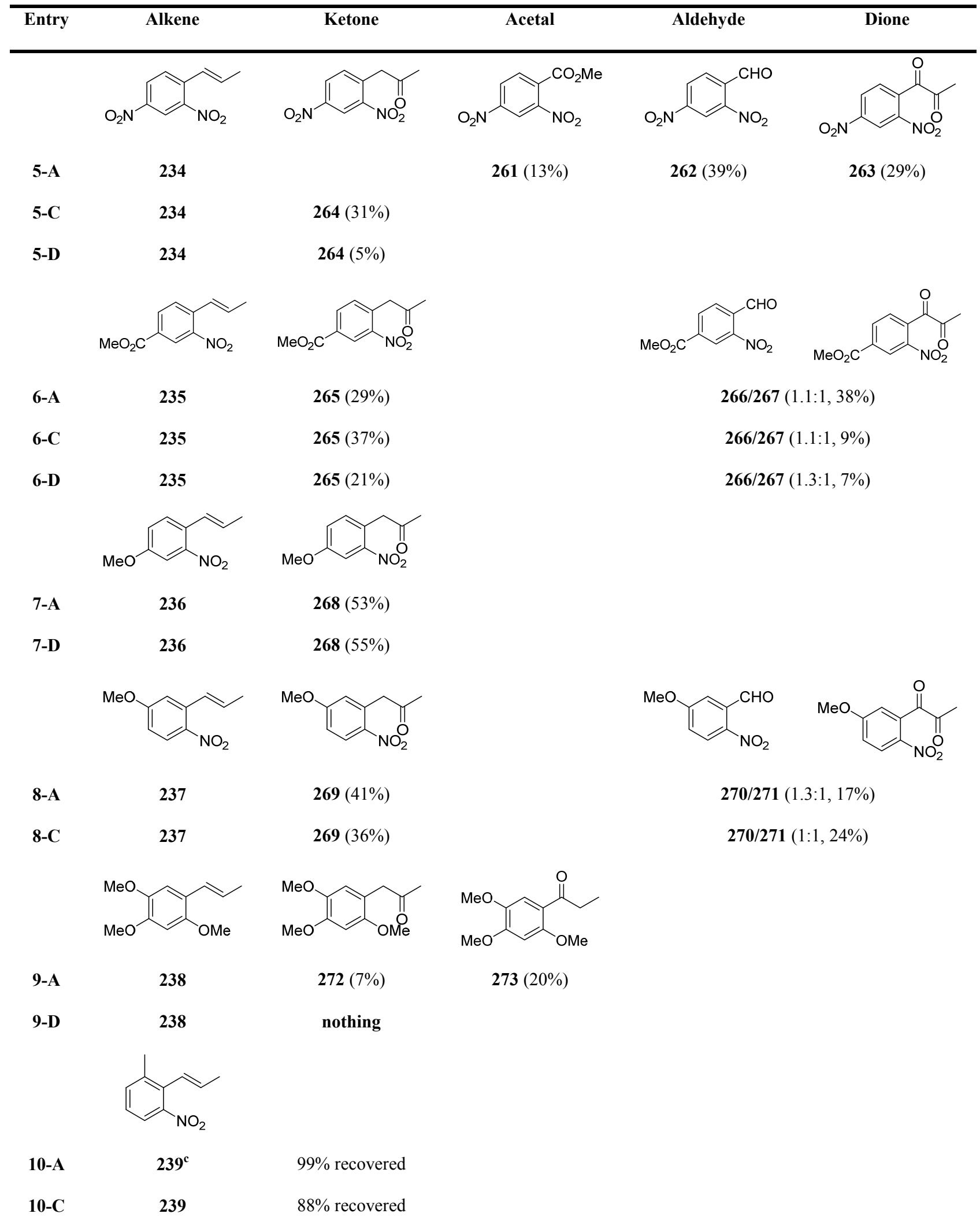


Table 5 (continued)

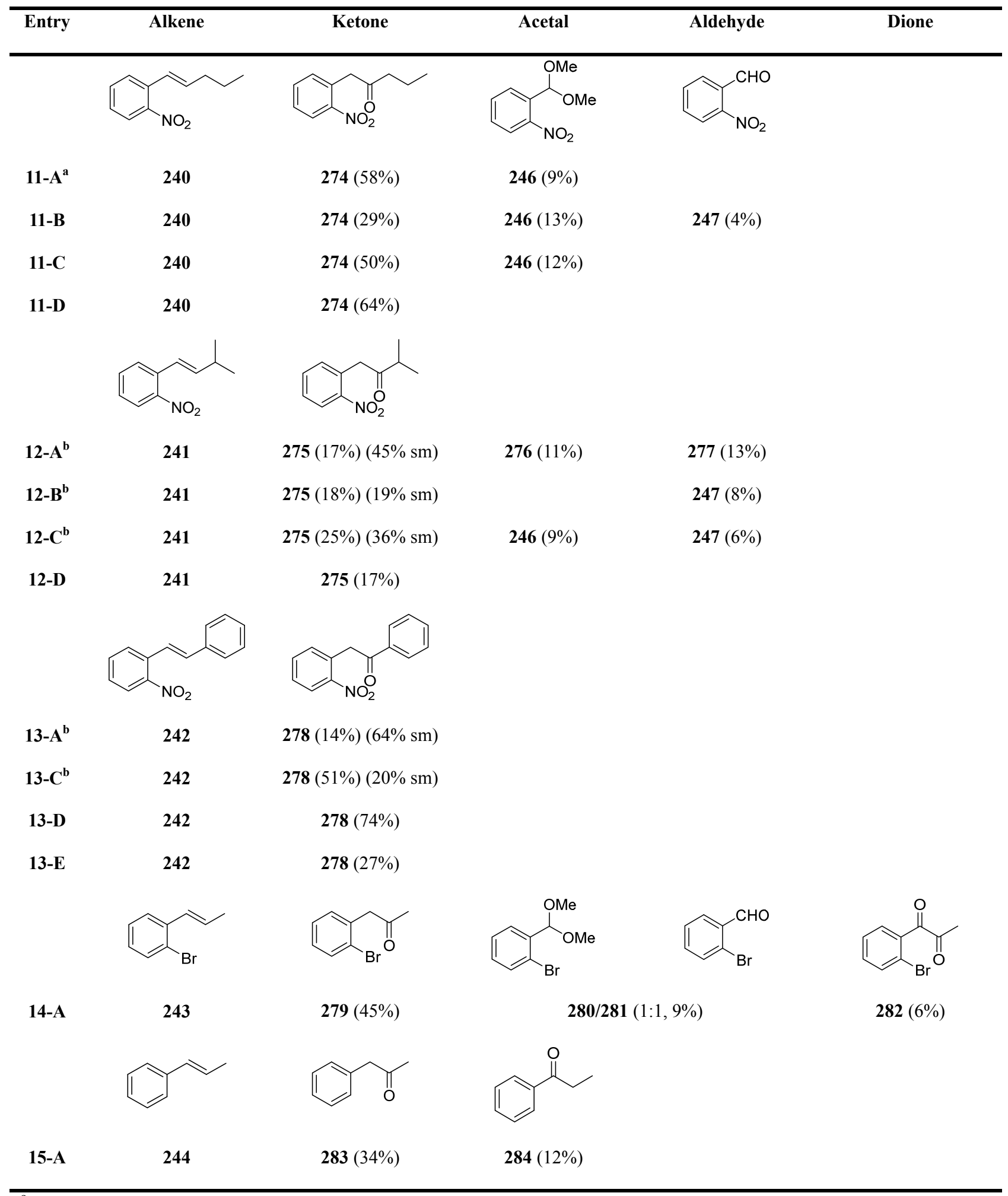

\footnotetext{
${ }^{\mathrm{a}} 97 \%$ Conversion after $72 \mathrm{~h}$.

${ }^{\mathrm{b}}$ Starting material was not completely consumed.

${ }^{\mathrm{c}}$ No reaction was observed, $99 \%$ sm was recovered.
} 


\section{Table 5 (continued)}

Conditions A: $10 \mathrm{~mol} \% \mathrm{PdCl}_{2}, 1$ equiv. $\mathrm{CuCl}, \mathrm{O}_{2}(1 \mathrm{~atm}), \mathrm{MeOH}: \mathrm{H}_{2} \mathrm{O}(10: 1), 50{ }^{\circ} \mathrm{C}, 20 \mathrm{~h}$.

Conditions B: $10 \mathrm{~mol} \% \mathrm{PdCl}_{2}, \mathrm{H}_{2} \mathrm{O}_{2}$ (10 equiv) with 50\% con. in aqueous solution, $\mathrm{MeOH}: \mathrm{H}_{2} \mathrm{O}(10: 1), 50{ }^{\circ} \mathrm{C}$, $48 \mathrm{~h}$.

Conditions C: 10 mol\% $\mathrm{PdCl}_{2}, \mathrm{H}_{2} \mathrm{O}_{2}$ (10 equiv) with 50\% con. in aqueous solution, 2,6-di-tert-butyl-p-cresol (10 mol \%), $\mathrm{MeOH}: \mathrm{H}_{2} \mathrm{O}(10: 1), 50{ }^{\circ} \mathrm{C}, 48 \mathrm{~h}$.

Conditions D: $10 \mathrm{~mol} \% \mathrm{PdCl}_{2}, t$-BuOOH (10 equiv) with 90\% con. in aqueous solution, 2,6-di-tert-butyl-pcresol (10 mol \%), MeOH: $\mathrm{H}_{2} \mathrm{O}(10: 1), 50{ }^{\circ} \mathrm{C}, 48 \mathrm{~h}$.

Conditions $\mathrm{E}: \mathrm{t}-\mathrm{BuOOH}$ (10 equiv) with $90 \%$ con. in aqueous solution was used in place of $\mathrm{CuCl}-\mathrm{O}_{2}$, no radical inhibitor.

These substrates, another challenging substrate class for the Tsuji-Wacker oxidation, were evaluated. ${ }^{157}$ Substituted alkenes with various functional groups were efficiently oxidized, although highly electron-deficient systems were suspected to lead to a lower yield in previous report. ${ }^{155}$ An underlying problem is the difficulty in predicting which pendant groups and which of the numerous possible variants of the Wacker-type oxidation will lead to the desired product for a given substrate. The selectivity in the Wacker-type oxidation of arylsubstituted alkenes appears to be under inherent substrate control and dependent on numerous factors, including substitution on the substrate and the precise conditions used, which can lead to a mixture of aldehyde, ketone, acetal or dione products. Highlighting this disparity, substrate such as $\mathbf{2 3 0}$ yielded methyl ketone product $\mathbf{2 4 5}$ in $73 \%$ yield in the presence of $\mathrm{CuCl}_{2}-\mathrm{O}_{2}$ (entry 1-A), while the acetal products $\mathbf{2 4 9}$ and $\mathbf{2 5 3}$ were observed as the predominant ones from similar substrates 231 and 232 under the same reaction condition (entries 2-A and 3-A). Additionally, the selectivity of these reactions can be affected by the choice of oxidant. For example, the use of the $\mathrm{H}_{2} \mathrm{O}_{2}$ favors the exclusive formation of 1-aryl- 
propanone 264 in $31 \%$ yield (entry $5-\mathrm{C}$ ), and $\mathrm{CuCl}-\mathrm{O}_{2}$ favors the formation of products including acetal 261 (13\%), aldehyde 262 (39\%), and dione 263 (29\%) (entry 5-A).

As described above, in our pursuit of the improvement of selectivity, we discovered a copper-free catalyst system for Wacker-type oxidations that utilizes palladium catalyst along with tert-butyl hydroperoxide (TBHP) as the oxidant and 2,6-di-tert-butyl-p-cresol as the radical inhibitor. This system successfully oxidized various functionalized aryl-substituted substrates with high selectivity ( $>98 \%$ ) for the $\alpha$-arylated ketone products (entries $1-4 \mathrm{D}, 6-7$ D, 11-13 D). The scope of condition A to E was then thoroughly evaluated, and it was found that, for some alkenes, it was sufficient to achieve good yields of desired ketones in $20 \mathrm{~h}$ (entries 4-A, 7-A, 8-A, 14-A) in the presence of $10 \mathrm{~mol} \% \mathrm{PdCl}_{2}, 1$ equiv. $\mathrm{CuCl}, \mathrm{O}_{2}(1 \mathrm{~atm})$ and $\mathrm{MeOH}: \mathrm{H}_{2} \mathrm{O}(10: 1)$ at $50{ }^{\circ} \mathrm{C}$. Steric hindered alkenes tended to react slower, where incomplete conversion was observed after reaction of $72 \mathrm{~h}$ (entries 10-13 A). No reaction was observed by ${ }^{1} \mathrm{H}$ NMR of the crude reaction mixture from 1-methyl-3-nitro-2-(1-propen-1-yl)benzene (239) using either $\mathrm{H}_{2} \mathrm{O}_{2}$ or $\mathrm{CuCl}-\mathrm{O}_{2}$. The starting material was recovered in high yields (entries 10-A and 10-C). It seems steric hindrance considerably affects the rate of olefin oxidation. Mixtures of inseparable aldehyde and dione were also isolated from several reaction mixtures, as determined by ${ }^{1} \mathrm{H}$ NMR (entries 1-4 A, 6-A, 8-A, 3-C, 6-C, 8-C, and 6D). With no exception, the TBHP-mediated catalyst system demonstrates high selectivity for the desired ketones, regardless of substitution on the substrates evaluated. This result is particularly interesting when compared with other modified conditions, where analogous substrates also formed other side products with different ratios and yields in a conditiondependent manner. 
To investigate the effect of the position of the pendent nitro group relative to the internal olefin, nitro-1-propen-1-yl-benzne (231 and 232) were also evaluated. When these substrates were subjected to the Condition A $\left[10 \mathrm{~mol} \% \mathrm{PdCl}_{2}, 1\right.$ equiv. $\mathrm{CuCl}, \mathrm{O}_{2}(1 \mathrm{~atm})$, $\mathrm{MeOH}: \mathrm{H}_{2} \mathrm{O}(10: 1), 50{ }^{\circ} \mathrm{C}, 20 \mathrm{~h}$ ] (entries 2-A, 3-A), the desired ketone products were not observed; instead, the products isolated were identified acetals $(\mathbf{2 4 9}, \mathbf{2 5 3})$ and mixtures of aldehydes and diones. When these substrates were subjected to the condition D, methyl ketones $\mathbf{2 4 5}$ and $\mathbf{2 5 2}$ were obtained as the only products (entries 2-D, 3-D).

Halogens, such as $\mathrm{F}$ and $\mathrm{Br}$ (entries 4, 14) as well as methoxy and methyl ester groups (entries 6-9) are apparently well-tolerated in the meta-/ortho- position of the nitroarene substrates. Reaction of 1-(2,4-dinitrophenyl)-1-propene (234) gave methyl ester 261 in addition to the dione 263, methyl 2,4-dinitrophenylbenzoate (262) (entry 5-A). It should be noted that the reported formation of this compound from reaction of 2,4-dinitro-1fluorobenzene with dimethoxycarbene followed by hydrolysis is in error. ${ }^{165}$ Oxidation of 1(3-methyl-1-butenyl)-2-nitrobenzene (241) using condition A (entry 12) afforded isomers 276 and $\mathbf{2 7 7}$ in $11 \%$ and $13 \%$ respectively in addition to the $\alpha$-arylated ketone $\mathbf{2 7 5}$.

\section{Figure 16: Products 276 and 277}

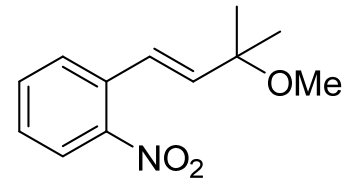

276<smiles>C=C(C)C(Cc1ccccc1[N+](=O)[O-])OC</smiles>

277

Cornell and Sigman reported a high selectivity for acetophenone formation upon oxidation of $p-/ m$ - or $o$-substituted styrenes with $t-\mathrm{BuOOH}$ in the presence of catalytic amounts of both a palladium(II) carbene complex and AgOTf. ${ }^{166}$ However, oxidation of 1phenyl-1-propene (244) was non-selective and gave an approximately 1:1 mixture of 1- 
phenyl-2-propanone (283) and 1-phenyl-1-propanone (284). We observed a somewhat more selective oxidation of (244) affording roughly a 3:1 ratio of 1-phenyl-2-propanone and 1phenyl-1-propanone (entry 15-A). The same 3:1 ratio of $\mathbf{2 8 3} / \mathbf{2 8 4}$ was reported using $\mathrm{PdCl}_{2}$, $\mathrm{CuCl}$, in $\mathrm{DMF}-\mathrm{H}_{2} \mathrm{O}(1: 1)$ at 1 atm of oxygen and ambient temperature. ${ }^{160} \mathrm{~A} 95 \%$ yield was reported without any concurrent double bond cleavage to benzaldehyde. Cleavage of the alkene to form benzaldehyde was also observed in Sigman's paper (2.3:1 ratio of oxidation: cleavage).

Overall, the results point out that these modified Wacker processes of aryl-substituted alkenes are also quite sensitive to and dependent on reaction conditions, which are believed to associate with different mechanistic scenarios. However, $t$-butyl hydroperoxide and hydrogen peroxide have proved to be efficient reoxidants for the oxidation of internal double bonds. 


\subsection{Conclusions}

In conclusion, we demonstrate that Wacker-type oxidation of aryl-substituted alkenes is feasible under modified Wacker-type oxidation conditions to yield $\alpha$-arylated ketones that are challenging or impossible to obtain using conventional reaction conditions. The selectivity in the modified Tsuji-Wacker oxidation of aryl-substituted alkenes appears to be dependent on numerous factors, including the substrate and the precise conditions used. The reaction conditions discussed above appear to work with a fairly wide range of substrates. 


\section{Chapter 4}

\section{Supporting information: experimental procedures}

4.1 Supporting information Chapter 1: Ring-expansion of 4-ethynyl-4-hydroxy-2,3-

substituted-2-cyclobuten-1-ones

4.2 Supporting information Chapter 2: Total synthesis of methyl linderone

4.3 Supporting information Chapter 3: Wacker-type oxidation of aryl-substituted alkenes 
General procedures. All NMR spectra were recorded in $\mathrm{CDCl}_{3}$. The chemical shifts are expressed in $\delta$ values relative to $\mathrm{Me}_{4} \mathrm{Si}\left(0.0 \mathrm{ppm},{ }^{1} \mathrm{H}\right.$ and $\left.{ }^{13} \mathrm{C}\right)$ or $\mathrm{CDCl}_{3}\left(77.0 \mathrm{ppm},{ }^{13} \mathrm{C}\right)$ internal standards. Tetrahydrofuran (THF) and diethyl ether were distilled from sodium benzophenone ketyl prior to use. Toluene, pyridine, hexanes, and ethyl acetate were distilled from calcium hydride. Chemicals prepared according to literature procedures have been footnoted the first time used; all other reagents were obtained from commercial sources and used as received. All reactions were performed under a nitrogen atmosphere in oven-dried glassware unless otherwise stated. The thermolysis reactions were performed in ACE-Glass pressure tubes capped with a Teflon screw cap. Solvents were removed from reaction mixtures and products on a rotary evaporator at water aspirator pressure. All alkanes, arenes, and etherial solvents are purified with activated alumina then Q5 (Q5 is an $\mathrm{O}_{2}$ scavenging $\mathrm{Cu}$-zeolite catalyst made by BASF). All other solvents with heteroatoms are dried through two columns of activated alumina.

Caution: 3,4-dialkoxy-3-cyclobutene-1,2-diones have been shown to cause contact dermatitis upon contact. ${ }^{25}$ 


\subsection{Supporting information Chapter 1: Ring-expansion of 4-ethynyl-4-hydroxy-2,3-}

substituted-2-cyclobuten-1-ones

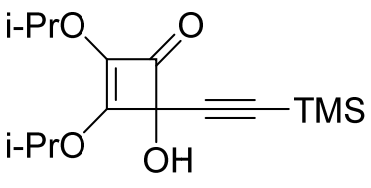

68<smiles>CCCOC1=C(OC(C)C)C(=O)C(=CNS(C)(=O)=O)C1=O</smiles>

69

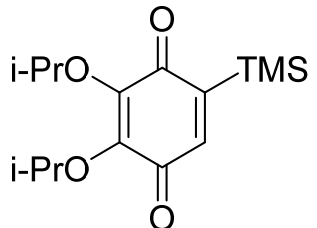

70

4,5-Bis(1-methylethoxy)-2-(1-trimethylsilylmethylene)-4-cyclopentene-1,3-dione (69) and 2,3-bis(1-methylethoxy)-5-trimethylsilyl-2,5-cyclohexadiene-1,4-dione (70).

A solution of $\mathbf{6 8}^{9}(296 \mathrm{mg}, 1.00 \mathrm{mmol})$ in benzene $(3 \mathrm{~mL})$ was heated at $140{ }^{\circ} \mathrm{C}$ for $3 \mathrm{~h}$ in an ACE-Glass pressure tube capped with a Teflon screw cap. The resulting dark mixture was cooled to ambient temperature and the solvent was removed at reduced pressure. The resulting crude product was purified by chromatography (hexanes/EtOAc, 98:2) to give an inseparable mixture of 69 and $70(1: 18$ ratio, $229 \mathrm{mg}, 0.773 \mathrm{mmol}, 77 \%)$ as a red solid. Spectral data for 70: $\mathrm{mp} 34-37{ }^{\circ} \mathrm{C} ;{ }^{1} \mathrm{H}$ NMR $(270 \mathrm{MHz}) \delta 6.71(\mathrm{~s}, 1 \mathrm{H}), 4.81$ (sept, $J=6.3 \mathrm{~Hz}$, 1H), 4.80 (sept, $J=6.1 \mathrm{~Hz}, 1 \mathrm{H}), 1.31(\mathrm{~d}, J=6.1 \mathrm{~Hz}, 6 \mathrm{H}), 1.28$ (d, J=6.1 Hz, 6H), $0.23(\mathrm{~s}, 9 \mathrm{H})$; ${ }^{13} \mathrm{C}$ NMR $(150 \mathrm{MHz}) \delta 188.1,184.7,150.4,146.4,145.3,142.0,75.9,75.7,22.6,-1.6$; IR (ATR) 2978, 1657, 1583, 1251, 1197, 1108, 910, 885, $841 \mathrm{~cm}^{-1}$; HRMS (ESI) calcd for $\mathrm{C}_{15} \mathrm{H}_{25} \mathrm{O}_{4} \mathrm{Si}\left(\mathrm{M}+\mathrm{H}^{+}\right)$297.1522; found 297.1517. Partial spectral data for 69: ${ }^{1} \mathrm{H}$ NMR (270 MHz) $\delta 6.89(\mathrm{~s}, 1 \mathrm{H}), 5.59$ (sept, $J=6.0 \mathrm{~Hz}, 1 \mathrm{H}), 5.54$ (sept, $J=6.1 \mathrm{~Hz}, 1 \mathrm{H}), 1.37$ (d, $J=6.1 \mathrm{~Hz}$ $6 \mathrm{H}), 1.35(\mathrm{~d}, J=6.1 \mathrm{~Hz}, 6 \mathrm{H})$. 


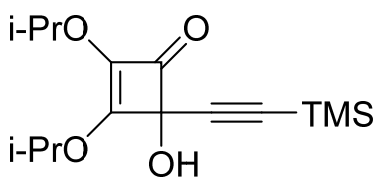

68<smiles>CCCOC1=C(OC(C)C)C(=O)C(=C([As])I)C1=O</smiles>

71

\section{2-(1-Iodo-1-trimethylsilylmethylene)-4,5-bis(1-methylethoxy)-4-cyclopentene-1,3-dione}

(71). To a solution of $\mathbf{6 8}(148 \mathrm{mg}, 0.500 \mathrm{mmol})$ in benzene $(1.5 \mathrm{~mL})$ was added NIS (124 mg, $0.550 \mathrm{mmol})$. The tube was capped with a Teflon screw cap and stirred for $3 \mathrm{~h}$ at ambient temperature. Removal of solvent under reduced pressure followed by chromatography (hexanes/EtOAc, 9:1) gave $71(137 \mathrm{mg}, 0.324 \mathrm{mmol}, 65 \%)$ as a yellow oil. ${ }^{1} \mathrm{H}$ NMR (270MHz) $\delta 5.62$ (sept, $J=6.1 \mathrm{~Hz}, 1 \mathrm{H}), 5.40$ (sept, $J=6.1 \mathrm{~Hz}, 1 \mathrm{H}), 1.35$ (d, $J=6.1 \mathrm{~Hz}, 6 \mathrm{H}), 1.34$ $(\mathrm{d}, J=6.1 \mathrm{~Hz}, 6 \mathrm{H}), 0.33(\mathrm{~s}, 9 \mathrm{H}) ;{ }^{13} \mathrm{C} \mathrm{NMR}(150 \mathrm{MHz}) \delta 183.9,183.9,151.2,148.6,140.8$, 127.3, 75.2, 75.0, 23.1, 22.9, 1.7; IR (ATR) 2987, 1678, 1613, 1304, 1246, 1065, $841 \mathrm{~cm}^{-1}$; HRMS (ESI) calcd for $\mathrm{C}_{15} \mathrm{H}_{24} \mathrm{IO}_{4} \mathrm{Si}\left(\mathrm{M}+\mathrm{H}^{+}\right)$423.0489; found 423.0486.

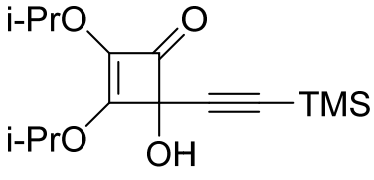

68<smiles>CC(C)OC1=C(OC(C)C)C(=O)C(=C(Br)Br)C1=O</smiles>

72

\section{2-(1-Bromo-1-trimethylsilylmethylene)-4,5-bis(1-methylethoxy)-4-cyclopentene-1,3-dione}

(72). Treatment of $68(75 \mathrm{mg}, 0.25 \mathrm{mmol})$ with NBS $(59 \mathrm{mg}, 0.33 \mathrm{mmol})$ in benzene $(0.75$ $\mathrm{mL})$ as described for $\mathbf{7 1}\left(80{ }^{\circ} \mathrm{C}, 6 \mathrm{~h}\right)$, gave after chromatography (hexanes/EtOAc, 99:1) 72 (38 mg, $0.10 \mathrm{mmol}, 40 \%$ ) as a brown oil. ${ }^{1} \mathrm{H}$ NMR $(270 \mathrm{MHz}) \delta 5.57$ (sept, $\left.J=6.1 \mathrm{~Hz}, 1 \mathrm{H}\right)$, $5.41($ sept, $J=6.1 \mathrm{~Hz}, 1 \mathrm{H}), 1.36(\mathrm{~d}, J=6.1 \mathrm{~Hz}, 6 \mathrm{H}), 1.36(\mathrm{~d}, J=6.1 \mathrm{~Hz}, 6 \mathrm{H}), 0.34(\mathrm{~s}, 9 \mathrm{H}) ;{ }^{13} \mathrm{C}$ NMR (150 MHz) $\delta 184.3,183.4,151.4,149.5,148.0,136.9,75.2,74.9,23.1,22.9,0.3$; IR 
(ATR) 2993, 1682, 1622, 1385, 1306, 1098, 1068, $850 \mathrm{~cm}^{-1}$; HRMS calcd for $\mathrm{C}_{15} \mathrm{H}_{24} \mathrm{BrO}_{4} \mathrm{Si}$ $\left(\mathrm{M}+\mathrm{H}^{+}\right)$375.0627; found 375.0619.

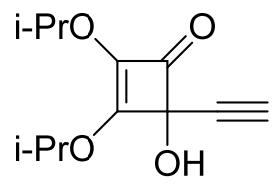

73<smiles>CC(C)OC1=C(OC(C)C)C(=O)C=CC1=O</smiles>

74

2,3-Bis(1-methylethoxy)-2,5-cyclohexadiene-1,4-dione (74). Treatment of $73^{9}$ (56 mg, 0.25 mmol) in benzene $(0.75 \mathrm{~mL})$ as described for $69\left(140{ }^{\circ} \mathrm{C}, 3 \mathrm{~h}\right)$ gave after chromatography (hexanes/EtOAc, 98:2) 74 (33 mg, $0.14 \mathrm{mmol}, 58 \%)$ as an orange-red oil. ${ }^{1} \mathrm{H}$ NMR (270 MHz) $\delta 6.60(\mathrm{~s}, 2 \mathrm{H}), 4.82(\mathrm{sept}, J=6.1 \mathrm{~Hz}, 2 \mathrm{H}), 1.30(\mathrm{~d}, J=6.1 \mathrm{~Hz}, 12 \mathrm{H}) ;{ }^{13} \mathrm{C}$ NMR $(67.5$ MHz) $\delta 184.8,145.8,134.7,76.1,22.6$; IR (ATR) 2983, 1662, 1588, 1375, 1291, 1187, 1098, $1063 \mathrm{~cm}^{-1}$; HRMS (ESI) calcd for $\mathrm{C}_{12} \mathrm{H}_{17} \mathrm{O}_{4}\left(\mathrm{M}+\mathrm{H}^{+}\right)$225.1127; found 225.1122.

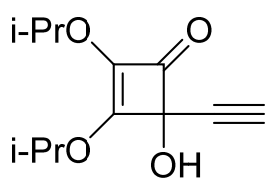

73<smiles>CCOC1=C(OC(C)C)C(=O)C(=CI)C1=O</smiles>

75

2-(Iodomethylene)-4,5-bis(1-methylethoxy)-4-cyclopentene-1,3-dione (75). Treatment of 73 (112 mg, $0.500 \mathrm{mmol})$ with NIS $(124 \mathrm{mg}, 0.550 \mathrm{mmol})$ in benzene $(1.5 \mathrm{~mL})$ as described for 71 (ambient temperature, 3 h), gave after chromatography (hexanes/EtOAc, 19:1 then 8:2) 75 (59.7 mg, $0.170 \mathrm{mmol}, 34 \%)$ as a pale orange oil. ${ }^{1} \mathrm{H}$ NMR $(270 \mathrm{MHz}) \delta 7.87(\mathrm{~s}, 1 \mathrm{H}), 5.62$ (sept, $J=6.1 \mathrm{~Hz}, 1 \mathrm{H}), 5.51$ (sept, $J=6.1 \mathrm{~Hz}, 1 \mathrm{H}), 1.38$ (d, $J=6.1 \mathrm{~Hz}, 6 \mathrm{H}), 1.36$ (d, $J=6.1 \mathrm{~Hz}$, $6 \mathrm{H}) ;{ }^{13} \mathrm{C}$ NMR $(150 \mathrm{MHz}) \delta 183.5,182.6,153.4,149.0,136.3,88.1,75.4,75.2,23.1,23.0$; 
IR (ATR) 2983, 1682, 1627, 1583, 1390, 1306, 1098, 1043, 910, $781 \mathrm{~cm}^{-1}$; HRMS (ESI) calcd for $\mathrm{C}_{12} \mathrm{H}_{16} \mathrm{IO}_{4}\left(\mathrm{M}+\mathrm{H}^{+}\right)$351.0093; found 351.0090.

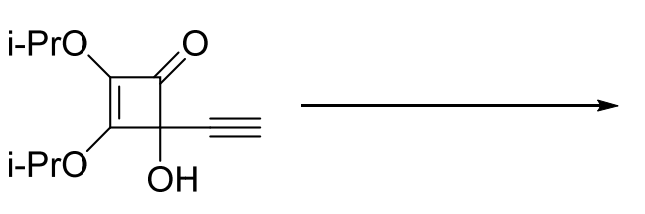

73<smiles>O=C1C(=O)C(O[InH])=C(O)C1=CBr</smiles>

76

2-(Bromomethylene)-4,5-bis(1-methylethoxy)-4-cyclopentene-1,3-dione (76). Treatment of $73(57 \mathrm{mg}, 0.25 \mathrm{mmol})$ with NBS $(55.0 \mathrm{mg}, 0.309 \mathrm{mmol})$ in benzene $(1.5 \mathrm{~mL})$ as described for $70\left(80{ }^{\circ} \mathrm{C}, 17 \mathrm{~h}\right)$ gave after chromatography (hexanes/EtOAc, 95:5), 76 (36 mg, 0.12 mmol, 47\%) as a yellow oil. ${ }^{1} \mathrm{H}$ NMR $(270 \mathrm{MHz}) \delta 7.12$ (s, 1H), 5.42 (sept, $\left.J=6.2 \mathrm{~Hz}, 1 \mathrm{H}\right)$, 5.36 (sept, $J=6.1 \mathrm{~Hz}, 1 \mathrm{H}), 1.23(\mathrm{~d}, J=6.1 \mathrm{~Hz}, 6 \mathrm{H}), 1.21(\mathrm{~d}, J=6.2 \mathrm{~Hz}, 6 \mathrm{H}) ;{ }^{13} \mathrm{C}$ NMR $(150$ MHz) $\delta 182.7,182.6,153.2,149.7,131.8,116.4,75.5,75.2,23.1,23.0$; IR (ATR) 2993, 1682, 1637, 1390, 1316, 1103, 910, $796 \mathrm{~cm}^{-1}$; HRMS (ESI) calcd for $\mathrm{C}_{12} \mathrm{H}_{16} \mathrm{BrO}_{4}\left(\mathrm{M}+\mathrm{H}^{+}\right)$303.0232; found 303.0227 .

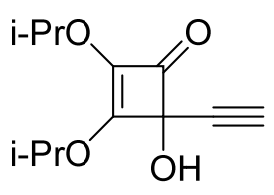

73<smiles>O=C1C=C(Cl)C(=O)C(O[PbH])=C1O[Na]</smiles>

77<smiles>O=C1C=CC(=O)C(O[InH])=C1O[InH]</smiles>

74

\section{5-Chloro-2,3-bis(1-methylethoxy)-2,5-cyclohexadiene-1,4-dione (77) and 2,3-bis(1-methyl}

ethoxy)-2,5-cyclohexadiene-1,4-dione (74). Treatment of 73 (110 mg, $0.491 \mathrm{mmol})$ with NCS $(72 \mathrm{mg}, 0.539 \mathrm{mmol})$ in toluene $(3 \mathrm{~mL})$ as described for $71\left(150{ }^{\circ} \mathrm{C}, 3 \mathrm{~h}\right)$ gave after chromatography (hexanes then hexanes/EtOAc, 98:2), in order of elution, 77 (30 mg, 0.116 
mmol, 24\%) and $74(60 \mathrm{mg}, 0.27 \mathrm{mmol}, 55 \%)$ both as orange oils. Analytical data for $77:{ }^{1} \mathrm{H}$ NMR (270 MHz) $\delta 6.82(\mathrm{~s}, 1 \mathrm{H}), 4.87$ (sept, $J=6.1 \mathrm{~Hz}, 1 \mathrm{H}), 4.76$ (sept, $J=6.1 \mathrm{~Hz}, 1 \mathrm{H}), 1.32$ (d, $J=6.1 \mathrm{~Hz}, 6 \mathrm{H}), 1.31(\mathrm{~d}, J=6.3 \mathrm{~Hz}, 6 \mathrm{H}) ;{ }^{13} \mathrm{C} \mathrm{NMR}(150 \mathrm{MHz}) \delta 182.3,177.1,146.1,145.6$, 142.0, 131.5, 76.7, 22.6; IR (ATR) 2987, 1659, 1590, 1389, 1254, 1096, 872, $779 \mathrm{~cm}^{-1}$; HRMS (ESI) calcd for $\mathrm{C}_{12} \mathrm{H}_{16} \mathrm{ClO}_{4}\left(\mathrm{M}+\mathrm{H}^{+}\right)$259.0737; found 259.0732.

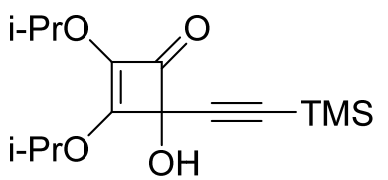

68

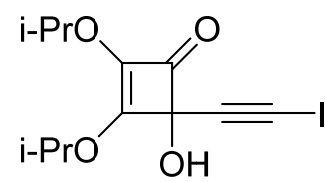

78

4-Hydroxy-2,3-bis(1-methylethoxy)-4-(2-iodoethynyl)-2-cyclobutene-1-one (78). A solution of $68(914 \mathrm{mg}, 3.08 \mathrm{mmol})$ under $\mathrm{N}_{2}$ in DMF $(30 \mathrm{~mL})$ was cooled to $0{ }^{\circ} \mathrm{C}$ and $\mathrm{AgNO}_{3}(38 \mathrm{mg}$, $0.22 \mathrm{mmol}$ ) was added in one portion. After stirring for $5 \mathrm{~min}$, NIS (764mg, $3.40 \mathrm{mmol}$ ) was added and the reaction was slowly warmed to room temperature overnight. The mixture was cooled to $0{ }^{\circ} \mathrm{C}$ and ice-water $(20 \mathrm{~mL})$ was added. The mixture was extracted with $\mathrm{Et}_{2} \mathrm{O}(6 \times 50$ $\mathrm{mL})$. The organic layers were washed with water followed by brine and dried (MgSO4). The solvent was removed under reduced pressure. Chromatography (hexanes/EtOAc, 7:3) gave 78 (777 mg, $2.22 \mathrm{mmol}, 72 \%$ ) as a pale yellow solid. Mp $108-110{ }^{\circ} \mathrm{C} ;{ }^{1} \mathrm{H}$ NMR $(270 \mathrm{MHz}) \delta$ 4.96 (sept, $J=6.1 \mathrm{~Hz}, 1 \mathrm{H}), 4.84$ (sept, $J=6.1 \mathrm{~Hz}, 1 \mathrm{H}), 3.75$ (s, 1H), 1.42 (d, J=6.3 Hz, 6H), $1.28(\mathrm{~d}, J=6.1 \mathrm{~Hz}, 3 \mathrm{H}), 1.27$ (d, $J=6.1 \mathrm{~Hz}, 3 \mathrm{H}) ;{ }^{13} \mathrm{C}$ NMR $(150 \mathrm{MHz}) \delta 180.0,164.1,134.3$, 88.9, 79.7, 78.2, 74.3, 22.7, 22.6, 22.5, 7.9; IR (ATR) 2988,1771,1617,1390,1325,1098, 999, 954, 910, $737 \mathrm{~cm}^{-1}$; HRMS (ESI) calcd for $\mathrm{C}_{12} \mathrm{H}_{16} \mathrm{IO}_{4}\left(\mathrm{M}+\mathrm{H}^{+}\right)$351.0093; found 351.0088. 


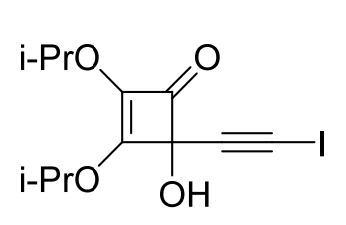

78

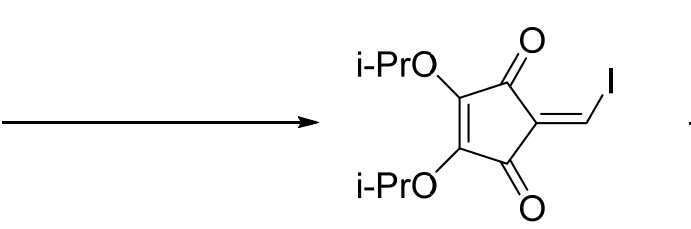

75<smiles>O=C1C=C(I)C(=O)C(O[Pb])=C1O</smiles>

79

2-(Iodomethylene)-4,5-bis(1-methylethoxy)-4-cyclopentene-1,3-dione (75) and 5-iodo-2,3-

bis(1-methylethoxy)-2,5-cyclohexadiene-1,4-dione (79). Treatment of 78 (84 mg, $0.24 \mathrm{mmol}$ ) in benzene $(0.75 \mathrm{~mL})$ as described for $69\left(140{ }^{\circ} \mathrm{C}, 3 \mathrm{~h}\right)$ gave after chromatography (hexanes/EtOAc, 98:2), in order of elution 79 (21 mg, $0.060 \mathrm{mmol}, 25 \%)$ and 75 (35.0 mg, $0.100 \mathrm{mmol}, 42 \%)$ both as orange oils. Analytical data for 79: ${ }^{1} \mathrm{H}$ NMR $(270 \mathrm{MHz}) \delta 7.50(\mathrm{~s}$, 1H), 4.83 (sept, $J=6.1 \mathrm{~Hz}, 1 \mathrm{H}), 4.69$ (sept, $J=6.1 \mathrm{~Hz}, 1 \mathrm{H}), 1.27$ (d, $J=6.1 \mathrm{~Hz}, 6 \mathrm{H}), 1.26$ (d, $J=6.1 \mathrm{~Hz}, 6 \mathrm{H}) ;{ }^{13} \mathrm{C}$ NMR $(150 \mathrm{MHz}) \delta 182.4,178.2,146.4,144.3,144.0,117.0,76.9,76.5$, 22.7; IR (ATR) 2983, 1667, 1578, 1390, 1251, 1182, 1103, $910 \mathrm{~cm}^{-1}$; HRMS (ESI) calcd for $\mathrm{C}_{12} \mathrm{H}_{16} \mathrm{IO}_{4}\left(\mathrm{M}+\mathrm{H}^{+}\right)$351.0093; found 351.0088.

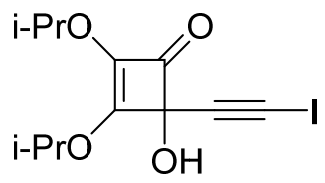

78<smiles>CCCOC1=C(O[In])C(=O)C(=C(I)I)C1=O</smiles>

80

2-(Diiodomethylene)-4,5-bis(1-methylethoxy)-4-cyclopentene-1,3-dione (80). Treatment of 78 (76 mg, $0.20 \mathrm{mmol})$ with NIS $(66.6 \mathrm{mg}, 0.296 \mathrm{mmol})$ in benzene $(0.75 \mathrm{~mL})$ as described for $\mathbf{7 0}\left(80{ }^{\circ} \mathrm{C}, 3 \mathrm{~h}\right)$ gave after chromatography (hexanes/EtOAc, $\left.95: 5\right) \mathbf{8 0}$ (45 mg, $0.094 \mathrm{mmol}$, $43 \%)$ as a pale yellow solid and $78(23.4 \mathrm{mg}, 0.0668,30 \%)$. Data for 80: $\mathrm{mp} 89-94{ }^{\circ} \mathrm{C} ;{ }^{1} \mathrm{H}$ NMR $(270 \mathrm{MHz}) \delta 5.51$ (sept, $J=6.1 \mathrm{~Hz}, 2 \mathrm{H}), 1.37(\mathrm{~d}, J=6.2 \mathrm{~Hz}, 12 \mathrm{H}) ;{ }^{13} \mathrm{C}$ NMR $(150 \mathrm{MHz})$ $\delta 182.7,149.8,133.2,75.5,23.0,17.8$; IR (ATR) 2983, 1672, 1617, 1385, 1311, 1103, 1078, 
910, $796 \mathrm{~cm}^{-1}$; HRMS (ESI) calcd for $\mathrm{C}_{12} \mathrm{H}_{15} \mathrm{I}_{2} \mathrm{O}_{4}\left(\mathrm{M}+\mathrm{H}^{+}\right)$476.9060; found 476.9055 .

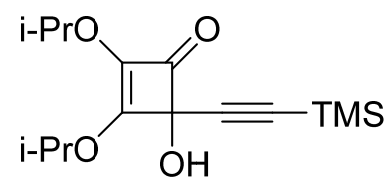

68

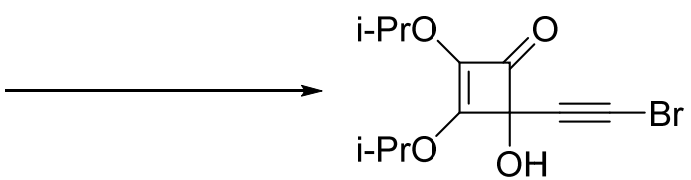

81

\section{4-Hydroxy-2,3-bis(1-methylethoxy)-4-(2-bromoethynyl)-2-cyclobutene-1-one (81).}

A solution of $68(1.00 \mathrm{~g}, 3.38 \mathrm{mmol})$ under a nitrogen atmosphere in DMF (30 $\mathrm{mL})$ was cooled to $0{ }^{\circ} \mathrm{C}$ and $\mathrm{AgNO}_{3}(40 \mathrm{mg}, 0.24 \mathrm{mmol}$ ) was added. After stirring for $5 \mathrm{~min}$, NBS (696 $\mathrm{mg}, 3.91 \mathrm{mmol}$ ) was added and the reaction was slowly warmed to room temperature overnight. The mixture was cooled to $0{ }^{\circ} \mathrm{C}$ and quenched with ice-water $(20 \mathrm{~mL})$. The mixture was extracted with ether $(3 \times 75 \mathrm{~mL})$. The combined organic layers were dried (MgSO4), filtered, and the solvent was removed under reduced pressure. The crude product was purified by chromatography (hexanes/EtOAc, 95:5) to afford 81 (485 mg, $1.60 \mathrm{mmol}$, $47 \%$ ) as a pale yellow solid. Mp $109-110{ }^{\circ} \mathrm{C} ;{ }^{1} \mathrm{H}$ NMR $(600 \mathrm{MHz}) \delta 4.95$ (sept, $J=6.0 \mathrm{~Hz}$, 1H), 4.88 (sept, $J=6.0 \mathrm{~Hz}, 1 \mathrm{H}), 2.76(\mathrm{~s}, 1 \mathrm{H}), 1.44(\mathrm{~d}, J=6.0 \mathrm{~Hz}, 3 \mathrm{H}), 1.44(\mathrm{~d}, J=6.0 \mathrm{~Hz}, 3 \mathrm{H})$, $1.31(\mathrm{~d}, J=6.6 \mathrm{~Hz}, 3 \mathrm{H}), 1.30(\mathrm{~d}, J=6.6 \mathrm{~Hz}, 3 \mathrm{H}) ;{ }^{13} \mathrm{C} \mathrm{NMR}(150 \mathrm{MHz}) \delta 180.1,164.2,134.0$, 79.1, 78.1, 75.0, 74.2, 49.8, 22.6, 22.6, 22.5, 22.4; IR (ATR) 3303, 1775, 1621, 1378, 1331, 1096, 1007, 953, 907, $783 \mathrm{~cm}^{-1}$; HRMS (ESI) calcd for $\mathrm{C}_{12} \mathrm{H}_{15} \mathrm{BrNaO}_{4}\left(\mathrm{M}+\mathrm{Na}^{+}\right) 325.0051$; found: 325.0045 . 


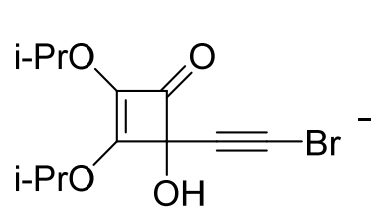

81<smiles>O=C1C(=CBr)C(=O)C(O[InH])=C1O[InH]</smiles>

76<smiles>O=C1C=C(Br)C(=O)C(OC(F)(F)F)=C1O</smiles>

82

\section{5-Bromo-2,3-bis(1-methylethoxy)-2,5-cyclohexadiene-1,4-dione (82) and 2-(bromo}

methylene)-4,5-bis(1-methylethoxy)-4-cyclopentene-1,3-dione (76). A solution of 81 (58 mg, $0.19 \mathrm{mmol})$ in benzene $(1.5 \mathrm{~mL})$ was treated as described for $69\left(140{ }^{\circ} \mathrm{C}, 3 \mathrm{~h}\right)$ gave after chromatography (hexanes/EtOAc, 98:2), in order of elution, 82 (20 mg, $0.066 \mathrm{mmol}, 34 \%)$ as a red-orange oil and $76(18.0 \mathrm{mg}, 0.0594 \mathrm{mmol}, 31 \%)$ as a yellowsolid. Analytical data for 82: ${ }^{1} \mathrm{H}$ NMR $(600 \mathrm{MHz}) \delta 7.10$ (s, 1H), 4.87 (sept, $\left.J=6.0 \mathrm{~Hz}, 1 \mathrm{H}\right), 4.75$ (sept, $\left.J=6.0 \mathrm{~Hz}, 1 \mathrm{H}\right)$, $1.32(\mathrm{~d}, J=6.0 \mathrm{~Hz}, 6 \mathrm{H}), 1.31(\mathrm{~d}, J=6.0 \mathrm{~Hz}, 6 \mathrm{H}) ;{ }^{13} \mathrm{C} \mathrm{NMR}(150 \mathrm{MHz}) \delta 182.3,177.1,146.2$, 145.5, 135.9, 135.3, 76.8, 76.6, 22.6; IR (ATR) 2987, 1652, 1582, 1254, 1181, 1096, 907, 802, $725 \mathrm{~cm}^{-1}$; HRMS (ESI) calcd for $\mathrm{C}_{12} \mathrm{H}_{16} \mathrm{BrO}_{4}\left(\mathrm{M}+\mathrm{H}^{+}\right)$303.0232; found: 303.0224 .

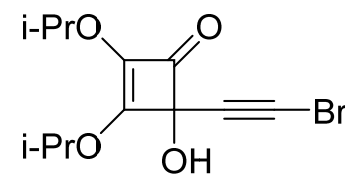

81<smiles>O=C1C(=O)C(=C(Br)I)C(O[Pb])=C1O[Pb]</smiles>

83

\section{2-(1-Bromo-1-iodomethylene)-4,5-bis(1-methylethoxy)-4-cyclopentene-1,3-dione (83).}

Treatment of 81 (78 mg, $0.26 \mathrm{mmol})$ with NIS $(62.4 \mathrm{mg}, 0.276 \mathrm{mmol})$ in benzene $(0.75 \mathrm{~mL})$ as described for $\mathbf{7 1}\left(80{ }^{\circ} \mathrm{C}, 3 \mathrm{~h}\right)$ gave after chromatography (hexanes/EtOAc, 95:5) $\mathbf{8 3}(75 \mathrm{mg}$, $0.18 \mathrm{mmol}, 68 \%$ ) as a pale yellow solid. Mp 109-113 ${ }^{\circ} \mathrm{C} ;{ }^{1} \mathrm{H}$ NMR $(600 \mathrm{MHz}) \delta 5.49$ (sept, $J=6.0 \mathrm{~Hz}, 1 \mathrm{H}), 5.49$ (sept, $J=6.0 \mathrm{~Hz}, 1 \mathrm{H}), 1.35(\mathrm{~d}, J=6.0 \mathrm{~Hz}, 6 \mathrm{H}), 1.35(\mathrm{~d}, J=6.0 \mathrm{~Hz}, 6 \mathrm{H}) ;{ }^{13} \mathrm{C}$ NMR (150 MHz) $\delta 182.1,181.6,150.2,149.6,131.4,75.5,75.4,61.5,23.0$; IR (ATR) 2983, 
$1679,1617,1304,1084,903,791,745,718 \mathrm{~cm}^{-1}$; HRMS (ESI) calcd for $\mathrm{C}_{12} \mathrm{H}_{15} \mathrm{BrIO}_{4}\left(\mathrm{M}+\mathrm{H}^{+}\right)$ 428.9198; found: 428.9195 .

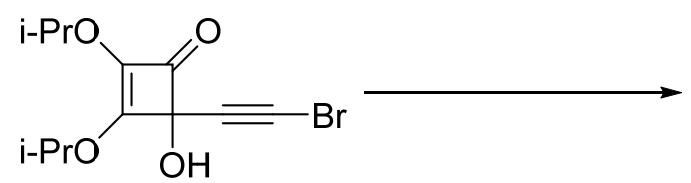

81<smiles>O=C1C(=O)C(=C(Br)Br)C(O[In])=C1O[In]</smiles>

84

2-(Dibromomethylene)-4,5-bis(1-methylethoxy)-4-cyclopentene-1,3-dione (84). Treatment of $81(75 \mathrm{mg}, 0.25 \mathrm{mmol})$ with NBS $(50.2 \mathrm{mg}, 0.282 \mathrm{mmol})$ in benzene $(0.75 \mathrm{~mL})$ as described for $71\left(80{ }^{\circ} \mathrm{C}, 3 \mathrm{~h}\right)$ gave after chromatography (hexanes/EtOAc, 98:2) 84 (43 mg, $0.11 \mathrm{mmol}, 46 \%)$ as an orange solid. $\mathrm{Mp} 103-106{ }^{\circ} \mathrm{C} ;{ }^{1} \mathrm{H} \mathrm{NMR}(600 \mathrm{MHz}) \delta 5.49$ (sept, $J=6.0 \mathrm{~Hz}, 2 \mathrm{H}), 1.36(\mathrm{~d}, J=6.0 \mathrm{~Hz}, 12 \mathrm{H}) ;{ }^{13} \mathrm{C} \mathrm{NMR}(150 \mathrm{MHz}) \delta 181.3,150.4,128.8,101.2$, 75.5, 23.0; IR (ATR) 2987, 1682, 1613, 1378, 1304, 1084, 899, 802, 748, $671 \mathrm{~cm}^{-1}$; HRMS (ESI) calcd for $\mathrm{C}_{12} \mathrm{H}_{14} \mathrm{Br}_{2} \mathrm{NaO}_{4}\left(\mathrm{M}+\mathrm{Na}^{+}\right)$402.9157; found: 402.9152 .

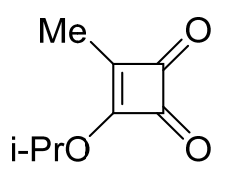

88

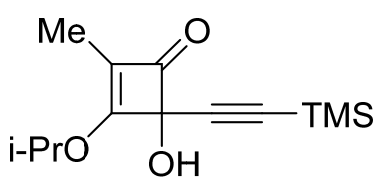

89

\section{4-Hydroxy-2-methyl-3-(1-methylethoxy)-4-(2-trimethylsilylethynyl)-2-cyclobutene-1-one}

(89). Butyllithium $(8.29 \mathrm{~mL}, 1.6 \mathrm{M}$ in hexane, $13.3 \mathrm{mmol})$ was added drop wise to a $-78{ }^{\circ} \mathrm{C}$ cold solution of trimethylsilylethyne $(2.7 \mathrm{~mL}, 13.9 \mathrm{mmol})$ in THF $(16 \mathrm{~mL})$ under a nitrogen atmosphere. The solution was stirred $\left(2 \mathrm{~h},-78^{\circ} \mathrm{C}\right)$ where after it was transferred via a cannula to a $-78{ }^{\circ} \mathrm{C}$ cold solution of 3-(1-methylethoxy)-4-methylcyclobut-3-ene-1,2-dione 88 (1.24 g, 
$7.95 \mathrm{mmol})$ in THF $(40 \mathrm{~mL})$. After stirring for $2 \mathrm{~h}, \mathrm{NH}_{4} \mathrm{Cl}(70 \mathrm{~mL})$ was added and the mixture was extracted with $\mathrm{Et}_{2} \mathrm{O}(5 \mathrm{x} 50 \mathrm{~mL})$. The combined organic layerswere dried (MgSO4) and the solvents were removed under reduced pressure. The crude product was purified by chromatography (hexanes/EtOAc, 8:2) affording 89 (1.26 g, $4.99 \mathrm{mmol}, 63 \%)$ as a pale yellow solid. Mp $84-88{ }^{\circ} \mathrm{C} ;{ }^{1} \mathrm{H}$ NMR $(270 \mathrm{MHz}) \delta 5.04$ (sept, $\left.J=6.1 \mathrm{~Hz}, 1 \mathrm{H}\right), 2.88$ (s, 1H), $1.67(\mathrm{~s}, 3 \mathrm{H}), 1.48(\mathrm{~d}, J=6.1 \mathrm{~Hz}, 3 \mathrm{H}), 1.45(\mathrm{~d}, J=6.3 \mathrm{~Hz}, 3 \mathrm{H}), 0.18(\mathrm{~s}, 9 \mathrm{H}) ;{ }^{13} \mathrm{C} \mathrm{NMR}$ $(150 \mathrm{MHz}) \delta 186.7,179.8,125.0,99.1,95.3,83.4,78.3,22.9,22.6,6.5,0.4$; IR (ATR) 2963, 1766, 1622, 1395, 1340, 1098, 850, $766 \mathrm{~cm}^{-1}$; HRMS (ESI) calcd for $\mathrm{C}_{13} \mathrm{H}_{21} \mathrm{O}_{3} \mathrm{Si}\left(\mathrm{M}+\mathrm{H}^{+}\right)$ 253.1260; found 253.1254.

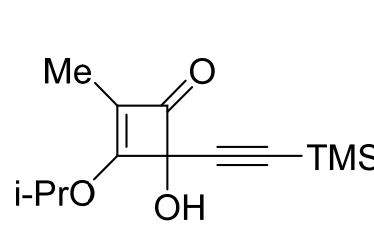

89

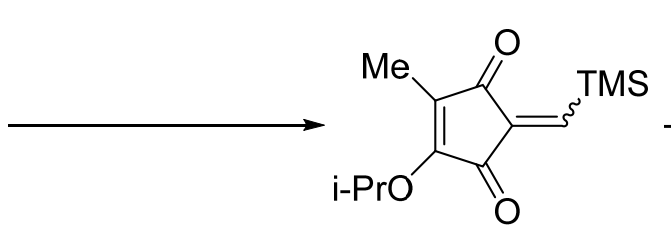

90

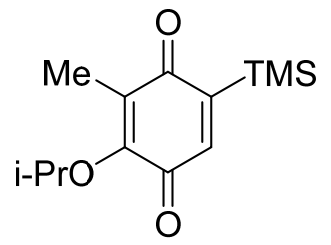

91

2-Trimethylsilylmethylene-4-(1-methylethoxy)-5-methyl-4-cyclopentene-1,3-dione (90) and 5-trimethylsily-3-methyl-2-(1-methylethoxy)-2,5-cyclohexadiene-1,4-dione (91). Treatment of $89(65 \mathrm{mg}, 0.26 \mathrm{mmol})$ in benzene $(0.75 \mathrm{~mL})$ as described for $69\left(140{ }^{\circ} \mathrm{C}, 3 \mathrm{~h}\right)$ gave after chromatography (hexanes/EtOAc, 98:2) an inseparable mixture of 90 (14 mg, $0.056 \mathrm{mmol}$, $22 \%, 1.2: 1$ ratio of isomers) and $91(21 \mathrm{mg}, 0.083 \mathrm{mmol}, 32 \%)$ as a pale yellow oil. Analytical data for 90 (both isomers) from the mixture: ${ }^{1} \mathrm{H}$ NMR $(600 \mathrm{MHz}) \delta 7.04(\mathrm{~s}, 1 \mathrm{H})$, 6.95 (s, 1H), 5.70 (sept, $J=6.1 \mathrm{~Hz}, 1 \mathrm{H}), 5.68$ (sept, $J=6.2 \mathrm{~Hz}, 1 \mathrm{H}), 1.97$ (s, 3H), 1.96 (s, 3H), $1.37(\mathrm{~d}, J=6.2 \mathrm{~Hz}, 6 \mathrm{H}), 1.36(\mathrm{~d}, J=6.2 \mathrm{~Hz}, 6 \mathrm{H}), 0.25$ (s, 9H), 0.24 (s, 9H); Analytical data for 91 from the mixture: ${ }^{1} \mathrm{H}$ NMR $(600 \mathrm{MHz}) \delta 6.70(\mathrm{~s}, 1 \mathrm{H}), 4.83$ (sept, $\left.J=6.2 \mathrm{~Hz}, 1 \mathrm{H}\right), 1.93$ (s, 
$3 \mathrm{H}), 1.29(\mathrm{~d}, J=6.2 \mathrm{~Hz}, 6 \mathrm{H}), 0.23(\mathrm{~s}, 9 \mathrm{H})$. Analytical data for 90 and $91:^{13} \mathrm{C} \mathrm{NMR}(150 \mathrm{MHz})$ $\delta 191.7,190.7,189.4,188.5,186.9,183.1,167.3,166.2,154.6,152.2,143.2,142.9,142.6$, 142.5, 142.0, 75.7, 74.7, 23.2, 22.9, 9.2, 7.0, 7.0, -0.8, -1.0, -1.6; IR (ATR) 2963, 1687, 1632, $1603,1390,1330,1251,1187,1108,845,766 \mathrm{~cm}^{-1}$; HRMS (ESI) calcd for $\mathrm{C}_{13} \mathrm{H}_{21} \mathrm{O}_{3} \mathrm{Si}$ $\left(\mathrm{M}+\mathrm{H}^{+}\right)$253.1260; found 253.1255.

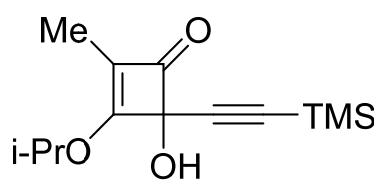

89

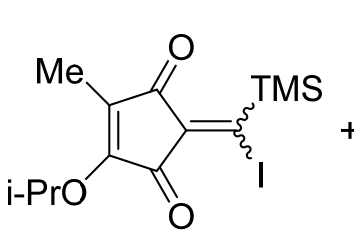

92

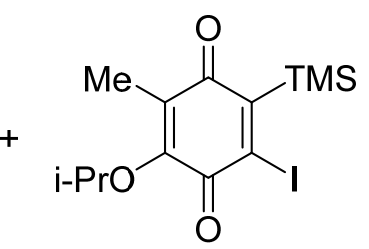

93

2-(1-Iodo-1-trimethylsilylmethylene)-4-(1-methylethoxy)-5-methyl-4-cyclopentene-1,3dione (92) and 6-iodo-5-trimethylsilyl-3-methyl-2-(1-methylethoxy)-2,5-cyclohexadiene1,4-dione (93). Treatment of 89 (64 $\mathrm{mg}, 0.25 \mathrm{mmol})$ with NIS (67 $\mathrm{mg}, 0.30 \mathrm{mmol})$ in benzene $(0.75 \mathrm{~mL})$ as described for $71\left(80{ }^{\circ} \mathrm{C}, 3 \mathrm{~h}\right)$ gave after chromatography (hexanes/EtOAc, 95:5) in order of elution $92(58.8 \mathrm{mg}, 0.155 \mathrm{mmol}, 61 \%, 1.5: 1$ ratio of isomers) as a yellowoil and $93(5 \mathrm{mg}, 0.013 \mathrm{mmol}, 5 \%)$ as a light yellow oil. Analytical data for 92: ${ }^{1} \mathrm{H}$ NMR $(270 \mathrm{MHz}) \delta(600 \mathrm{MHz}) 5.72(\mathrm{sept}, J=6.1 \mathrm{~Hz}, 1 \mathrm{H}), 5.54(\mathrm{sept}, J=6.1 \mathrm{~Hz}$, 1H), 1.96 (s, 3H), 1.89 (s, 3H), 1.37 (d, J=6.2 Hz, 6H), 1.35 (d, J=6.1 Hz, 6H), 0.37 (s, 9H), $0.36(\mathrm{~s}, 9 \mathrm{H}) ;{ }^{13} \mathrm{C}$ NMR $(150 \mathrm{MHz}) \delta 189.1,188.2,185.7,185.6,167.6,163.2,142.1,142.0$, 136.6, 132.6, 131.4, 130.9, 75.1, 74.7, 23.3, 23.1, 7.7, 6.5, 1.7, 1.4; IR (ATR) 2988, 1682, 1622, 1385, 1330, 1123, 1019, $771 \mathrm{~cm}^{-1}$; HRMS (ESI) calcd for $\mathrm{C}_{13} \mathrm{H}_{20} \mathrm{IO}_{3} \mathrm{Si}\left(\mathrm{M}+\mathrm{H}^{+}\right)$ 379.0226; found 379.0222. Analytical data for 93: ${ }^{1} \mathrm{H}$ NMR (270 MHz) $\delta 4.90$ (sept, $J=6.2$ $\mathrm{Hz}, 1 \mathrm{H}), 1.91(\mathrm{~s}, 3 \mathrm{H}), 1.41(\mathrm{~d}, J=6.1 \mathrm{~Hz}, 3 \mathrm{H}), 1.32(\mathrm{~d}, J=6.1 \mathrm{~Hz}, 3 \mathrm{H}), 0.23(\mathrm{~s}, 9 \mathrm{H}) ;{ }^{13} \mathrm{C} \mathrm{NMR}$ 
$(150 \mathrm{MHz}) \delta 173.3,168.5,151.2,107.7,97.1,89.0,74.2,22.9,22.7,8.9,0.5$; IR (ATR) 2988, 1781, 1662, 1306, 1251, 1108, 1053, $841 \mathrm{~cm}^{-1}$; HRMS (ESI) calcd for $\mathrm{C}_{13} \mathrm{H}_{19} \mathrm{INaO}_{3} \mathrm{Si}$ $\left(\mathrm{M}+\mathrm{Na}^{+}\right)$401.0046; found 401.0039.

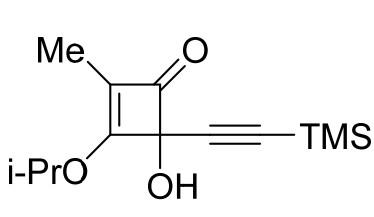

89
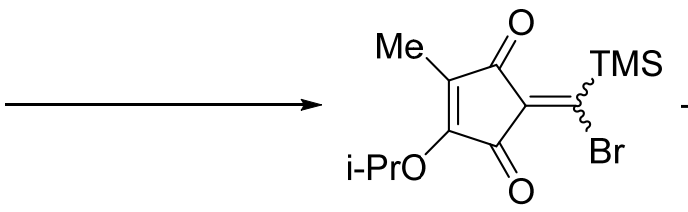

94

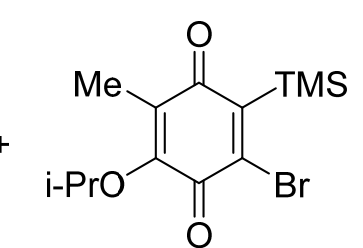

95

2-(1-Bromo-1-trimethylsilylmethylene)-4-(1-methylethoxy)-5-methyl-4-cyclopentene-1,3-di one (94) and 6-bromo-5-trimethylsily-3-methyl-2-(1-methylethoxy)-2,5-cyclohexadiene-1,4dione (95). Treatment of 89 (64 mg, $0.26 \mathrm{mmol})$ with NBS (65 mg, $0.37 \mathrm{mmol})$ in benzene $(0.75 \mathrm{~mL})$ as described for $\mathbf{7 1}\left(80{ }^{\circ} \mathrm{C}, 3 \mathrm{~h}\right)$ gave after chromatography (hexanes/EtOAc, 95:5), in order of elution, 94 (55 $\mathrm{mg}, 0.17 \mathrm{mmol}, 65 \%, 2: 1$ ratio of isomers) as a pale yellow oil and 95 (13 mg, $0.039 \mathrm{mmol}, 15 \%)$ as a colorless oil. Analytical data for 94: ${ }^{1} \mathrm{H}$ NMR $(270 \mathrm{MHz}$, major isomer) $\delta 5.69(\mathrm{sept}, J=6.1 \mathrm{~Hz}, 1 \mathrm{H}), 1.90(\mathrm{~s}, 3 \mathrm{H}), 1.37(\mathrm{~d}, J=5.9 \mathrm{~Hz}, 6 \mathrm{H}), 0.36(\mathrm{~s}, 9 \mathrm{H})$; ${ }^{1} \mathrm{H}$ NMR (270 MHz, minor isomer) $\delta 5.54$ (sept, $\left.J=6.1 \mathrm{~Hz}, 1 \mathrm{H}\right), 1.96$ (s, 3H), 1.35 (d, $J=5.9$ $\mathrm{Hz}, 6 \mathrm{H}), 0.35$ (s, 9H); ${ }^{13} \mathrm{C}$ NMR $(150 \mathrm{MHz}) \delta 189.1,187.8,186.5,185.1,167.3,164.0,151.0$, $137.9,137.7,136.9,133.5,75.0,74.6,23.3,23.1,7.4,6.7,0.28,0.023$; IR (ATR) 2988, 1687, 1627, 1390, 1330, 1133, 1103, $870 \mathrm{~cm}^{-1}$; HRMS (ESI) calcd for $\mathrm{C}_{13} \mathrm{H}_{20} \mathrm{BrO}_{3} \mathrm{Si}\left(\mathrm{M}+\mathrm{H}^{+}\right)$ 331.0365; found 331.0362. Analytical data for 95: ${ }^{1} \mathrm{H}$ NMR (270 MHz) $\delta 4.94$ (sept, $J=6.1$ $\mathrm{Hz}, 1 \mathrm{H}), 2.01(\mathrm{~s}, 3 \mathrm{H}), 1.45(\mathrm{~d}, J=6.1 \mathrm{~Hz}, 6 \mathrm{H}), 0.55(\mathrm{~s}, 9 \mathrm{H}) ;{ }^{13} \mathrm{C}$ NMR $(150 \mathrm{MHz}) \delta 171.1$, $166.5,160.9,136.5,114.4,104.0,75.7,22.8,21.0,9.6,2.0$; IR (ATR) 2993, 1786, 1632, 1316, 1256, 1029, 855, $742 \mathrm{~cm}^{-1}$; HRMS (ESI) calcd for $\mathrm{C}_{13} \mathrm{H}_{19} \mathrm{BrNaO}_{3} \mathrm{Si}\left(\mathrm{M}+\mathrm{Na}^{+}\right)$353.0185; 
found 353.0176 .

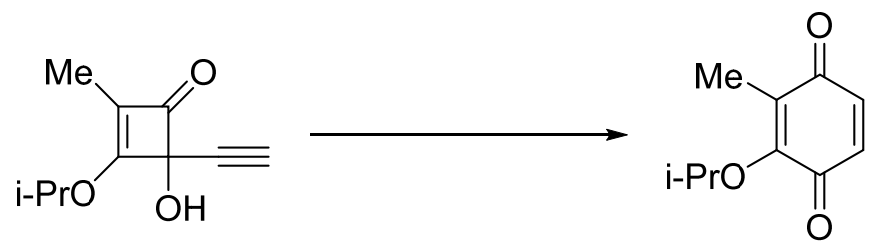

96

97

3-Methyl-2-(1-methylethoxy)-2,5-cyclohexadiene-1,4-dione (97). Treatment of $96^{62}$ (64 mg, $0.35 \mathrm{mmol})$ in benzene $(0.75 \mathrm{~mL})$ as described for $69\left(140{ }^{\circ} \mathrm{C}, 3 \mathrm{~h}\right)$ gave after chromatography (hexanes/EtOAc, 98:2) 97 (38 mg, $0.21 \mathrm{mmol}, 85 \%)$ as a yellowish-brown oil. ${ }^{1} \mathrm{H}$ NMR $(270 \mathrm{MHz}) \delta 6.68(\mathrm{~d}, J=10.1 \mathrm{~Hz}, 1 \mathrm{H}), 6.59(\mathrm{~d}, J=10.1 \mathrm{~Hz}, 1 \mathrm{H}), 4.83$ (sept, $J=6.1 \mathrm{~Hz}, 1 \mathrm{H}), 1.95(\mathrm{~s}, 3 \mathrm{H}), 1.30(\mathrm{~d}, J=6.1 \mathrm{~Hz}, 6 \mathrm{H}) ;{ }^{13} \mathrm{C} \mathrm{NMR}(150 \mathrm{MHz}) \delta 188.4,183.5$, 154.7, $136.4, \quad 134.8, \quad 130.9, \quad 76.1, \quad 22.9, \quad 22.5, \quad 9.0 ; \quad$ IR $\quad$ (ATR) $2983,1652,1593,1385,1306,1192,1098,1019,850,801 \mathrm{~cm}^{-1}$; HRMS (ESI) calcd for $\mathrm{C}_{10} \mathrm{H}_{13} \mathrm{O}_{3}$ $\left(\mathrm{M}+\mathrm{H}^{+}\right)$181.0865; found 181.0859.

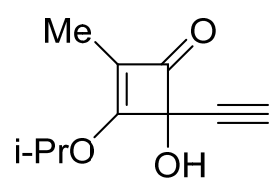

96

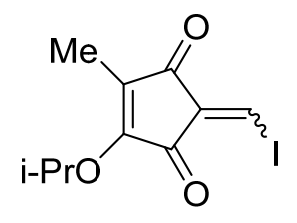

98

\section{2-(1-Iodomethylene)-4-methyl-5-(1-methylethoxy)-4-cyclopentene-1,3-dione (98).}

Treatment of 96 (120 mg, $0.66 \mathrm{mmol})$ and NIS (164 mg, $0.729 \mathrm{mmol})$ in toluene $(5 \mathrm{~mL})$ as described for $71\left(150{ }^{\circ} \mathrm{C}, 3 \mathrm{~h}\right)$ gave after chromatography (hexanes/EtOAc, 19:1) 98 (130 mg, $0.426 \mathrm{mmol}, 64 \%$, 13:1 ratio of double bond isomers) as an orange solid. $\mathrm{Mp} 47-52{ }^{\circ} \mathrm{C}$; Major isomer: ${ }^{1} \mathrm{H}$ NMR (270 MHz) $\delta 8.08$ (s, 1H), 5.75 (sept, J=6.1 Hz, 1H), 1.91 (s, 3H), $1.38(\mathrm{~d}, J=6.1 \mathrm{~Hz}, 6 \mathrm{H}) ;{ }^{13} \mathrm{C}$ NMR $(67.5 \mathrm{MHz}) \delta 187.3,185.8,168.2,137.1,133.2,92.1,75.2$, 
23.2, 6.7; Minor isomer: ${ }^{1} \mathrm{H}$ NMR (270 MHz) $\delta 8.01$ (s, 1H), 5.67 (pent, $\left.J=6.1 \mathrm{~Hz}, 1 \mathrm{H}\right), 1.95$ (s, 3H), $1.35(\mathrm{~d}, J=6.5 \mathrm{~Hz}, 6 \mathrm{H})$; partial data ${ }^{13} \mathrm{C}$ NMR $(67.5 \mathrm{MHz}) \delta 91.4,75.0,23.1,7.35$; IR (ATR) 1734, 1680, 1618, 1326, $1106 \mathrm{~cm}^{-1}$; HRMS (ESI) calcd for $\mathrm{C}_{10} \mathrm{H}_{12} \mathrm{IO}_{3}\left(\mathrm{M}+\mathrm{H}^{+}\right)$ 306.9826; found 306.9822 .

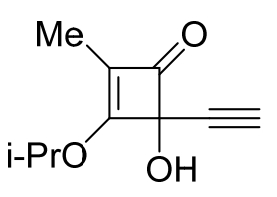

96

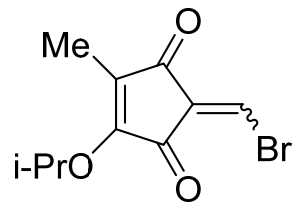

99

2-(1-Bromomethylene)-4-(1-methylethoxy)-5-methyl-4-cyclopentene-1,3-dione (99).

Treatment of 96 (50 mg, $0.28 \mathrm{mmol})$ with NBS (51 mg, $0.28 \mathrm{mmol})$ in benzene $(3 \mathrm{~mL})$ as described for $71\left(80{ }^{\circ} \mathrm{C}, 3 \mathrm{~h}\right)$ gave after chromatography (hexanes) 99 (42 mg, $0.16 \mathrm{mmol}, 59 \%$ as a 2.8:1 ratio of double bond isomers) as a yellow oil. ${ }^{1} \mathrm{H}$ NMR (270 MHz, major isomer) $\delta$ 7.58 (s, 1H), 5.74 (sept, J=6.1 Hz, 1H), 1.93 (s, 3H),1.39 (d, J=6.1 Hz, 6H); ${ }^{1} \mathrm{H}$ NMR (270 MHz, minor isomer) $\delta 7.51(\mathrm{~s}, 1 \mathrm{H}), 5.66(\mathrm{sept}, J=6.2 \mathrm{~Hz}, 1 \mathrm{H}), 1.97(\mathrm{~s}, 3 \mathrm{H}), 1.36(\mathrm{~d}, J=6.1 \mathrm{~Hz}$, $6 \mathrm{H}) ;{ }^{13} \mathrm{C}$ NMR $(67.5 \mathrm{MHz}) \delta 187.2,187.2,183.9,184.9,184.7,167.9,164.5,139.1,134.3$, 132.4, 132.3, 119.3, 119.0, 75.3, 75.1, 23.2, 23.1, 7.3, 6.9; IR (ATR) 2986, 1689, 1636, 1393, 1327, 1269, 1015, $764 \mathrm{~cm}^{-1}$; HRMS (ESI) calcd for $\mathrm{C}_{10} \mathrm{H}_{12} \mathrm{BrO}_{3}\left(\mathrm{M}+\mathrm{H}^{+}\right)$258.9971; found 258.9964. 


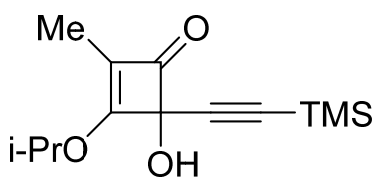

89<smiles>CC(=O)OC1=C(C)C(=O)C(=C(I)I)C1=O</smiles>

101

\section{2-(Diiodomethylene)-4-(1-methylethoxy)-5-methyl-4-cyclopentene-1,3-dione (101).}

Treatment of a $0{ }^{\circ} \mathrm{C}$ cold solution of $89(549 \mathrm{mg}, 3.05 \mathrm{mmol})$ in DMF $(30 \mathrm{~mL})$ under $\mathrm{N}_{2}$ with $\mathrm{AgNO}_{3}(48 \mathrm{mg}, 0.28 \mathrm{mmol})$ and NIS $(762 \mathrm{mg}, 3.39 \mathrm{mmol})$ was added and the reaction was slowly warmed to room temperature overnight. The mixture was cooled to $0{ }^{\circ} \mathrm{C}$ and ice-water (20 $\mathrm{mL}$ ) was added and the resulting mixture was allowed to warm to ambient temperature. The mixture was extracted with ether $(6 \times 50 \mathrm{~mL})$. The combined organic layers were washed with water and brine, dried (MgSO4), filtered, and the solvent was removed under reduced pressure. The crude product was purified by chromatography (hexanes/EtOAc, 9:1) to afford 101 (209 mg, $0.483 \mathrm{mmol}, 28 \%$ ) as a yellow solid. Mp 75-80 ${ }^{\circ} \mathrm{C} ;{ }^{1} \mathrm{H}$ NMR $(270 \mathrm{MHz}) \delta 5.65$ (sept, $J=6.1 \mathrm{~Hz}, 1 \mathrm{H}), 1.90(\mathrm{~s}, 3 \mathrm{H}), 1.37(\mathrm{~d}, J=6.1 \mathrm{~Hz}, 6 \mathrm{H}) ;{ }^{13} \mathrm{C}$ NMR $(150 \mathrm{MHz}) \delta 187.6$, 184.3, 165.0, 134.6, 134.3, 75.4, 23.2, 22.7, 7.1; IR (ATR) 2988, 1687, 1622, 1558, 1390, 1321, 1118, 1098, 900, $677 \mathrm{~cm}^{-1}$; HRMS (ESI) calcd for $\mathrm{C}_{10} \mathrm{H}_{11} \mathrm{I}_{2} \mathrm{O}_{3}\left(\mathrm{M}+\mathrm{H}^{+}\right)$432.8798; found 432.8791 .

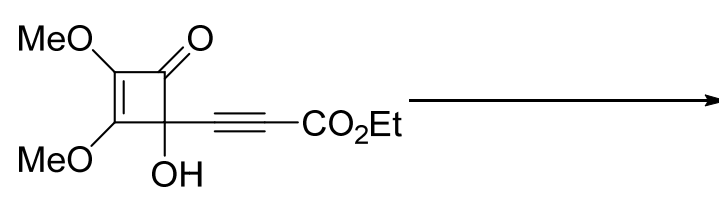

102<smiles>CCOC(=O)C(I)=C1C(=O)C(OC)=C(OC)C1=O</smiles>

104

Ethyl 2-(3,4-dimethoxy-2,5-dioxo-3-cyclopenten-1-ylene)-2-iodoethanoate (104).

Treatment of $\mathbf{1 0 2}^{12}(60 \mathrm{mg}, 0.25 \mathrm{mmol})$ with NBS $(63.2 \mathrm{mg}, 0.281 \mathrm{mmol})$ in benzene $(0.75$ 
$\mathrm{mL}$ ) as described for $\mathbf{7 1}\left(80{ }^{\circ} \mathrm{C}, 3 \mathrm{~h}\right)$, gave after chromatography (hexanes/EtOAc, 9:1) 104 (65 mg, $0.18 \mathrm{mmol}, 71 \%$ ) as a yellow solid. Mp 103-107 ${ }^{\circ} \mathrm{C} ;{ }^{1} \mathrm{H}$ NMR (270 MHz) $\delta 4.38$ (q, $J=7.1 \mathrm{~Hz}, 2 \mathrm{H}), 4.29(\mathrm{~s}, 3 \mathrm{H}), 4.24(\mathrm{~s}, 3 \mathrm{H}), 1.35(\mathrm{t}, J=7.1 \mathrm{~Hz}, 3 \mathrm{H}) ;{ }^{13} \mathrm{C} \mathrm{NMR}(150 \mathrm{MHz}) \delta$ $181.5,180.3,166.1,153.8,149.9,131.7,93.7,62.9,60.2,60.2,13.7$; IR (ATR) 1726, 1675, 1629, 1589, 1465, 1431, 1329, 1236, 1146, 1093, 1017, 953, 852, $787 \mathrm{~cm}^{-1}$; HRMS calcd for $\mathrm{C}_{11} \mathrm{H}_{12} \mathrm{IO}_{6}\left(\mathrm{M}+\mathrm{H}^{+}\right)$366.9679; found: 366.9676 .

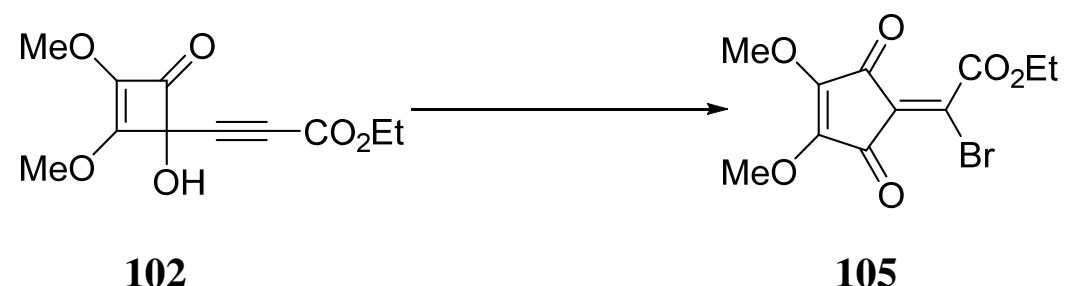

Ethyl 2-(3,4-dimethoxy-2,5-dioxo-3-cyclopenten-1-ylene)-2-bromoethanoate (105).

Treatment of $102(60 \mathrm{mg}, 0.25 \mathrm{mmol})$ with NBS $(50 \mathrm{mg}, 0.28 \mathrm{mmol})$ in benzene $(0.75 \mathrm{~mL})$ as described for $\mathbf{7 1}\left(80^{\circ} \mathrm{C}, 3 \mathrm{~h}\right)$, gave after chromatography (hexanes/EtOAc, 9:1) 105 (30 mg, $0.095 \mathrm{mmol}, 38 \%)$ as a yellow oil; ${ }^{1} \mathrm{H}$ NMR $(270 \mathrm{MHz}) \delta 4.40(\mathrm{q}, J=7.1 \mathrm{~Hz}, 2 \mathrm{H}), 4.30$ (s, 3H), $4.26(\mathrm{~s}, 3 \mathrm{H}), 1.37$ (t, $J=7.1 \mathrm{~Hz}, 3 \mathrm{H}) ;{ }^{13} \mathrm{C} \mathrm{NMR}(150 \mathrm{MHz}) \delta 181.5,180.3,166.1,153.8$, 149.9, 131.7, 93.7, 62.9, 60.24, 60.17, 13.7; IR (ATR) 1734, 1686, 1642, 1594, 1467, 1339, 1255, 1155, 1103, $1027 \mathrm{~cm}^{-1}$; HRMS calcd for $\mathrm{C}_{11} \mathrm{H}_{11} \mathrm{BrNaO}_{6}\left(\mathrm{M}+\mathrm{Na}^{+}\right)$340.9637; found 340.9634 . 


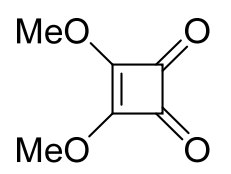

7

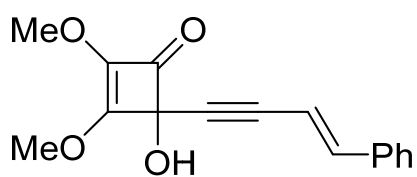

137

\section{2,3-Dimethoxy-4-hydroxy-4-[(E)-4-phenyl-3-buten-1-yn-1-yl]-2-cyclobuten-1-one (137).}

Butyllithium $\left(0.82 \mathrm{~mL}, 1.30 \mathrm{mmol}, 1.60 \mathrm{M}\right.$ in hexane) was added drop wise to a $-78{ }^{\circ} \mathrm{C}$ cold solution of E-4-phenyl-but-3-en-1-yne $(175 \mathrm{mg}, 1.37 \mathrm{mmol})$ in THF $(8 \mathrm{~mL})$. The reaction mixture was stirred $\left(-78{ }^{\circ} \mathrm{C}, 2 \mathrm{~h}\right)$ followed by transfer via a cannula to a $-78{ }^{\circ} \mathrm{C}$ cold solution of 3,4-dimethoxy-3-cyclobutene-1,2-dione (7) (189 mg, $1.33 \mathrm{mmol})$ in THF (20 mL). After stirring for $2 \mathrm{~h}\left(-78{ }^{\circ} \mathrm{C}\right)$, a saturated solution of $\mathrm{NH}_{4} \mathrm{Cl}(50 \mathrm{~mL}$, aqueous) was added and the mixture was extracted with ether $(3 \times 70 \mathrm{~mL})$. The combined organic layers were dried (MgSO4), filtered, and the solvents were removed under reduced pressure. The crude product was purified by chromatography (hexanes/EtOAc, 8:2) to give 137 (170 $\mathrm{mg}, 0.628 \mathrm{mmol}$, 47\%) as a yellow oil. ${ }^{1} \mathrm{H}$ NMR (600 MHz) $\delta ~ 7.36-7.27(5 \mathrm{H}), 7.01(\mathrm{~d}, J=16.2 \mathrm{~Hz}, 1 \mathrm{H}), 6.18$ (d, $J=16.2 \mathrm{~Hz}, 1 \mathrm{H}), 4.22(\mathrm{~s}, 3 \mathrm{H}), 3.98(\mathrm{~s}, 3 \mathrm{H}) ;{ }^{27}{ }^{13} \mathrm{C}$ NMR $(150 \mathrm{MHz}) \delta 180.8,164.8,143.0$, $135.7,135.5,129.0,128.7,126.4,106.5,88.3,84.9,79.0,60.2,58.6$; IR (ATR) 3365, 2958, 2180, 1772, 1627, 1351, 1046, 957, 868, 746, $685 \mathrm{~cm}^{-1}$; HRMS (ESI) calcd for $\mathrm{C}_{16} \mathrm{H}_{15} \mathrm{O}_{4}$ $\left(\mathrm{M}+\mathrm{H}^{+}\right)$271.0970, found: 271.0966. 


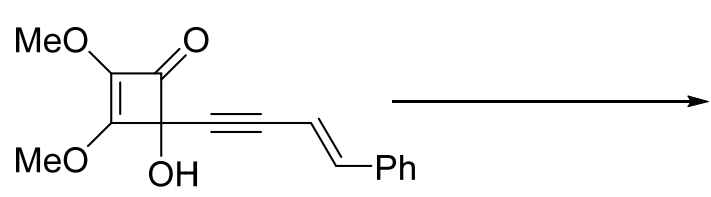

137

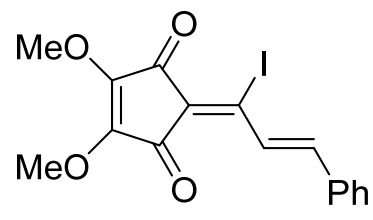

138

\section{4,5-Dimethoxy-[(E)-2-(1-iodo-3-phenyl-2-propen-1-ylidene)]-4-cyclopentene-1,3-dione}

(138). Treatment of 137 (55 mg, $0.20 \mathrm{mmol})$ with NIS (50mg, 0.22 $\mathrm{mmol})$ in benzene $(0.75 \mathrm{~mL})$ as described for $71\left(80{ }^{\circ} \mathrm{C}, 3 \mathrm{~h}\right)$ gave after chromatography (hexanes/EtOAc, 9:1) $138(30 \mathrm{mg}, 0.075 \mathrm{mmol}, 37 \%)$ as a yellow oil. ${ }^{1} \mathrm{H}$ NMR $(600 \mathrm{MHz}) \delta 8.38(\mathrm{~d}, J=14.4 \mathrm{~Hz}$, 1H), 7.65 (d, J=7.8 Hz, 2H), 7.41-7.36 (m, 4H), 4.29 (s, 3H), 4.26 (s, 3H); ${ }^{13} \mathrm{C}$ NMR (150 MHz) $\delta 184.1,184.0,151.3,150.8,148.4,135.5,130.2,129.0,128.7,126.8,126.4,115.4,60.1$, 60.1; IR (ATR) 2929, 1674, 1632, 1468, 1332, 1093, 1041, 760, $695 \mathrm{~cm}^{-1}$; HRMS (ESI) calcd for $\mathrm{C}_{16} \mathrm{H}_{14} \mathrm{IO}_{4}\left(\mathrm{M}+\mathrm{H}^{+}\right)$396.9937; found: 396.9934 .

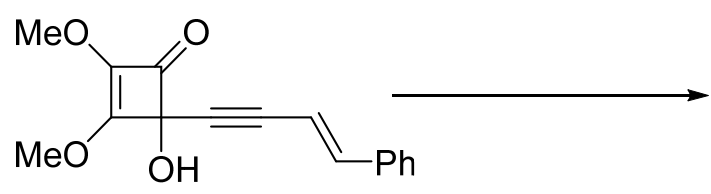

137

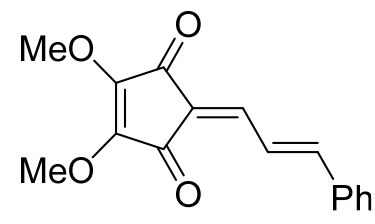

139

\section{4,5-Dimethoxy-2-[(E)-3-phenyl-2-propen-1-ylidene]-4-cyclopente-1,3-dione (139).}

Treatment of $137(55 \mathrm{mg}, 0.20 \mathrm{mmol})$ in benzene $(0.75 \mathrm{~mL})$ as described for $69\left(140{ }^{\circ} \mathrm{C}, 3 \mathrm{~h}\right)$ gave after chromatography (hexanes/EtOAc, 85:15) 139 (30 mg, $0.11 \mathrm{mmol}, 54 \%$ ) as a yellow solid. Mp 114-119 ${ }^{\circ} \mathrm{C} ;{ }^{1} \mathrm{H}$ NMR $(600 \mathrm{MHz}) \delta 8.11(\mathrm{dd}, J=15.6$ and $11.4 \mathrm{~Hz}, 1 \mathrm{H}), 7.58$ (d, $J=7.8 \mathrm{~Hz}, 2 \mathrm{H}), 7.39-7.35(3 \mathrm{H}), 7.13(\mathrm{~d}, J=12.0 \mathrm{~Hz}, 1 \mathrm{H}), 7.09$ (d, $J=15.6 \mathrm{~Hz}, 1 \mathrm{H}), 4.28$ (s, 3H), 4.27 (s, 3H); ${ }^{13} \mathrm{C}$ NMR (150 MHz) $\delta 186.0,185.8,151.8,150.3,147.0,136.1,135.8$, 130.0, 128.9, 128.0, 124.5, 123.2, 59.9, 59.9; IR (ATR) 2962, 1669, 1632, 1608, 1468, 1435 , 
1322, 1102, 1060, 999, 788, $760 \mathrm{~cm}^{-1}$; HRMS (ESI) calcd for $\mathrm{C}_{16} \mathrm{H}_{15} \mathrm{O}_{4}\left(\mathrm{M}+\mathrm{H}^{+}\right): 271.0970$; Found: 271.0967.<smiles>COC1=C(OC)C(=O)C(=C(I)/C=C/c2ccccc2)C1=O</smiles>

138

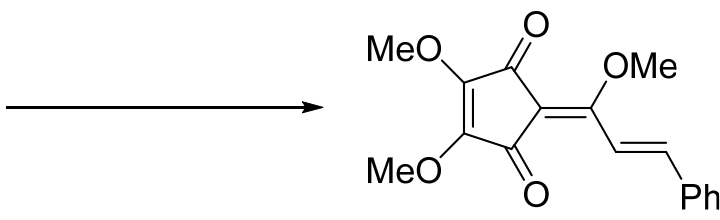

107

4,5-Dimethoxy-[(E)-2-(1-methoxy-3-phenyl-2-propen-1-ylidene)]-4-cyclopentene-1,3-dione (methyl linderone). Treatment of $138(28 \mathrm{mg}, 0.072 \mathrm{mmol})$ with $\mathrm{K}_{2} \mathrm{CO}_{3}(10 \mathrm{mg}, 0.073 \mathrm{mmol})$ in $\mathrm{MeOH}(5 \mathrm{~mL})$ at $60^{\circ} \mathrm{C}$ for 3 days gave after solvent removal and chromatography (hexanes/EtOAc, 9:1) methyl linderone (19 mg, $0.064 \mathrm{mmol}, 89 \%$ ) as a yellow oil. ${ }^{1} \mathrm{H}$ NMR and ${ }^{13} \mathrm{C}$ NMR data were in complete accordance with literature values. ${ }^{15}$

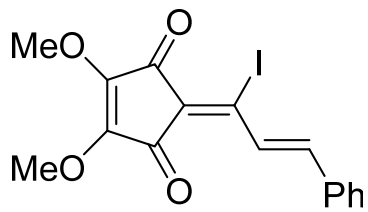

138<smiles>COC1=C(OC)C(=O)C(=C(C)C=Cc2ccccc2)C1=O</smiles>

140

\section{4,5-Dimethoxy-2-[(E)-1-(N,N-dimethylamino)-3-phenyl-2-propen-1-ylidene]-4-cyclopente-}

1,3-dione (140). Treatment of 138 (10 mg, $0.0263 \mathrm{mmol})$ with $p$-toluenesulfonic acid $(0.2 \mathrm{mg}$, $0.001 \mathrm{mmol})$ in a mixture of DMF $(1.8 \mathrm{~mL})$ and $\mathrm{H}_{2} \mathrm{O}(0.2 \mathrm{~mL})$ at $100{ }^{\circ} \mathrm{C}$. Water $(5 \mathrm{~mL})$ was added and the mixture was extracted with EtOAc $(3 \times 50 \mathrm{~mL})$. The combined organic phases were dried (MgSO4) and filtered. The solvent was removed under reduced pressure. Purification by chromatography (hexanes/EtOAc, 85:15) gave 140 (8 mg, $0.025 \mathrm{mmol}, 95 \%)$ as a yellow oil. ${ }^{1} \mathrm{H}$ NMR (600 MHz) $\delta 7.52(\mathrm{dd}, J=7.8$ and $1.8 \mathrm{~Hz}, 2 \mathrm{H}), 7.39-7.33(\mathrm{~m}, 3 \mathrm{H})$, 
7.04 (d, J=16.2 Hz, 1H), 6.75 (d, J=16.2 Hz, 1H), 4.05 (s, 6H), 3.21 (s, 6H); ${ }^{13} \mathrm{C}$ NMR (150 MHz) $\delta 187.5,160.5,145.0,142.6,139.3,135.2,129.9,128.8,128.0,120.9,96.5,59.8,44.0$; IR (ATR) 2929, 1646, 1543, 1482, 1407, 1313, 1004, $765 \mathrm{~cm}^{-1}$; HRMS (ESI) calcd for $\mathrm{C}_{18} \mathrm{H}_{19} \mathrm{NNaO}_{4}\left(\mathrm{M}+\mathrm{Na}^{+}\right)$336.1212; found: 336.1210. 


\subsection{Supporting information Chapter 3: Wacker-type oxidation of aryl-substituted}

\section{alkenes}

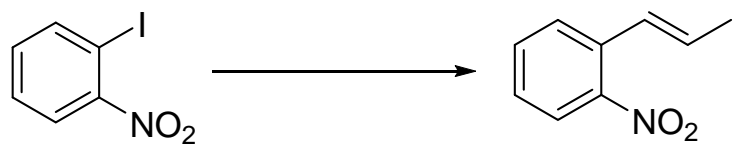

230

2-Nitro-1-(1-propen-1-yl)benzene (230). ${ }^{167}$ To a solution of $\mathrm{Pd}(\mathrm{dba})_{2}(870 \mathrm{mg}, 1.51 \mathrm{mmol})$ and $\mathrm{PPh}_{3}(1.60 \mathrm{~g}, 6.08 \mathrm{mmol})$ in toluene $(80 \mathrm{~mL})$ under $\mathrm{N}_{2}$ atmosphere was added tributyl-1-propen-1-yltin ${ }^{168}$ (12.62 g, $\left.38.12 \mathrm{mmol}\right)$ and 1-iodo-2-nitrobenzene (7.55 g, 30.3 mmol). The mixture was heated at reflux for $48 \mathrm{~h}$. The solvent was removed under reduced pressure and $\mathrm{Et}_{2} \mathrm{O}(200 \mathrm{~mL})$ was added. The solution was washed with $\mathrm{NH}_{4} \mathrm{OH}$ (10\%-aqueous, $6 \times 100 \mathrm{~mL}), \mathrm{H}_{2} \mathrm{O}(3 \times 100 \mathrm{~mL})$, brine $(100 \mathrm{~mL})$. The organic phase was dried $\left(\mathrm{MgSO}_{4}\right)$, filtered, and the solvent was removed under reduced pressure. The crude product was purified by chromatography (hexanes/EtOAc, 99:1) to give 230 (3.02 g, $18.5 \mathrm{mmol}, 49 \%$ ) as a pale yellow oil.

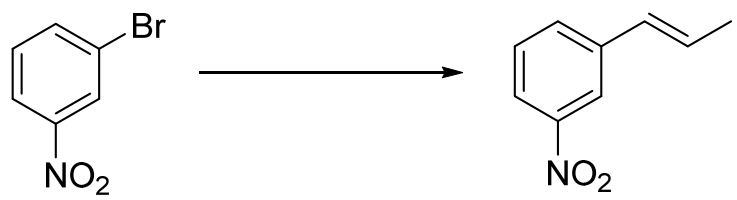

231

3-Nitro-1-(1-propen-1-yl)benzene (231). ${ }^{169}$ Treatment of 1-bromo-3-nitrobenzene (716 mg, $3.55 \mathrm{mmol})$ with tributyl-1-propen-1-yltin $(1.40 \mathrm{~g}, 4.22 \mathrm{mmol})$ a solution of $\mathrm{Pd}(\mathrm{dba})_{2}(105 \mathrm{mg}$, $0.183 \mathrm{mmol})$ and $\mathrm{PPh}_{3}(183 \mathrm{mg}, 0.699 \mathrm{mmol})$ in toluene $(50 \mathrm{~mL})$, as described for $\mathbf{1}$, gave after work up and chromatography (hexanes/EtOAc, 98:2) 231 (339 mg, $2.08 \mathrm{mmol}, 49 \%$ ) as 
a pale yellow oil.<smiles>C/C=C/c1ccc([N+](=O)[O-])cc1</smiles>

232

4-Nitro-1-(1-propen-1-yl)benzene (232). ${ }^{170}$ Treatment of 1-bromo-4-nitrobenzene (713 mg, $3.53 \mathrm{mmol})$ with tributyl 1-propen-1-yltin $(1.40 \mathrm{~g}, 4.23 \mathrm{mmol})$ a solution of $\operatorname{Pd}(\mathrm{dba})_{2}(107 \mathrm{mg}$, $0.186 \mathrm{mmol})$ and $\mathrm{PPh}_{3}(183 \mathrm{mg}, 0.698 \mathrm{mmol})$ in toluene $(50 \mathrm{~mL})$, as described for 230 , gave after work up and chromatography (hexanes/EtOAc, 99:1) 232 (396 mg, $2.43 \mathrm{mmol}, 57 \%$ ) as a pale yellow oil.

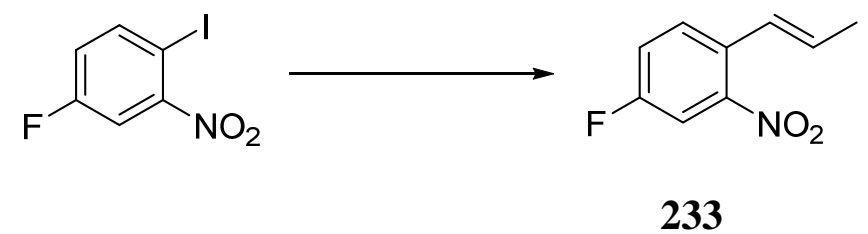

4-Fluoro-2-nitro-1-(1-propen-1-yl)benzene (233). Treatment of 4-fluoro-2-nitro-iodobenzene (967 mg, $3.62 \mathrm{mmol})$ with tributyl 1-propen-1-yltin $(1.45 \mathrm{~g}, 4.38 \mathrm{mmol})$ a solution of $\operatorname{Pd}(\mathrm{dba})_{2}(106 \mathrm{mg}, 0.185 \mathrm{mmol})$ and $\mathrm{PPh}_{3}(194 \mathrm{mg}, 0.740 \mathrm{mmol})$ in toluene $(50 \mathrm{~mL})$, as described for 230, gave after work up and chromatography (hexanes/EtOAc, 98:2) 233 (579 $\mathrm{mg}, 3.20 \mathrm{mmol}, 73 \%$ ) as a pale yellow oil. Spectral data from a 1.9:1 mixture of E/Z-233. E-233: ${ }^{1} \mathrm{H}$ NMR $(600 \mathrm{MHz}) \delta 7.61(\mathrm{dd}, J=8.4,2.4 \mathrm{~Hz}, 1 \mathrm{H}), 7.57(\mathrm{dd}, J=8.4,5.4 \mathrm{~Hz}, 1 \mathrm{H})$, 7.26 (dt, $J=8.4,2.4 \mathrm{~Hz}, 1 \mathrm{H}), 6.81$ (d, $J=15.6 \mathrm{~Hz}, 1 \mathrm{H}), 6.19$ (dq, $J=15.6,7.2 \mathrm{~Hz}, 1 \mathrm{H}), 1.93$ (dd, $J=7.2,1.8 \mathrm{~Hz}, 3 \mathrm{H}) ;{ }^{13} \mathrm{C}$ NMR $\delta(150 \mathrm{MHz}) 160.7\left(\mathrm{~d}, J_{C F}=248.7 \mathrm{~Hz}\right), 147.4,131.6,130.0(\mathrm{~d}$, $\left.J_{C F}=8.1 \mathrm{~Hz}\right), 129.7\left(\mathrm{~d}, J_{C F}=3.8 \mathrm{~Hz}\right), 125.2,120.4\left(\mathrm{~d}, J_{C F}=21.3 \mathrm{~Hz}\right), 111.6\left(\mathrm{~d}, J_{C F}=26.1 \mathrm{~Hz}\right)$, 
18.7. Z-233: ${ }^{1} \mathrm{H}$ NMR $\delta(600 \mathrm{MHz}) 7.74(\mathrm{dd}, J=8.4,2.4 \mathrm{~Hz}, 1 \mathrm{H}), 7.37(\mathrm{dd}, J=8.4,5.4 \mathrm{~Hz}, 1 \mathrm{H})$, $7.31(\mathrm{dt}, J=8.4,2.4 \mathrm{~Hz}, 1 \mathrm{H}), 6.66$ (d, $J=11.4 \mathrm{~Hz}, 1 \mathrm{H}), 5.94$ (dq, $J=11.4,7.2 \mathrm{~Hz}, 1 \mathrm{H}), 1.71$ (dd, $J=7.2,1.8 \mathrm{~Hz}, 3 \mathrm{H}) ;{ }^{13} \mathrm{C} \mathrm{NMR}(150 \mathrm{MHz}) \delta 160.7\left(\mathrm{~d}, J_{C F}=249.3 \mathrm{~Hz}\right), 148.7,133.4\left(\mathrm{~d}, J_{C F}=7.5\right.$ $\mathrm{Hz}), 129.2,128.7\left(\mathrm{~d}, J_{C F}=4.4 \mathrm{~Hz}\right), 125.1,120.0\left(\mathrm{~d}, J_{C F}=20.7 \mathrm{~Hz}\right), 112.0\left(\mathrm{~d}, J_{C F}=26.1 \mathrm{~Hz}\right)$, 14.2. IR (ATR) 2918, 1527, 1490, 1343, 1240, 1131, 944, 874, 816, 789, 753, $676 \mathrm{~cm}^{-1}$; HRMS (ESI) calcd for $\mathrm{C}_{9} \mathrm{H}_{9} \mathrm{FNO}_{2}\left(\mathrm{M}+\mathrm{H}^{+}\right)$182.0617; found 182.0612 .

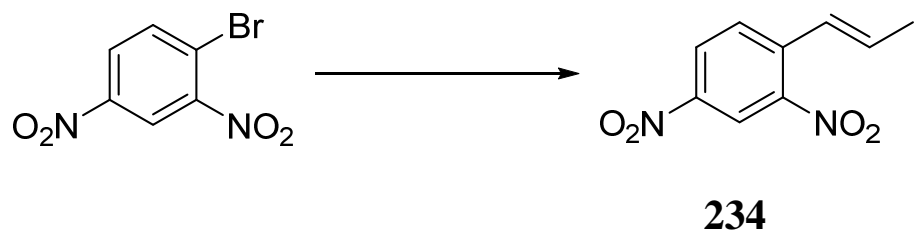

2,4-Dinitro-1-(1-propen-1-yl)benzene (234). Treatment of 1-bromo-2,4-dinitronitrobenzene (865 mg, $3.50 \mathrm{mmol})$ with tributyl 1-propen-1-yltin $(1.40 \mathrm{~g}, 4.24 \mathrm{mmol})$ a solution of $\mathrm{Pd}(\mathrm{dba})_{2}(101 \mathrm{mg}, 0.175 \mathrm{mmol})$ and $\mathrm{PPh}_{3}(186 \mathrm{mg}, 0.711 \mathrm{mmol})$ in toluene $(50 \mathrm{~mL})$, as described for 230, gave after work up and chromatography (hexanes/EtOAc, 9:1) 234 (453 $\mathrm{mg}, 2.18 \mathrm{mmol}, 51 \%$ ) as a pale orange-brown oil. Spectral data from a 1:1.8 mixture of E/Z-234. E-234: ${ }^{1} \mathrm{H}$ NMR (600 MHz) $\delta 8.74$ (d, $\left.J=2.4 \mathrm{~Hz}, 1 \mathrm{H}\right), 8.36$ (dd, $\left.J=9.0,2.4 \mathrm{~Hz}, 1 \mathrm{H}\right)$, $7.79(\mathrm{~d}, J=9.0 \mathrm{~Hz}, 1 \mathrm{H}), 6.91(\mathrm{dd}, J=15.6,1.8 \mathrm{~Hz}, 1 \mathrm{H}), 6.51(\mathrm{dq}, J=15.6,6.6 \mathrm{~Hz}, 1 \mathrm{H}), 2.02(\mathrm{dd}$, $J=6.6,1.8 \mathrm{~Hz}, 3 \mathrm{H}) . Z-234:{ }^{1} \mathrm{H}$ NMR $(600 \mathrm{MHz}) \delta 8.86(\mathrm{~d}, J=2.4 \mathrm{~Hz}, 1 \mathrm{H}), 8.42(\mathrm{dd}, J=8.4,2.4$ $\mathrm{Hz}, 1 \mathrm{H}), 7.62(\mathrm{~d}, J=8.4 \mathrm{~Hz}, 1 \mathrm{H}), 6.76(\mathrm{dd}, J=12.0,1.8 \mathrm{~Hz}, 1 \mathrm{H}), 6.13(\mathrm{dq}, J=12.0,7.2 \mathrm{~Hz}, 1 \mathrm{H})$, 1.79 (dd, $J=7.2,1.8 \mathrm{~Hz}, 6 \mathrm{H})$. IR (ATR) 2918, 1596, 1522, 1446, 1340, 959, 915, 834, 767, 736, 716, $698 \mathrm{~cm}^{-1}$; HRMS (ESI) calcd for $\mathrm{C}_{9} \mathrm{H}_{9} \mathrm{~N}_{2} \mathrm{O}_{4}\left(\mathrm{M}+\mathrm{H}^{+}\right)$209.0562; found 209.0557. 


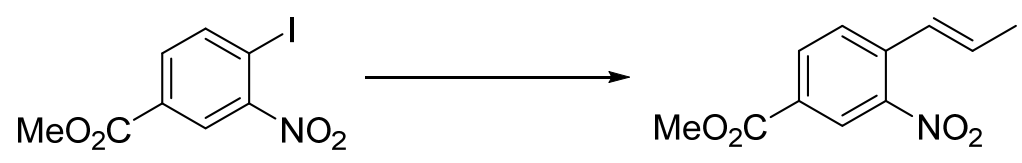

235

4-Carbomethoxy-2-nitro-1-(1-propen-1-yl)benzene (235). 1-Bromo-4-carbomethoxy-2-

nitrobenzene $(865 \mathrm{mg}, 3.50 \mathrm{mmol})$ was treated with $\mathrm{Pd}(\mathrm{dba})_{2}(84 \mathrm{mg}, 0.15 \mathrm{mmol}), \mathrm{PPh}_{3}(154$ $\mathrm{mg}, 0.587 \mathrm{mmol})$, and tributyl 1-propen-1-yltin $(1.17 \mathrm{~g}, 3.52 \mathrm{mmol})$ in toluene $(50 \mathrm{~mL})$ as described for 230. Work up and purification by chromatography (hexanes/EtOAc, 95:5) gave 235 (364 mg, $1.64 \mathrm{mmol}, 56 \%$ ) as a pale yellow oil. Spectral data from a 1:1.2 mixture of E/Z-235. E-235: ${ }^{1} \mathrm{H}$ NMR (270 MHz) $\delta 8.50$ (d, $\left.J=1.6 \mathrm{~Hz}, 1 \mathrm{H}\right), 8.15$ (dd, $\left.J=7.9,1.6 \mathrm{~Hz}, 1 \mathrm{H}\right)$, $7.66(\mathrm{~d}, J=8.3 \mathrm{~Hz}, 1 \mathrm{H}), 6.87$ (dd, $J=15.4,1.8 \mathrm{~Hz}, 1 \mathrm{H}), 6.41$ (dq, $J=15.4,6.7 \mathrm{~Hz}, 1 \mathrm{H}), 3.95$ (s, 3H), $1.98(\mathrm{dd}, J=6.7,1.8 \mathrm{~Hz}, 3 \mathrm{H}) . Z-235:{ }^{1} \mathrm{H}$ NMR $(270 \mathrm{MHz}) \delta 8.63(\mathrm{~d}, J=1.6 \mathrm{~Hz}, 1 \mathrm{H})$, 8.21(dd, $J=8.1,1.6 \mathrm{~Hz}, 1 \mathrm{H}), 7.48(\mathrm{~d}, J=8.1 \mathrm{~Hz}, 1 \mathrm{H}), 6.73$ (dd, $J=11.5,1.8 \mathrm{~Hz}, 1 \mathrm{H}), 6.03$ (dq, $J=11.5,7.1 \mathrm{~Hz}, 1 \mathrm{H}), 3.97(\mathrm{~s}, 3 \mathrm{H}), 1.76(\mathrm{dd}, J=7.1,1.8 \mathrm{~Hz}, 3 \mathrm{H})$. HRMS (ESI) calcd for $\mathrm{C}_{11} \mathrm{H}_{12} \mathrm{NO}_{4}\left(\mathrm{M}+\mathrm{H}^{+}\right)$222.0766; found 222.0761.<smiles>COc1ccc(I)c([N+](=O)[O-])c1</smiles><smiles>C</smiles><smiles>C/C=C/c1ccc(OC)cc1[N+](=O)[O-]</smiles>

236

4-Methoxy-2-nitro-1-(1-propen-1-yl)benzene (236). 4-Methoxy-2-nitro-1-iodobenzene (884 $\mathrm{mg}, 3.17 \mathrm{mmol})$ was treated with $\mathrm{Pd}(\mathrm{dba})_{2}(91 \mathrm{mg}, 0.16 \mathrm{mmol}), \mathrm{PPh}_{3}(166 \mathrm{mg}, 0.634 \mathrm{mmol})$, and tributyl 1-propen-1-yltin $(1.27 \mathrm{~g}, 3.80 \mathrm{mmol})$ in toluene $(50 \mathrm{~mL})$ as described for 230 . Work up and purification by chromatography (hexanes/EtOAc, 95:5) gave 236 (195 mg, $1.01 \mathrm{mmol}, 32 \%)$ as a pale yellow oil. Spectral data from a 1.7:1 mixture of E/Z-236. E-236: 
${ }^{1} \mathrm{H}$ NMR (270 MHz) $\delta 7.48(\mathrm{~d}, J=8.7 \mathrm{~Hz}, 1 \mathrm{H}), 7.38(\mathrm{~d}, J=2.6 \mathrm{~Hz}, 1 \mathrm{H}), 7.08$ (dd, J=8.1, 2.8 Hz, 1H), 6.78 (dd, J=15.7, 1.8 Hz, 1H), 6.13 (dq, J=15.4, $6.5 \mathrm{~Hz}, 1 \mathrm{H}), 3.85$ (s, 3H), 1.91 (dd, $J=6.5,1.8 \mathrm{~Hz}, 3 \mathrm{H}) ;{ }^{13} \mathrm{C}$ NMR $(67.5 \mathrm{MHz}) \delta 158.5,147.9,129,7,129.3,126.0,125.7,120.0$, 108.4, 55.8, 18.7. Z-236: ${ }^{1} \mathrm{H}$ NMR (270 MHz) $\delta 7.52(\mathrm{~d}, J=2.6 \mathrm{~Hz}, 1 \mathrm{H}), 7.28$ (d, J=8.7 Hz, 1H), 7.12 (overlapping E-isomer, $1 \mathrm{H}), 6.64$ (dd, $J=11.3,1.8 \mathrm{~Hz}, 1 \mathrm{H}), 5.88$ (dq, $J=11.5,7.1 \mathrm{~Hz}$, 1H), $3.88(\mathrm{~s}, 3 \mathrm{H}), 1.71(\mathrm{dd}, J=7.1,1.8 \mathrm{~Hz}, 3 \mathrm{H}) ;{ }^{13} \mathrm{C} \mathrm{NMR}(67.5 \mathrm{MHz}) \delta 158.6,148.8,132.7$, 128.1, 125.7, 125.0, 119.4, 108.9, 55.8, 14.3. IR (ATR) 2915, 2841, 1619, 1522, 1346, 1286, 1253, 1033, 961, 839, 814, 784, $679 \mathrm{~cm}^{-1}$; HRMS (ESI) calcd for $\mathrm{C}_{10} \mathrm{H}_{12} \mathrm{NO}_{3}\left(\mathrm{M}+\mathrm{H}^{+}\right)$ 194.0817; found 194.0812.

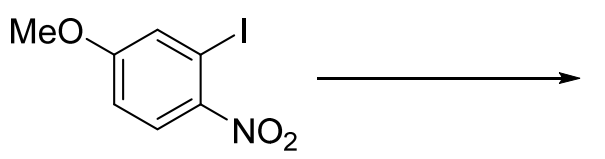<smiles>C/C=C/c1cc(OC)ccc1[N+](=O)[O-]</smiles>

237

5-Methoxy-2-nitro-1-(1-propen-1-yl)-benzene (237). 5-Methoxy-2-nitro-1-iodobenzene (283 $\mathrm{mg}, 1.01 \mathrm{mmol})$ was treated with $\mathrm{Pd}(\mathrm{dba})_{2}(29.8 \mathrm{mg}, 0.052 \mathrm{mmol}), \mathrm{PPh}_{3}(57.6 \mathrm{mg}, 0.22$ $\mathrm{mmol})$, and tributyl 1-propen-1-yltin $(411 \mathrm{mg}, 1.24 \mathrm{mmol})$ in toluene $(50 \mathrm{~mL})$ as described for 230. Work up and purification by chromatography (hexanes/EtOAc, 8:2) affording 237 (89.7 $\mathrm{mg}, 0.464 \mathrm{mmol}, 37 \%)$ as a pale yellow oil. Spectral data from a 1.8:1 mixture of E/Z-237. E-237: ${ }^{1} \mathrm{H}$ NMR (600 MHz) $\delta 7.99(\mathrm{~d}, J=9.6 \mathrm{~Hz}, 1 \mathrm{H}), 6.99(\mathrm{dd}, J=15.6,1.2 \mathrm{~Hz}, 1 \mathrm{H})$, $6.96(\mathrm{~d}, J=2.4 \mathrm{~Hz}, 1 \mathrm{H}), 6.19$ (dq, $J=15.6,6.6 \mathrm{~Hz}, 1 \mathrm{H}), 3.89$ (s, 3H), 1.94 (dd, $J=6.6,1.2 \mathrm{~Hz}$, 3H). Z-237: ${ }^{1} \mathrm{H}$ NMR (600 MHz) $\delta 8.11(\mathrm{~d}, J=9.6 \mathrm{~Hz}, 1 \mathrm{H}), 6.86(\mathrm{dd}, J=9.0,2.4 \mathrm{~Hz}, 1 \mathrm{H}), 6.77$ (dd, $J=12,1.8 \mathrm{~Hz}, 1 \mathrm{H}), 5.91(\mathrm{dq}, J=12,7.2 \mathrm{~Hz}, 1 \mathrm{H}), 3.89$ (s, 3H), 1.74 (dd, $J=7.2,1.8 \mathrm{~Hz}$, $3 \mathrm{H}) .6 .82-6.80(\mathrm{~m}, 2 \mathrm{H})$ could not be assigned to the specific proton for the two isomers. IR 
(ATR) 2917, 2845, 1620, 1524, 1351, 1285, 1255, 1034, 962, 837, 813, 783, $678 \mathrm{~cm}^{-1}$; HRMS (ESI) calcd for $\mathrm{C}_{10} \mathrm{H}_{11} \mathrm{NNaO}_{3}\left(\mathrm{M}+\mathrm{H}^{+}\right)$216.0631; found 216.0630.

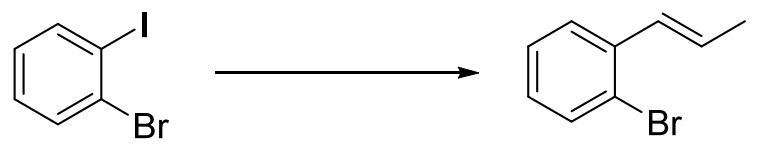

243

2-Bromo-1-(1-propen-1-yl)-benzene (243). ${ }^{171}$ 2-Bromo-1-iodobenzene (1.02g, $\left.3.10 \mathrm{mmol}\right)$ was treated with $\mathrm{Pd}(\mathrm{dba})_{2}(72.2 \mathrm{mg}, 0.126 \mathrm{mmol}), \mathrm{PPh}_{3}(132 \mathrm{mg}, 0.504 \mathrm{mmol})$, and tributyl 1-propen-1-yltin $(728 \mathrm{mg}, 2.57 \mathrm{mmol})$ in toluene $(50 \mathrm{~mL})$ as described for 230. Work up and purification by chromatography (hexanes/EtOAc, 8:2) gave 243 (203 mg, $1.03 \mathrm{mmol}, 40 \%$ ) as a pale yellow oil.<smiles>[R16]c1ccccc1C(=O)C(C)=O</smiles>

Typical oxidation procedure using Condition A: 1-(2-Nitrophenyl)-2-propanone (245), ${ }^{172}$ 1-(1,1-dimethoxymethyl)-2-nitrobenzene $\quad(246),{ }^{173} \quad$ 2-nitrobenzaldehyde $\quad(247),{ }^{174}$ and 1-(2-nitrophenyl)-1,2-propandione (248). ${ }^{175}$ To a suspension of $\mathrm{PdCl}_{2}(15.5 \mathrm{mg}, 0.087 \mathrm{mmol})$ and $\mathrm{CuCl}(69 \mathrm{mg}, 0.70 \mathrm{mmol})$ in a solution of $\mathrm{MeOH}(1 \mathrm{~mL})$ and $\mathrm{H}_{2} \mathrm{O}(200 \mu \mathrm{L})$ was added $230(100 \mathrm{mg}, 0.614 \mathrm{mmol})$ dissolved in $\mathrm{MeOH}(1 \mathrm{~mL})$. The reaction flask was attached to a balloon filled with oxygen and the mixture was stirred at $50{ }^{\circ} \mathrm{C}$ for $20 \mathrm{~h}$. The resulting mixture was diluted with $\mathrm{H}_{2} \mathrm{O}(50 \mathrm{~mL})$ and extracted with EtOAc $(4 \times 50 \mathrm{~mL})$. The combined organic phases were dried $\left(\mathrm{MgSO}_{4}\right)$, filtered, and the solvents were removed under reduced 
pressure. The crude product was purified by chromatography (hexanes/EtOAc, 8:2) to give in order of elution 246 (4.9 mg, $0.025 \mathrm{mmol}, 4 \%)$, an inseparable mixture of 247 and 248 (1:1 ratio, $13.9 \mathrm{mg} ; 6.10 \mathrm{mg}, 0.0404 \mathrm{mmol}, 6.4 \%$ 247; $7.80 \mathrm{mg}, 0.0404 \mathrm{~mol}, 6.4 \%$ 248) and 245 (79.9 mg, $0.45 \mathrm{mmol}, 73 \%$ ) all as a pale yellow oils.

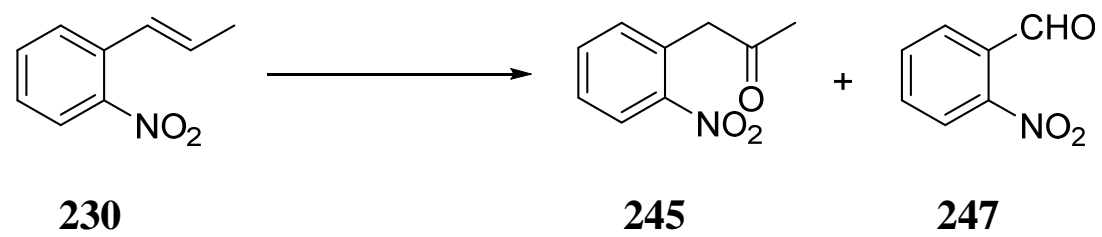

Typical oxidation procedure using Condition B: 1-(2-Nitrophenyl)-2-propanone (245) and 2-nitrobenzaldehyde (247). To a suspension of $\mathrm{PdCl}_{2}(10.2 \mathrm{mg}, 0.058)$ in $\mathrm{H}_{2} \mathrm{O}_{2}$ (50\%-aqueous, $300 \mu \mathrm{L}, 6.40 \mathrm{mmol})$ was added 230 (99.2 $\mathrm{mg}, 0.608 \mathrm{mmol})$. After $48 \mathrm{~h}$ at 50 ${ }^{\circ} \mathrm{C}$, the resulting mixture worked up and purified as described using Conditions A to give after chromatography (hexanes/EtOAc, 8:2) in order of elution 247 (7.4 mg, 0.049mmol, 8\%) and 245 (20.1 mg, $0.11 \mathrm{mmol}, 18 \%)$ both as pale yellow oils.<smiles>C/C=C/c1ccccc1[N+](=O)[O-]</smiles>

230<smiles>CC(=O)Cc1ccccc1[N+](=O)[O-]</smiles>

245<smiles>COC(OC)c1ccccc1[N+](=O)[O-]</smiles>

246<smiles>O=Cc1ccccc1[N+](=O)[O-]</smiles>

247

Typical oxidation procedure using Condition C: 1-(2-Nitrophenyl)-2-propanone (245), 1-(1,1-dimethoxymethyl)-2-nitrobenzene (246), and 2-nitrobenzaldehyde (247). To a suspension of $\mathrm{PdCl}_{2}(14.2 \mathrm{mg}, 0.080 \mathrm{mmol})$ and 2,6-di-tert-butyl-p-cresol (15.0 mg, 0.068 mmol) in a solution of $\mathrm{MeOH}(1 \mathrm{~mL}), \mathrm{H}_{2} \mathrm{O}(200 \mu \mathrm{L})$ and $\mathrm{H}_{2} \mathrm{O}_{2}(50 \%$-aqueous, $300 \mu \mathrm{L}, 6.40$ mmol) was added to 230 (106 mg, $0.648 \mathrm{mmol})$ dissolved in $\mathrm{MeOH}(1 \mathrm{~mL})$. The reaction 
mixture was stirred at $50{ }^{\circ} \mathrm{C}$ for $48 \mathrm{~h}$. The resulting mixture worked up and purified as described using Conditions A to give in order of elution after chromatography (hexanes/EtOAc, 8:2) 246 (2.3 mg, $0.012 \mathrm{mmol}, 2 \%$ ), 247 (20.8 mg, $0.138 \mathrm{mmol}, 21 \%$ ), and $245(83.4 \mathrm{mg}, 0.466 \mathrm{mmol}, 72 \%)$ all as pale yellow oils.

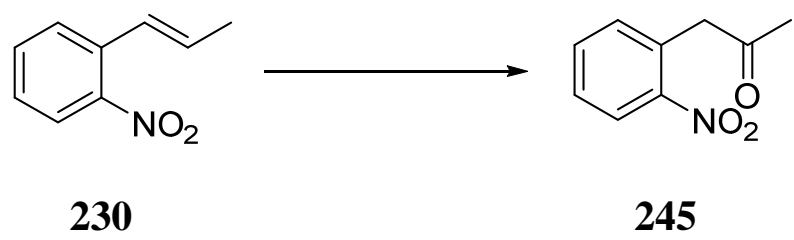

Typical oxidation procedure using Condition D: 1-(2-Nitrophenyl)-2-propanone (245). To a suspension of $\mathrm{PdCl}_{2}(5.8 \mathrm{mg}, 0.033 \mathrm{mmol})$ and 2,6-di-tert-butyl-p-cresol (6.3 $\mathrm{mg}, 0.029$ mmol) in a solution of $\mathrm{MeOH}(500 \mu \mathrm{L}), \mathrm{H}_{2} \mathrm{O}(100 \mu \mathrm{L})$ and $t$-butyl hydrogenperoxide (TBHP, 90\%-aqueous, $267 \mu \mathrm{L}, 2.49 \mathrm{mmol})$ was added $230(31.0 \mathrm{mg}, 0.190 \mathrm{mmol})$ dissolved in $\mathrm{MeOH}(500 \mu \mathrm{L})$. The reaction mixture was stirred at $50{ }^{\circ} \mathrm{C}$ for $48 \mathrm{~h}$. The mixture was diluted with $\mathrm{H}_{2} \mathrm{O}(50 \mathrm{~mL})$ and extracted with EtOAc $(4 \times 50 \mathrm{~mL})$. The combined organic phases were dried $\left(\mathrm{MgSO}_{4}\right)$, filtered, and the solvents were removed under reduced pressure. The crude product was purified by chromatography (hexanes/EtOAc, 8:2) to give $245(31.3 \mathrm{mg}$, $0.175 \mathrm{mmol}, 92 \%$ ) as a pale yellow oil. 


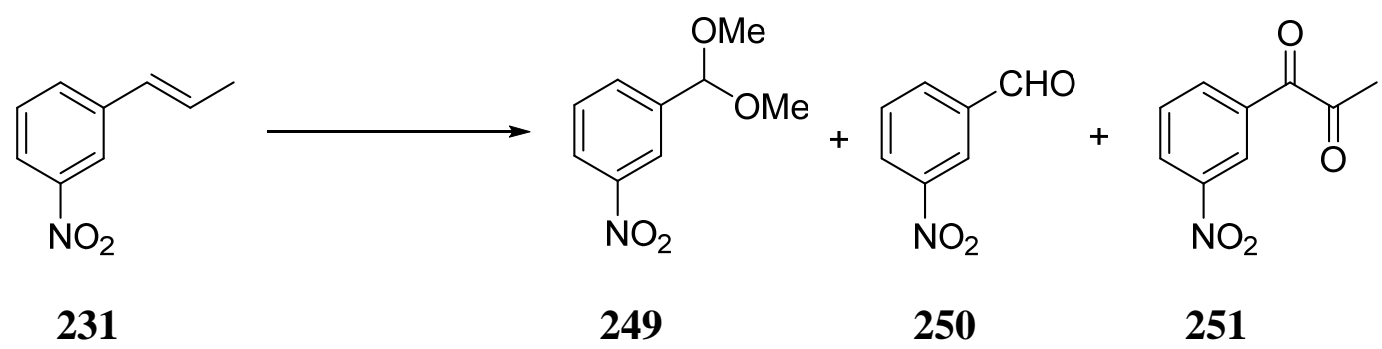

1-(1,1-Dimethoxymethyl)-3-nitrobenzene (249), ${ }^{176}$ 3-nitrobenzaldehyde (250), ${ }^{177}$ and 1-(3-nitrophenyl)-1,2-propandione (251). ${ }^{178}$ A solution of 231 (116 mg, $0.709 \mathrm{mmol}$ ) in $\mathrm{MeOH}(1 \mathrm{~mL})$ was added to a suspension of $\mathrm{PdCl}_{2}(12.5 \mathrm{mg}, 0.0705 \mathrm{mmol})$ and $\mathrm{CuCl}(69.0$ $\mathrm{mg}, 0.70 \mathrm{mmol})$ in a solution of $\mathrm{MeOH}(1 \mathrm{~mL})$ and $\mathrm{H}_{2} \mathrm{O}(200 \mu \mathrm{L})$ under an atmosphere of oxygen, as described for 230 in Condition $\mathrm{A}\left(50{ }^{\circ} \mathrm{C}, 20 \mathrm{~h}\right)$. Extraction and purification by chromatography (hexanes/EtOAc, 8:2) gave in order of elution 249 (41.4 mg, $0.210 \mathrm{mmol}$, $30 \%)$ as a colorless oil and an inseparable mixture of 250 and 251 (1:1 ratio, $17.2 \mathrm{mg} ; 7.55$ $\mathrm{mg}, 0.050 \mathrm{mmol}, 7 \% 250 ; 9.66 \mathrm{mg}, 0.050 \mathrm{mmol}, 7 \% \mathrm{251}$ ) as a yellow solid. Analytical data for 251: ${ }^{1} \mathrm{H}$ NMR $(600 \mathrm{MHz}) \delta 8.89(\mathrm{t}, J=2.4 \mathrm{~Hz}, 1 \mathrm{H}), 8.48(\mathrm{dt}, J=7.2,2.4 \mathrm{~Hz}, 1 \mathrm{H}), 8.40(\mathrm{td}$, $J=8.4,1.8 \mathrm{~Hz}, 1 \mathrm{H}), 7.71(\mathrm{t}, J=8.4 \mathrm{~Hz}, 1 \mathrm{H}), 2.58(\mathrm{~s}, 3 \mathrm{H}) ;{ }^{13} \mathrm{C}$ NMR (150 MHz) 198.5, 187.7, 148.4, 135.7, 133.3, 130.0, 128.4, 125.3, 26.0; IR (ATR) 1704, 1615, 1533, 1352, 1170, 1093, $818,711,677 \mathrm{~cm}^{-1}$.

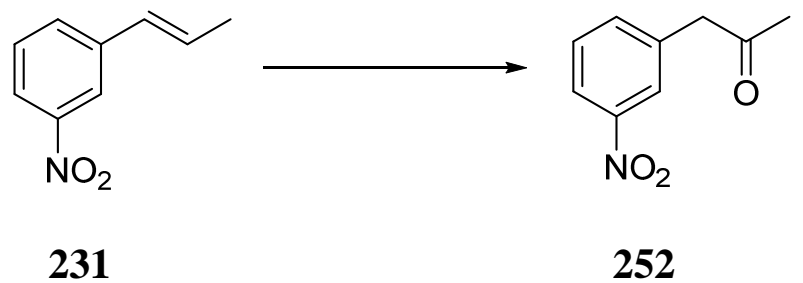

1-(3-Nitrophenyl)-2-propanone (252). ${ }^{179}$ To a suspension of $\mathrm{PdCl}_{2}(5.6 \mathrm{mg}, 0.032 \mathrm{mmol})$ and 2,6-di-tert-butyl-p-cresol $(6.1 \mathrm{mg}, 0.028 \mathrm{mmol})$ in a solution of $\mathrm{MeOH}(500 \mu \mathrm{L}), \mathrm{H}_{2} \mathrm{O}(100$ $\mu \mathrm{L}$ ) and TBHP (90\%-aqueous, $267 \mu \mathrm{L}, 2.49 \mathrm{mmol})$ was added 231 (40.6 mg, 0.249mmol) 
dissolved in $\mathrm{MeOH}(500 \mu \mathrm{L})$. The reaction mixture was stirred at $50{ }^{\circ} \mathrm{C}$ for $48 \mathrm{~h}$. The mixture was diluted with $\mathrm{H}_{2} \mathrm{O}(50 \mathrm{~mL})$ and extracted with EtOAc $(4 \times 50 \mathrm{~mL})$. The combined organic phases were dried $\left(\mathrm{MgSO}_{4}\right)$, filtered, and the solvents were removed under reduced pressure. The crude product was purified by chromatography (hexanes/EtOAc, 8:2) to give 252 (15.3 $\mathrm{mg}, 0.140 \mathrm{mmol}, 34 \%$ ) as a pale yellow oil.<smiles>C/C=C/c1ccc([N+](=O)[O-])cc1</smiles>

1-(1,1-Dimethoxymethyl)-4-nitrobenzene (253), ${ }^{180}$ 4-nitrobenzaldehyde (254), ${ }^{177}$ and 1-(4-nitrophenyl)-1,2-propandione (255). ${ }^{181}$ A solution of $232^{182}(57.0 \mathrm{mg}, 0.349 \mathrm{mmol})$ in $\mathrm{MeOH}(500 \mu \mathrm{L})$ was added to a suspension of $\mathrm{PdCl}_{2}(6.3 \mathrm{mg}, 0.036 \mathrm{mmol})$ and $\mathrm{CuCl}(35.2$ $\mathrm{mg}, 0.36 \mathrm{mmol})$ in a solution of $\mathrm{MeOH}(500 \mu \mathrm{L})$ and $\mathrm{H}_{2} \mathrm{O}(100 \mu \mathrm{L})$ under an atmosphere $\mathrm{O}_{2}$, as described for 230 in Condition $\mathrm{A}\left(50{ }^{\circ} \mathrm{C}, 20 \mathrm{~h}\right)$. Extraction and purification by chromatography (hexanes/EtOAc, 95:5) gave in order of elution, 253 (21.8 mg, $0.11 \mathrm{mmol}$, $32 \%)$ as a colorless oil and an inseparable mixture of 254 and 255 (1:1 ratio, $11.7 \mathrm{mg} ; 5.1 \mathrm{mg}$, $0.034 \mathrm{mmol}, 10 \% 254 ; 6.6 \mathrm{mg}, 0.034 \mathrm{mmol}, 10 \% 255)$ as a yellow solid. 
<smiles>C/C=C/c1ccc([N+](=O)[O-])cc1</smiles>

1-(1,1-Dimethoxymethyl)-4-nitrobenzene (253), 4-nitrobenzaldehyde (254), and 1-(4-nitrophenyl)-1,2-propandione (255). To a suspension of $\mathrm{PdCl}_{2}$ (7.5 $\mathrm{mg}, 0.042 \mathrm{mmol}$ ) and 2,6-di-tert-butyl-p-cresol $(7.9 \mathrm{mg}, 0.036 \mathrm{mmol})$ in a solution of $\mathrm{MeOH}(500 \mu \mathrm{L}), \mathrm{H}_{2} \mathrm{O}$ (100 $\mu \mathrm{L})$ and $\mathrm{H}_{2} \mathrm{O}_{2}(50 \%$-aqueous, $150 \mu \mathrm{L}, 3.20 \mathrm{mmol})$ was added $232(56.6 \mathrm{mg}, 0.347 \mathrm{mmol})$ dissolved in $\mathrm{MeOH}(500 \mu \mathrm{L})$. The reaction mixture was stirred at $50{ }^{\circ} \mathrm{C}$ for $48 \mathrm{~h}$. The mixture was diluted with $\mathrm{H}_{2} \mathrm{O}(50 \mathrm{~mL})$ and extracted with EtOAc $(4 \times 50 \mathrm{~mL})$. The combined organic phases were dried $\left(\mathrm{MgSO}_{4}\right)$, filtered, and the solvents were removed under reduced pressure. The crude product was purified by chromatography (hexanes/EtOAc, 8:2) to give in order of elution $253(23.0 \mathrm{mg}, 0.117 \mathrm{mmol}, 34 \%)$ as a colorless oil and an inseparable mixture of 254 and 255 (1:1 ratio, $8.7 \mathrm{mg} ; 3.8 \mathrm{mg}, 0.025 \mathrm{mmol}, 7 \% 254 ; 4.9 \mathrm{mg}, 0.025 \mathrm{mmol}, 7 \% 255$ ) as a yellow solid.

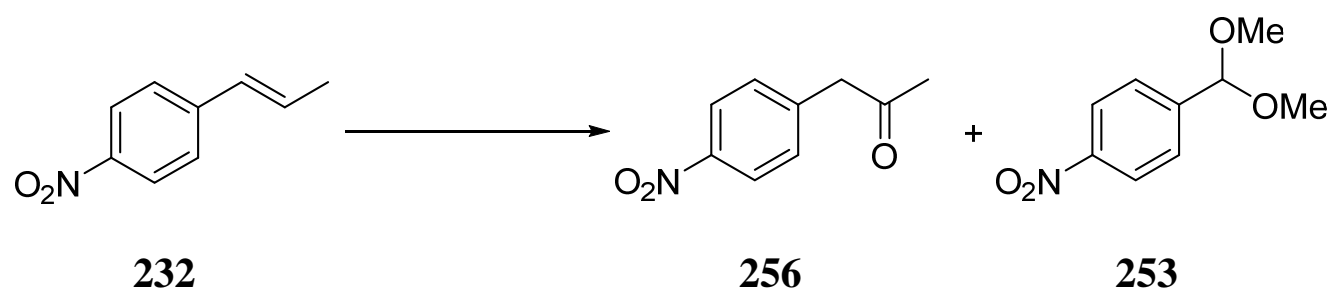

1-(1,1-Dimethoxymethyl)-4-nitrobenzene (253) and 1-(4-nitrophenyl)-2-propanone (256). ${ }^{183}$ To a suspension of $\mathrm{PdCl}_{2}(6.6 \mathrm{mg}, 0.037 \mathrm{mmol})$ and 2,6-di-tert-butyl-p-cresol (6.1 $\mathrm{mg}, 0.028 \mathrm{mmol})$ in a solution of $\mathrm{MeOH}(500 \mu \mathrm{L}), \mathrm{H}_{2} \mathrm{O}(100 \mu \mathrm{L})$ and $\mathrm{TBHP}(90 \%$-aqueous, $267 \mathrm{~mL}, 2.49 \mathrm{mmol})$ was added 232 (40.6 mg, 0.249mmol) dissolved in $\mathrm{MeOH}(500 \mu \mathrm{L})$. 
The reaction mixture was stirred at $50{ }^{\circ} \mathrm{C}$ for $72 \mathrm{~h}$. The mixture was diluted with $\mathrm{H}_{2} \mathrm{O}(50 \mathrm{~mL})$ and extracted with EtOAc $(4 \times 50 \mathrm{~mL})$. The combined organic phases were dried $\left(\mathrm{MgSO}_{4}\right)$, filtered, and the solvents were removed under reduced pressure. The crude product was purified by chromatography (hexanes/EtOAc, 95:5) to give in order of elution 253 (0.9 mg, $0.0046 \mathrm{mmol}, 2 \%)$ as a colorless oiland $256(24.7 \mathrm{mg}, 0.138 \mathrm{mmol}, 55 \%)$ as a pale yellow oil.

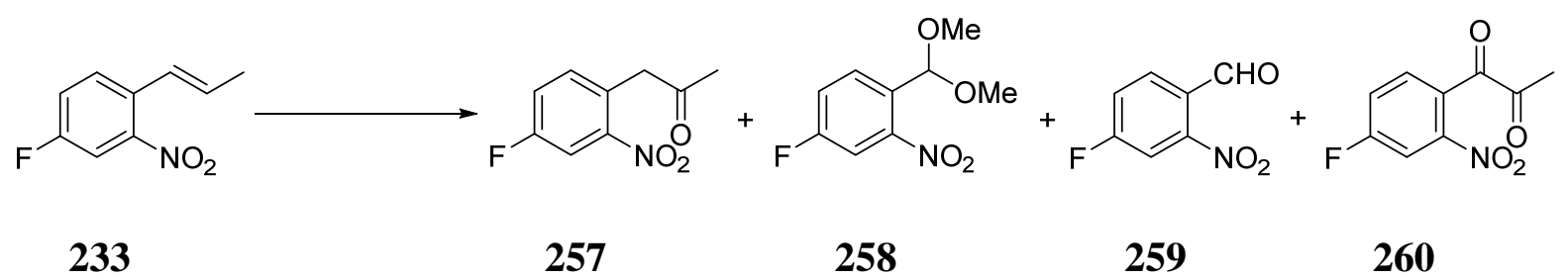

1-(4-Fluoro-2-nitrophenyl)-2-propanone (257), 4-fluoro-1-(1,1-dimethoxymethyl)2-nitrobenzene (258), 4-fluoro-2-nitrobenzaldehyde(259), and 1-(4-fluoro-2-

nitrophenyl)-1,2-propanedione (260). A solution of 233 (65.2 $\mathrm{mg}, 0.36 \mathrm{mmol})$ in $\mathrm{MeOH}$ $(500 \mu \mathrm{L})$ was added to a suspension of $\mathrm{PdCl}_{2}(6.5 \mathrm{mg}, 0.037 \mathrm{mmol})$ and $\mathrm{CuCl}(34.8 \mathrm{mg}$, $0.352 \mathrm{mmol})$ in a solution of $\mathrm{MeOH}(500 \mu \mathrm{L})$ and $\mathrm{H}_{2} \mathrm{O}(100 \mu \mathrm{L})$ under an atmosphere of oxygen, as described for 230 in Condition A $\left(50{ }^{\circ} \mathrm{C}, 20 \mathrm{~h}\right)$. Extraction and purification by chromatography (hexanes/EtOAc, 9:1) gave in order of elution, 258 (2.2 mg, 0.010mmol, 3\%) as a colorless oil, an inseparable mixture of 259 and 260 (1:1 ratio, $6.8 \mathrm{mg} ; 3.0 \mathrm{mg}, 0.018$ mmol, 5\% 259; $3.8 \mathrm{mg}, 0.018 \mathrm{mmol}, 5 \% 260)$ as a pale yellow oil, and 257 (39.2 $\mathrm{mg}, 0.199$ mmol, 55\%) as a pale yellow oil. Spectral data for 257: ${ }^{1} \mathrm{H}$ NMR $(600 \mathrm{MHz}) \delta 7.86(\mathrm{dd}$, $J=8.4,2.4 \mathrm{~Hz}, 1 \mathrm{H}), 7.32(\mathrm{dt}, J=9.0,3.0 \mathrm{~Hz}, 1 \mathrm{H}), 7.57(\mathrm{dd}, J=9,5.4 \mathrm{~Hz}, 1 \mathrm{H}), 4.10(\mathrm{~s}, 2 \mathrm{H})$, $2.33(\mathrm{~s}, 3 \mathrm{H}) ;{ }^{13} \mathrm{C}$ NMR $(150 \mathrm{MHz}) \delta 203.2,162.2,160.5,134.8\left(\mathrm{~d}, J_{C F}=8.0 \mathrm{~Hz}\right), 126.3(\mathrm{~d}$, 
$\left.J_{C F}=4.7 \mathrm{~Hz}\right), 120.8\left(\mathrm{~d}, J_{C F}=20.6 \mathrm{~Hz}\right), 112.9\left(\mathrm{~d}, J_{C F}=26.3 \mathrm{~Hz}\right), 47.9$, 29.9. IR (ATR) 1720, 1532, 1499, 1360, 1237, 1163, 944, 878, $807 \mathrm{~cm}^{-1}$. Spectral data for 258: ${ }^{1} \mathrm{H}$ NMR (600 MHz) $\delta 7.80(\mathrm{dd}, J=9.0,5.4 \mathrm{~Hz}, 1 \mathrm{H}), 7.56(\mathrm{dd}, J=8.4,2.4 \mathrm{~Hz}, 1 \mathrm{H}), 7.31(\mathrm{td}, J=7.8,2.4 \mathrm{~Hz}, 1 \mathrm{H})$, $5.88(\mathrm{~s}, 1 \mathrm{H}), 3.40(\mathrm{~s}, 6 \mathrm{H}) ;{ }^{13} \mathrm{C} \mathrm{NMR}(150 \mathrm{MHz}) \delta 161.9\left(\mathrm{~d}, J_{\mathrm{C}, \mathrm{F}}=251.3 \mathrm{~Hz}\right), 149.4,130.1(\mathrm{~d}$, $\left.J_{\mathrm{C}, \mathrm{F}}=8.1 \mathrm{~Hz}\right), 129.0,119.5\left(\mathrm{~d}, J_{\mathrm{C}, \mathrm{F}}=20.6 \mathrm{~Hz}\right), 112.1\left(\mathrm{~d}, J_{\mathrm{C}, \mathrm{F}}=26.4 \mathrm{~Hz}\right), 99.6,54.6$; IR (ATR) 2961, 1736, 1540, 1364, 1262, 1233, 1105, 1058, 877, $806 \mathrm{~cm}^{-1}$; HRMS (ESI) calcd for $\mathrm{C}_{9} \mathrm{H}_{11} \mathrm{FO}_{4}\left(\mathrm{M}+\mathrm{H}^{+}\right)$216.0672; found 216.0667. Spectral data for diketone 260 from the mixture with 259 (1.26:1 ratio): ${ }^{1} \mathrm{H}$ NMR $(600 \mathrm{MHz}) \delta 7.88$ (dd, J=7.8, $\left.1.8 \mathrm{~Hz}, 1 \mathrm{H}\right), 7.63$ (dd, $J=8.4,5.4 \mathrm{~Hz}, 1 \mathrm{H}), 7.53-7.48(\mathrm{~m}, 1 \mathrm{H}), 2.56(\mathrm{~s}, 3 \mathrm{H})$; Spectral data for mixture of $\mathbf{2 5 9}$ and $\mathbf{2 6 0}$ : ${ }^{13} \mathrm{C}$ NMR $(150 \mathrm{MHz}) \delta 195.9,188.5,186.5,165.6,164.7,163.9,163.0,132.3,132.2,132.2$, $132.2,128.2,128.2,127.5,127.5,122.1,122.0,121.4,121.2,112.6,112.4,112.0,111.8,24.2$; IR (ATR) 3099, 1701, 1610, 1535, 1347, 1219, 1231, 1167, 882, 826, $809 \mathrm{~cm}^{-1}$. 259: HRMS (ESI) calcd for $\mathrm{C}_{7} \mathrm{H}_{4} \mathrm{FNNaO}_{3}\left(\mathrm{M}+\mathrm{H}^{+}\right)$192.0073; found 192.0069. 260: HRMS (ESI) calcd for $\mathrm{C}_{9} \mathrm{H}_{7} \mathrm{FNO}_{4}\left(\mathrm{M}+\mathrm{H}^{+}\right)$212.0359; found 212.0354.

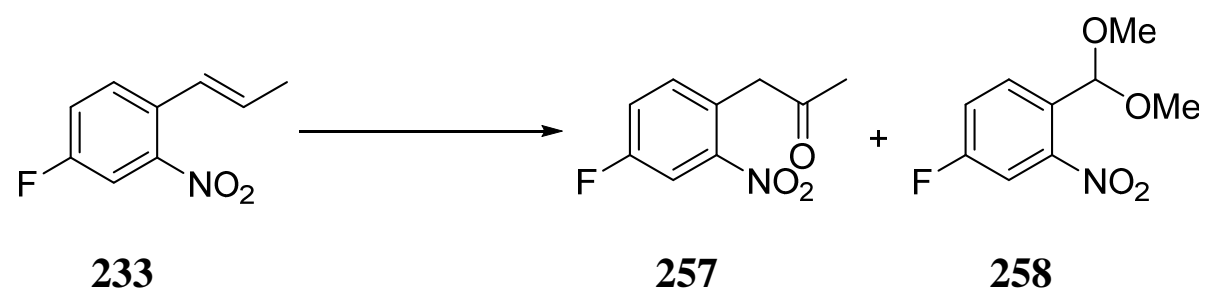

1-(4-Fluoro-2-nitrophenyl)-2-propanone (257) and 4-fluoro-1-(1,1-dimethoxymethyl)-2-

nitrobenzene (258). Compound 233 (47.6 mg, $0.263 \mathrm{mmol})$ dissolved in $\mathrm{MeOH}(500 \mu \mathrm{L})$ was added to a suspension of $\mathrm{PdCl}_{2}(7.8 \mathrm{mg}, 0.044 \mathrm{mmol}), 2,6$-di-tert-butyl-p-cresol $(7.8 \mathrm{mg}$, $0.035 \mathrm{mmol})$, and $\mathrm{H}_{2} \mathrm{O}_{2}(50 \%$-aqueous, $150 \mu \mathrm{L}, 3.20 \mathrm{mmol})$ in $\mathrm{MeOH}(500 \mu \mathrm{L})$ and $\mathrm{H}_{2} \mathrm{O}$ 
$(100 \mu \mathrm{L})$. After $48 \mathrm{~h}$ at $50{ }^{\circ} \mathrm{C}$, the mixture was worked up and purified as described in Condition $\mathrm{C}$ to give after chromatography (hexanes/EtOAc, 9:1), in order of elution, 258 (9.4 $\mathrm{mg}, 0.044 \mathrm{mmol}, 17 \%)$ and $257(18.3 \mathrm{mg}, 0.093 \mathrm{mmol}, 35 \%)$ both as a yellow oils.

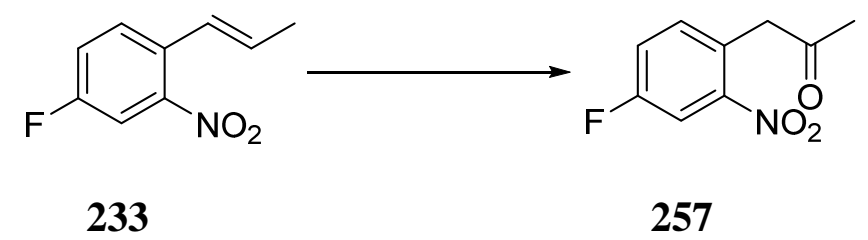

1-(4-Fluoro-2-nitrophenyl)-2-propanone (257). Compound 233 (45.8 mg, $0.253 \mathrm{mmol}$ ) dissolved in $\mathrm{MeOH}(500 \mu \mathrm{L})$ was added to a suspension of $\mathrm{PdCl}_{2}(5.8 \mathrm{mg}, 0.033 \mathrm{mmol})$, 2,6-di-tert-butyl-p-cresol $(5.7 \mathrm{mg}, 0.026 \mathrm{mmol})$ and TBHP (90\%-aqueous, $267 \mu \mathrm{L}, 2.49$ mmol) in a solution of $\mathrm{MeOH}(500 \mu \mathrm{L})$ and $\mathrm{H}_{2} \mathrm{O}(100 \mu \mathrm{L})$. After $48 \mathrm{~h}$ at $50{ }^{\circ} \mathrm{C}$, the mixture was worked up and purified as described in Conditions D to give after chromatography (hexanes/EtOAc, 9:1) 257 (26.7 $\mathrm{mg}, 0.135 \mathrm{mmol}, 54 \%)$ as a pale yellow oil.<smiles>C/C=C/c1ccc([N+](=O)[O-])cc1[N+](=O)[O-]</smiles>
Methyl 2,4-dinitrobenozate (261), ${ }^{184}$ 2,4-dinitrobenzaldehyde (262), ${ }^{186} 1$-(2,4-dinitrophenyl)1,2-propanedione (263). A solution of $234(68.7 \mathrm{mg}, 0.330 \mathrm{mmol})$ in $\mathrm{MeOH}(500 \mu \mathrm{L})$ was added to a suspension of $\mathrm{PdCl}_{2}(7.0 \mathrm{mg}, 0.039 \mathrm{mmol})$ and $\mathrm{CuCl}(35.4 \mathrm{mg}, 0.358 \mathrm{mmol})$ in a solution of $\mathrm{MeOH}(500 \mu \mathrm{L})$ and $\mathrm{H}_{2} \mathrm{O}(100 \mu \mathrm{L})$ under an atmosphere of oxygen, as described for 230 in Condition $\mathrm{A}\left(50{ }^{\circ} \mathrm{C}, 20 \mathrm{~h}\right)$. Extraction and purification by chromatography (hexanes/EtOAc, 95:5) gave in order of elution 263 (23.5 mg, 0.096mmol, 29\%), 261 (9.6 mg, 
$0.042 \mathrm{mmol}, 13 \%)$, and $262(25.3 \mathrm{mg}, 0.129 \mathrm{mmol}, 39 \%)$ all as pale yellow oils. Spectral data for 263: ${ }^{1} \mathrm{H}$ NMR (600 MHz) $\delta 9.02(\mathrm{dd}, J=2.4,1 \mathrm{H}), 8.65$ (dd, $\left.J=8.4,2.4 \mathrm{~Hz}, 1 \mathrm{H}\right), 7.79$ (dd, $J=8.4 \mathrm{~Hz}, 1 \mathrm{H}), 2.60(\mathrm{~s}, 1 \mathrm{H}) ;{ }^{13} \mathrm{C}$ NMR $(150 \mathrm{MHz}) \delta 195.3,187.4,149.5,147.6,137.9,131.4$, 129.1, 119.4, 24.0; IR (ATR) 1717, 1601, 1536, 1345, 1170, 903, 835, 736, $721 \mathrm{~cm}^{-1}$.

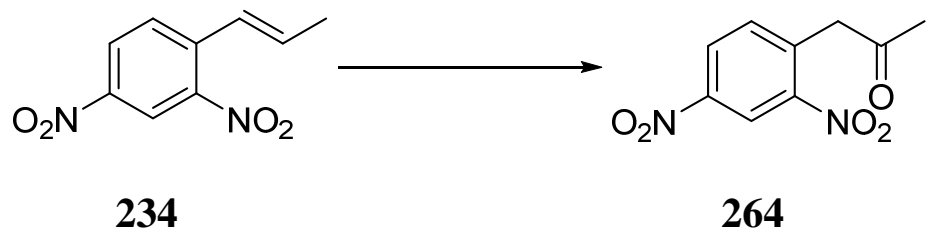

1-(2,4-Dinitrophenyl)-2-propanone (264). ${ }^{185}$ To a suspension of $\mathrm{PdCl}_{2}$ (7.8 mg, $\left.0.044 \mathrm{mmol}\right)$ and 2,6-di-tert-butyl-p-cresol $(7.5 \mathrm{mg}, 0.034 \mathrm{mmol})$ in a solution of $\mathrm{MeOH}(500 \mu \mathrm{L}), \mathrm{H}_{2} \mathrm{O}$ (100 $\mu \mathrm{L})$ and $\mathrm{H}_{2} \mathrm{O}_{2}(50 \%$-aqueous, $150 \mu \mathrm{L}, 3.20 \mathrm{mmol})$ was added 234 (40.9 mg, 0.196mmol) dissolved in $\mathrm{MeOH}(500 \mu \mathrm{L})$. The reaction mixture was stirred at $50{ }^{\circ} \mathrm{C}$ for $48 \mathrm{~h}$. The mixture was diluted with $\mathrm{H}_{2} \mathrm{O}(50 \mathrm{~mL})$ and extracted with EtOAc $(4 \times 50 \mathrm{~mL})$. The combined organic phases were dried $\left(\mathrm{MgSO}_{4}\right)$, filtered, and the solvents were removed under reduced pressure. The crude product was purified by chromatography (hexanes/EtOAc, 95:5) to give 264 (13.5 $\mathrm{mg}, 0.060 \mathrm{mmol}, 31 \%$ ) as a yellow oil.

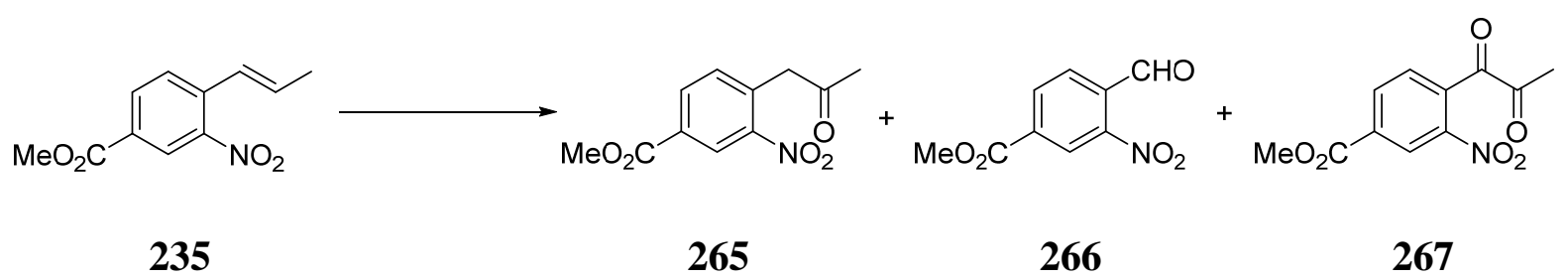

1-(4-Carbomethoxy-2-nitrophenyl)-2-propanone (265), ${ }^{186}$ 4-carbomethoxy-2-

nitrobenzaldehyde (266), ${ }^{187}$ and 1-(4-carbomethoxy-2-nitrophenyl)-1,2-propanedione (267). A solution of $235(68.2 \mathrm{mg}, 0.308 \mathrm{mmol})$ in $\mathrm{MeOH}(500 \mu \mathrm{L})$ was added to a suspension of 
$\mathrm{PdCl}_{2}(6.5 \mathrm{mg}, 0.037 \mathrm{mmol})$ and $\mathrm{CuCl}(30.3 \mathrm{mg}, 0.306 \mathrm{mmol})$ in a solution of $\mathrm{MeOH}(500 \mu \mathrm{L})$ and $\mathrm{H}_{2} \mathrm{O}(100 \mu \mathrm{L})$ under an atmosphere of oxygen, as described 230 in Condition $\mathrm{A}\left(50{ }^{\circ} \mathrm{C}\right.$, 20 h). Extraction and purification by chromatography (hexanes/EtOAc, 95:5) gave in order of elutionan inseparable mixture of 266 and 267 (1.1:1 ratio, $26.9 \mathrm{mg} ; 12.9 \mathrm{mg}, 0.0615 \mathrm{mmol}$, $20 \%$ 266; $14.0 \mathrm{mg}, 0.0559 \mathrm{mmol}, 18 \%$ 267) and 265 (21.5mg, $0.0906 \mathrm{mmol}, 29 \%)$ both as pale yellow oils.

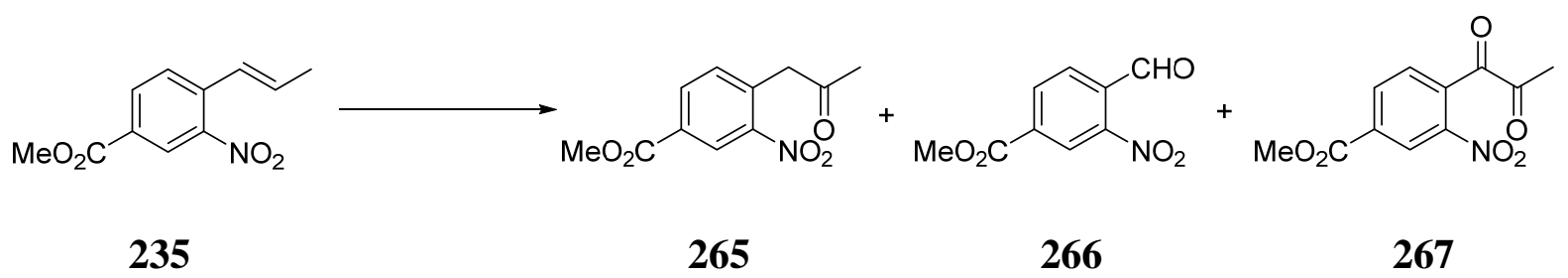

1-(4-Carbomethoxy-2-nitrophenyl)-2-propanone (265), 4-carbomethoxy-2-

nitrobenzaldehyde (266), and 1-(4-carbomethoxy-2-nitrophenyl)-1,2-propanedione (267). To a suspension of $\mathrm{PdCl}_{2}(5.0 \mathrm{mg}, 0.028 \mathrm{mmol})$ and 2,6-di-tert-butyl-p-cresol (5.8 mg, 0.026 mmol) in a solution of $\mathrm{MeOH}(500 \mu \mathrm{L}), \mathrm{H}_{2} \mathrm{O}(100 \mu \mathrm{L})$ and $\mathrm{H}_{2} \mathrm{O}_{2}(50 \%$-aqueous, $150 \mu \mathrm{L}, 3.20$ mmol) was added $235(55.5 \mathrm{mg}, 0.251 \mathrm{mmol})$ dissolved in $\mathrm{MeOH}(500 \mu \mathrm{L})$. The reaction mixture was stirred at $50{ }^{\circ} \mathrm{C}$ for $48 \mathrm{~h}$. The mixture was diluted with $\mathrm{H}_{2} \mathrm{O}(50 \mathrm{~mL})$ and extracted with EtOAc $(4 \times 50 \mathrm{~mL})$. The combined organic phases were dried $\left(\mathrm{MgSO}_{4}\right)$, filtered, and the solvents were removed under reduced pressure. The crude product was purified by chromatography (hexanes/EtOAc, 95:5) to give in order of elutionan inseparable mixture of 266 and 267 (1.1:1 ratio, $5.2 \mathrm{mg} ; 2.7 \mathrm{mg}, 0.012 \mathrm{mmol}, 5 \%$ 266; $2.7 \mathrm{mg}, 0.011$ mmol, 4\% 267) and $265(22.3 \mathrm{mg}, 0.094 \mathrm{mmol}, 37 \%)$ all as pale yellow oils. 


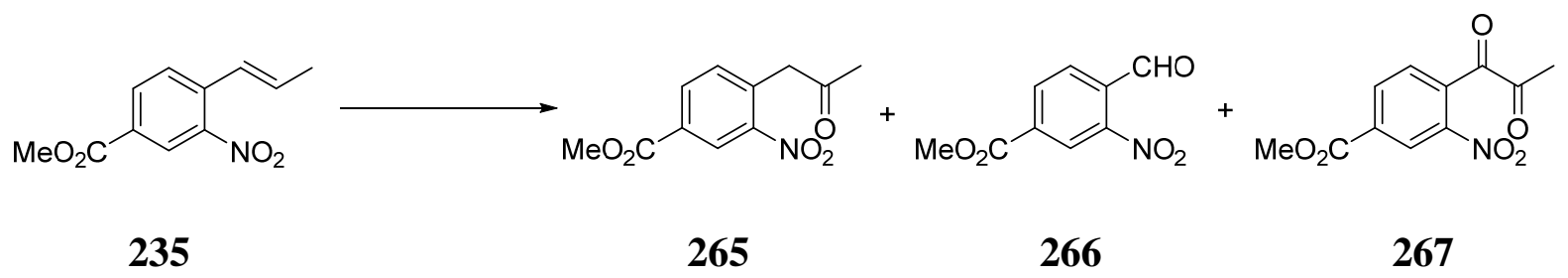

\section{1-(4-Carbomethoxy-2-nitrophenyl)-2-propanone (265), 4-carbomethoxy-2-}

nitrobenzaldehyde (266) and 1-(4-carbomethoxy-2-nitrophenyl)-1,2-propanedione (267).

To a suspension of $\mathrm{PdCl}_{2}(5.8 \mathrm{mg}, 0.033 \mathrm{mmol})$ and 2,6-di-tert-butyl-p-cresol (5.5 mg, 0.025 mmol) in a solution of $\mathrm{MeOH}(500 \mu \mathrm{L}), \mathrm{H}_{2} \mathrm{O}(100 \mu \mathrm{L})$ and $\mathrm{TBHP}(90 \%$-aqueous, $267 \mu \mathrm{L}$, $2.49 \mathrm{mmol})$ was added $235(55.3 \mathrm{mg}, 0.250 \mathrm{mmol})$ dissolved in $\mathrm{MeOH}(500 \mu \mathrm{L})$. The reaction mixture was stirred at $50{ }^{\circ} \mathrm{C}$ for $48 \mathrm{~h}$. The mixture was diluted with $\mathrm{H}_{2} \mathrm{O}(50 \mathrm{~mL})$ and extracted with EtOAc $(4 \times 50 \mathrm{~mL})$. The combined organic phases were dried $\left(\mathrm{MgSO}_{4}\right)$, filtered, and the solvents were removed under reduced pressure. The crude product was purified by chromatography (hexanes/EtOAc, 9:1) to give in order of elutionan inseparable mixture of 266 and 267 (1.3:1 ratio, $3.4 \mathrm{mg} ; 1.8 \mathrm{mg}, 0.0084 \mathrm{mmol}, 4 \%$ 266; $1.63 \mathrm{mg}, 0.0065$ mmol, 3\% 267) and 265 (12.5 mg, $0.0527 \mathrm{mmol}, 21 \%)$ as pale yellow oils. Partial spectral data of 267 from the mixture: ${ }^{1} \mathrm{H}$ NMR $(600 \mathrm{MHz}) \delta 8.81(\mathrm{~d}, J=1.6 \mathrm{~Hz}, 1 \mathrm{H}), \sim 8.4$ (overlapping with 266), $6.96(\mathrm{~d}, \mathrm{~J}=3.0 \mathrm{~Hz}, 1 \mathrm{H}), 4.01$ (s, 3H), 2.58 (s, 3H).

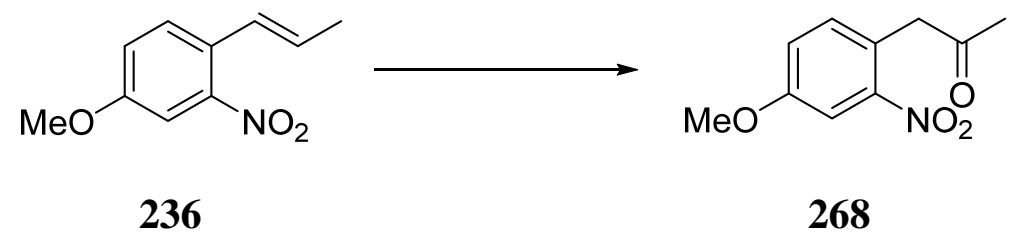

1-(4-Methoxy-2-nitrophenyl)-2-propanone (268). ${ }^{188}$ A solution of 236 (41.1 mg, 0.213mmol) in $\mathrm{MeOH}(500 \mu \mathrm{L})$ was added to a suspension of $\mathrm{PdCl}_{2}(4.1 \mathrm{mg}, 0.023 \mathrm{mmol})$ and $\mathrm{CuCl}(22.6$ $\mathrm{mg}, 0.2283 \mathrm{mmol})$ in a solution of $\mathrm{MeOH}(500 \mu \mathrm{L})$ and $\mathrm{H}_{2} \mathrm{O}(100 \mu \mathrm{L})$ under $\mathrm{O}_{2}$, as described 
for 230 in Condition $\mathrm{A}\left(50{ }^{\circ} \mathrm{C}, 20 \mathrm{~h}\right)$. Extraction and purification by chromatography (hexanes/EtOAc, 95:5) gave 268 (23.7 $\mathrm{mg}, 0.113 \mathrm{mmol}, 53 \%)$ as a pale yellow oil.

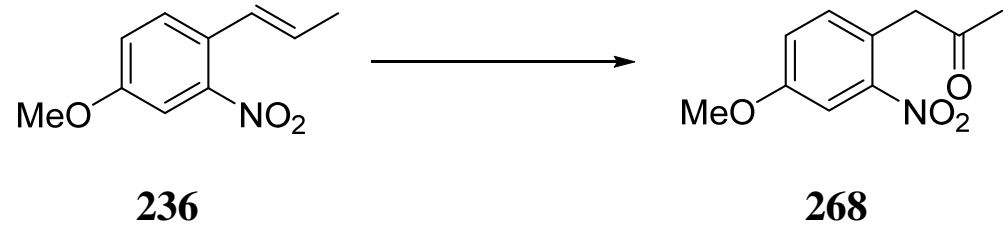

1-(4-Methoxy-2-nitrophenyl)-2-propanone (268). To a suspension of $\mathrm{PdCl}_{2}$ (5.6 mg, 0.032 $\mathrm{mmol})$ and 2,6-di-tert-butyl-p-cresol $(5.5 \mathrm{mg}, 0.025 \mathrm{mmol})$ in a solution of $\mathrm{MeOH}(500 \mu \mathrm{L})$, $\mathrm{H}_{2} \mathrm{O}(100 \mu \mathrm{L})$ and TBHP (90\%-aqueous, $\left.267 \mu \mathrm{L}, 2.49 \mathrm{mmol}\right)$ was added 236 (40.3 $\mathrm{mg}, 0.209$ mmol) dissolved in $\mathrm{MeOH}(500 \mu \mathrm{L})$. The reaction mixture was stirred at $50{ }^{\circ} \mathrm{C}$ for $48 \mathrm{~h}$. The mixture was diluted with $\mathrm{H}_{2} \mathrm{O}(50 \mathrm{~mL})$ and extracted with EtOAc $(4 \times 50 \mathrm{~mL})$. The combined organic phases were dried $\left(\mathrm{MgSO}_{4}\right)$, filtered, and the solvents were removed under reduced pressure. The crude product was purified by chromatography (hexanes/EtOAc, 9:1) to give $268(23.8 \mathrm{mg}, 0.114 \mathrm{mmol}, 55 \%)$ as a pale yellow oil.

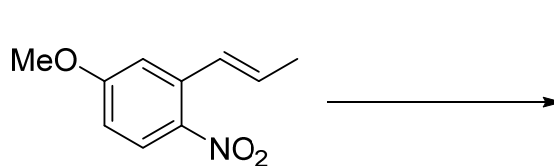

237<smiles>COc1ccc([N+](=O)[O-])c(CC(C)=O)c1</smiles>

269<smiles>COc1ccc([N+](=O)[O-])c(C=O)c1</smiles>
270<smiles>COc1ccc([N+](=O)[O-])c(C(=O)C(C)=O)c1</smiles>

271

1-(5-Methoxy-2-nitrophenyl)-2-propanone (269), 5-methoxy-2-nitro-benzaldehyde (270), ${ }^{189}$ and 1-(5-methoxy-2-nitrophenyl)-1,2-propanedione (271). A solution of 237 (65.0 mg, $0.336 \mathrm{mmol})$ in $\mathrm{MeOH}(500 \mu \mathrm{L})$ was added to a suspension of $\mathrm{PdCl}_{2}(6.2 \mathrm{mg}, 0.035 \mathrm{mmol})$ and $\mathrm{CuCl}(34.9 \mathrm{mg}, 0.352 \mathrm{mmol})$ in a solution of $\mathrm{MeOH}(500 \mu \mathrm{L})$ and $\mathrm{H}_{2} \mathrm{O}(100 \mu \mathrm{L})$ under $\mathrm{O}_{2}$, as described for 230 in Condition $\mathrm{A}\left(50^{\circ} \mathrm{C}, 20 \mathrm{~h}\right)$. Extraction and purification by 
chromatography (hexanes/EtOAc, 95:5) gave in order of elutionan inseparable mixture of 270 and 271 (1.3:1 ratio, $11.5 \mathrm{mg} ; 5.9 \mathrm{mg}, 0.033 \mathrm{mmol}, 10 \%$ 270; $5.6 \mathrm{mg}, 0.0251 \mathrm{mmol}, 7 \% 271)$ and 269 (28.7 mg, $0.137 \mathrm{mmol}, 41 \%)$ both as pale yellow oils. Spectral data for 269: ${ }^{1} \mathrm{H}$ NMR (600 MHz) $\delta 8.19(\mathrm{~d}, J=9.0 \mathrm{~Hz}, 1 \mathrm{H}), 6.89(\mathrm{dd}, J=9.6,3.0 \mathrm{~Hz}, 1 \mathrm{H}), 6.44(\mathrm{~d}, J=2.4 \mathrm{~Hz}$,

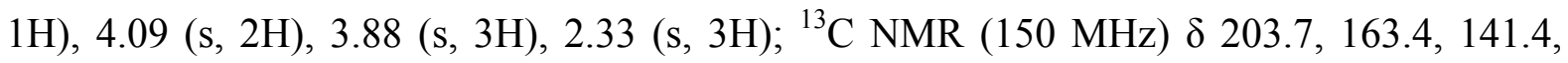
133.5, 128.1, 118.7, 112.9, 55.9, 49.2, 30.0; IR (ATR) 1721, 1581, 1509, 1335, 1292, 1261, $1162,1085,843 \mathrm{~cm}^{-1}$. Spectral data for 271 from the mixture of 270/271: ${ }^{1} \mathrm{H}$ NMR $(600 \mathrm{MHz})$ $\delta 8.17(\mathrm{~d}, J=9.0 \mathrm{~Hz}, 1 \mathrm{H}), 7.10(\mathrm{dd}, J=9.0,3.0 \mathrm{~Hz}, 1 \mathrm{H}), 6.96(\mathrm{~d}, J=3.0 \mathrm{~Hz}, 1 \mathrm{H}), 3.94(\mathrm{~s}, 3 \mathrm{H})$, 2.57 (s, 3H); ${ }^{13} \mathrm{C}$ NMR (100 MHz) $\delta 196.0,189.6,164.7,135.6,126.6,116.7,114.6,56.4$, 24.2; IR (ATR) 2945, 1706, 1582, 1513, 1485, 1333, 1290, 1239, 1190, 1026, 933, 849, 743 $\mathrm{cm}^{-1}$; HRMS (ESI) calcd for $\mathrm{C}_{10} \mathrm{H}_{9} \mathrm{NNaO}_{5}\left(\mathrm{M}+\mathrm{Na}^{+}\right)$246.0378; found 246.0374.

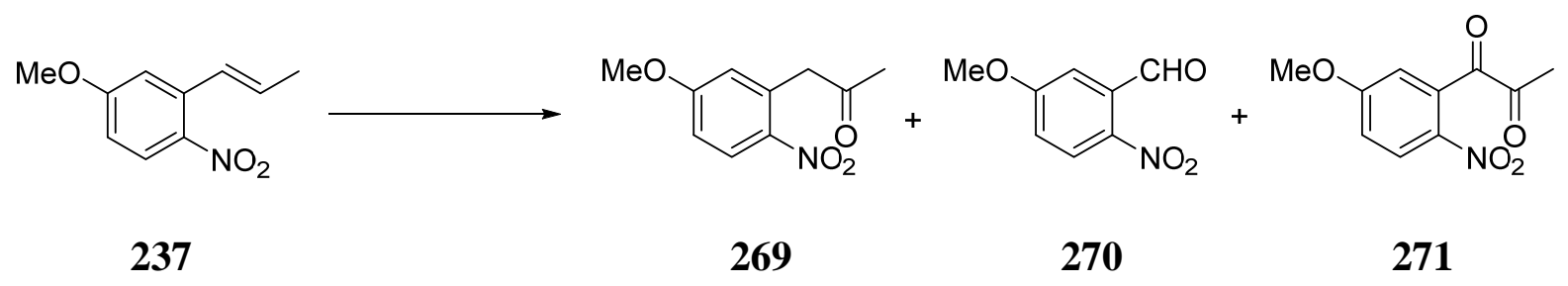

1-(5-Methoxy-2-nitrophenyl)-2-propanone (269), 5-methoxy-2-nitro-benzaldehyde (270), and 1-(5-methoxy-2-nitrophenyl)-1,2-propanedione (271). To a suspension of $\mathrm{PdCl}_{2}(5.7$ $\mathrm{mg}, 0.032 \mathrm{mmol})$ and 2,6-di-tert-butyl-p-cresol (5.6 $\mathrm{mg}, 0.025 \mathrm{mmol})$ in a solution of $\mathrm{MeOH}$ $(500 \mu \mathrm{L}), \mathrm{H}_{2} \mathrm{O}(100 \mu \mathrm{L})$ and $\mathrm{H}_{2} \mathrm{O}_{2}(50 \%$-aqueous, $150 \mu \mathrm{L}, 3.20 \mathrm{mmol})$ was added 237 (20.1 $\mathrm{mg}, 0.104 \mathrm{mmol})$ dissolved in $\mathrm{MeOH}(500 \mu \mathrm{L})$. The reaction mixture was stirred at $50{ }^{\circ} \mathrm{C}$ for $48 \mathrm{~h}$. The mixture was diluted with $\mathrm{H}_{2} \mathrm{O}(50 \mathrm{~mL})$ and extracted with EtOAc $(4 \times 50 \mathrm{~mL})$. The combined organic phases were dried $\left(\mathrm{MgSO}_{4}\right)$, filtered, and the solvents were removed under 
reduced pressure. The crude product was purified by chromatography (hexanes/EtOAc, 95:5) to give in order of elutionan inseparable mixture of 270 and $271(1: 1$ ratio, $5.0 \mathrm{mg} ; 2.3 \mathrm{mg}$, $0.012 \mathrm{mmol}, 12 \%$ 270; $2.8 \mathrm{mg}, 0.012 \mathrm{mmol}, 12 \%$ 271) and 269 (7.8 mg, $0.037 \mathrm{mmol}, 36 \%)$ both as pale yellow oils.<smiles>C/C=C/c1cc(OC)c(OC)cc1OC</smiles>

238<smiles>CCCC(=O)c1cc(OC)c(OC)cc1OC</smiles>

272 273

\section{1-(2,4,5-Trimethoxyphenyl)-2-propanone (272) ${ }^{190}$ and 1-(2,4,5-trimethoxyphenyl)-1-}

propanone (273). ${ }^{191}$ To a suspension of $\mathrm{PdCl}_{2}(24.2 \mathrm{mg}, 0.136 \mathrm{mmol})$ and $\mathrm{CuCl}(140 \mathrm{mg}$, $1.41 \mathrm{mmol})$ in a solution of $\mathrm{MeOH}(2 \mathrm{~mL})$ and $\mathrm{H}_{2} \mathrm{O}(400 \mu \mathrm{L})$ was added $238(292 \mathrm{mg}, 1.40$ mmol) dissolved in $\mathrm{MeOH}(2 \mathrm{~mL})$. The reaction flask was attached to a balloon filled with oxygen and the mixture was stirred at $50{ }^{\circ} \mathrm{C}$ for $20 \mathrm{~h}$. The mixture was diluted with $\mathrm{H}_{2} \mathrm{O}(50$ $\mathrm{mL})$ and extracted with EtOAc $(4 \times 50 \mathrm{~mL})$. The combined organic phases were dried $\left(\mathrm{MgSO}_{4}\right)$, filtered, and the solvents were removed under reduced pressure. The crude product was purified by chromatography (hexanes/EtOAc, 8:2) to give in order of elution 273 (62 mg, $0.276 \mathrm{mmol}, 20 \%)$ and $272(21.7 \mathrm{mg}, 0.097 \mathrm{mmol}, 7 \%)$ both as pale yellow oils.

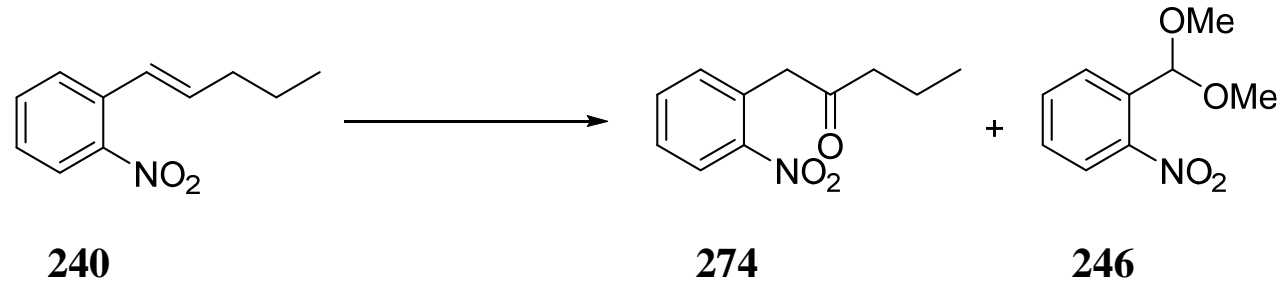

1-(2-Nitrophenyl)-2-pentanone (274) $)^{192}$ and 1-(1,1-dimethoxymethyl)-2-nitrobenzene (246). 
To a suspension of $\mathrm{PdCl}_{2}(12.0 \mathrm{mg}, 0.068 \mathrm{mmol})$ and $\mathrm{CuCl}(61.4 \mathrm{mg}, 0.620 \mathrm{mmol})$ in a solution of $\mathrm{MeOH}(1 \mathrm{~mL})$ and $\mathrm{H}_{2} \mathrm{O}(200 \mu \mathrm{L})$ was added 1-(2-nitrophenyl)-1-pentene (240) ${ }^{163}$ (113 $\mathrm{mg}, 0.589 \mathrm{mmol})$ dissolved in $\mathrm{MeOH}(1 \mathrm{~mL})$. The reaction flask was attached to a balloon filled with oxygen and the mixture was stirred at $50{ }^{\circ} \mathrm{C}$ for $72 \mathrm{~h}$. The mixture was diluted with $\mathrm{H}_{2} \mathrm{O}(50 \mathrm{~mL})$ and extracted with EtOAc $(4 \times 50 \mathrm{~mL})$. The combined organic phases were dried $\left(\mathrm{MgSO}_{4}\right)$, filtered, and the solvents were removed under reduced pressure. The crude product was purified by chromatography (hexanes/EtOAc, 8:2) to give in order of elution 246 (10.7 mg, 0.054mmol, 9\%) and $274(71.6 \mathrm{mg}, 0.45 \mathrm{mmol}, 58 \%)$ as pale yellow oils.

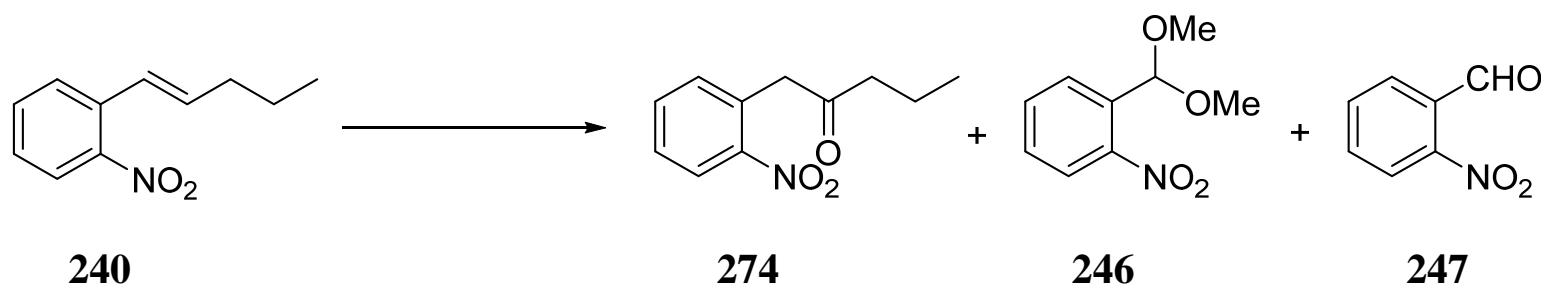

1-(2-Nitrophenyl)-2-pentanone (274), 1-(1,1-dimethoxymethyl)-2-nitrobenzene (246), and 2-nitrobenzaldehyde (247). To a suspension of $\mathrm{PdCl}_{2}(13.0 \mathrm{mg}, 0.073 \mathrm{mmol})$ and $\mathrm{H}_{2} \mathrm{O}_{2}$ (50\%-aqueous, $300 \mu \mathrm{L}, 6.40 \mathrm{mmol})$ in a solution of $\mathrm{MeOH}(1 \mathrm{~mL})$ and $\mathrm{H}_{2} \mathrm{O}(200 \mu \mathrm{L})$ was added 240 (117 $\mathrm{mg}, 0.610 \mathrm{mmol})$ dissolved in $\mathrm{MeOH}(1 \mathrm{~mL})$. The reaction mixture was stirred at $50{ }^{\circ} \mathrm{C}$ for $72 \mathrm{~h}$. The mixture was diluted with $\mathrm{H}_{2} \mathrm{O}(50 \mathrm{~mL})$ and extracted with EtOAc $(4 \times 50 \mathrm{~mL})$. The combined organic phases were dried $\left(\mathrm{MgSO}_{4}\right)$, filtered, and the solvents were removed under reduced pressure. The crude product was purified by chromatography (hexanes/EtOAc, 8:2) to give in order of elution 246 (15.9 mg, 0.081 mmol, 13\%), 247 (3.2 $\mathrm{mg}, 0.021 \mathrm{mmol}, 4 \%)$, and $274(36.7 \mathrm{mg}, 0.177 \mathrm{mmol}, 29 \%)$ as pale yellow oils. 


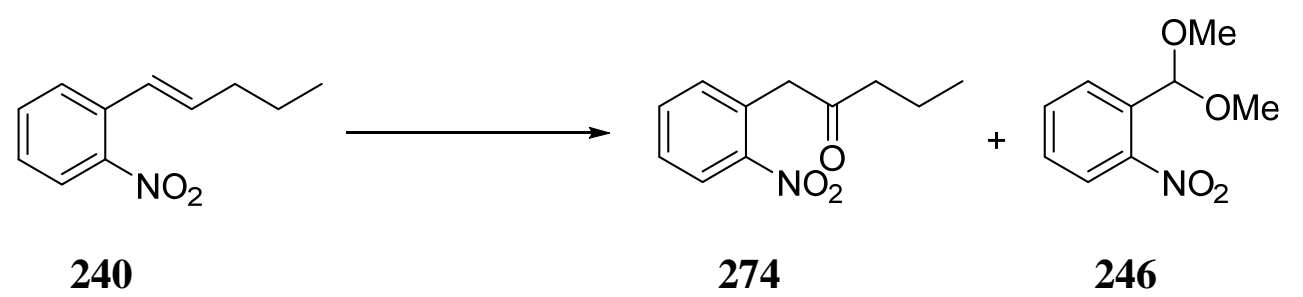

1-(2-Nitrophenyl)-2-pentanone (274) and 1-(dimethoxymethyl)-2-nitrobenzene (246). To a suspension of $\mathrm{PdCl}_{2}(6.7 \mathrm{mg}, 0.038 \mathrm{mmol})$ and 2,6-di-tert-butyl-p-cresol (5.4 mg, 0.025 mmol) in a solution of $\mathrm{MeOH}(500 \mu \mathrm{L}), \mathrm{H}_{2} \mathrm{O}(100 \mu \mathrm{L})$ and $\mathrm{H}_{2} \mathrm{O}_{2}$ (aqueous-50\%, $150 \mu \mathrm{L}, 3.20$ mmol) was added $240(48.3 \mathrm{mg}, 0.252 \mathrm{mmol})$ dissolved in $\mathrm{MeOH}(500 \mu \mathrm{L})$. The reaction mixture was stirred at $50{ }^{\circ} \mathrm{C}$ for $96 \mathrm{~h}$. The mixture was diluted with $\mathrm{H}_{2} \mathrm{O}(50 \mathrm{~mL})$ and extracted with EtOAc $(4 \times 50 \mathrm{~mL})$. The combined organic phases were dried $\left(\mathrm{MgSO}_{4}\right)$, filtered, and the solvents were removed under reduced pressure. The crude product was purified by chromatography (hexanes/EtOAc, 8:2) to give in order of elution 246 (5.9 mg, $0.030 \mathrm{mmol}, 12 \%)$ as a pale yellow oiland $274(26.4 \mathrm{mg}, 0.127 \mathrm{mmol}, 50 \%)$ as a pale yellow oil.

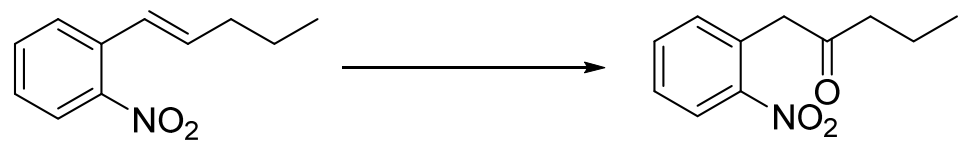

240 274

1-(2-Nitrophenyl)-2-pentanone (274). To a suspension of $\mathrm{PdCl}_{2}(6.3 \mathrm{mg}, 0.0355 \mathrm{mmol})$ and 2,6-di-tert-butyl-p-cresol $(6.3 \mathrm{mg}, 0.0295 \mathrm{mmol})$ in a solution of $\mathrm{MeOH}(500 \mu \mathrm{L}), \mathrm{H}_{2} \mathrm{O}(100$ $\mu \mathrm{L})$ and TBHP (90\%-aqueous, $267 \mu \mathrm{L}, 2.49 \mathrm{mmol})$ was added 240 (47.3 $\mathrm{mg}, 0.247 \mathrm{mmol})$ dissolved in $\mathrm{MeOH}(500 \mu \mathrm{L})$. The reaction mixture was stirred at $50{ }^{\circ} \mathrm{C}$ for $72 \mathrm{~h}$. The mixture was diluted with $\mathrm{H}_{2} \mathrm{O}(50 \mathrm{~mL})$ and extracted with EtOAc $(4 \times 50 \mathrm{~mL})$. The combined organic phases were dried $\left(\mathrm{MgSO}_{4}\right)$, filtered, and the solvents were removed under reduced pressure. 
The crude product was purified by chromatography (hexanes/EtOAc, 8:2) to give 274 (32.8 $\mathrm{mg}, 0.158 \mathrm{mmol}, 64 \%$ ) as a pale yellow oil.

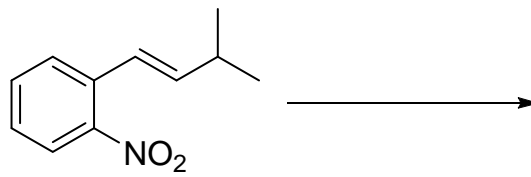

241<smiles>CC(C)C(=O)Cc1ccccc1[N+](=O)[O-]</smiles>

275<smiles>COC(C)(C)/C=C/c1ccccc1[N+](=O)[O-]</smiles>

276<smiles>C=C(C)C(Cc1ccccc1[N+](=O)[O-])OC</smiles>

277

3-Methyl-1-(2-nitrophenyl)-2-butanone (275), ${ }^{193}$ 1-(2-nitrophenyl)-3-methoxy-3-methyl-1-

butene (276), 4-(2-nitrophenyl)-3-methoxy-2-methyl-1-butene (277). To a suspension of $\mathrm{PdCl}_{2}(11.4 \mathrm{mg}, 0.064 \mathrm{mmol})$ and $\mathrm{CuCl}(62.1 \mathrm{mg}, 0.627 \mathrm{mmol})$ in a solution of $\mathrm{MeOH}(1 \mathrm{~mL})$ and $\mathrm{H}_{2} \mathrm{O}(200 \mu \mathrm{L})$ was added 1-(2-nitrophenyl)-3-methyl-1-butene (241) ${ }^{194}$ (116 mg, 0.334 mmol) dissolved in $\mathrm{MeOH}(1 \mathrm{~mL})$. The reaction flask was attached to a balloon filled with oxygen and the mixture was stirred at $50{ }^{\circ} \mathrm{C}$ for $72 \mathrm{~h}$. The mixture was diluted with $\mathrm{H}_{2} \mathrm{O}(50$ $\mathrm{mL})$ and extracted with EtOAc $(4 \times 50 \mathrm{~mL})$. The combined organic phases were dried $\left(\mathrm{MgSO}_{4}\right)$, filtered, and the solvents were removed under reduced pressure. The crude product was dissolved in $5 \mathrm{~mL}$ of Sat. $\mathrm{NaHSO}_{4}$ to remove the aldehyde and extracted with $5 \mathrm{~mL}$ of ether. The product was then purified by chromatography (hexanes/EtOAc, 95:5) to give in order of elution starting material $(51.7 \mathrm{mg}, 0.27 \mathrm{mmol}, 45 \%), 277(17.7 \mathrm{mg}, 0.080 \mathrm{mmol}$, 13\%), 276 (15.1 mg, $0.068 \mathrm{mmol}, 11 \%)$, and 275 (21.5 mg, $0.10 \mathrm{mmol}, 17 \%)$ as pale yellow oils. Spectral data for 277: ${ }^{1} \mathrm{H}$ NMR $(600 \mathrm{MHz}) \delta 7.88(\mathrm{dd}, J=8.4,1.2 \mathrm{~Hz}, 1 \mathrm{H}), 7.50(\mathrm{td}$, $J=7.8,1.2 \mathrm{~Hz}, 1 \mathrm{H}), 7.38$ (dd, J=7.2,1.2 Hz, 1H), 7.36 (td, J=7.8,1.8 Hz, 1H), 4.93 (pent, $J=1.2 \mathrm{~Hz}, 1 \mathrm{H}), 4.89$ (pent, $J=0.7 \mathrm{~Hz}, 1 \mathrm{H}), 3.76$ (dd, $J=8.5,4.5 \mathrm{~Hz}, 1 \mathrm{H}), 3.15$ (dd, $J=13.8$, 8.4Hz, 1H), $3.12(\mathrm{~s}, 3 \mathrm{H}), 3.08(\mathrm{dd}, J=13.8,4.2 \mathrm{~Hz}, 1 \mathrm{H}), 1.74(\mathrm{t}, J=1.2 \mathrm{~Hz}, 3 \mathrm{H}) ;{ }^{13} \mathrm{C} \mathrm{NMR}(150$ 
MHz) $\delta 149.8,143.7,133.8,133.3,132.4,127.3,124.4,113.8,85.1,56.3,37.7,16.8$; IR (ATR) 2934, 1578, 1524, 1449, 1348, 1096, 905, 861, 785, 739, $668 \mathrm{~cm}^{-1}$; HRMS (ESI) calcd for $\mathrm{C}_{12} \mathrm{H}_{15} \mathrm{NNaO}_{3}\left(\mathrm{M}+\mathrm{Na}^{+}\right) 244.0944$; found 244.0944.

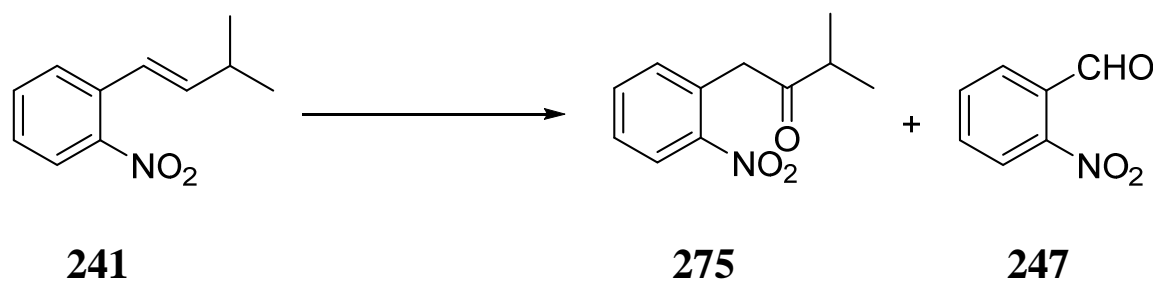

3-Methyl-1-(2-nitrophenyl)-2-butanone (275) and 2-nitrobenzaldehyde (247). Tо а suspension of $\mathrm{PdCl}_{2}(13.1 \mathrm{mg}, 0.074 \mathrm{mmol})$ and $\mathrm{H}_{2} \mathrm{O}_{2}(50 \%$-aqueous, $300 \mu \mathrm{L}, 6.40 \mathrm{mmol})$ in a solution of $\mathrm{MeOH}(1 \mathrm{~mL})$ and $\mathrm{H}_{2} \mathrm{O}(200 \mu \mathrm{L})$ was added $241(117 \mathrm{mg}, 0.611 \mathrm{mmol})$ dissolved in $\mathrm{MeOH}(1 \mathrm{~mL})$. The reaction mixture was stirred at $50{ }^{\circ} \mathrm{C}$ for $72 \mathrm{~h}$. The mixture was diluted with $\mathrm{H}_{2} \mathrm{O}(50 \mathrm{~mL})$ and extracted with EtOAc $(4 \times 50 \mathrm{~mL})$. The combined organic phases were dried $\left(\mathrm{MgSO}_{4}\right)$, filtered, and the solvents were removed under reduced pressure. The crude product was purified by chromatography (hexanes/EtOAc, 8:2) to give in order of elution starting material $(21.8 \mathrm{mg}, 0.11 \mathrm{mmol}, 19 \%)$, and inseparable mixture of 275 and $247(2.2: 1$ ratio, $31.1 \mathrm{mg} ; 23.3 \mathrm{mg}, 0.112 \mathrm{mmol}, 18 \% 275 ; 7.7 \mathrm{mg}, 0.0512 \mathrm{mmol}, 8 \% 247)$ as pale yellow oils.

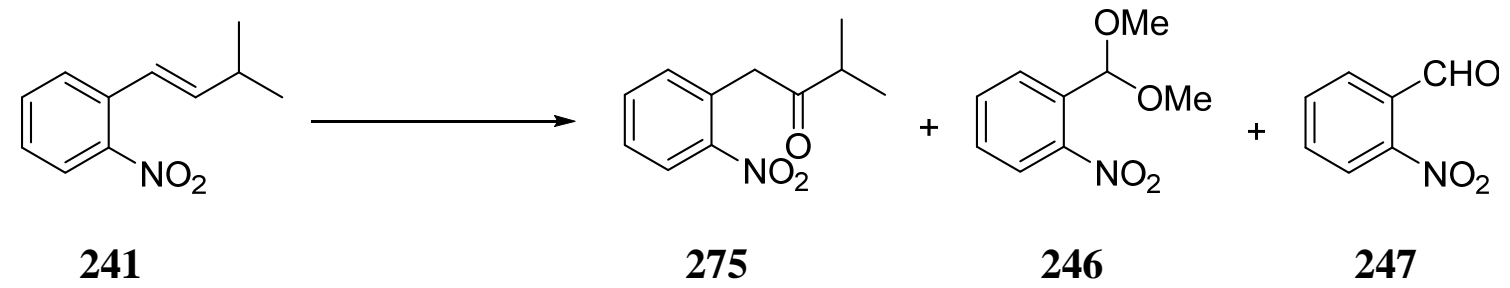

3-Methyl-1-(2-nitrophenyl)-2-butanone (275), 1-(1,1-dimethoxymethyl)-2-nitrobenzene 
(246), and 2-nitrobenzaldehyde (247). To a suspension of $\mathrm{PdCl}_{2}(5.7 \mathrm{mg}, 0.032 \mathrm{mmol})$ and 2,6-di-tert-butyl-p-cresol $(5.8 \mathrm{mg}, 0.026 \mathrm{mmol})$ in a solution of $\mathrm{MeOH}(500 \mu \mathrm{L}), \mathrm{H}_{2} \mathrm{O}(100$ $\mu \mathrm{L})$ and $\mathrm{H}_{2} \mathrm{O}_{2}(50 \%$-aqueous, $150 \mu \mathrm{L}, 3.20 \mathrm{mmol})$ was added 241 (47.1 $\left.\mathrm{mg}, 0.246 \mathrm{mmol}\right)$ dissolved in $\mathrm{MeOH}(500 \mu \mathrm{L})$. The reaction mixture was stirred at $50{ }^{\circ} \mathrm{C}$ for $96 \mathrm{~h}$. The mixture was diluted with $\mathrm{H}_{2} \mathrm{O}(50 \mathrm{~mL})$ and extracted with EtOAc $(4 \times 50 \mathrm{~mL})$. The combined organic phases were dried $\left(\mathrm{MgSO}_{4}\right)$, filtered, and the solvents were removed under reduced pressure. The crude product was purified by chromatography (hexanes/EtOAc, 8:2) to give in order of elution starting material (16.9 mg, $0.088 \mathrm{mmol}, 36 \%), 246$ (4.5 mg, 0.023mmol, 9\%) and an inseparable mixture of 275 and 247 (4.2:1 ratio, $14.9 \mathrm{mg} ; 12.7 \mathrm{mg}, 0.613 \mathrm{mmol}, 25 \%$ 275; $2.2 \mathrm{mg}, 0.0146 \mathrm{mmol}, 6 \% 247)$ as yellow oils.

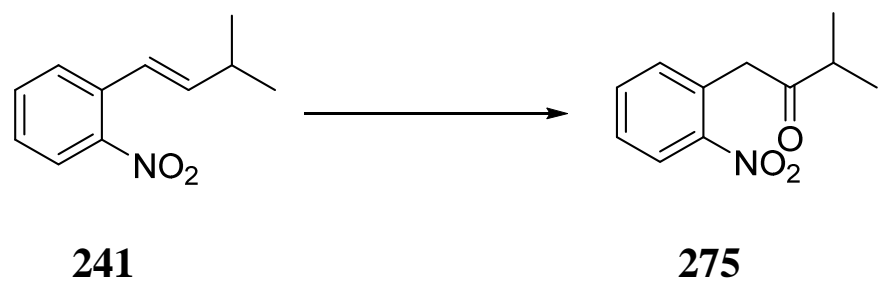

3-Methyl-1-(2-nitrophenyl)-2-butanone (275). To a suspension of $\mathrm{PdCl}_{2}$ (5.4 mg, 0.030 $\mathrm{mmol})$ and 2,6-di-tert-butyl-p-cresol $(5.6 \mathrm{mg}, 0.025 \mathrm{mmol})$ in a solution of $\mathrm{MeOH}(500 \mu \mathrm{L})$, $\mathrm{H}_{2} \mathrm{O}(100 \mu \mathrm{L})$ and TBHP (90\%-aqueous, $\left.267 \mu \mathrm{L}, 2.49 \mathrm{mmol}\right)$ was added 241 (47.8 $\mathrm{mg}, 0.250$ mmol) dissolved in $\mathrm{MeOH}(500 \mu \mathrm{L})$. The reaction mixture was stirred at $50{ }^{\circ} \mathrm{C}$ for $96 \mathrm{~h}$. The mixture was diluted with $\mathrm{H}_{2} \mathrm{O}(50 \mathrm{~mL})$ and extracted with EtOAc $(4 \times 50 \mathrm{~mL})$. The combined organic phases were dried $\left(\mathrm{MgSO}_{4}\right)$, filtered, and the solvents were removed under reduced pressure. The crude product was purified by chromatography (hexanes/EtOAc, 8:2) to give 275 (9.0 $\mathrm{mg}, 0.043 \mathrm{mmol}, 17 \%)$ as a pale yellow oil. 
<smiles>O=[N+]([O-])c1ccccc1/C=C/c1ccccc1</smiles>

242

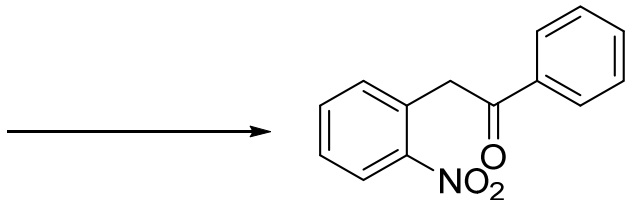

278

2-(2-Nitrophenyl)-1-phenyl-ethanone (278). ${ }^{\mathbf{1 7 2}}$ To a suspension of $\mathrm{PdCl}_{2}$ (14.5 mg, 0.0818 mmol) and $\mathrm{CuCl}(70.7 \mathrm{mg}, 0.714 \mathrm{mmol})$ in a solution of $\mathrm{MeOH}(1 \mathrm{~mL})$ and $\mathrm{H}_{2} \mathrm{O}(200 \mu \mathrm{L})$ was added 2-nitro-1-(2-phenylethenyl)benzene (242) ${ }^{195}$ (152 $\left.\mathrm{mg}, 0.675 \mathrm{mmol}\right)$ dissolved in $\mathrm{MeOH}(1 \mathrm{~mL})$. The reaction flask was attached to a balloon filled with oxygen and the mixture was stirred at $50{ }^{\circ} \mathrm{C}$ for $48 \mathrm{~h}$. The mixture was diluted with $\mathrm{H}_{2} \mathrm{O}(50 \mathrm{~mL})$ and extracted with EtOAc $(4 \times 50 \mathrm{~mL})$. The combined organic phases were dried $\left(\mathrm{MgSO}_{4}\right)$, filtered, and the solvents were removed under reduced pressure. The crude product was purified by chromatography (hexanes/EtOAc, 95:5) to give 278 (23.4 mg, $0.097 \mathrm{mmol}, 14 \%$ ) as a light brown oil.<smiles>O=[N+]([O-])c1ccccc1/C=C/c1ccccc1</smiles>

242<smiles>O=C(Cc1ccccc1[N+](=O)[O-])c1ccccc1</smiles>

278

2-(2-Nitrophenyl)-1-phenyl-ethanone (278). To a suspension of $\mathrm{PdCl}_{2}$ (14.4 mg, 0.0812 $\mathrm{mmol})$ and 2,6-di-tert-butyl-p-cresol (17.8 $\mathrm{mg}, 0.0808 \mathrm{mmol})$ in a solution of $\mathrm{MeOH}(1 \mathrm{~mL})$, $\mathrm{H}_{2} \mathrm{O}(200 \mu \mathrm{L})$ and $\mathrm{H}_{2} \mathrm{O}_{2}(50 \%$-aqueous, $300 \mu \mathrm{L}, 6.40 \mathrm{mmol})$ was added 242 (15.0 mg, 0.067 mmol) dissolved in $\mathrm{MeOH}(1 \mathrm{~mL})$. The reaction mixture was stirred at $50{ }^{\circ} \mathrm{C}$ for $68 \mathrm{~h}$. The mixture was diluted with $\mathrm{H}_{2} \mathrm{O}(50 \mathrm{~mL})$ and extracted with EtOAc $(4 \times 50 \mathrm{~mL})$. The combined organic phases were dried $\left(\mathrm{MgSO}_{4}\right)$, filtered, and the solvents were removed under reduced 
pressure. The crude product was purified by chromatography (hexanes/EtOAc, 8:2) to give $278(8.2 \mathrm{mg}, 0.034 \mathrm{mmol}, 51 \%)$ as a light brown oil.

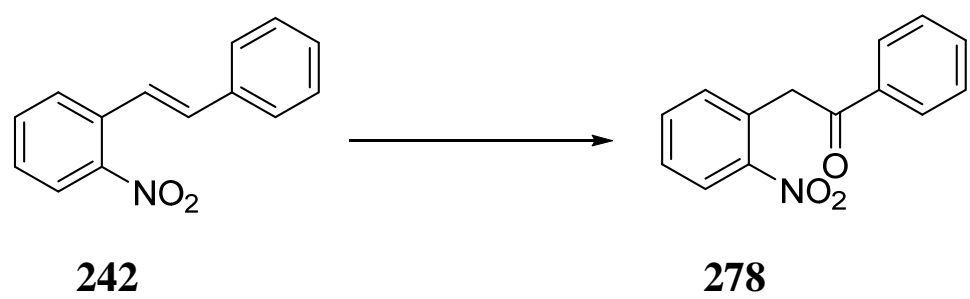

2-(2-Nitrophenyl)-1-phenyl-ethanone (278). To a suspension of $\mathrm{PdCl}_{2}(5.5 \mathrm{mg}, 0.031 \mathrm{mmol})$ and 2,6-di-tert-butyl-p-cresol (5.8 mg, $0.026 \mathrm{mmol})$ in a solution of $\mathrm{MeOH}(500 \mu \mathrm{L}), \mathrm{H}_{2} \mathrm{O}$ $(100 \mu \mathrm{L})$ and TBHP (90\%-aqueous, $267 \mu \mathrm{L}, 2.49 \mathrm{mmol})$ was added 242 (49.1 mg, 0.218 mmol) dissolved in $\mathrm{MeOH}(500 \mu \mathrm{L})$. The reaction mixture was stirred at $50{ }^{\circ} \mathrm{C}$ for $72 \mathrm{~h}$. The mixture was diluted with $\mathrm{H}_{2} \mathrm{O}(50 \mathrm{~mL})$ and extracted with EtOAc $(4 \times 50 \mathrm{~mL})$. The combined organic phases were dried $\left(\mathrm{MgSO}_{4}\right)$, filtered, and the solvents were removed under reduced pressure. The crude product was purified by chromatography (hexanes/EtOAc, 8:2) to give $278(38.9 \mathrm{mg}, 0.161 \mathrm{mmol}, 74 \%)$ as a pale brown oil.

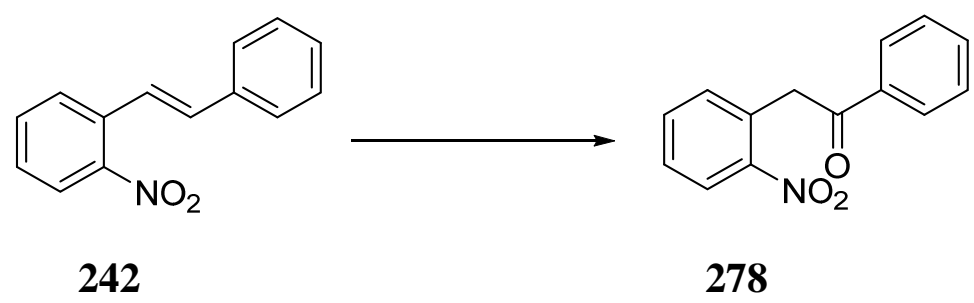

2-(2-Nitrophenyl)-1-phenyl-ethanone (278). To a suspension of $\mathrm{PdCl}_{2}(6.6 \mathrm{mg}, 0.037 \mathrm{mmol})$ in a solution of $\mathrm{MeOH}(500 \mu \mathrm{L}), \mathrm{H}_{2} \mathrm{O}(100 \mu \mathrm{L})$ and TBHP (90\%-aqueous, $\left.267 \mu \mathrm{L}, 2.49 \mathrm{mmol}\right)$ was added $242(50.5 \mathrm{mg}, 0.224 \mathrm{mmol})$ dissolved in $\mathrm{MeOH}(500 \mu \mathrm{L})$. The reaction mixture was stirred at $50{ }^{\circ} \mathrm{C}$ for $72 \mathrm{~h}$. The mixture was diluted with $\mathrm{H}_{2} \mathrm{O}(50 \mathrm{~mL})$ and extracted with 
EtOAc $(4 \times 50 \mathrm{~mL})$. The combined organic phases were dried $\left(\mathrm{MgSO}_{4}\right)$, filtered, and the solvents were removed under reduced pressure. The crude product was purified by chromatography (hexanes/EtOAc, 8:2) to give 278 (14.6 mg, $0.060 \mathrm{mmol}, 27 \%$ ) as a light brown oil.

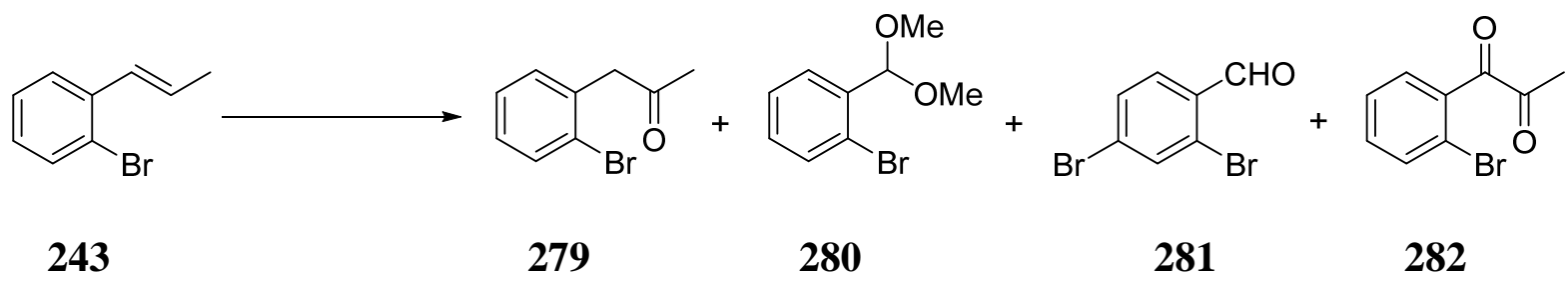
1-(2-Bromophenyl)-2-propanone (279), ${ }^{196}$ 1-bromo-2-(1,1-dimethoxymethyl)benzene (280), ${ }^{197}$ and 2-bromobenzaldehyde (281), 1-(2-bromophenyl)-1,2-propanedione (282). A solution of $243(133 \mathrm{mg}, 0.672 \mathrm{mmol})$ in $\mathrm{MeOH}(1 \mathrm{~mL})$ was added to a suspension of $\mathrm{PdCl}_{2}$ (12.9 $\mathrm{mg}, 0.073 \mathrm{mmol})$ and $\mathrm{CuCl}(69.8 \mathrm{mg}, 0.71 \mathrm{mmol})$ in a solution of $\mathrm{MeOH}(1 \mathrm{~mL})$ and $\mathrm{H}_{2} \mathrm{O}(200 \mu \mathrm{L})$ under an atmosphere of oxygen, as described for 230 in Condition $\mathrm{A}\left(50{ }^{\circ} \mathrm{C}, 20\right.$ h). Extraction and purification by chromatography (hexanes/EtOAc, 98:2) gave in order of elution, an inseparable mixture of $\mathbf{2 8 0}$ and $\mathbf{2 8 1}$ (7:1 ratio, $13.1 \mathrm{mg} ; 11.7 \mathrm{mg}, 0.051 \mathrm{mmol}, 8 \%$ 280; $1.34 \mathrm{mg}, 0.0073 \mathrm{mmol}, 1 \%$ 281), 282 (9 mg, $0.040 \mathrm{mmol}, \leq 6 \%$ ), and 279 (64.5 mg, 0.30 mmol, 45\%) as pale yellow oils. Spectral data for impure 1-(2-bromophenyl)-1,2-propane dione 282: ${ }^{1} \mathrm{H}$ NMR (600 MHz) $\delta 7.61(\mathrm{dd}, J=7.2,1.8 \mathrm{~Hz}, 1 \mathrm{H}), 7.57$ (dd, $\left.J=7.2,2.4 \mathrm{~Hz}, 1 \mathrm{H}\right)$, $7.45(\mathrm{td}, J=7.2,1.8 \mathrm{~Hz}, 1 \mathrm{H}), 7.41(\mathrm{td}, J=7.2,1.8 \mathrm{~Hz}, 1 \mathrm{H}), 2.59(\mathrm{~s}, 3 \mathrm{H}) ;{ }^{13} \mathrm{C} \mathrm{NMR}(100 \mathrm{MHz})$ 197.9, 193.4, 136.3, 133.6, 133.1, 131.4, 127.7, 121.0, 25.1; IR (ATR) 2970, 1715, 1688, 1587, 1434, 1356, 1172, 1053, 1027, 903, 802, $738 \mathrm{~cm}^{-1}$; HRMS (ESI) calcd for $\mathrm{C}_{9} \mathrm{H}_{8} \mathrm{BrO}_{2}$ $\left(\mathrm{M}+\mathrm{H}^{+}\right)$226.9708; found 226.9702. 


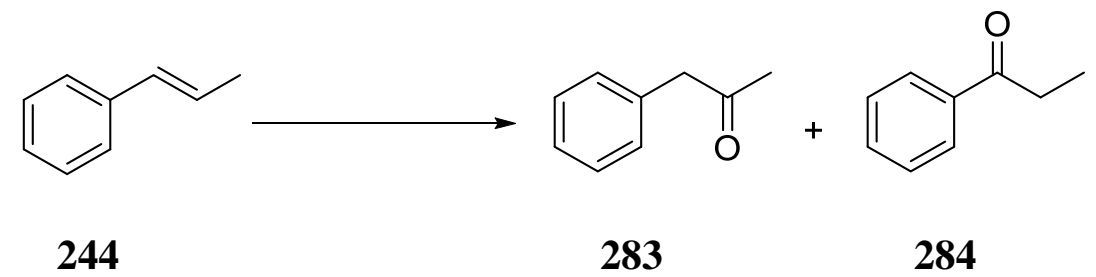

1-Phenyl-2-propanone $(283)^{198}$ and 1-phenyl-1-propanone (284). A solution of 1-propen-1-yl-benzene $(\mathbf{2 4 4})^{199}(95.3 \mathrm{mg}, 0.806 \mathrm{mmol})$ in $\mathrm{MeOH}(1 \mathrm{~mL})$ was added to a suspension of $\mathrm{PdCl}_{2}(14.3 \mathrm{mg}, 0.081 \mathrm{mmol})$ and $\mathrm{CuCl}(79.8 \mathrm{mg}, 0.81 \mathrm{mmol})$ in a solution of $\mathrm{MeOH}(1 \mathrm{~mL})$ and $\mathrm{H}_{2} \mathrm{O}(200 \mu \mathrm{L})$ under an atmosphere of oxygen, as described for 230 in Condition $\mathrm{A}\left(50{ }^{\circ} \mathrm{C}, 20 \mathrm{~h}\right)$. Extraction and purification by chromatography (hexanes/EtOAc, 9:1) gave in order of elution, $284(16.0 \mathrm{mg}, 0.099 \mathrm{mmol}, 12 \%)$ and 283 (44.2 $\mathrm{mg}, 0.27 \mathrm{mmol}$, $34 \%)$ as colorless oils. 


\section{References and Notes}

1 Karlsson, J. O.; Nguyen, N. V.; Foland, L. D.; Moore, H. W. J. Am. Chem. Soc. 1985, 107, 3392.

2 Moore, H. W.; Decker, O. H. W. Chem. Rev. 1986, 86, 821.

3 Moore, H. W. Science 1977, 197, 521.

4 Moore, H. W.; Czernick, R. Med. Res. Rev. 1981, 1, 249.

5 Kikuchi, H.; Tsukitani, Y.; Iguchi, K.; Yamada, Y. Tetrahedron Lett. 1982, 23, 25.

6 Iguchi, K.; Kaneta, S.; Mori, K.; Yamada, Y.; Honda, A.; Mori, Y. Tetrahedron Lett. 1985, 26, 5787.

7 Baker, B. J.; Okuda, R. K.; Yu, P. T. K.; Scheuer, P. J. J. Am. Chem. Soc. 1985, 107, 2976.

8 Reed, M.; Perri, S. T.; Pollart, D.; Foland, L. D.; Moore, H. W. J. Org. Chem. 1988, 53, 2411.

9 Liebeskind, L. S.; Fengl, R. W.; Wirtz, K. R.; Shawe, T. T. J. Org. Chem. 1988, 53, 2482.

10 Perri, S. T.; Foland, L. D.; Decker, O. H. W.; Moore, H. W. J. Org. Chem. 1986, 51, 3067.

11 Decker, O. H. W.; Moore, H. W. J. Org. Chem. 1987, 52, 1174.

12 Foland, L. D.; Karlsson, J. O.; Perri, S. T.; Schwabe, R.; Xu, S. L.; Patil, S.; Moore, H. W.

J. Am. Chem. Soc. 1989, 111, 975.

13 Hashimoto, T. Yakugaku Azsshi 1967, 87, 535.

14 Back, H.; Alt, H. Angew. Chem., Int. Ed. Engl. 1967, 6, 944.

15 Foland, L. D.; Decker, O. H. W.; Moore, H. W. J. Am. Chem. Soc. 1989, 111, 989.

16 Thomson, R. H. Naturally Occurring Quinones III; Chapmann and Hall: London, 1987.

17 Thomson, R. H. Naturally Occurring Quinones; Academic: New York, 1976. 
Xin-Sheng, Y.; Ebizuka, Y.; Noguchi, H.; Kiuchi, F.; Seto. H.; Sankawa, U. Tetrahedron Lett. 1984, 5541.

19 Zhon Yao Zhi, Chinese Academy of Medicinal Sciences, Ed.; People’s Hygenic Publisher: 1979, 1, 569.

20 Kruchi, F.; Shibuya, M.; Sankawa, U. Chem. Pharm. Bull. 1982, 30, 754.

21 Kruchi, F.; Shibuya, M.; Sankawa, U. Ibid. 1982, 30, 2279.

22 Hayashi, M.; Unemoto, T.; Minami-Kakinuma, S.; Tanaka, H.; Omura, S. J. Antibiot. 1982, 35, 1078

23 Watanabe, S.; Shimizu, H. J. Antibiot. 1985, 38, 1447.

24 Chang, C. J.; Floss, H. G.; Soong, P.; Gang, C. T. J. Antibiot. 1975, 28, 156.

25 Liebeskind, L. S.; Jewell, C. F.; Iyer, S. Ibid. 1986, 51, 3066.

26 Bernady, K. F.; Floyd, M. B.; Poletto, J. F.; Weiss, M. J. J. Org. Chem. 1979, 44, 1438.

27 Naruta, Y.; Uno, H.; Maruyama, K. Chem. Lett. 1982, 609.

28 Ellestad, G. Z.; Kuntsmann, M. P.; Whaley, H. A,; Patterson, E. L. J. Am. Chem. Soc. 1968, 90, 1325.

29 Ichihara, A.; Ubukata, M.; Oikawa, H.; Murakami, K.; Sakamura, S. Tetrahedron Lett. 1980, 4469.

30 Kraus, G. A,; Roth, B. J. Org. Chem. 1978, 43, 4923.

31 Enhsen, A.; Karabelas, K.; Heerding, J. M.; Moore, H. W. J. Org. Chem. 1990, 55, 1177.

32 Reed, M. W.; Perri, S. T.; Pollart, D. J.; Foland, L. D.; Moore, H. W. J. Org. Chem. 1988, 53, 2477.

33 Beyerman, H. C.; Bontekoe, J. S. Proc. Chem. Soc. 1961, 249. 
Read, G.; Westlake, D. W. S.; Vining, L. C. Can. J. Biochem. 1969, 47, 1071.

Yamamoto, H.; Moriyama, K.; Jinnouchi, H.; Yagishita, K. J. Antibiot. 1980, 33, 320.

36

Moore, H. W. J. Org. Chem. 1967, 32, 1996.

37

38

Tetrahedron Lett. 1982, 5331.

47 Kobayashi, M.; Yasuzawa, T.; Yoshihara, M.; Son, B. W.; Kyogoku, Y.; Kitagawa, I. Chem. Pharm. Bull. 1983, 11, 1440.

48 Nagaoka, H.; Iguchi, K.; Miyakoshi, T.; Yamada, N.; Yamada, Y. Ibid. 1986, 223.

49

Iguchi, K.; Kaneta, S.; Mori, K.; Yamada, Y.; Honda, A.; Mori, Y. J. Chem. Soc., Chem.

Commun. 1986, 981.

50 Nagaoka, H.; Miyaoka, H.; Miyakoshi, Y.; Yamada, Y. Ibid. 1986, 108, 5019.

51 Fukushima, M.; Kato, T.; Yamada, Y.; Kitagawa, I.; kurozumi, S.; Scheuer, P. J. Proc. Am. Assoc. Cancer Res. 1985, 26, 249. 
Katsin, N.; R. Ikan, R. Synth. Commun. 1977, 7, 185.

Pohmakotr, M.; Chancharunee, S. Tetrahedron Lett. 1984, 4141.

54

Lumpur, Malaysia, 1988, 1, 371.

67

68

69

70

Phytochemistry 1998, 47, 891.

71 Kiang, A. K.; Lee, H. H.; Sim, K. Y. J. Chem. Soc. 1962, 438.

Block, E.; Wall, A.; Zubieta, J. J. Am. Chem. Soc. 1985, 107, 1783.

Verlaak, J. M. J.; Klunder, A. J. H.; Zwanenburg, B. Tetrahedron Lett. 1982, 5436.

Boeckmann, R. J.; Naegely, P. C.; Arthur, S. D. J. Org. Chem. 1980, 45, 752.

Corey, E. J.; Mehrotra, M. M. J. Am. Chem. Soc. 1984, 106, 3384.

Sasai, H.; Shibasaki, M. Tetrahedron Lett. 1987, 333.

Yamanoto, Y.; Ohno, M.; Eguchi, S. Tetrahedron Lett. 1995, 36, 5539.

Yamamoto, Y.; Noda, M.; Ohno, M.; Eguchi, S. J. Org. Chem. 1997, 62, 1292.

Mitchell, D.; Liebeskind, L. S. Ibid. 1990, 112, 291.

Liebeskind, L. S.; Foster, B. S. J. Am. Chem. Soc. 1990, 112, 8612.

Nishikawa, T.; Shibuya, S.; Hosokawa, S.; Isobe, M. Synlett. 1994, 485.

Kiang, A. K.; Lee, H. H.; Sim, K. Y. Proc. Chem. Soc. London 1961, 455.

Liu, S. Y.; Hisada, S.; Inagaki, I. Phytochemistry 1973, 12, 233.

Corner, E. J. H. Wayside Trees of Malaya, 3rd ed. The Malayan Nature Society, Kuala

Ichino, K.; Tanaka, H.; Ito, K.; Tanaka, T.; Mizuno, M. J. Nat. Prod. 1988, 51, 915.

Komae, H.; Hayashi, N.; Phytochemistry 1972, 11, 853.

Lee, H. H. Tetrahedron Lett. 1968, 40, 4243.

Leong, Y. -W.; Harrison, L. J.; Bennett, G. J.; Kadir, A. A.; Connolly, J. D. 
Chia, Y. C.; Wu, J.-B.; Wu, Y.-C. Tetrahedron Lett. 2000, 41, 2199.

Wu, J. B.; Cheng, Y. D.; Kuo, S. C.; Wu, T. S.; Iitaka, Y.; Ebizuka, Y.; Sankawa, U. Chem. Pharm. Bull. 1994, 42, 2202.

74 Aoyama, Y.; Konoike, T.; Kanda, A.; Naya, N.; Nakajima, M. Bioorg. Med. Chem. Lett. 2001, 11, 1695.

75 Lee, S. M.; Baek, S.W.; Lee, C.H.; Lee, H. B.; Kho,Y. H. Nat. Prod. Sci. 2002, 8,100.

76 Hwang, E. I.; Lee, Y. M.; Lee, S. M.; Yeo, W. H.; Moon, J. S.; Te, H.; Park, K. D. D.; Kim, S. U. Planta Med. 2007, 73, 679.

77 Wang, Z.; Walter, M.; Selwood, T.; Rubin, H.; Schechter, N. M. Biol. Chem. 1998, 379, 167.

78 Ihara, M.; Urata, H.; Kinoshita, A.; Suzumiya, J.; Sasaguri, M.; Kikuchi, M.; Ideishi, M.; Arakawa, K. Hypertension 1999, 33, 1399.

79 Takai, S.; Yuda, A.; Jin, D.; Nishimoto, M.; Sakaguchi, M.; Sasaki, S.; Miyazaki, M. FEBS Lett. 2000, 467, 141.

80 Oh, H. M.; Choi, S. K.; Lee, J. M.; Lee, S.-K.; Kim, H.-Y.; Han, D. C.; Kim, H. M.; Son, K. H.; Kwon, B. M. Bioorg. Med. Chem. 2005, 13, 6182.

81 Wang, S.-Y.; Lan, X.-Y.; Xiao, J.-H.; Yang, J.-C.; Kao, Y.-T.; Chang, S.-T. Phytother. Res. 2008, 22, 213.

82 Kim, G. -O.; Jin, Y. J.; Ko, R. -K.; Choi, H. -M.; Kang, M. -C.; Han, J. -H.; KO, K. -H. PCT Int. Appl. WO 20,110,556,037 (CAN 154: 557389), 2011.

83 Birch, A. J. J. Chem. Soc. 1951, 3026.

84 Kiang, A. K.; Lee, H. H.; Sim, K.Y. J. Chem. Soc. 1962, 4338. 
Chem. 2011, 76, 2744.

95 Chittimalla, S. K.; Chang, T.-C.; Liu, T.-C.; Hsieh, H. P.; Liao, C.-C. Tetrahedron 2008, 64, 2586

96 Kim, Y.-W.; Hackett, J. C.; Brueggemeier, R. W. J. Med. Chem. 2004, 47, 4032.

97 Xu, Q. L.; Gao, H. Y.; Yousufuddin, M.; Ess, D. H.; Kürti, L. J. Am. Chem. Soc. 2013, 135, 14048.

98 Schlummer, B.; Scholz, U. In Modern Arylation Methods. Ackermann, L. Ed. Wiley-VCH: Weinheim, 2009, 69.

99 Kessar, S. V. In Comprehensive Organic Synthesis. Trost, B. M.; Fleming, I.; Semmelhack, M. F. Eds. Pergamon Press: New York, 1991, 4, Chapter 2.3.

100 Semmelhack, M. F.; Bargar, T. J. Org. Chem. 1977, 42, 1481.

101 Beugelmans, R.; Ginsburg, H. Heterocycles 1985, 23, 1197. 
Finet, J. P. Chem. Rev. 1989, 89, 1487.

Jenkins, S. S. J. Am. Chem. Soc. 1933, 55, 2896.

104

Yadav, D. K.; Gautam, A. K.; Kureel, J.; Srivastava, K.; Sahai, M.; Singh, D.;

Chattopadhyay, N.; Maurya, R. Bioorg. Med. Chem. Lett. 2011, 21, 677.

105

Landers, B.; Berini, C.; Wang, C.; Navarro, O. J. Org. Chem. 2011, 76, 1390.

106 Fox, J. M.; Huang, X.; Chieffi, A.; Buchwald, S. L. J. Am. Chem. Soc. 2000, 122, 1360.

107 Miao, T.; Wang, G.-W. Chem. Commun. 2011, 47, 9501.

108 Kuwajima, I.; Urabe, H. J. Am. Chem. Soc. 1982, 104, 6831.

109 Palucki, M.; Buchwald, S. L. J. Am. Chem. Soc. 1997, 119, 11108.

110 Hamann, B. C.; Hartwig, J. F. J. Am. Chem. Soc. 1997, 119, 12382.

111 Terao, Y.; Satoh, T.; Miura, M.; Nomura, M. Bull. Chem. Soc. Jpn. 1999, 72, 2345.

112 Viciu, M. S.; Germaneau, R. F.; Nolan, S. P. Org. Lett. 2002, 4, 4053.

113 Viciu, M. S.; Germaneau, R. F.; Navarro-Fernandez, O.; Stevens, E. D.; Nolan, S. P. Organometallics 2002, 21, 5470.

114 Singh, R.; Nolan, S. P. J. Organomet. Chem. 2005, 690, 5832.

115 Navarro, O.; Marion, N.; Scott, N. M.; Gonza'lez, J.; Amoroso, D.; Bell, A.; Nolan, S. P. Tetrahedron 2005, 61, 9716.

116 Schnyder, A.; Indolese, A. F.; Studer, M.; Blaser, H.-U. Angew. Chem., Int. Ed. 2002, 41, 3668.

117 Lavallo, V.; Canac, Y.; Prasang, C.; Donnadieu, B.; Bertrand, G. Angew. Chem., Int. Ed. 2005, 44, 5705.

118 Adjabeng, G.; Brenstrum, T.; Frampton, C. S.; Robertson, A. J.; Hillhouse, J.; McNulty, 
J.; Capretta, A. J. Org. Chem. 2004, 69, 5082.

119 Churruca, F.; SanMartin, R.; Tellitu, I.; Dominguez, E. Tetrahedron Lett. 2006, 47, 3233.

120 Schuster, E. M.; Botoshansky, M.; Gandelman, M. Angew. Chem., Int. Ed. 2008, 47, 4555.

121 Khartulyari, A. S.; Maier, M. E. Eur. J. Org. Chem. 2007, 317.

122 Ahman, J.; Wolfe, J. P.; Troutman, M. V.; Palucki, M.; Buchwald, S. L. J. Am. Chem. Soc. 1998, 120, 1918.

123 Chen, G.; Kwong, F. Y.; Chan, H. O.; Yu, W.-Y.; Chan, A. S. C. Chem. Commun. 2006, 1413.

124 Carril, M.; SanMartin, R.; Churruca, F.; Tellitu, I.; Dominguez, E. Org. Lett. 2005, 7, 4787.

125 Churruca, F.; SanMartin, R.; Tellitu, I.; Dominguez, E. Org. Lett. 2002, 4, 1591.

126 Churruca, F.; SanMartin, R.; Carril, M.; Tellitu, I.; Dominguez, E. Tetrahedron 2004, 60, 2393.

127 Gupta, M.; Nair, V. Tetrahedron Lett. 2005, 46, 1165.

128 Nicolaou, K. C.; Xu, H. Chem. Commun. 2006, 600.

129 Jira, R. In Applied Homogeneous Catalysis with Organometallic Compounds, 2nd ed.

(Eds.: B. Cornils, W. A. Herrmann), Wiley-VCH, Weinheim, 2002, 38.

130 Smidt, J.; Hafner, W.; Jira, R.; Sieber, R.; Sedlmeier, S.; Sabel, A. Angew. Chem. 1962, 74, 93.

131 Phillips F. C. Am. Chem. J. 1894, 16, 255.

132 Fahey, D. R.; Zeuch, E. A. J. Org. Chem. 1974, 39, 3276. 
Applications. Springer-Verlag Berlin Heidelberg, 2009, 564.

138 Keith, J. A.; Henry, P. M. Angew. Chem. Int. Ed. 2009, 48, 9038.

139

140

141

142

143

144

145 1980, 102, 1047.

146

147

148

149

150

151

Blot,V.; Tessier, A.; Planchat, A.; Jacquemin, D.; Dubreuil, D.; Pipelier, M. Eur. J. Org. Chem. 
2013, 7083.

152 Hansford, K. A.; Zanzarova, V.; Dörr, A.; Lubell. W. D. J. Comb. Chem. 2004, 6, 893.

153 Saroukou, M.; Skalski, T.; Skene W.G.; Lubell, W. D. Tetrahedron, 2014, 70, 450.

154 Sims E. A.; DeForest, C. A.; Anseth, K. S. Tetrahedron Lett. 2011, 52, 1871.

155 Michel, B. W.; Camelio, A. M.; Cornell, C. N.; Sigman, M. S.; J. Am. Chem. Soc. 2009, 131, 6076.

156 McCombs, J. R.; Michel, B. W.; Sigman, M. S. J. Org. Chem. 2011, 76, 3609.

157 Muzart, J. Tetrahedron 2007, 63, 7505.

158 Schnapperelle, I.; Hummel, W.; Gröger, H. Chem. Eur. J. 2012, 18, 1073.

159 Mitsudome, T.; Mitzumo, K.; Mizugaki, T.; Jitsukawa, K.; Kaneda, K. Angew. Chem. Int. Ed. 2010, 49, 1238.

160 Ross, J. P.; Couture, P.; Warkentin, J. Can. J. Chem. 1997, 75, 1331.

161 Cornell, C. N. ; Sigman, M. S. J. Am. Chem. Soc. 2005, 127, 2796.

162 Keinan, E.; Seth, K. K.; Lamed, R. J. Am. Chem. Soc. 1986, 108, 3474.

163 Okuro, K.; Gurnham, J.; Alper, H. J. Org. Chem. 2011, 76, 4715.

164 Gruber, M.; Chouzier, S.; Koehler, K.; Djakovitch, L. Applied Catalysis A: 2004, 265, 161.

165 Kulkarni, M. G.; Shaikh, Y. B.; Borhade, A. S.; Chavan, S. W.; Dhondge, A. P.; Gaikwad, D. D.; Desai, M. P.; Birhade, D. R.; Dhatrak, N. R. Tetrahedron Lett. 2013, 54, 2293.

166 Zhang, G.; Xie, X.; Wang, Y.; Wen, X.; Zhao, Y.; Ding, C. Org. Biomol. Chem. 2013, 11, 2947.

167 Thimmaiah, M.; Zhang, X.; Fang, S. Tetrahedron Lett. 2008, 49, 5605. 
Org. Lett. 2013, 15, 2062.

173 Gopinath, R.; Haque, S. J.; Patel, B. K. J. Org. Chem. 2002, 67, 5842.

174 Aridoss, G.; Laali, K. K. J. Org. Chem. 2011, 76, 8088.

175

Org. Chem. 2001, 14, 859.

177 Aridoss, G.; Laali, K. K. J. Org. Chem. 2011, 76, 8088.

178 295.

179 Hering, T.; Hari, D. P.; König, B. J. Org. Chem. 2012, 77, 10347.

180 Ito, S.; Hayashi, A.; Komai, H.; Yamaguchi, H.; Kubota, Y.; Asami, M. Tetrahedron 2011, 67, 2081.

181 Bovicelli, P.; Sanetti, A. Tetrahedron 1996, 52, 10969.

182

183

184

185

Meurer, E. C.; Gozzo, F. C.; Augusti, R.; Eberlin, M. N. Eur. J. Mass. Spectrom. 2003, 9,

Broos, R. Bulletin des Societes Chimiques Belges 1986, 95,135.

Hering, T.; Hari, D. P.; König, B. J. Org. Chem. 2012, 77, 10347.

Ross, J. P.; Couture, P.; Warkentin, J. Can. J. Chem. 1997, 75, 131.

Gallardo, I., Guirado, G.; Marquet, J. J. Org. Chem. 2003, 68, 7334. 
Pamukcu, R.; Paizza, G. A. 2002, US 6410584 [CAN137:47109].

187

Conner, S. E.; Mantio, N. B.; Zhu, G.; Herr, R. J. PCT Int. Appl. 2005, 2005066136. [CAN 143:153366].

188 Molinaro, C.; Mowat, J.; Gosselin, F.; O’Shea, P.; Marcoux, J. -F.; Angelaud, R.; Davies, I. W. J. Org. Chem. 2007, 72, 1856.

189 Fürstner, A.; Jumbam, D. N.; Seidel, G. Chem. Ber. 1994, 127, 1125.

190 Neudorffer, A.; Mueller, M.; Martinez, C. -M.; Mechan, A.; McCann, U.; Ricaurte, G. A.; Largeron. M. Chem. Res. Toxicol. 2011, 24, 968.

191 Joshi, B. P.; Sharma, A.; Sinha, A. K. Can. J. Chem. 2005, 83, 1826.

192 Raucher, S.; Koolpe, G. A. J. Org. Chem. 1983, 48, 2066.

193 Eynard, T.; Franc, C. PCT Int. Appl. 2006, WO 2006120031 [CAN145:505444].

194 Pirrung, M. C.; Liu, Y.; Deng, L.; Halstead, D. K.; Li, Z.; May, J. F.; Wedel, M.; Austin, D. A.; Webster, N. J. G. J. Am. Chem. Soc. 2005, 127, 4609.

195 Sundberg, R. J. J. Org. Chem. 1965, 30, 3604.

196 Viswanathan, R.; Prabhakaran, E. N.; Plotkin, M. A.; Johnston, J. N. J. Am. Chem. Soc. 2003, 125, 163.

197 Martin, C.; Mailliet, P.; Maddaluno, J. J. Org. Chem. 2001, 66, 3797.

198 Mitsudome, T.; Umetami, T.; Nosaka, N.; Mori, K.; Mizugaki, T.; Ebitani, K.; Kaneda, K. Angew. Chem. Int. Ed. 2006, 45, 481.

199 Thimmaiah, M.; Zhang, X.; Fang, S. Tetrahedron Lett. 2008, 49, 5605. 


\section{Appendix}

\section{${ }^{1} \mathrm{H}$ and ${ }^{13} \mathrm{C}$ NMR Spectra}

- $\quad{ }^{1} \mathrm{H}$ and ${ }^{13} \mathrm{C}$ NMR for Chapter 1: Ring-expansion of 4-ethynyl-4-hydroxy-2,3substituted-2-cyclobuten-1-ones

- ${ }^{1} \mathrm{H}$ and ${ }^{13} \mathrm{C}$ NMR for Chapter 2: Total synthesis of methyl linderone

- $\quad{ }^{1} \mathrm{H}$ and ${ }^{13} \mathrm{C}$ NMR for Chapter 3: Wacker-type oxidation of aryl-substituted alkenes

208 
${ }^{1} \mathrm{H}$ and ${ }^{13} \mathrm{C}$ for Chapter 1

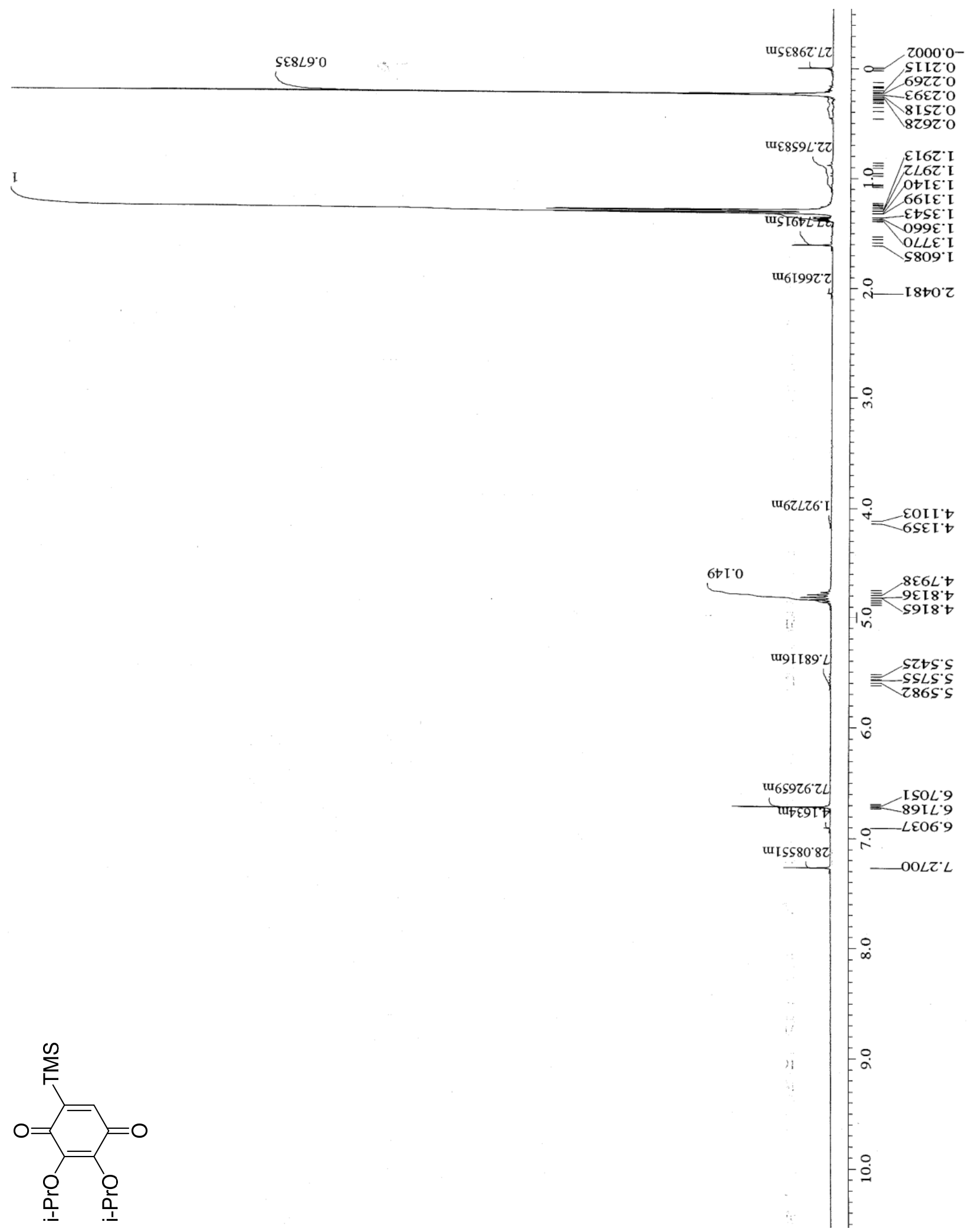

Figure 17: ${ }^{1} \mathrm{H}$ NMR of 2,3-bis(1-methylethoxy)-5-trimethylsilyl-2,5-cyclohexadiene- 


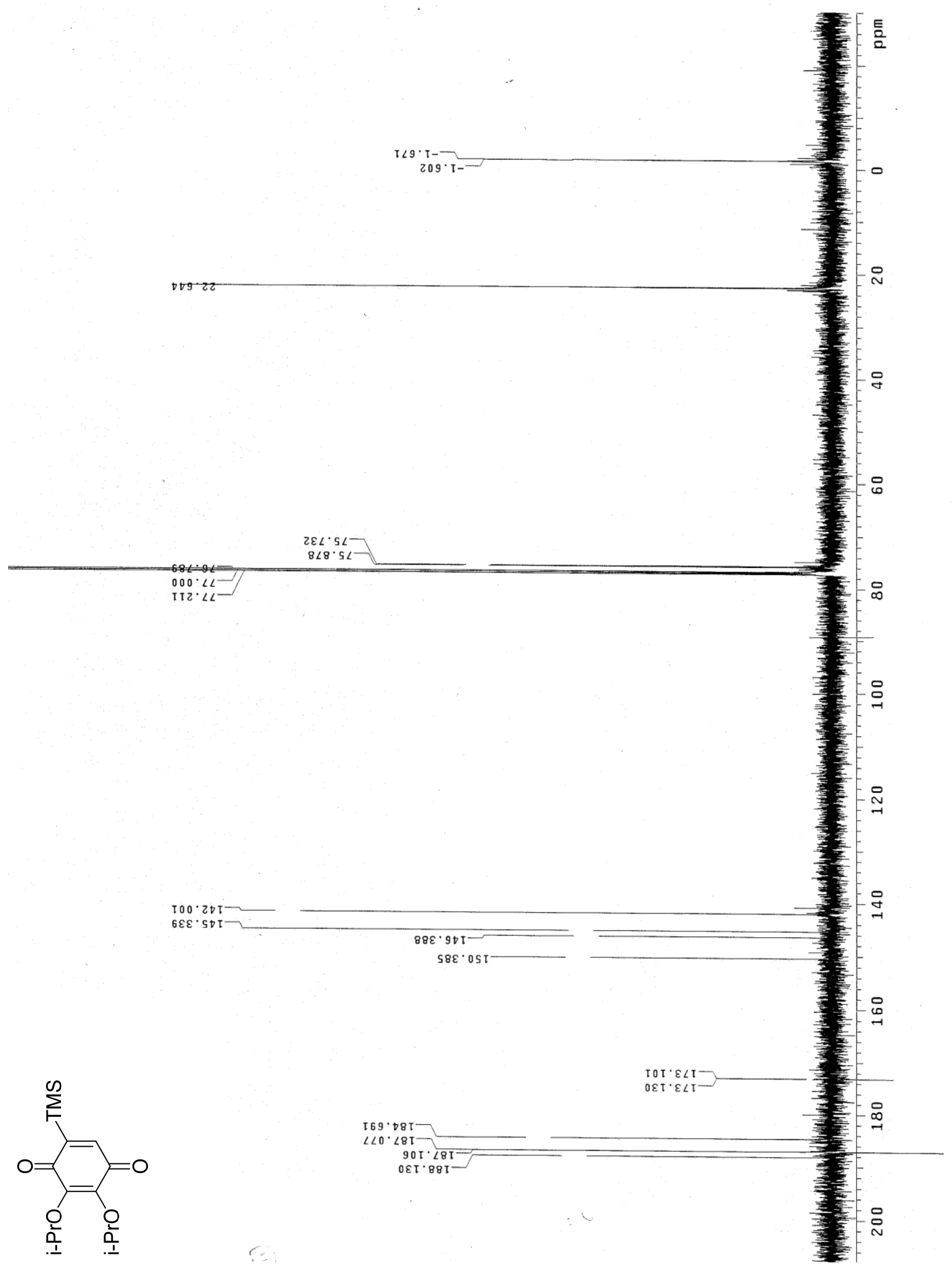

Figure 18: ${ }^{13} \mathrm{C}$ NMR of 2,3-bis(1-methylethoxy)-5-trimethylsilyl-2,5-cyclohexadiene- 


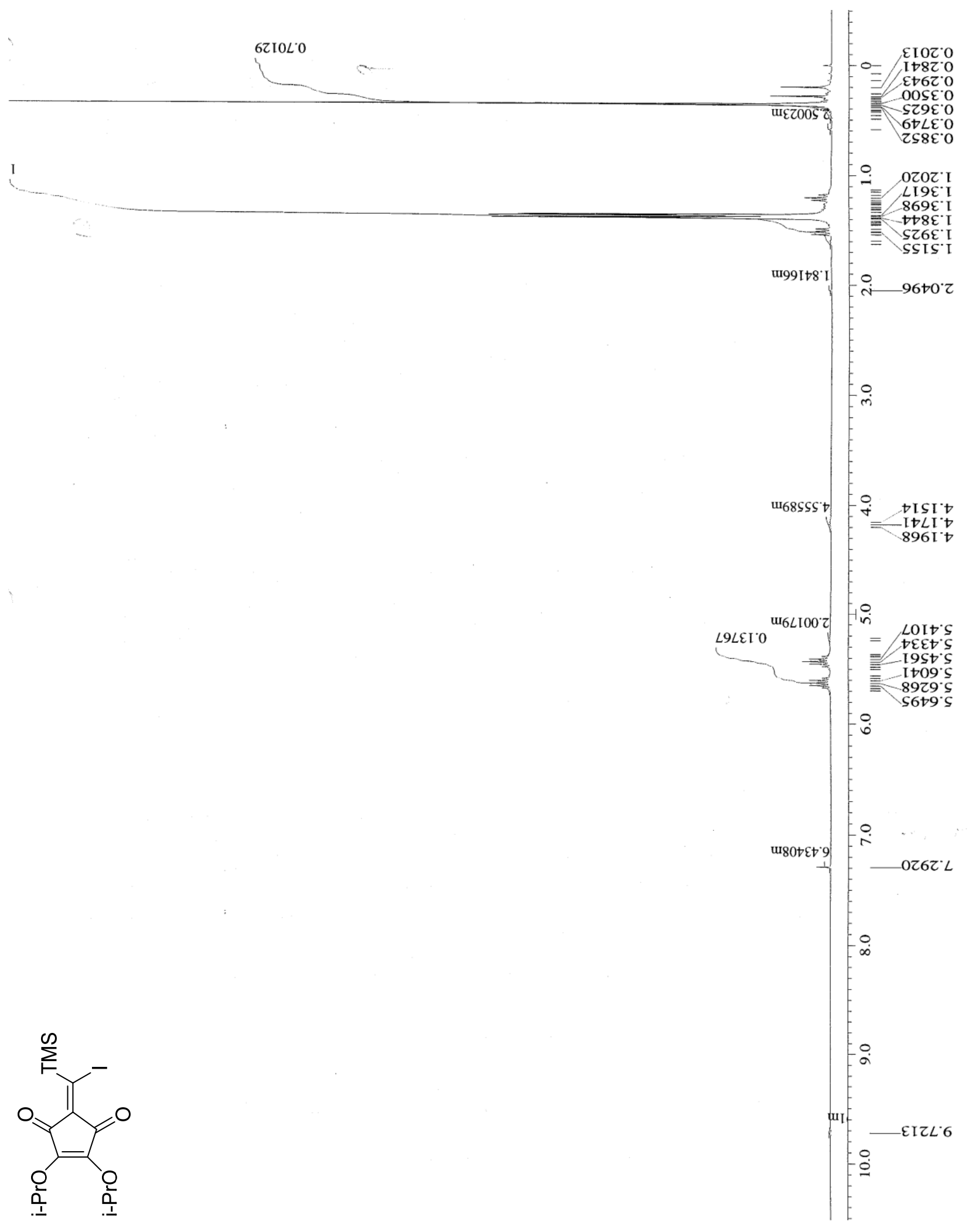

Figure 19: ${ }^{1} \mathrm{H}$ NMR of 2-(1-iodo-1-trimethylsilylmethylene)-4,5-bis(1-methylethoxy)-

4-cyclopentene-1,3-dione (71) 


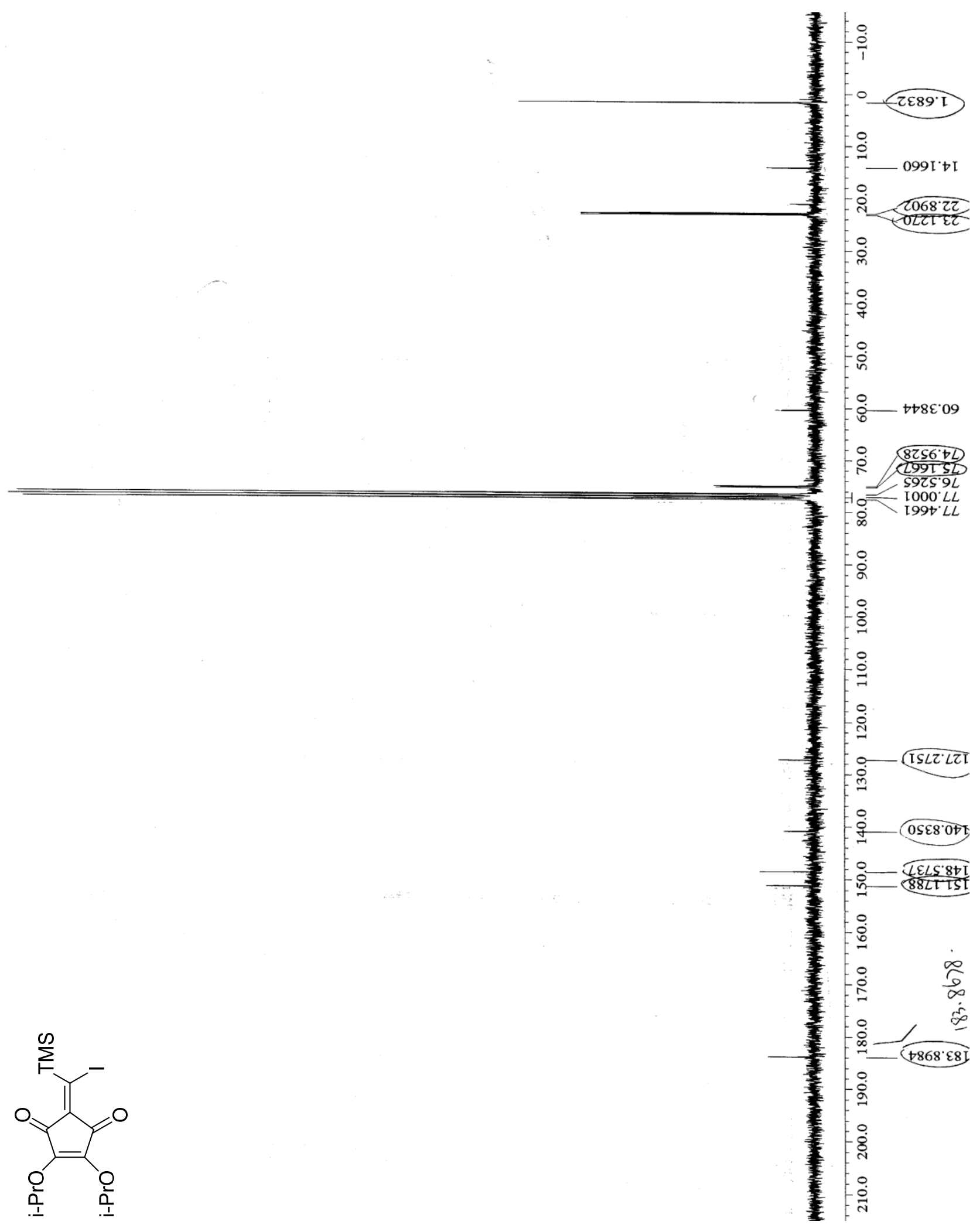

Figure 20: ${ }^{13} \mathrm{C}$ NMR of 2-(1-iodo-1-trimethylsilylmethylene)-4,5-bis(1-methylethoxy)-

4-cyclopentene-1,3-dione (71) 


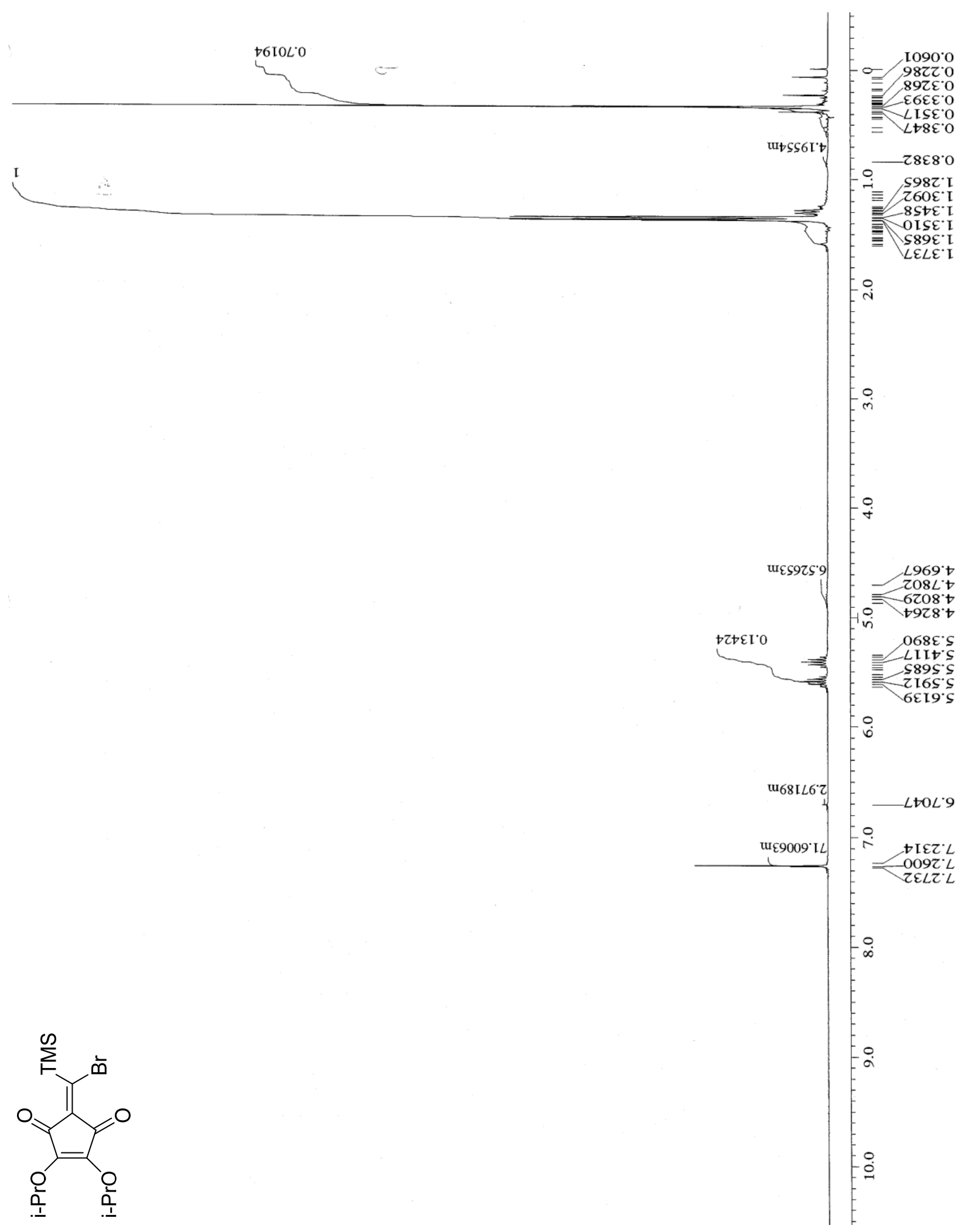

Figure 21: ${ }^{1} \mathrm{H}$ NMR of 2-(1-bromo-1-trimethylsilylmethylene)-4,5-bis(1-methylethoxy)-4-

cyclopentene-1,3-dione (72) 


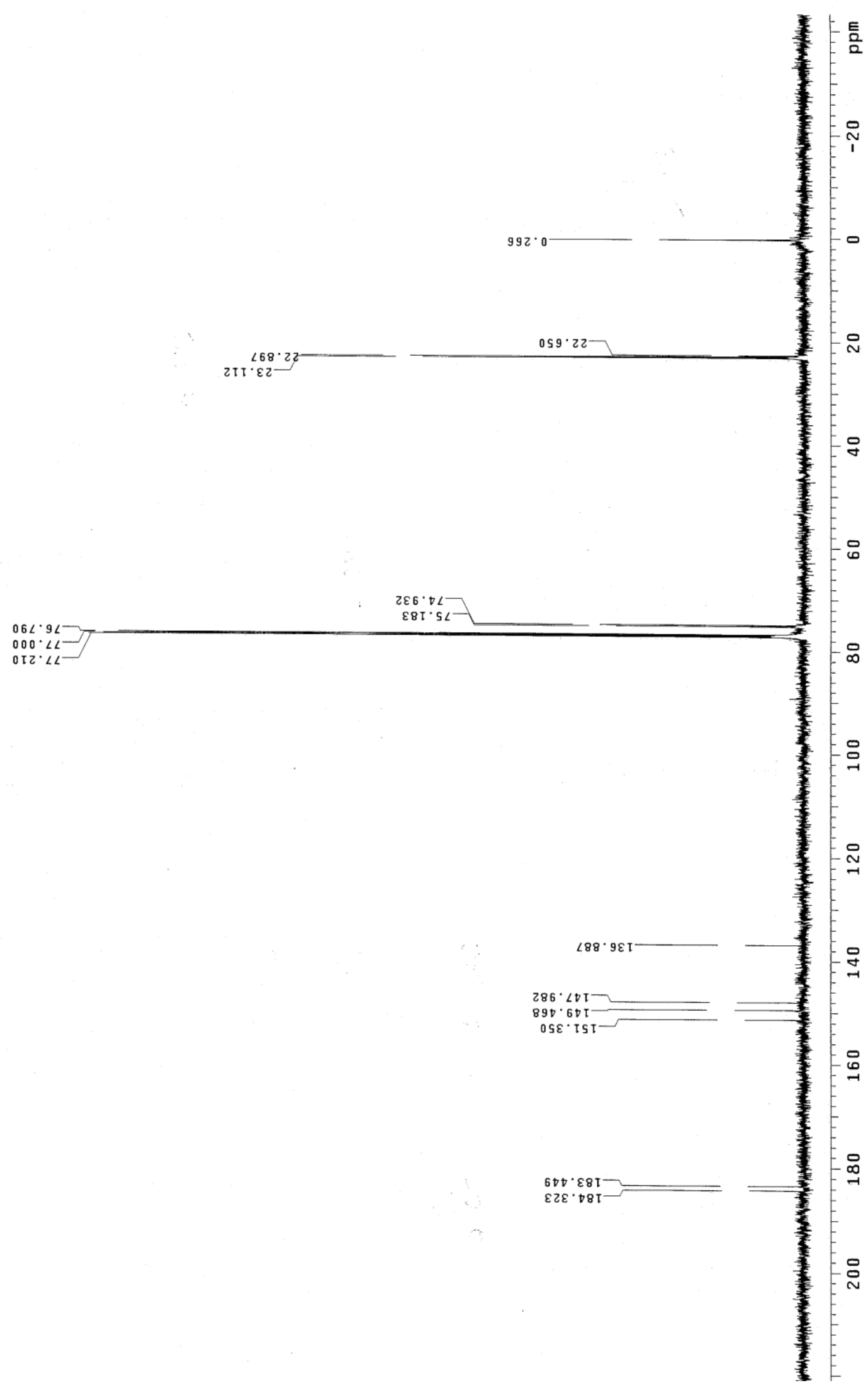

Figure 22: ${ }^{13} \mathrm{C}$ NMR of 2-(1-bromo-1-trimethylsilylmethylene)-4,5-bis(1-methylethoxy)-4-

cyclopentene-1,3-dione (72) 


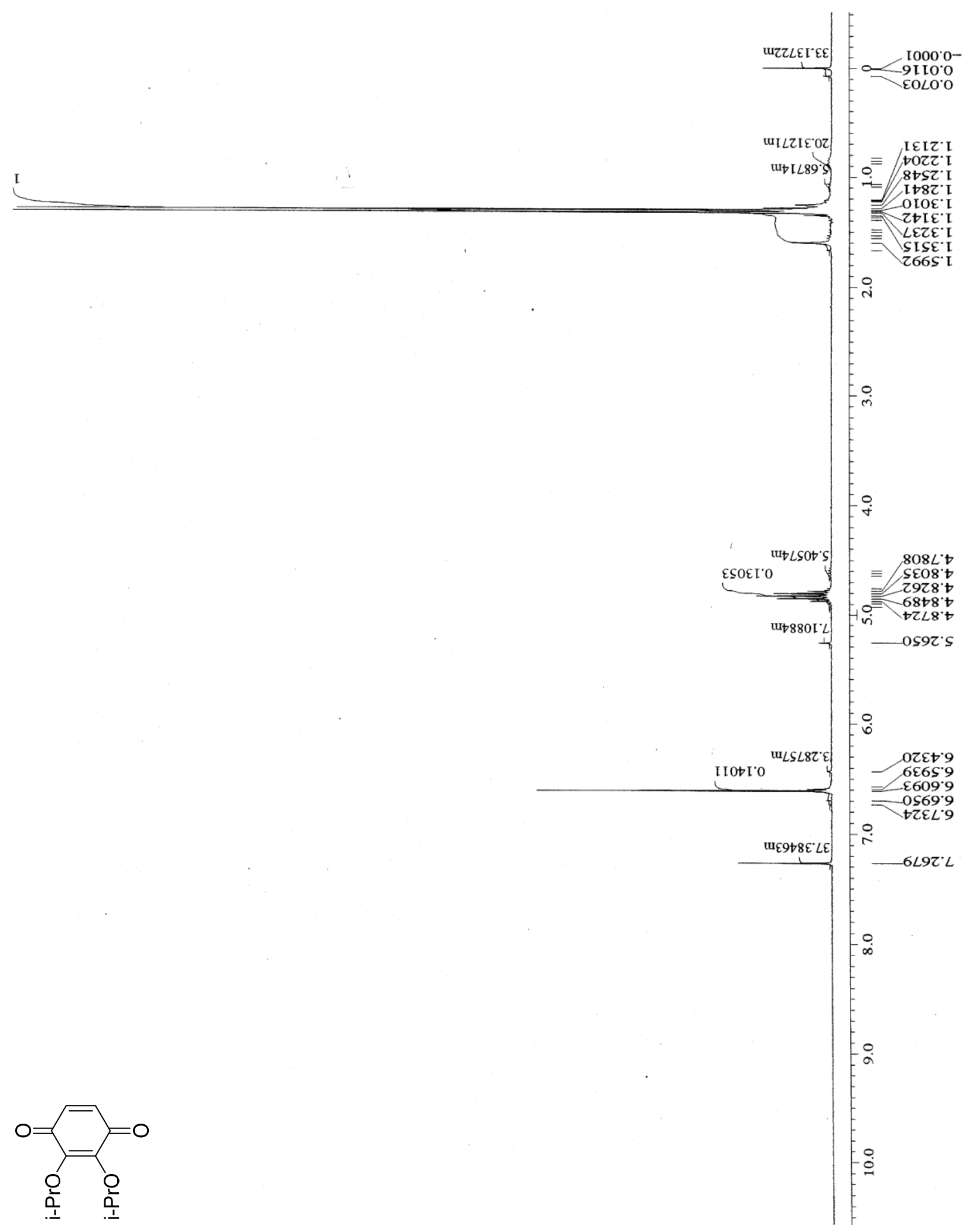

Figure 23: ${ }^{1} \mathrm{H}$ NMR of 2,3-bis(1-methylethoxy)-2,5-cyclohexadiene-1,4-dione (74) 


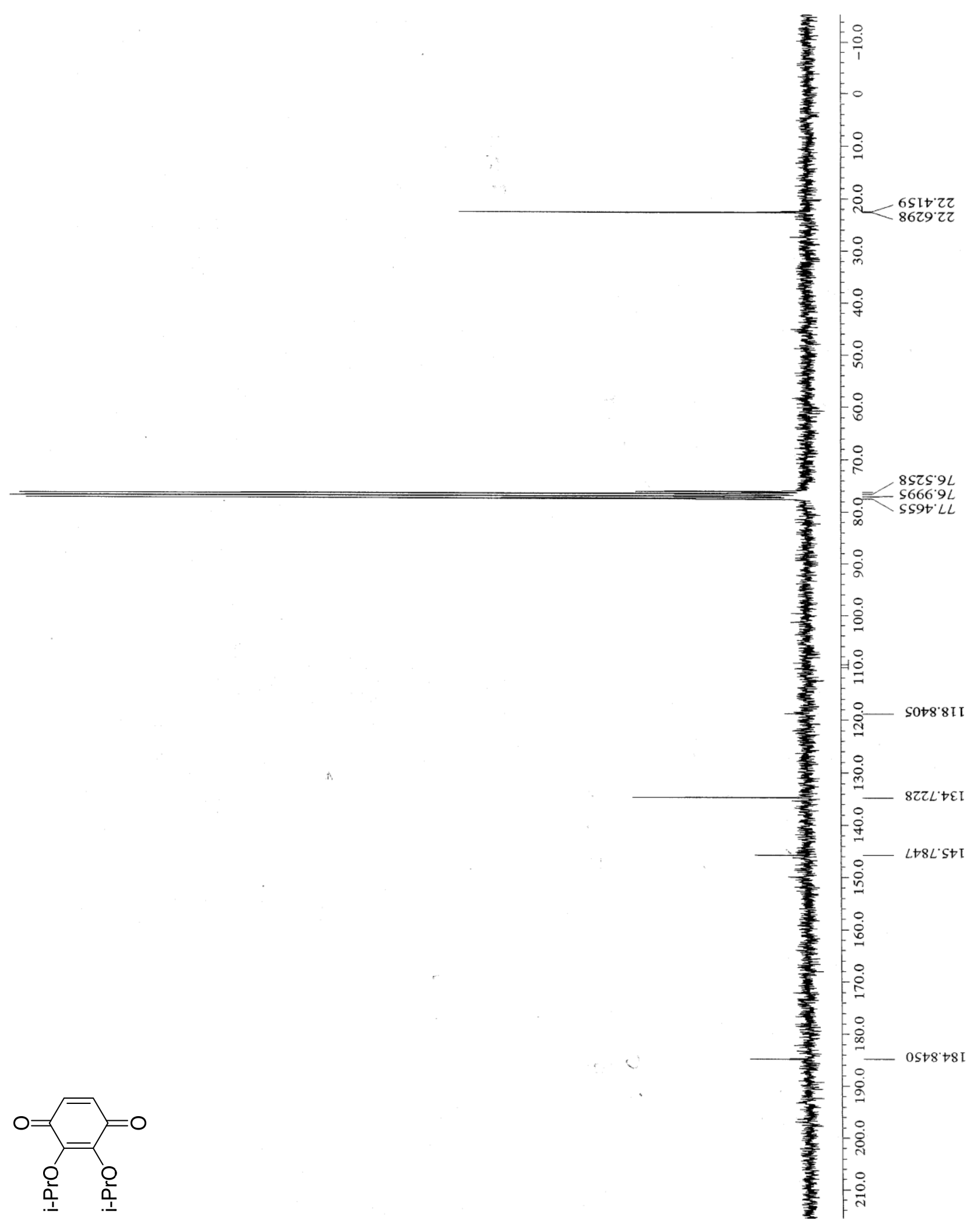

Figure $24:{ }^{13} \mathrm{C}$ NMR of 2,3-bis(1-methylethoxy)-2,5-cyclohexadiene-1,4-dione (74) 


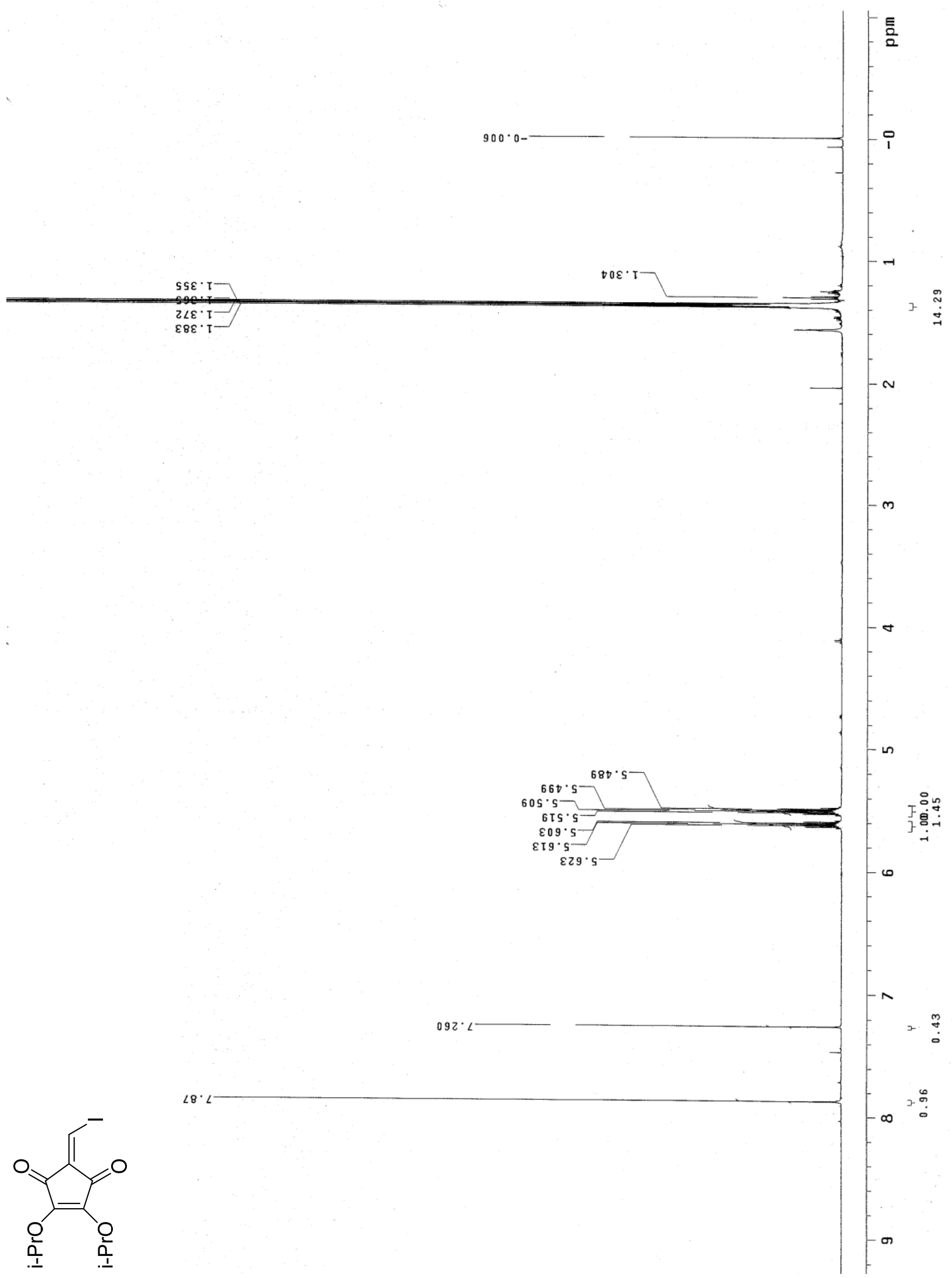

Figure 25: ${ }^{1} \mathrm{H}$ NMR of 2-(iodomethylene)-4,5-bis(1-methylethoxy)-4-cyclopentene- 


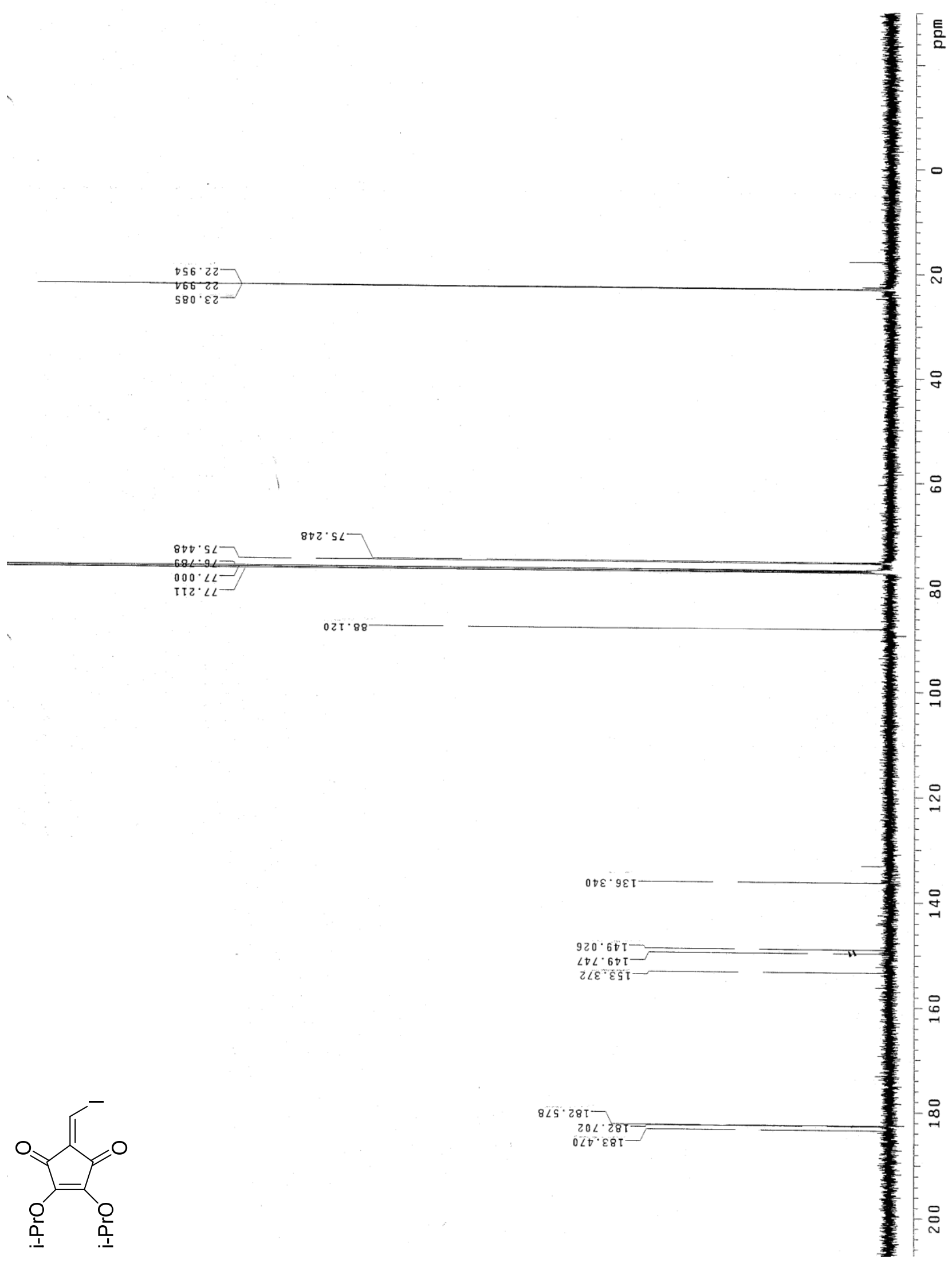

Figure 26: ${ }^{13} \mathrm{C}$ NMR of 2-(iodomethylene)-4,5-bis(1-methylethoxy)-4-cyclopentene- 


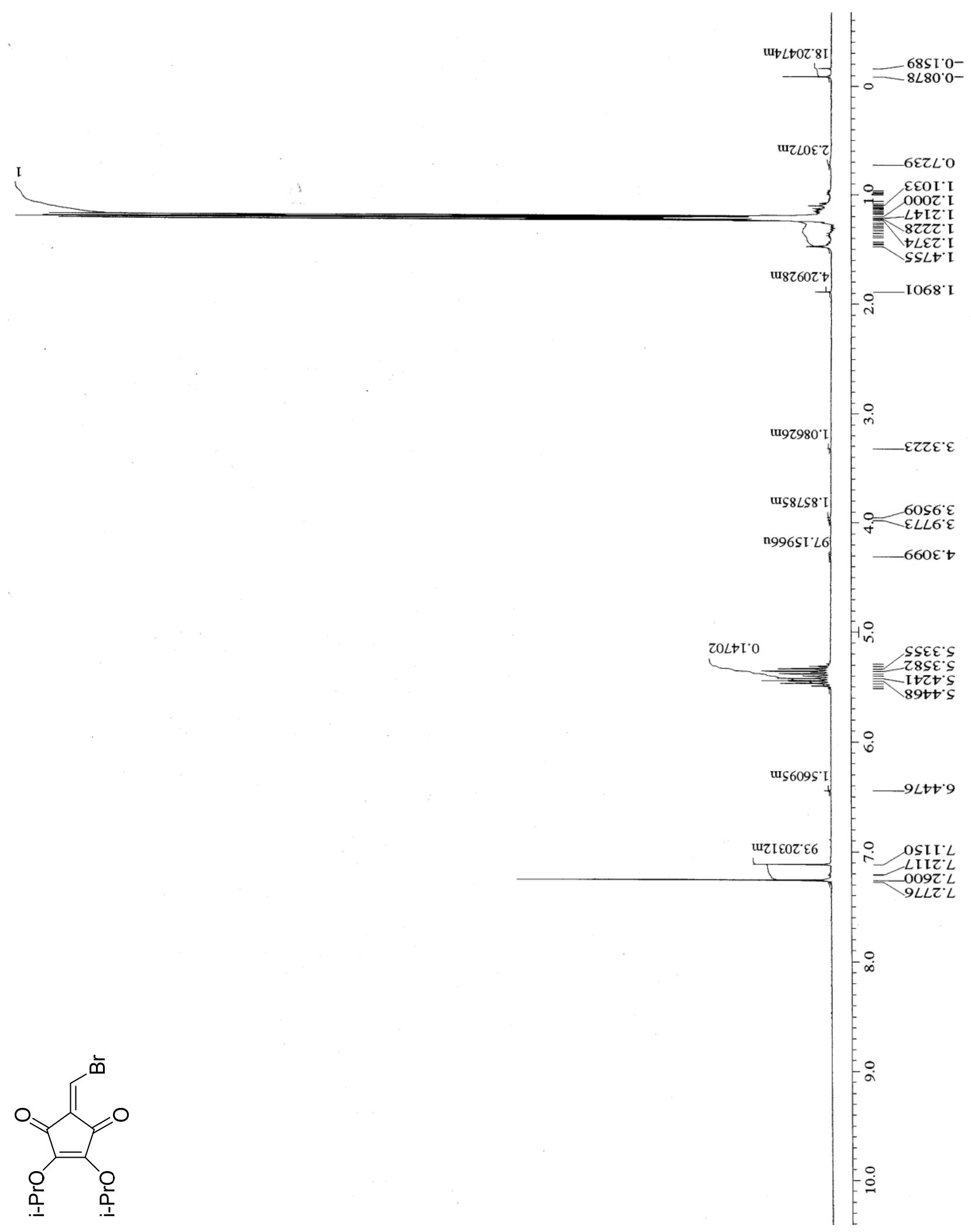

Figure 27: ${ }^{1} \mathrm{H}$ NMR of 2-(bromomethylene)-4,5-bis(1-methylethoxy)-4-cyclopentene-

1,3-dione (76) 


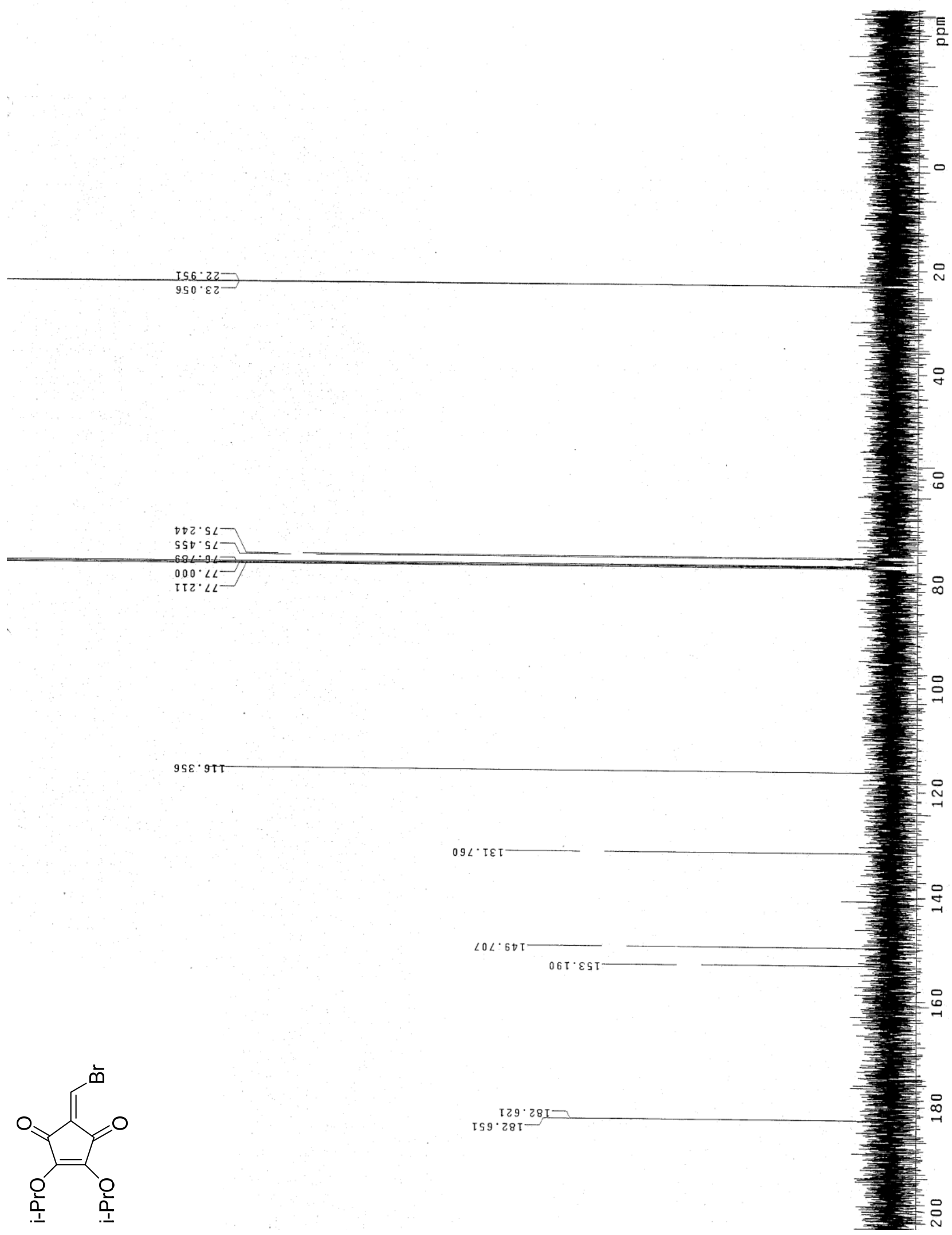

Figure 28: ${ }^{13} \mathrm{C}$ NMR of 2-(bromomethylene)-4,5-bis(1-methylethoxy)-4-cyclopentene-

1,3-dione (76) 


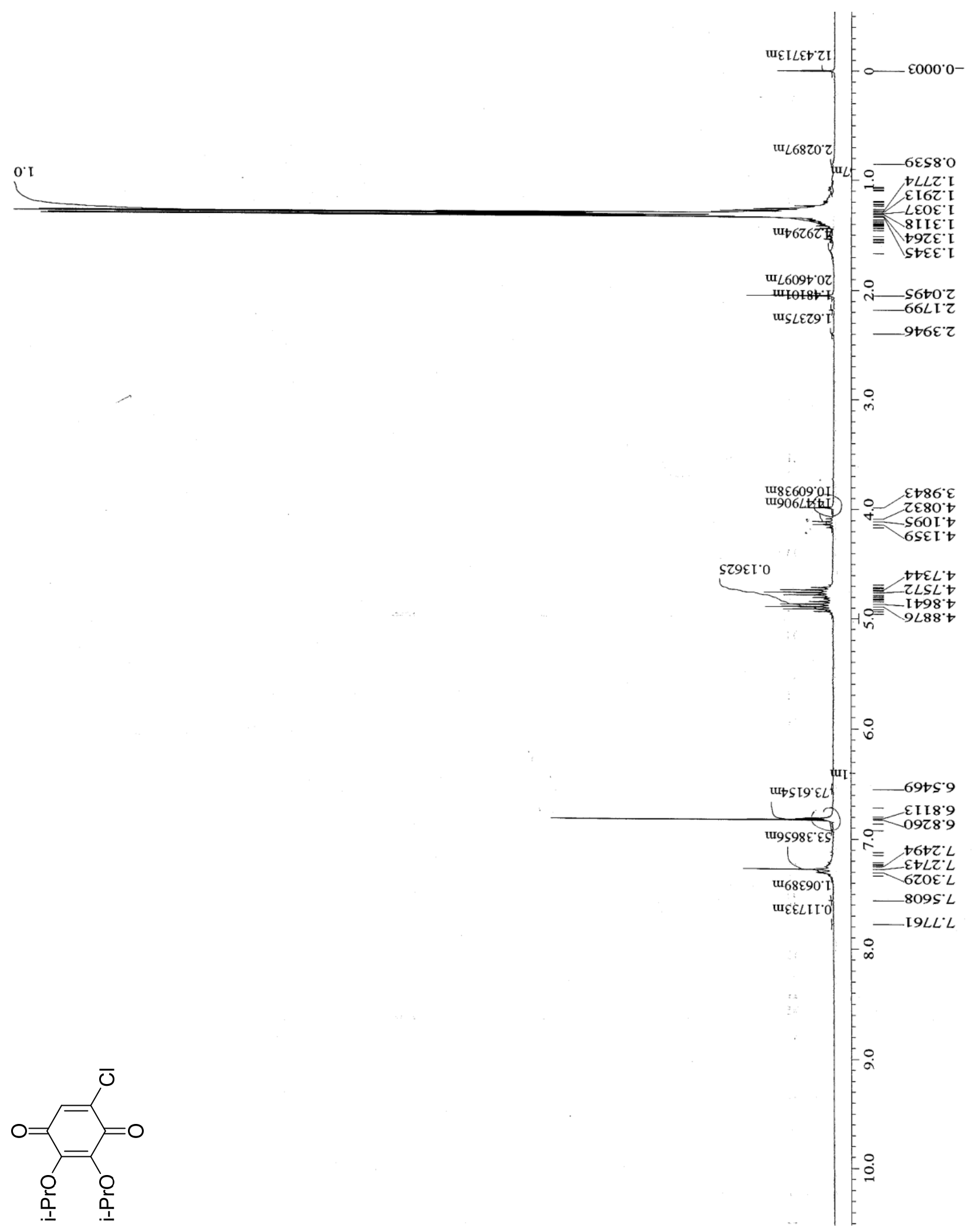

Figure 29: ${ }^{1} \mathrm{H}$ NMR of 5-chloro-2,3-bis(1-methylethoxy)-2,5-cyclohexadiene-1,4-dione (77) 


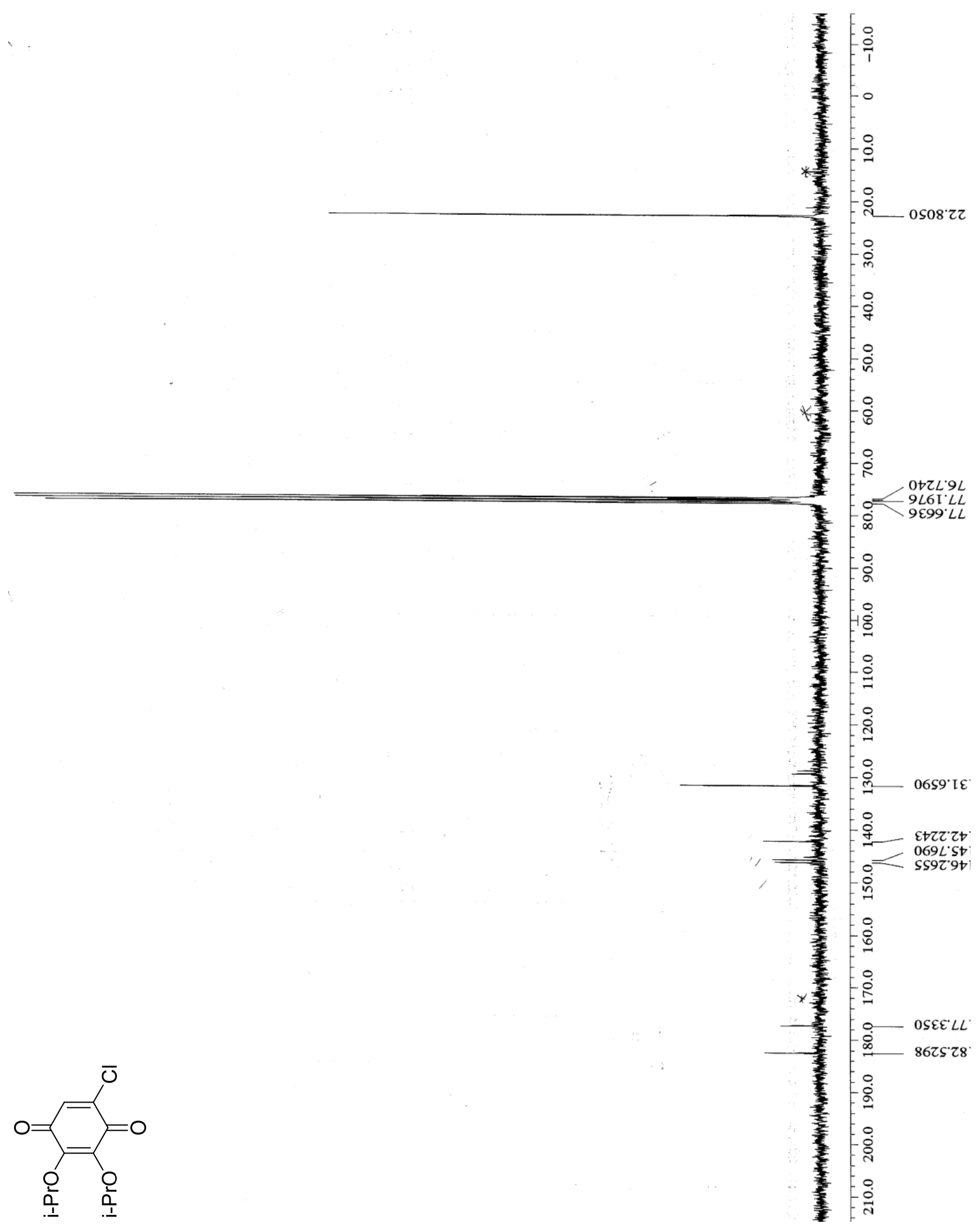

Figure 30: ${ }^{13} \mathrm{C}$ NMR of 5-chloro-2,3-bis(1-methylethoxy)-2,5-cyclohexadiene-1,4-dione (77) 


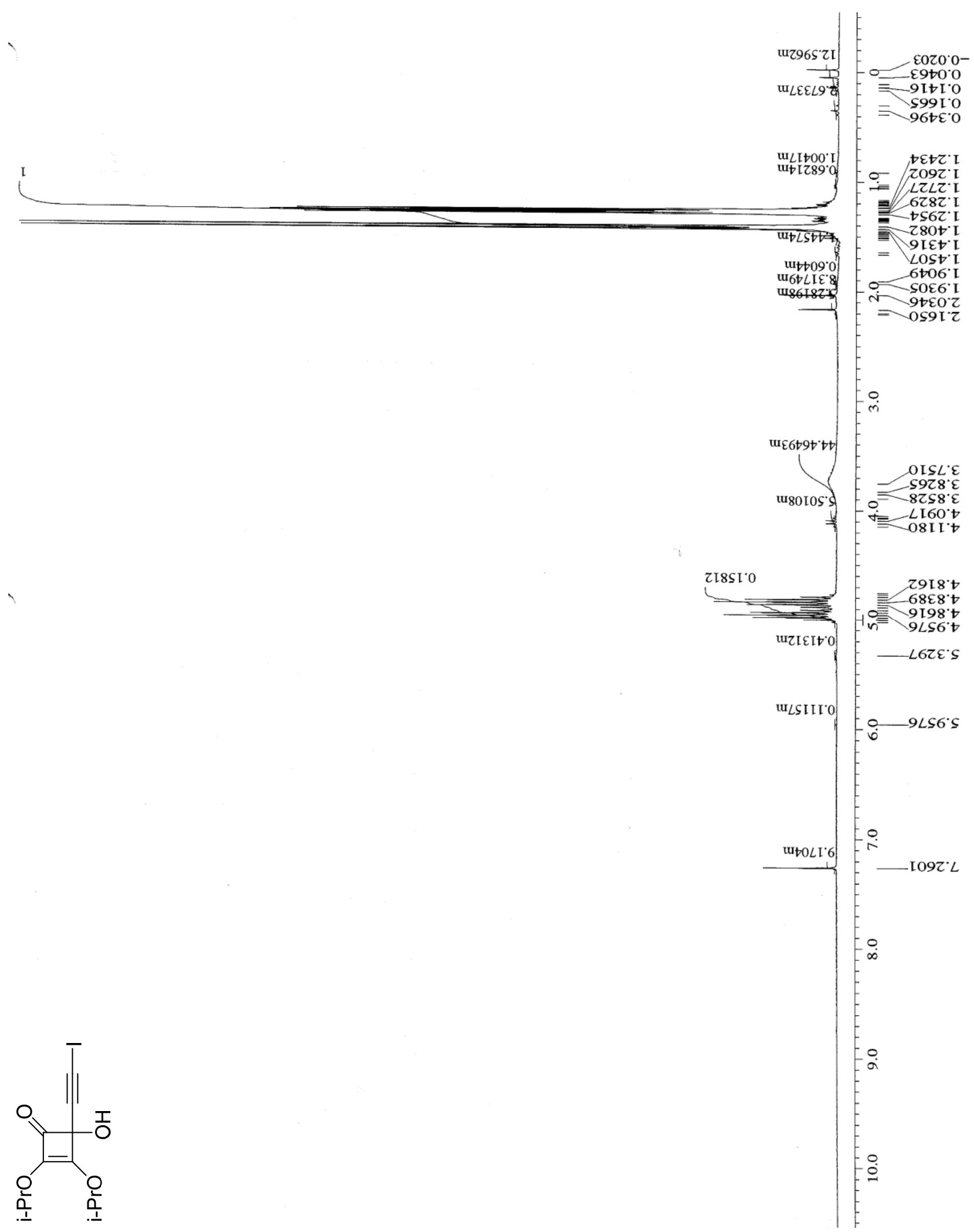

Figure 31: ${ }^{1} \mathrm{H}$ NMR of 4-hydroxy-2,3-bis(1-methylethoxy)-4-(2-iodoethynyl)-2-

cyclobutene-1-one (78) 


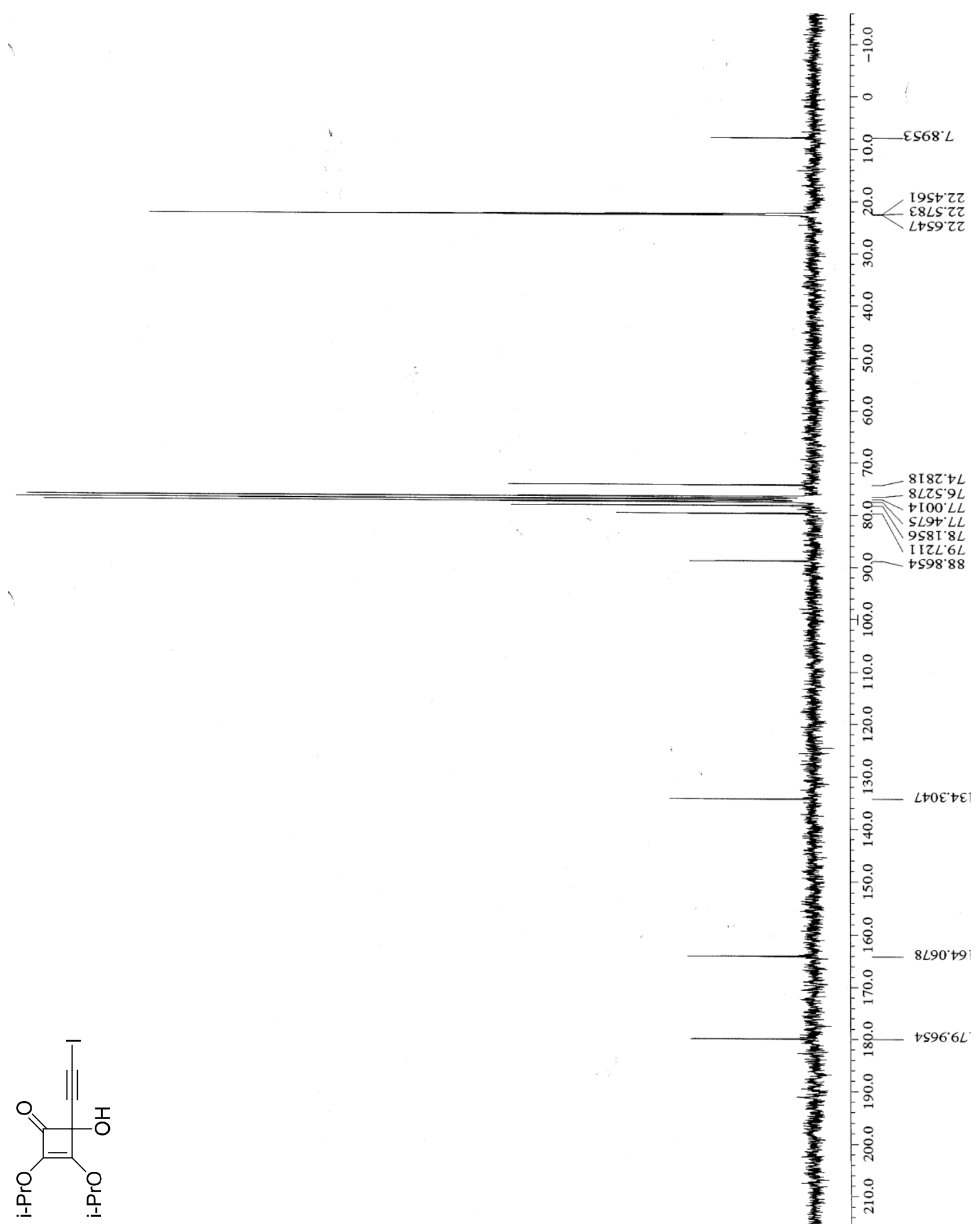

Figure 32: ${ }^{13} \mathrm{C}$ NMR of 4-hydroxy-2,3-bis(1-methylethoxy)-4-(2-iodoethynyl)-2-

cyclobutene-1-one (78) 


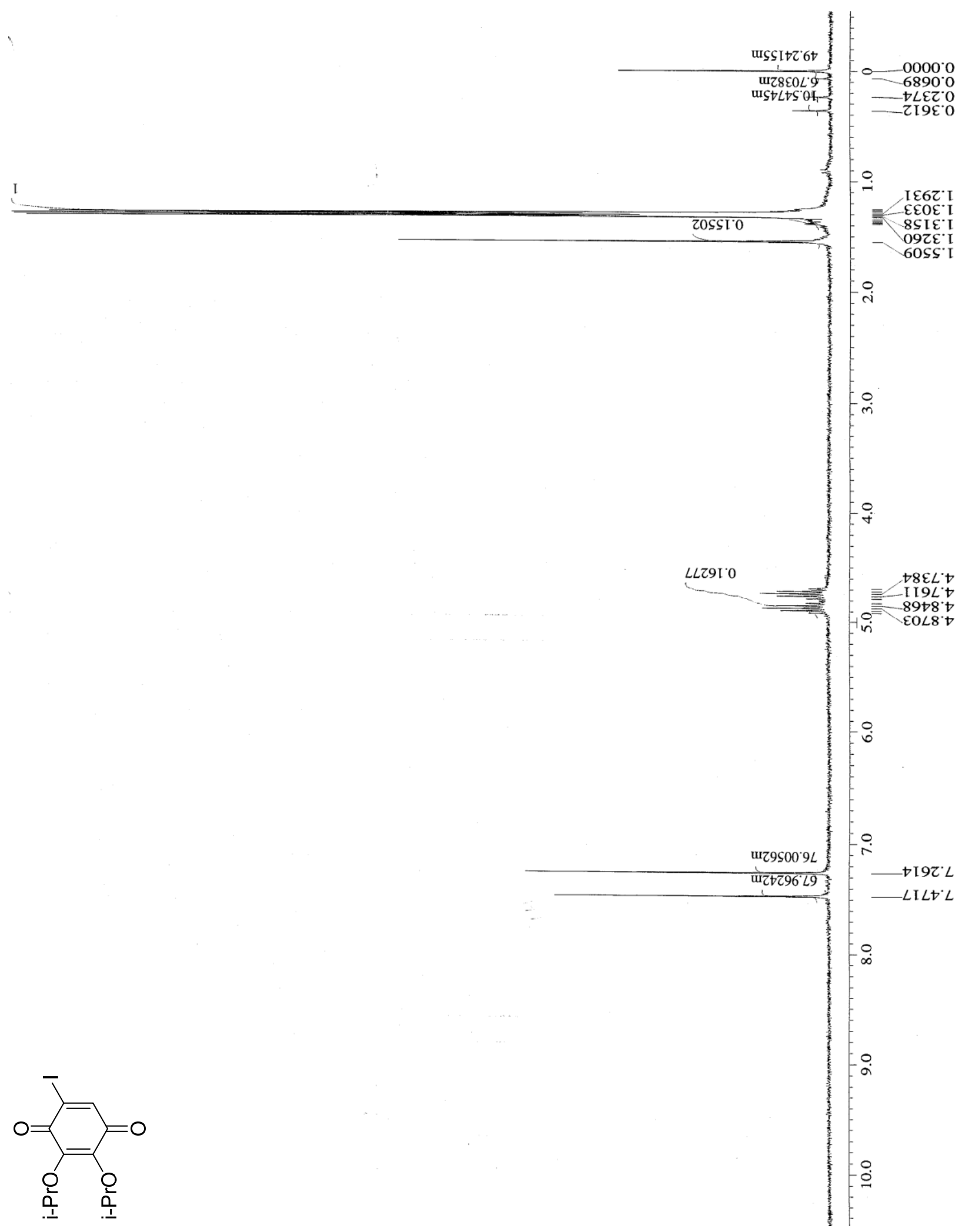

Figure 33: ${ }^{1} \mathrm{H}$ NMR of 5-iodo-2,3-bis(1-methylethoxy)-2,5-cyclohexadiene-1,4-dione (79) 


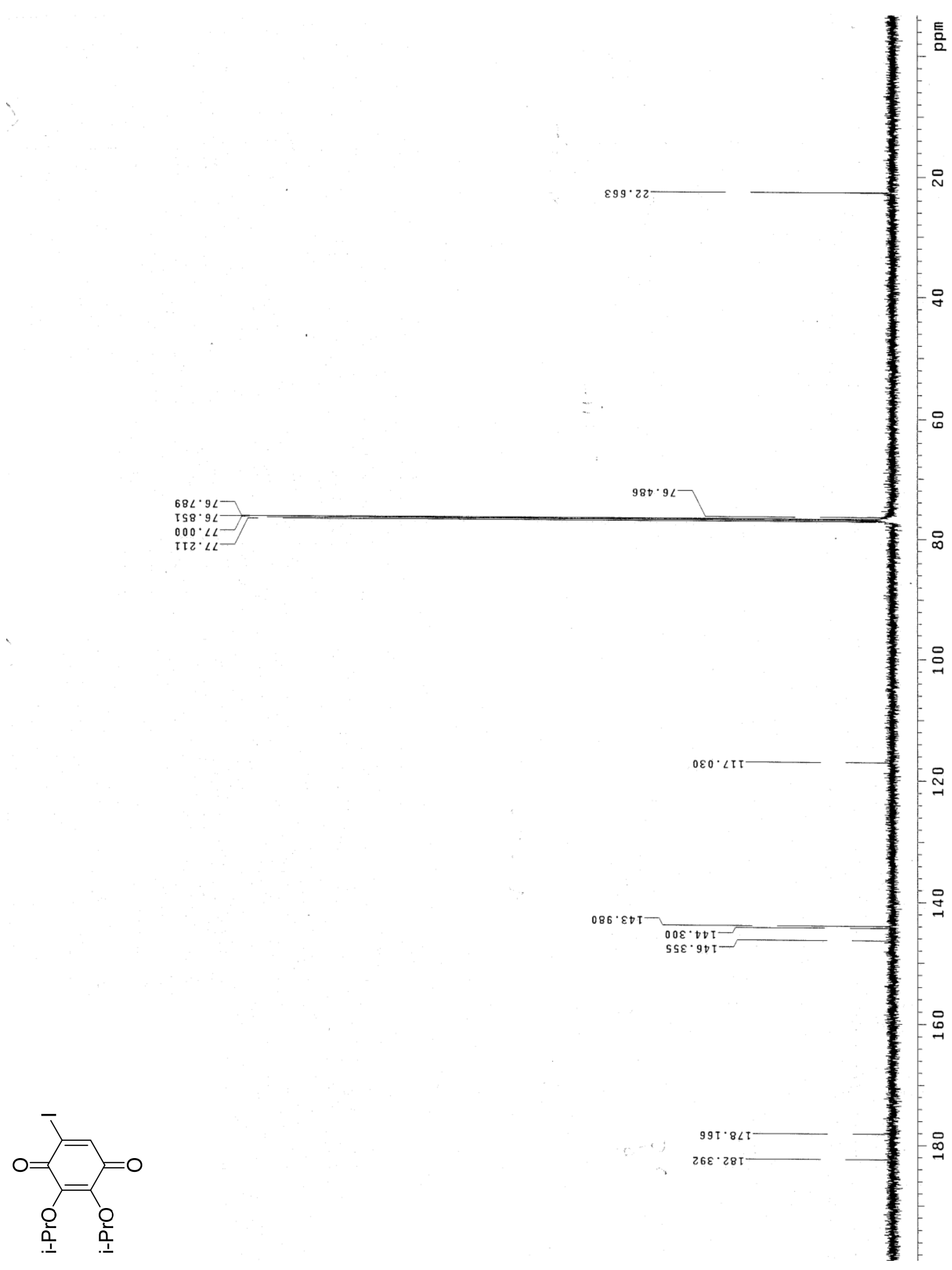

Figure 34: ${ }^{13} \mathrm{C}$ NMR of 5-iodo-2,3-bis(1-methylethoxy)-2,5-cyclohexadiene-1,4-dione (79) 


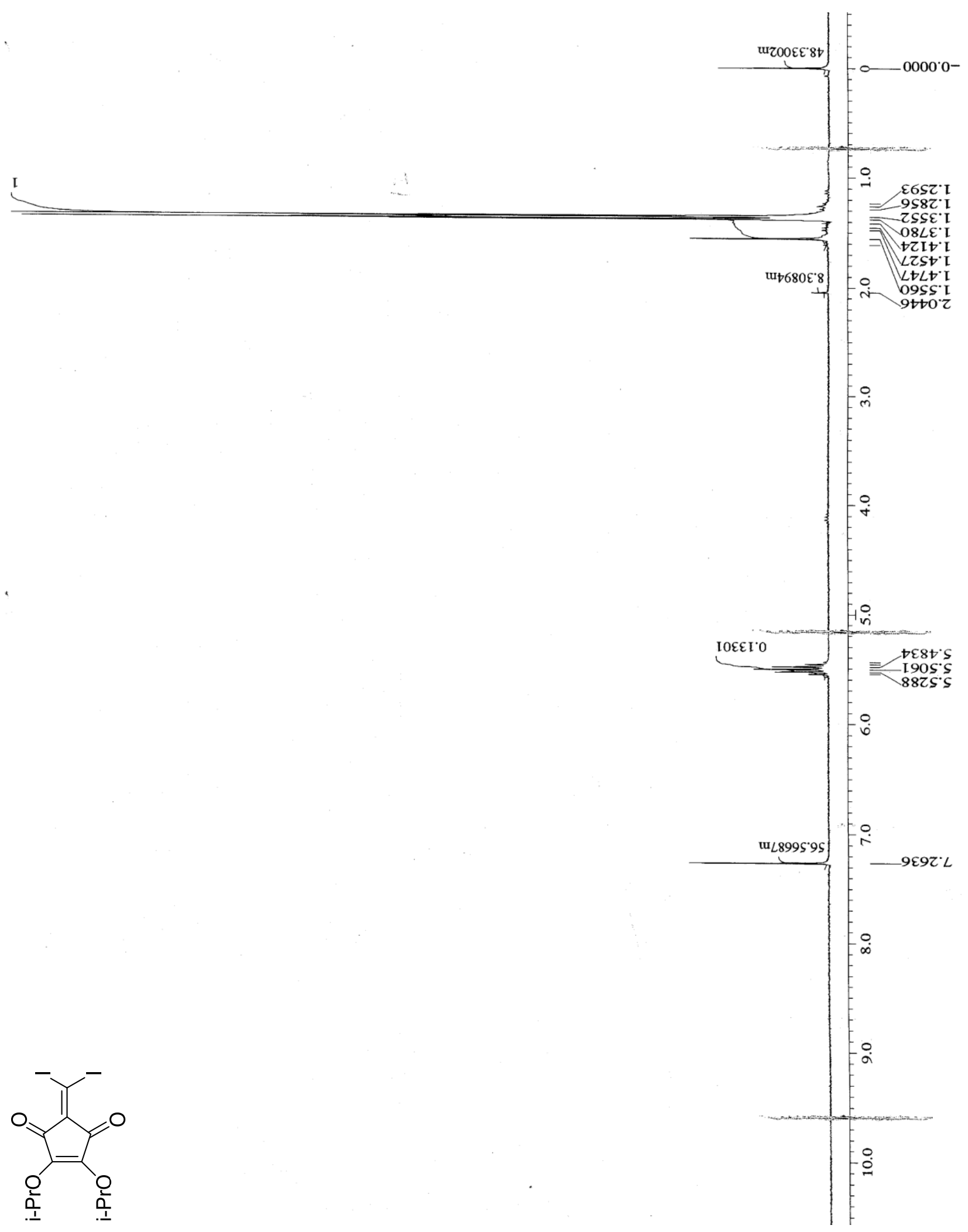

Figure 35: ${ }^{1} \mathrm{H}$ NMR of 2-(diiodomethylene)-4,5-bis(1-methylethoxy)-4-cyclopentene-

1,3-dione (80) 


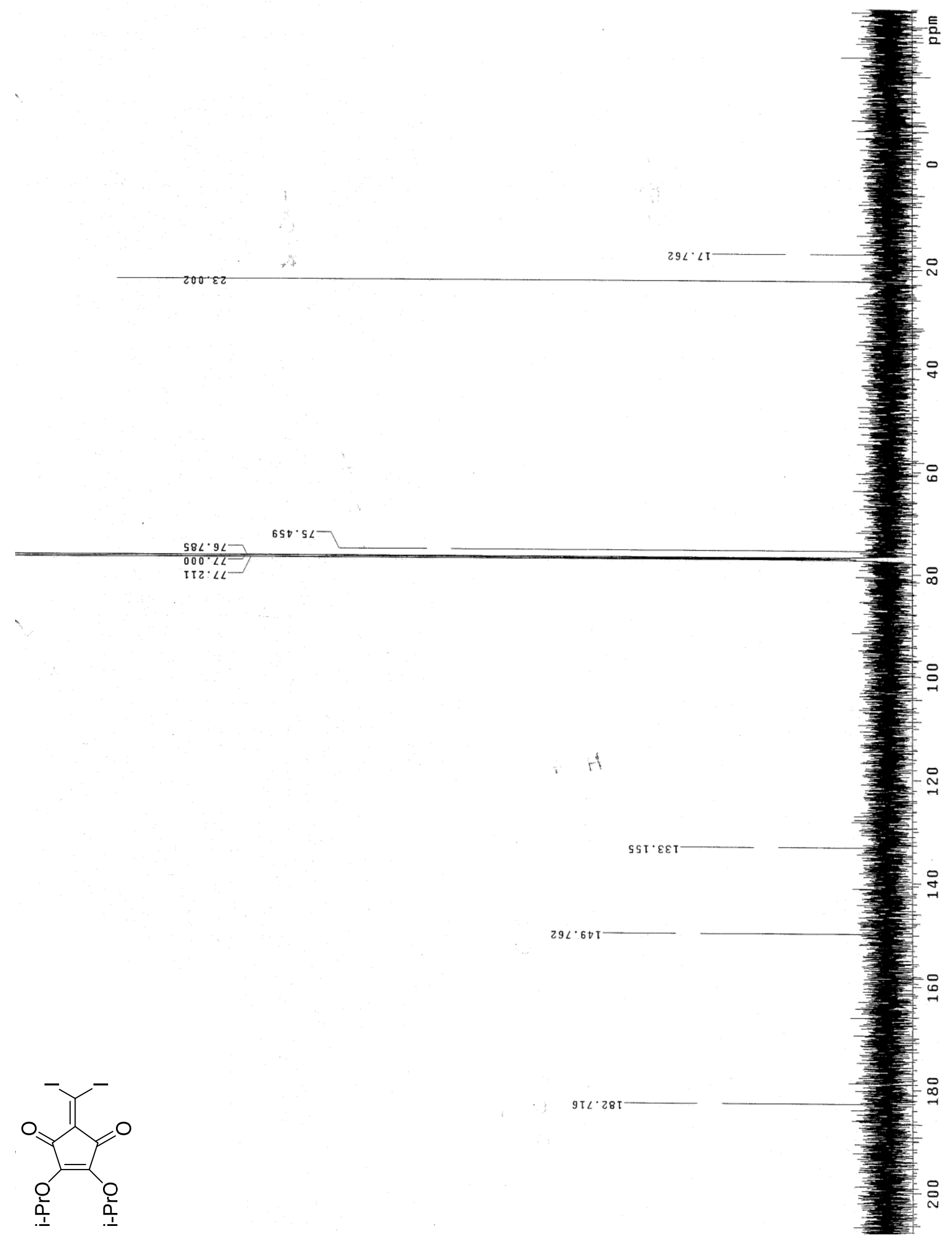

Figure 36: ${ }^{13} \mathrm{C}$ NMR of 2-(diiodomethylene)-4,5-bis(1-methylethoxy)-4-cyclopentene- 


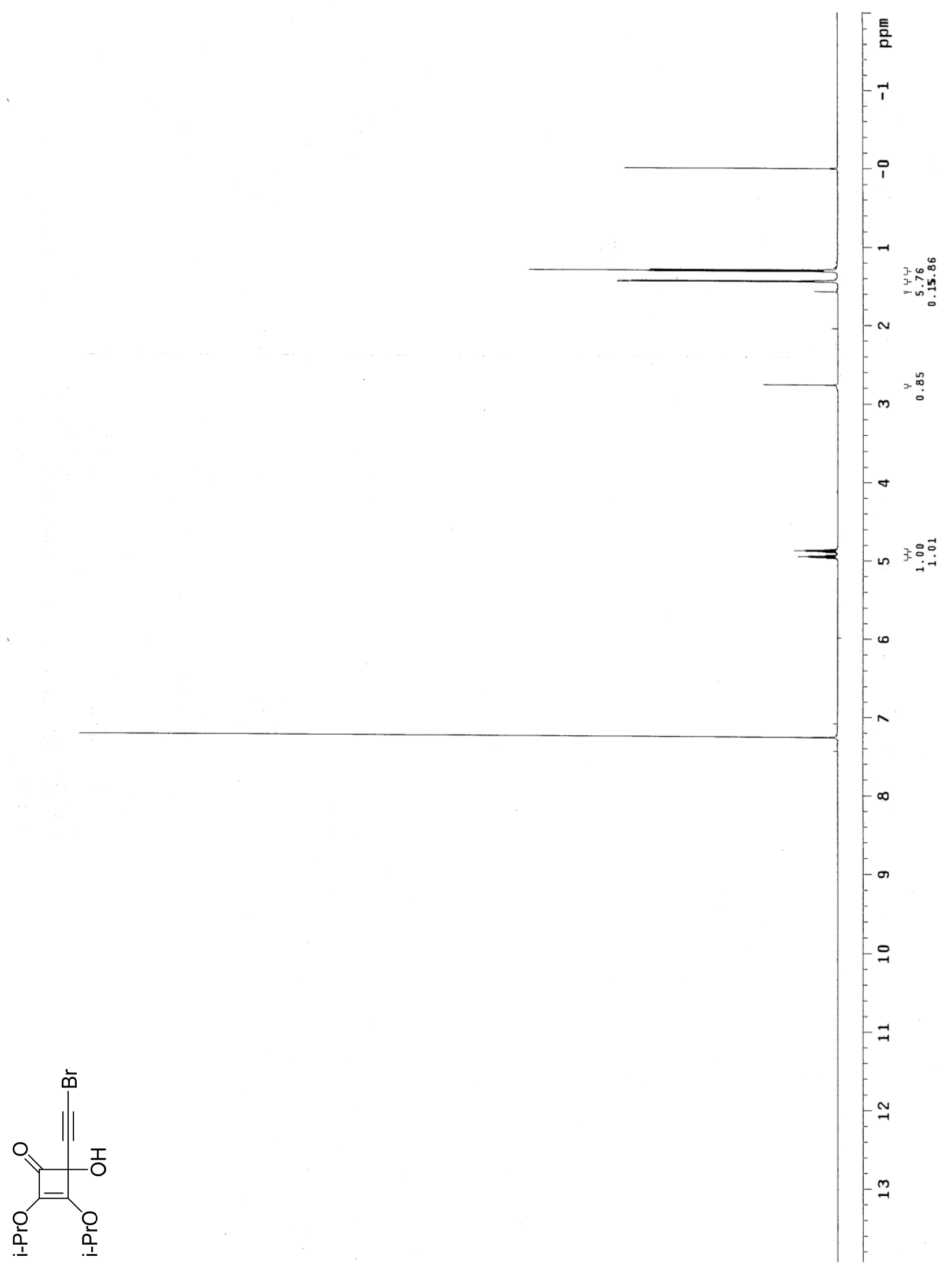

Figure 37: ${ }^{1} \mathrm{H}$ NMR of 4-hydroxy-2,3-bis(1-methylethoxy)-4-(2-bromoethynyl)-2-

cyclobutene-1-one (81) 


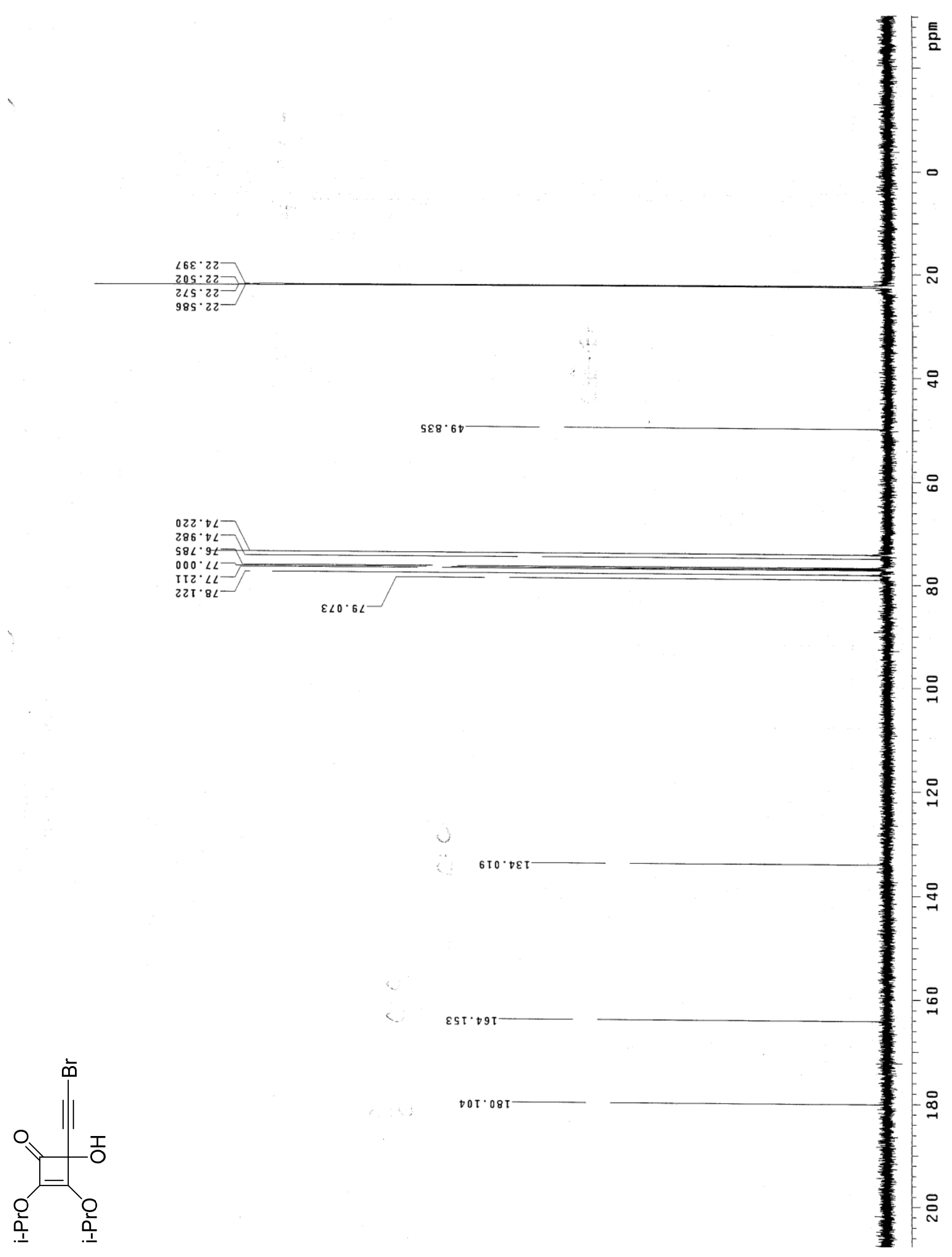

Figure 38: ${ }^{13} \mathrm{C}$ NMR of 4-hydroxy-2,3-bis(1-methylethoxy)-4-(2-bromoethynyl)-2-

cyclobutene-1-one (81) 


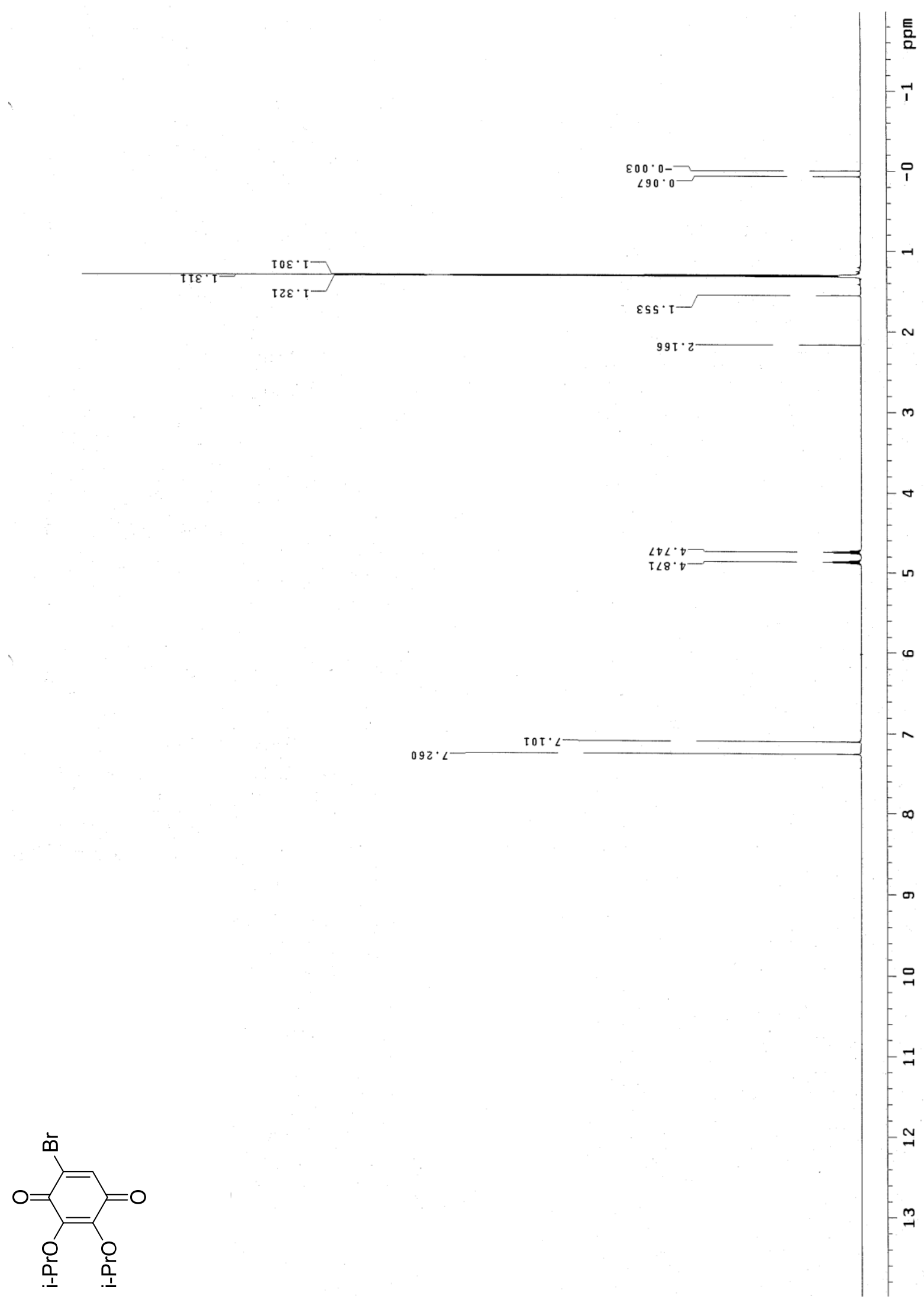

Figure 39: ${ }^{1} \mathrm{H}$ NMR of 5-bromo-2,3-bis(1-methylethoxy)-2,5-cyclohexadiene-1,4-dione (82) 


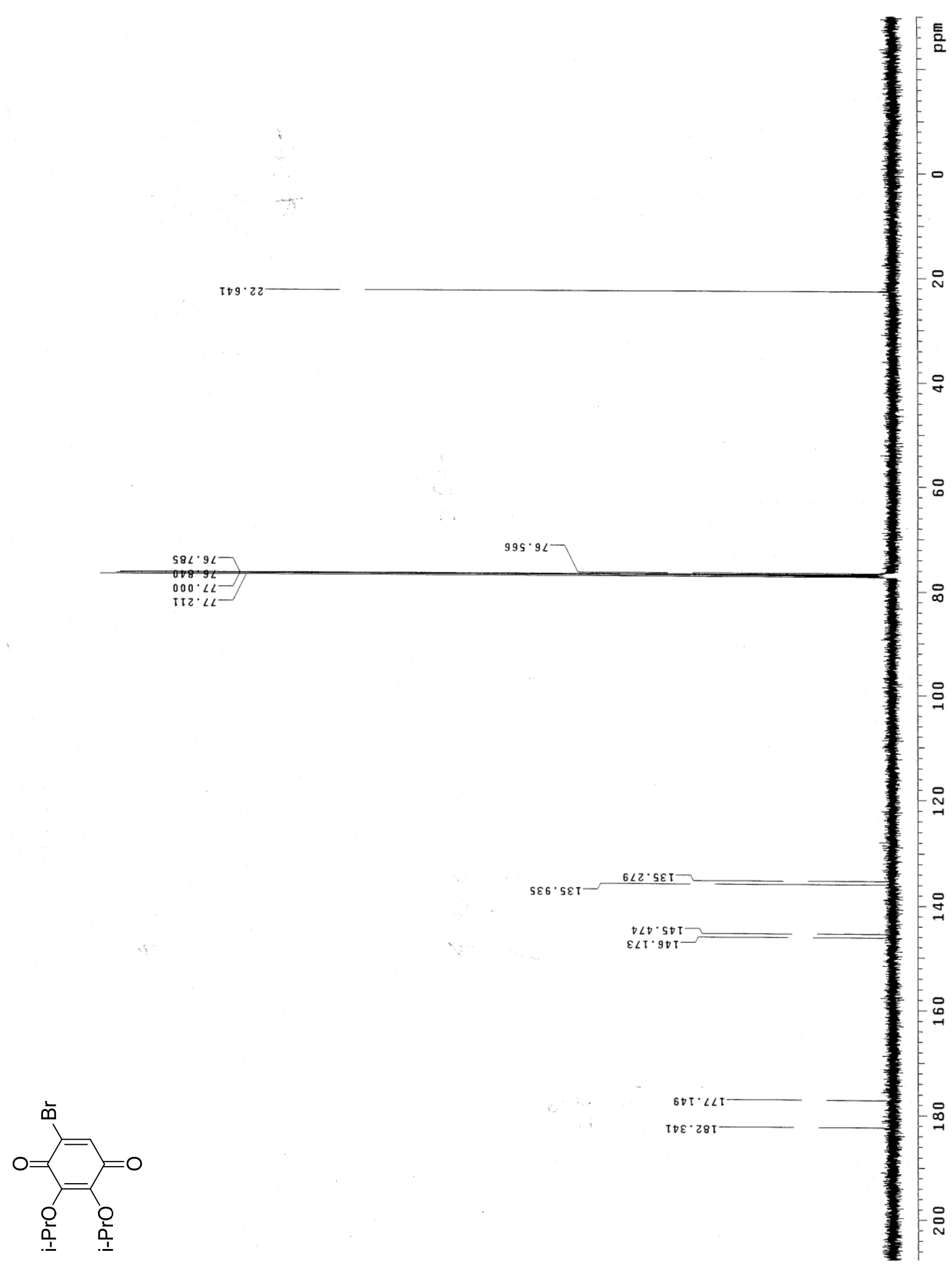

Figure 40: ${ }^{13} \mathrm{C}$ NMR of 5-bromo-2,3-bis(1-methylethoxy)-2,5-cyclohexadiene-1,4-dione (82) 


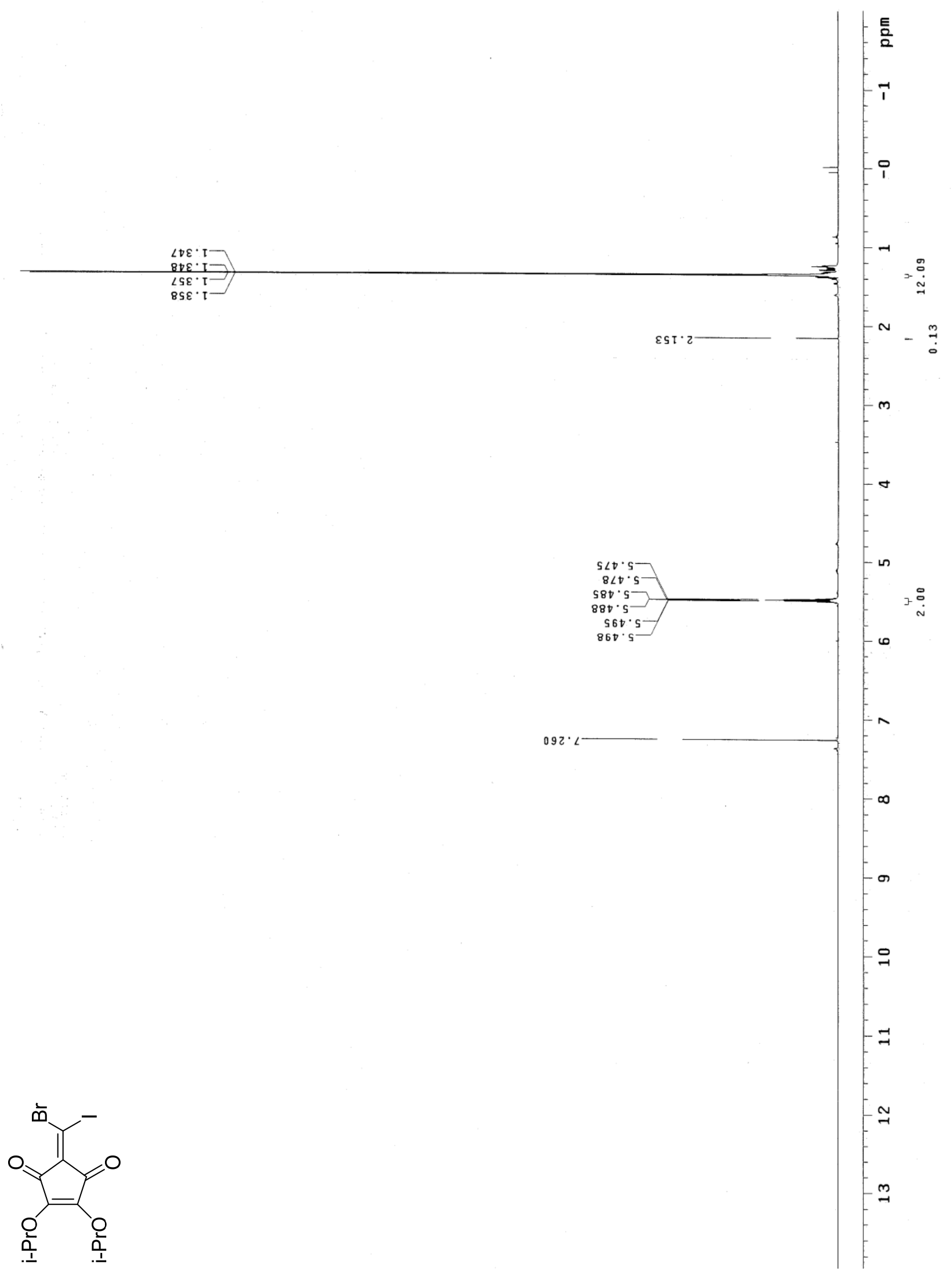

Figure 41: ${ }^{1} \mathrm{H}$ NMR of 2-(1-bromo-1-iodomethylene)-4,5-bis(1-methylethoxy)-4-

cyclopentene-1,3-dione (83) 


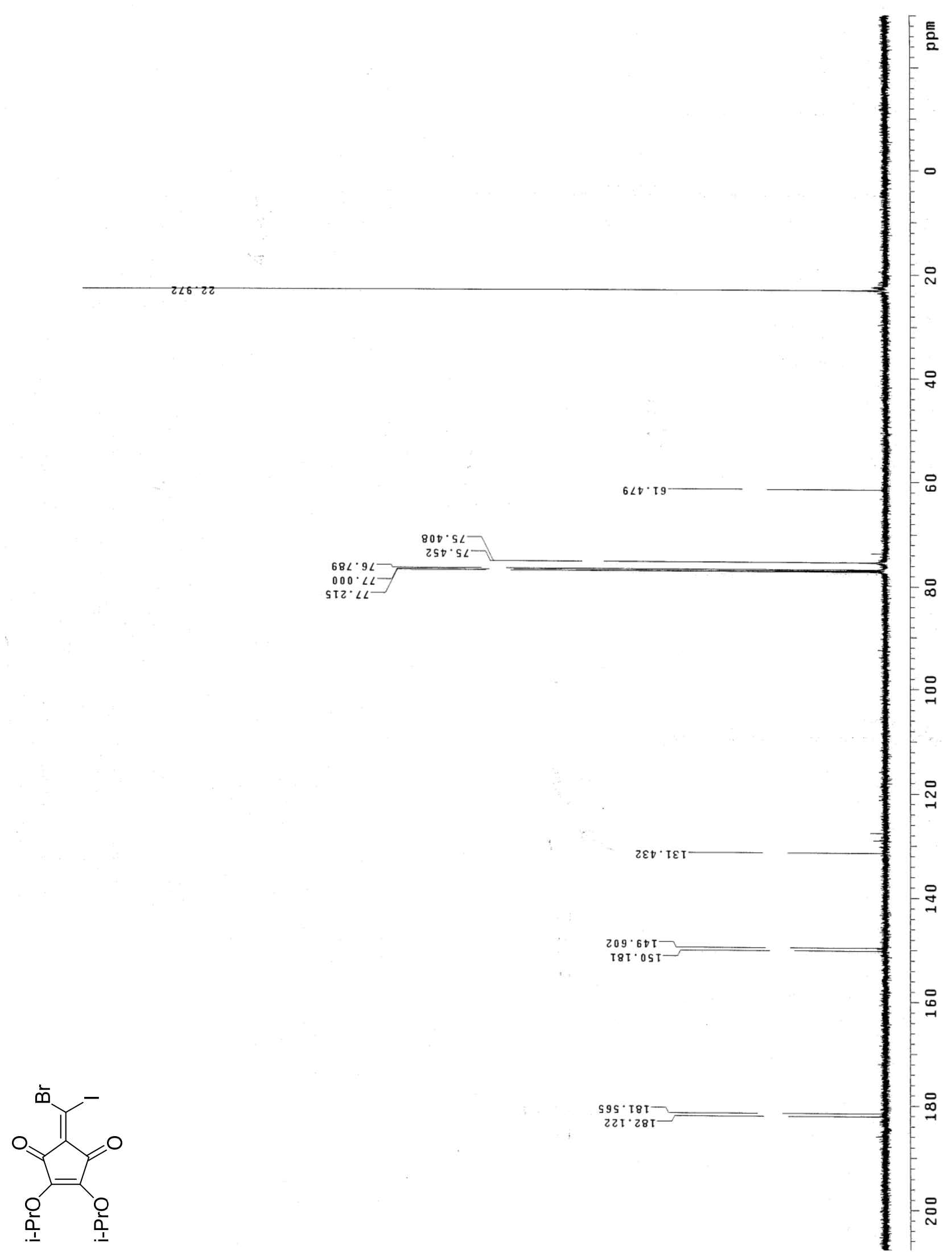

Figure 42: ${ }^{13} \mathrm{C}$ NMR of 2-(1-bromo-1-iodomethylene)-4,5-bis(1-methylethoxy)-4-

cyclopentene-1,3-dione (83) 


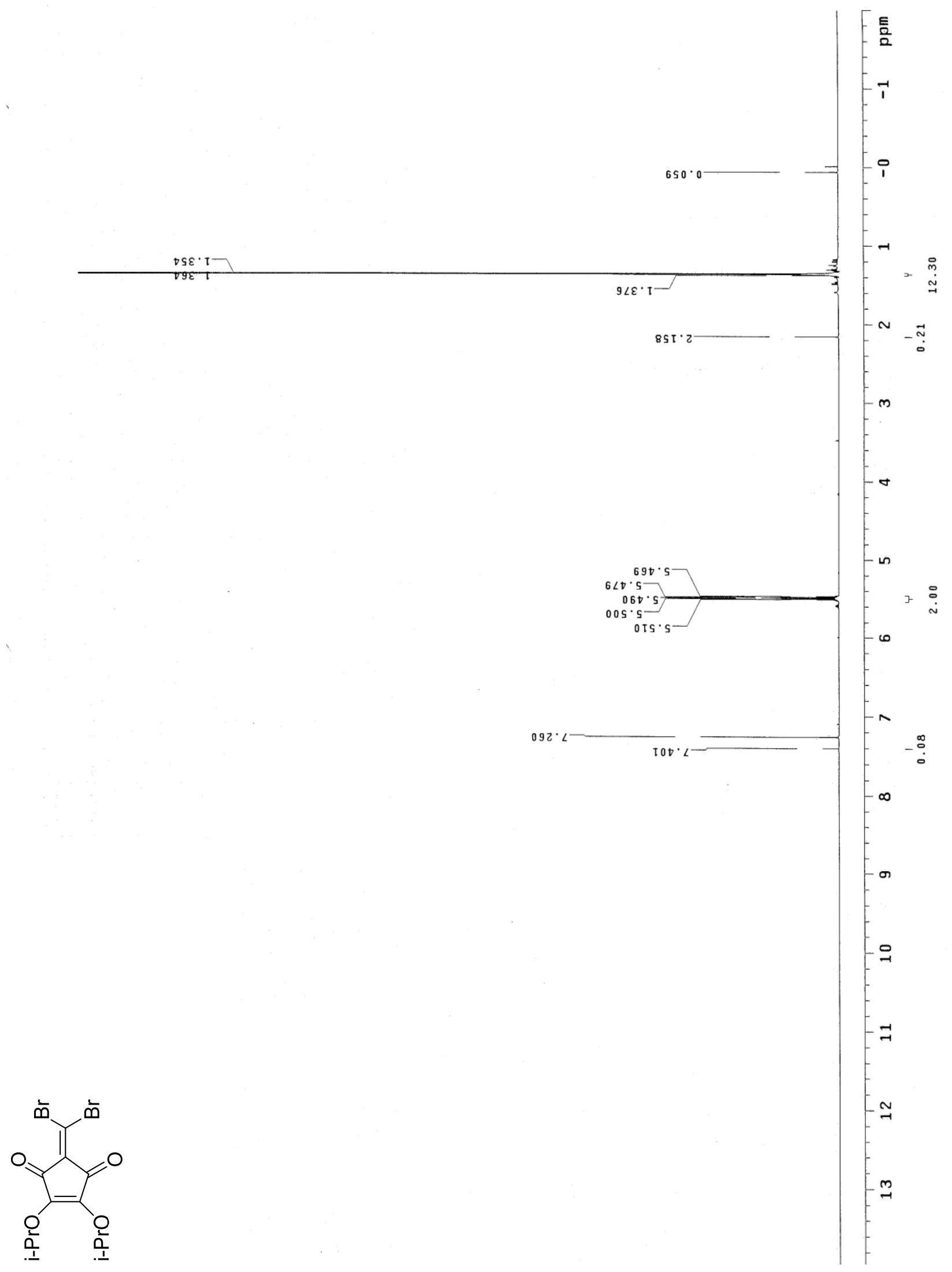

Figure 43: ${ }^{1} \mathrm{H}$ NMR of 2-(dibromomethylene)-4,5-bis(1-methylethoxy)-4-cyclopentene- 


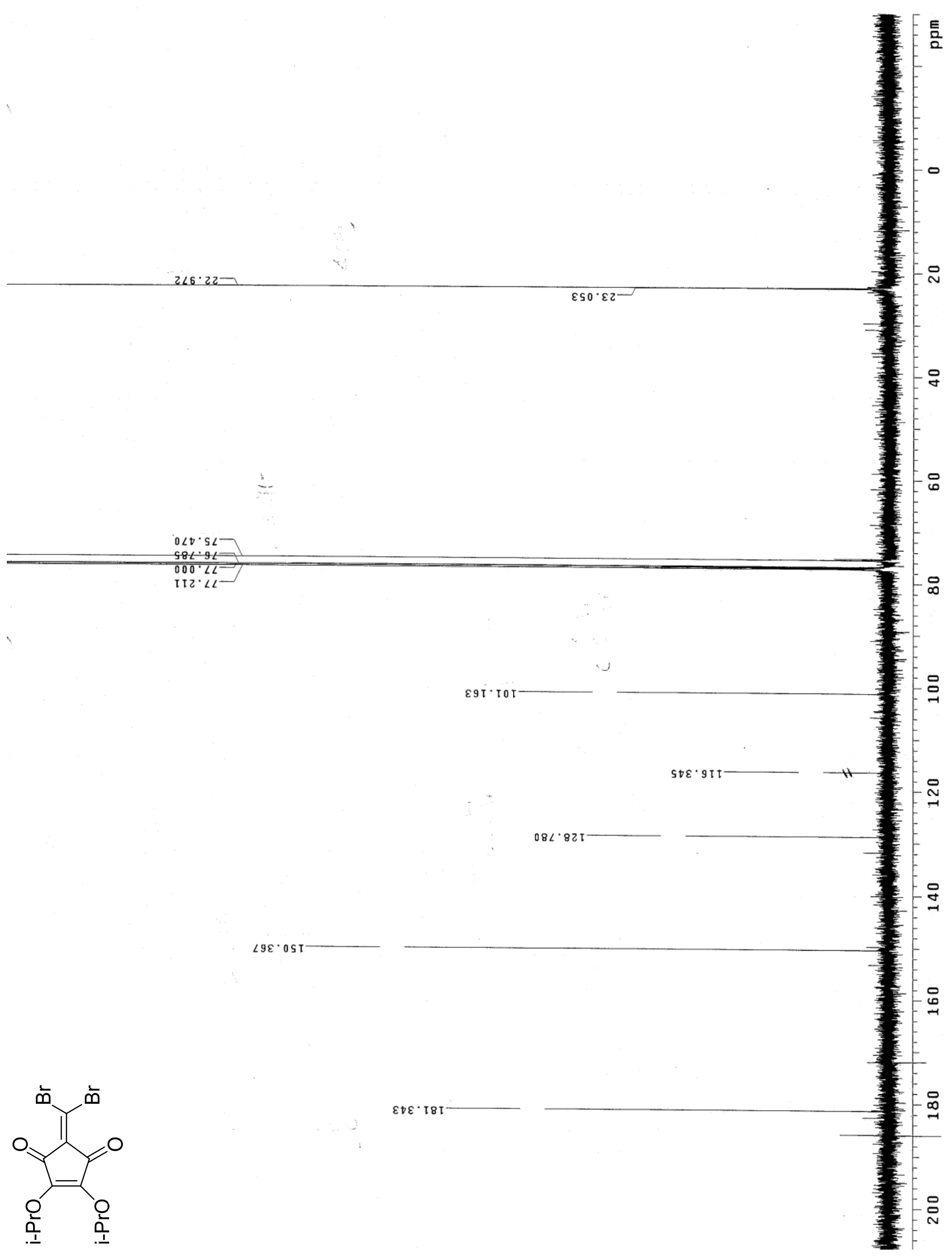

Figure 44: ${ }^{13} \mathrm{C}$ NMR of 2-(dibromomethylene)-4,5-bis(1-methylethoxy)-4-cyclopentene- 


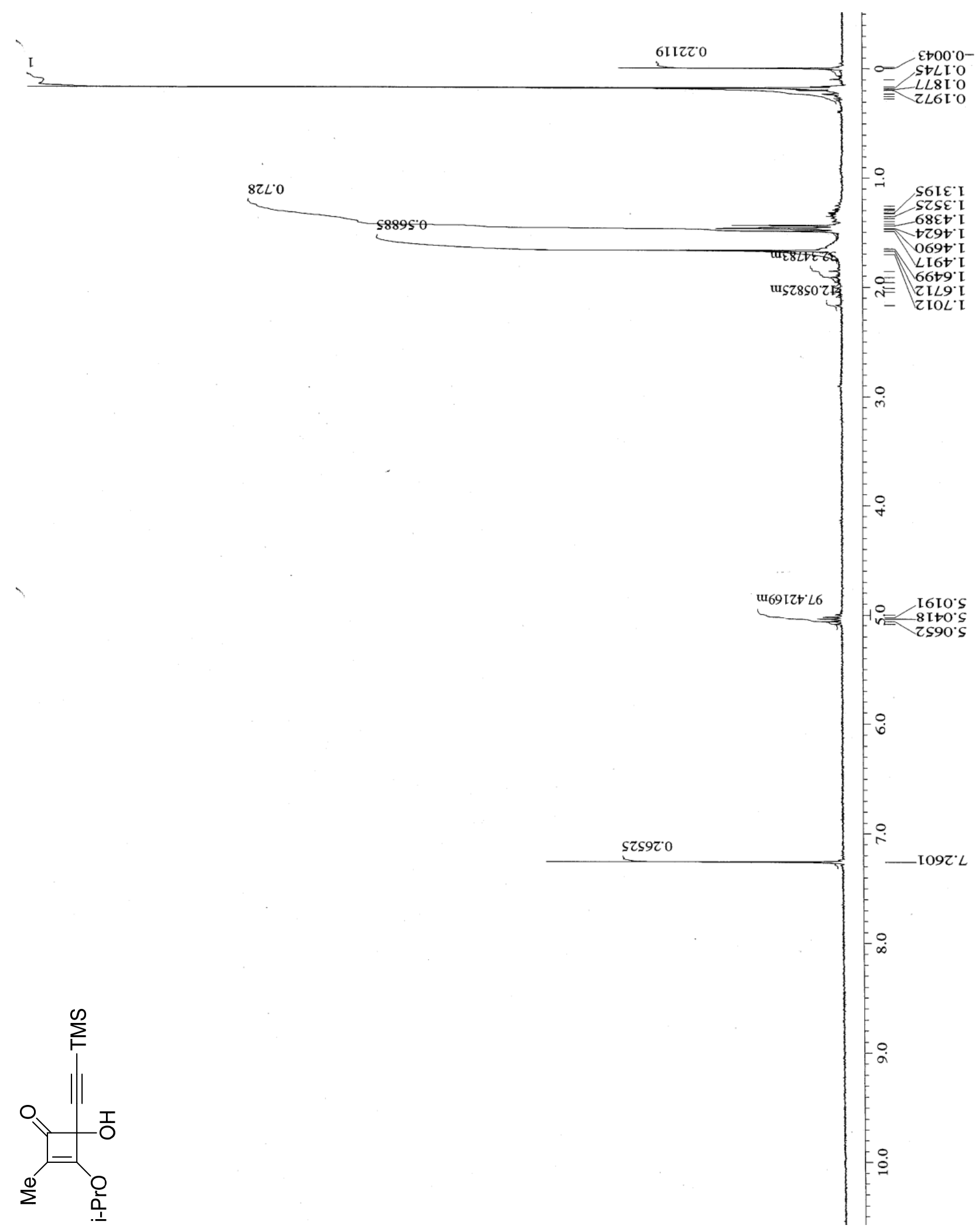

Figure 45: ${ }^{1} \mathrm{H}$ NMR of 4-hydroxy-2-methyl-3-(1-methylethoxy)-4-(2-trimethylsilylethynyl)-

2-cyclobutene-1-one (89) 


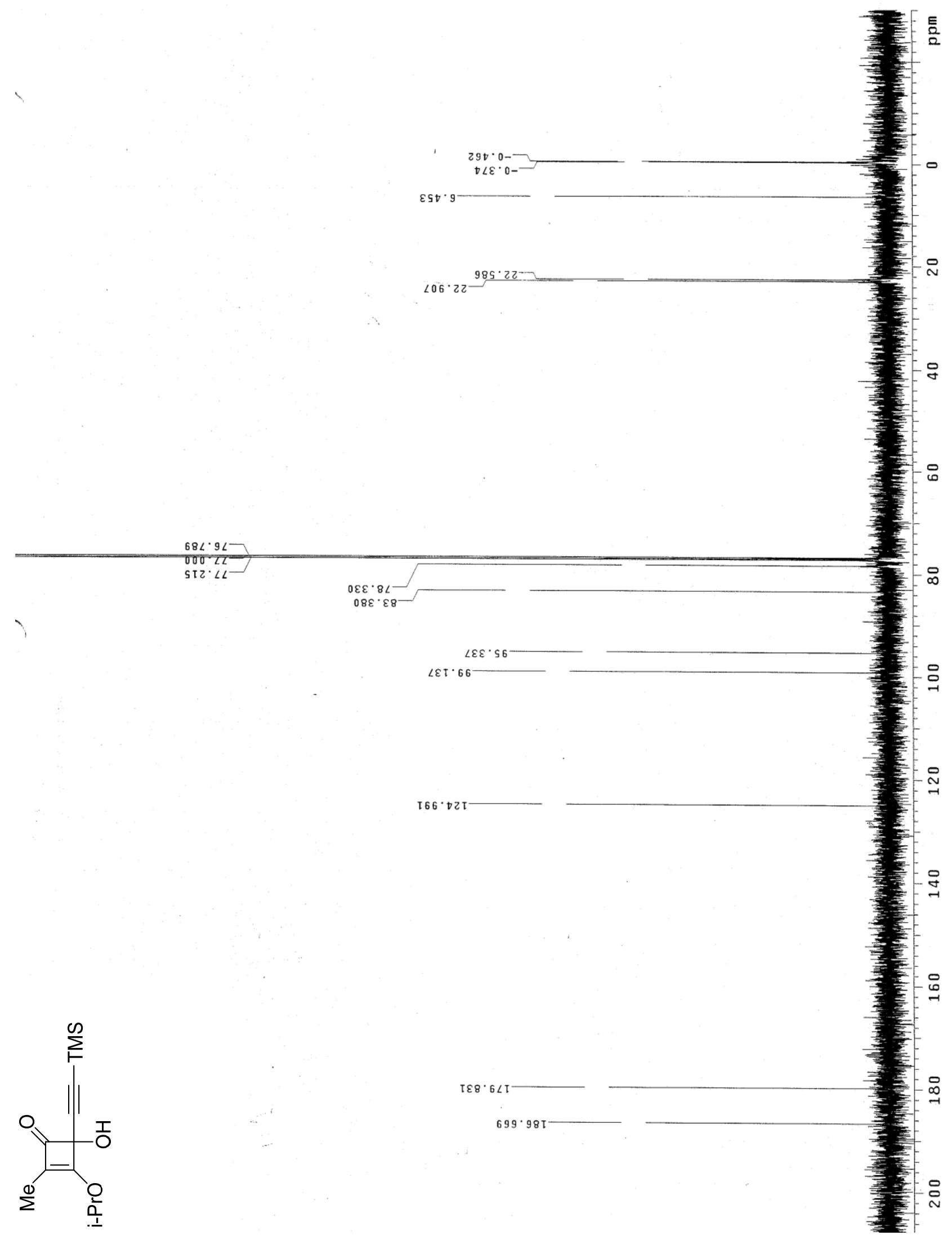

Figure 46: ${ }^{13} \mathrm{C}$ NMR of 4-hydroxy-2-methyl-3-(1-methylethoxy)-4-(2-trimethylsilylethynyl)- 


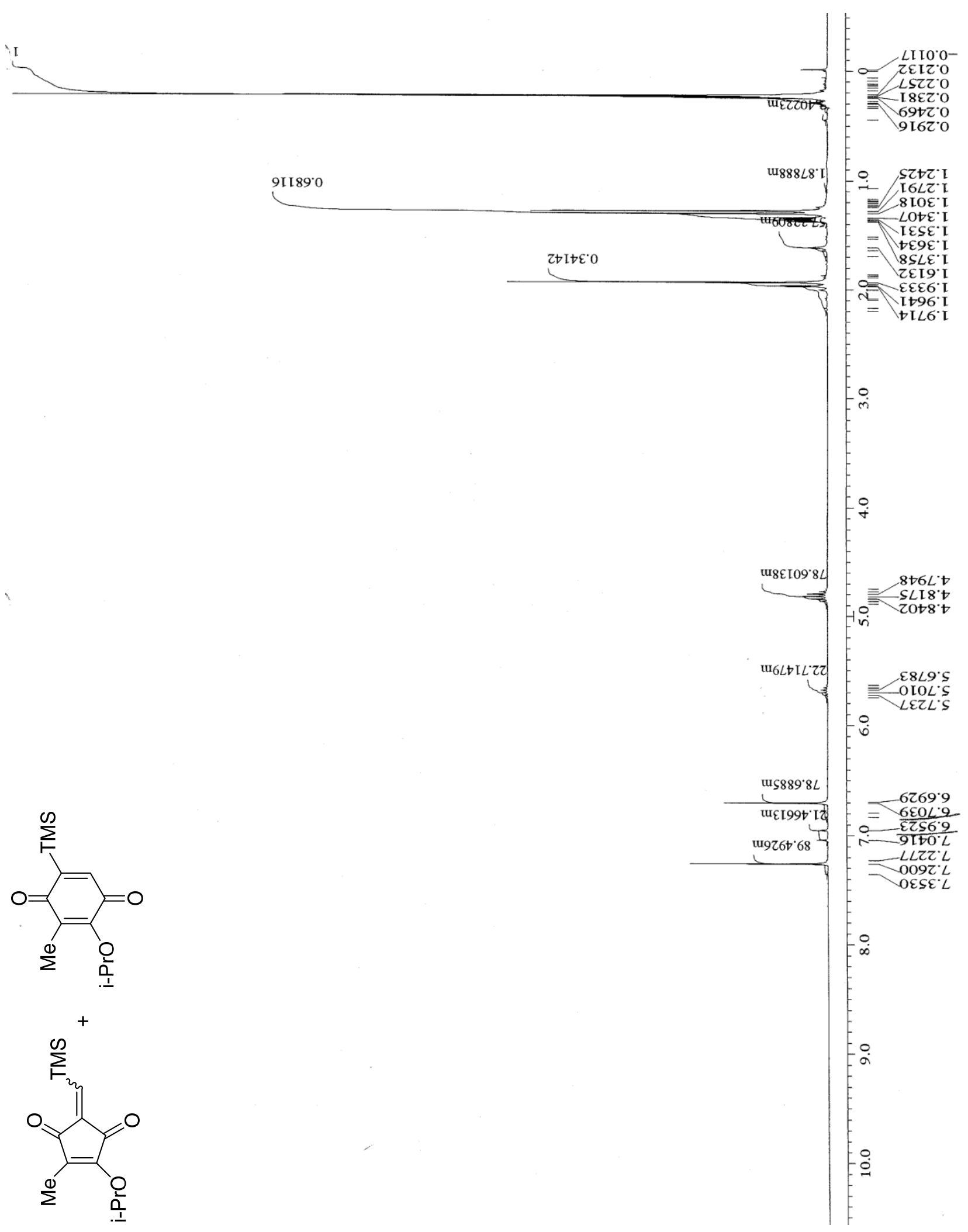

Figure 47: ${ }^{1} \mathrm{H}$ NMR of 2-trimethylsilylmethylene-4-(1-methylethoxy)-5-methyl-4-

cyclopentene-1,3-dione (90) and 5-trimethylsily-3-methyl-2-(1-methylethoxy)-2,5-

cyclohexadiene-1,4-dione (91) 


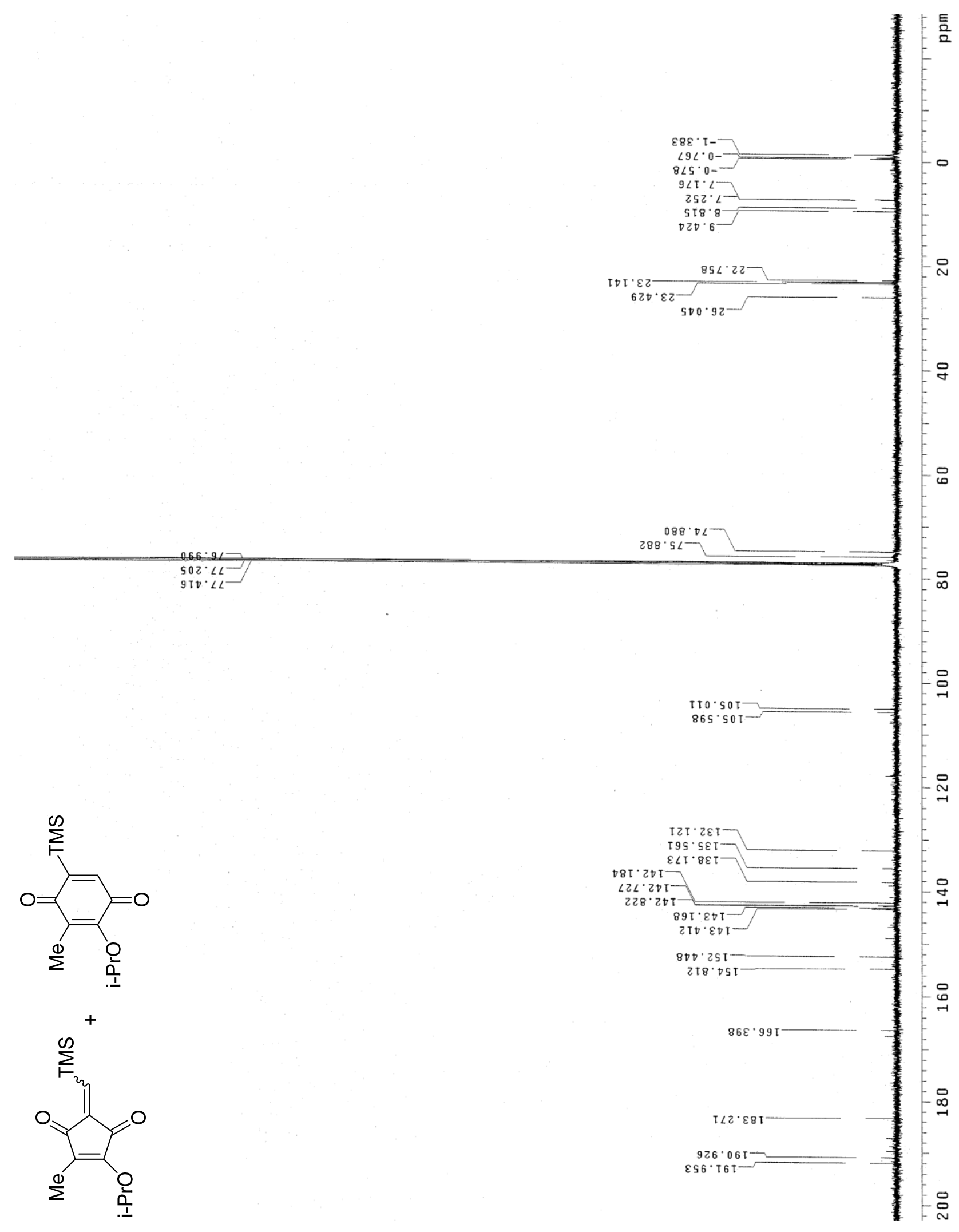

Figure 48: ${ }^{13} \mathrm{C}$ NMR of 2-trimethylsilylmethylene-4-(1-methylethoxy)-5-methyl-4cyclopentene-1,3-dione (90) and 5-trimethylsily-3-methyl-2-(1-methylethoxy)-2,5cyclohexadiene-1,4-dione (91) 


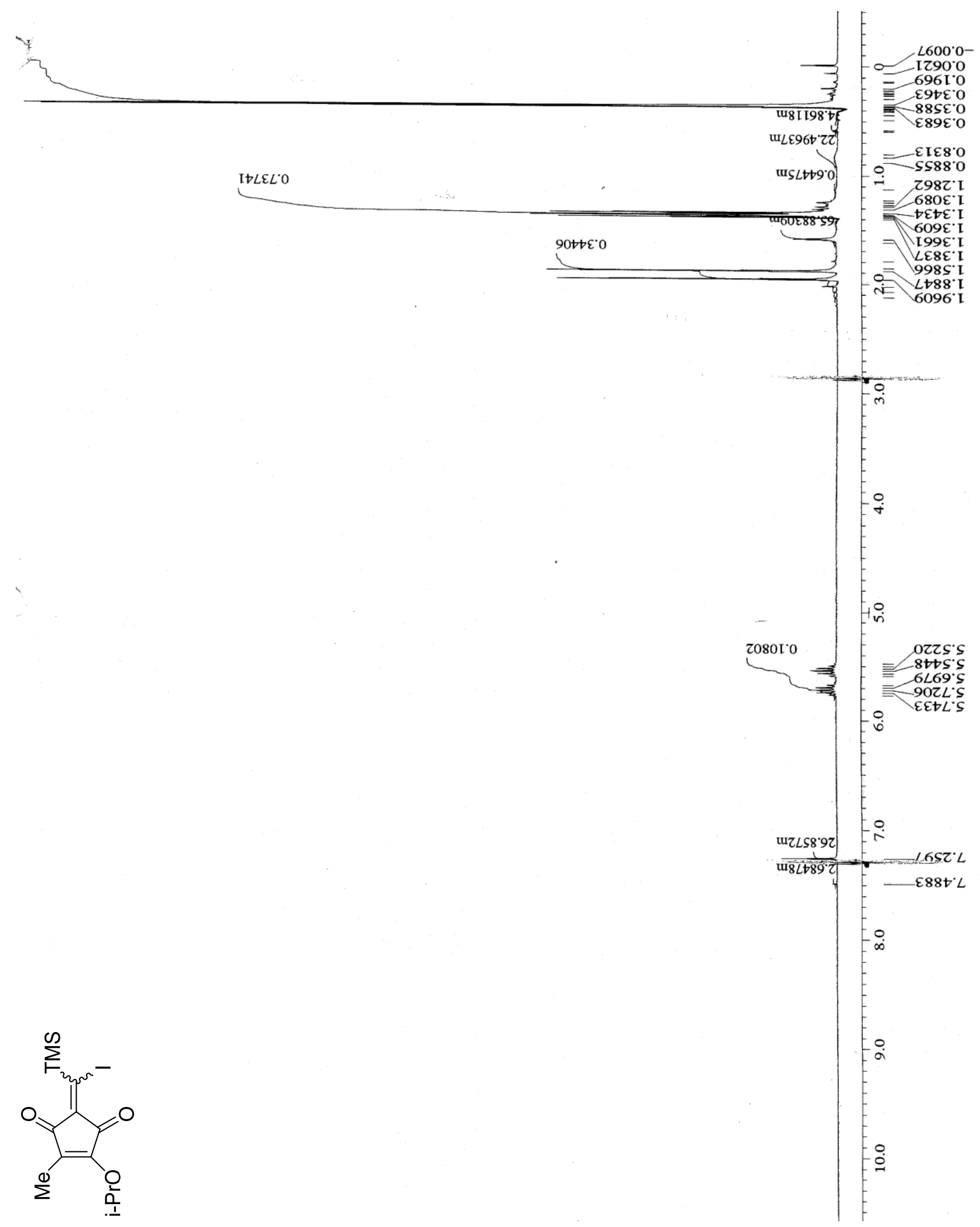

Figure 49: ${ }^{1} \mathrm{H}$ NMR of 2-(1-iodo-1-trimethylsilylmethylene)-4-(1-methylethoxy)-5-methyl-4-

cyclopentene-1,3-dione (92) 


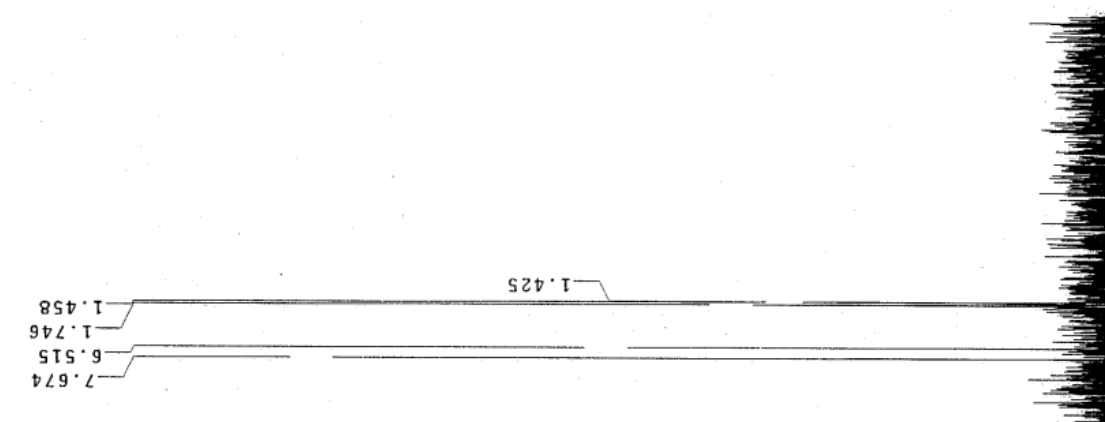

$\angle 0 T \cdot \varepsilon \tau^{-}$
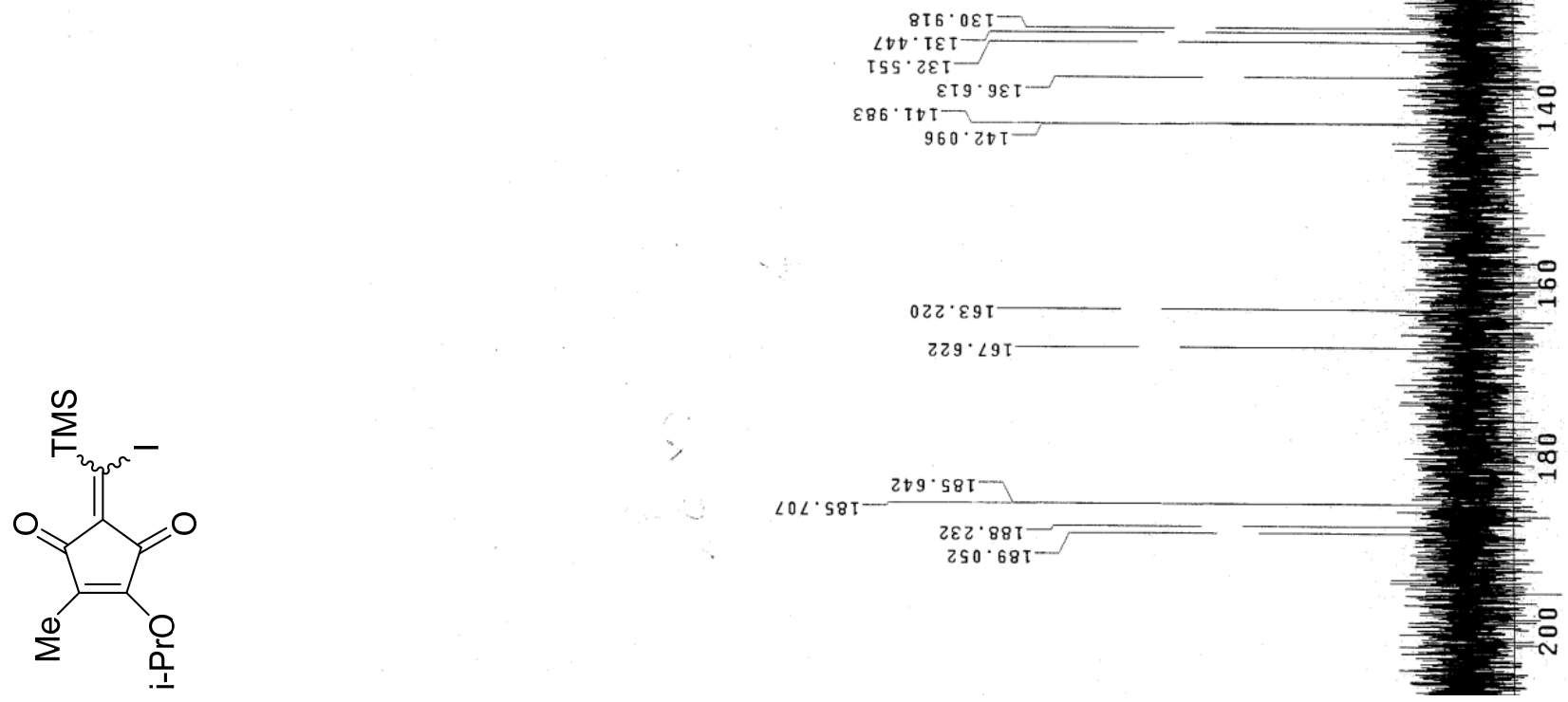

Figure 50: ${ }^{13} \mathrm{C}$ NMR of 2-(1-iodo-1-trimethylsilylmethylene)-4-(1-methylethoxy)-5-methyl4-cyclopentene-1,3-dione (92) 


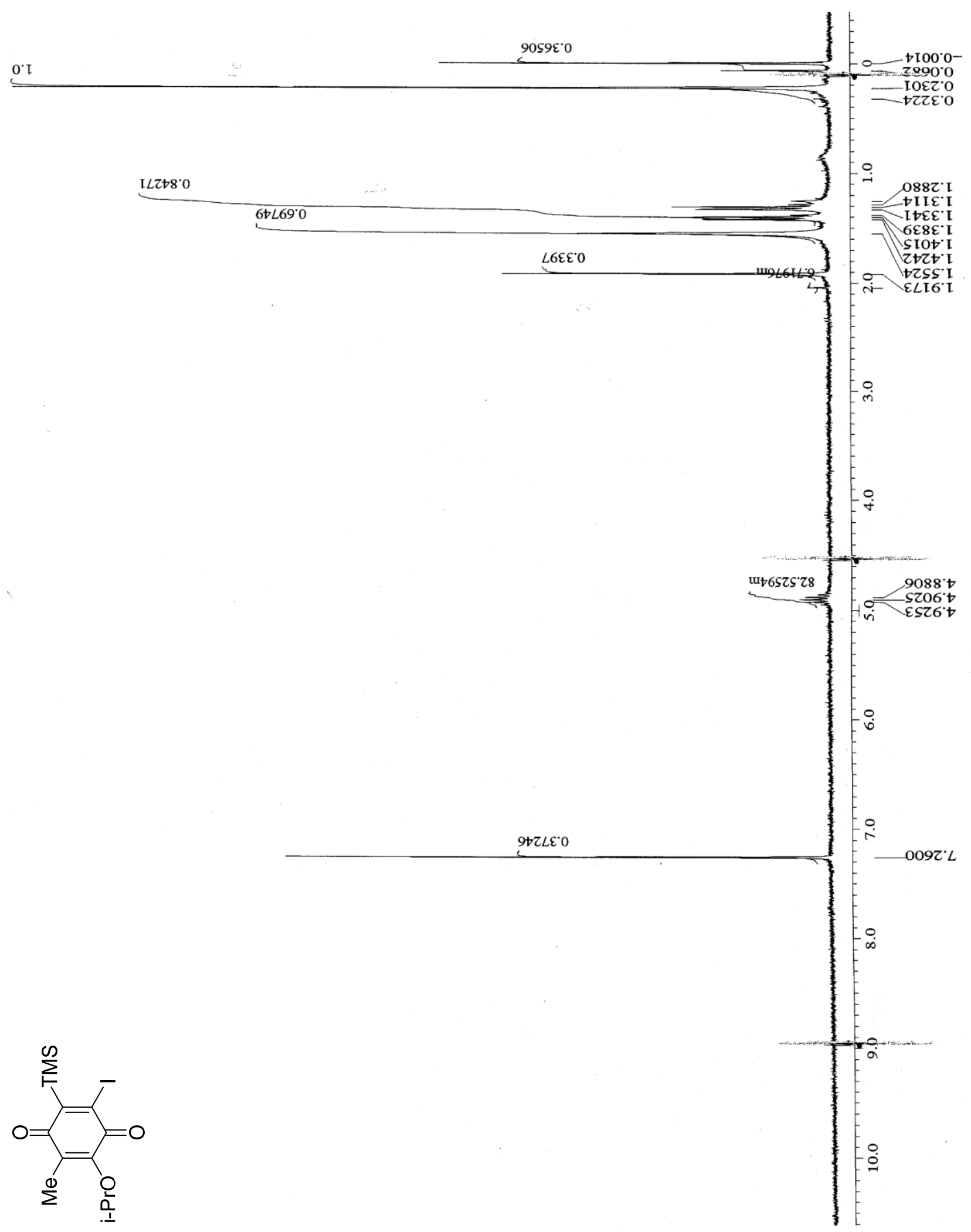

Figure 51: ${ }^{1} \mathrm{H}$ NMR of 6-iodo-5-trimethylsilyl-3-methyl-2-(1-methylethoxy)-2,5-

cyclohexadiene-1,4-dione (93) 


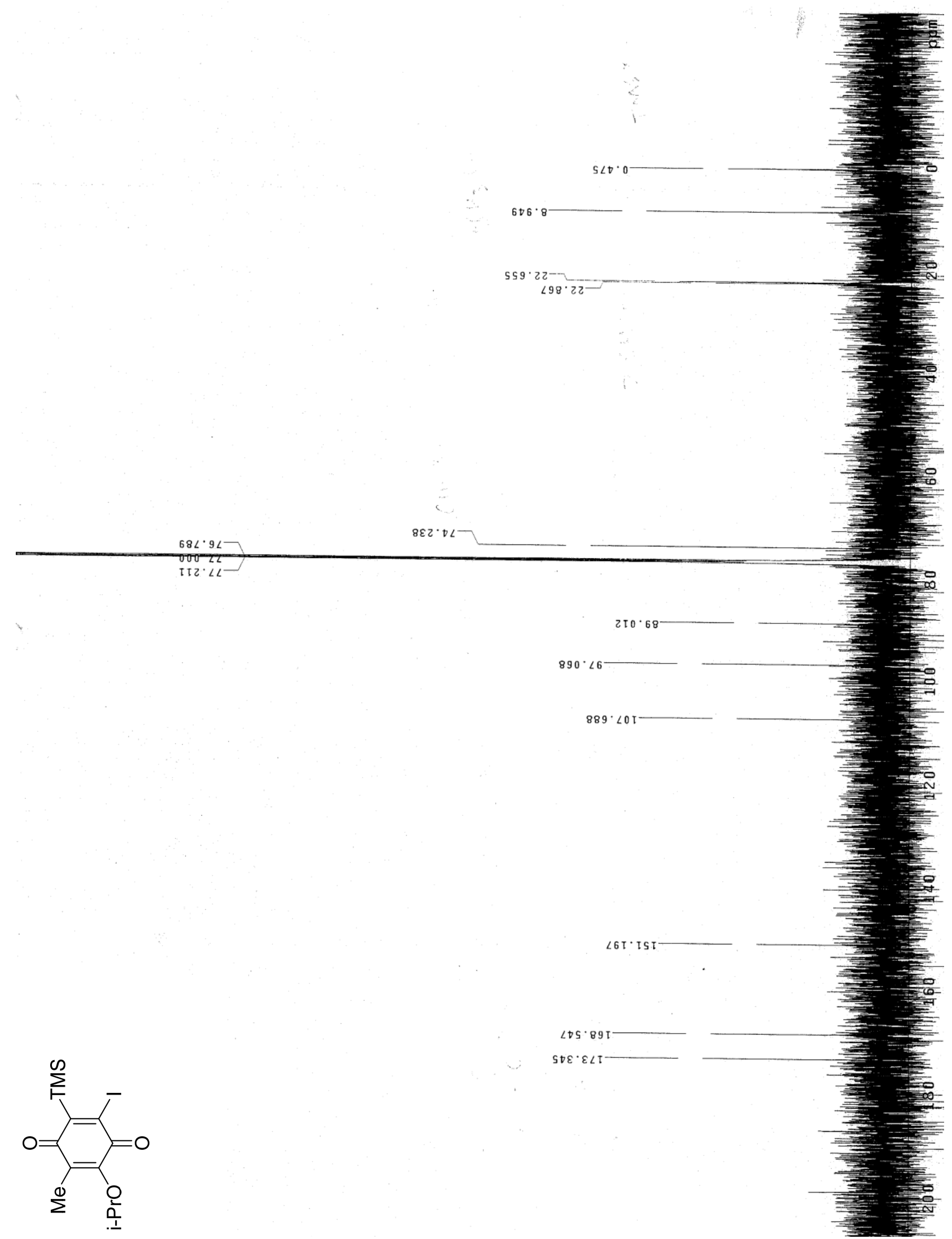

Figure 52: ${ }^{13} \mathrm{C}$ NMR of 6-iodo-5-trimethylsilyl-3-methyl-2-(1-methylethoxy)-2,5-

cyclohexadiene-1,4-dione (93) 


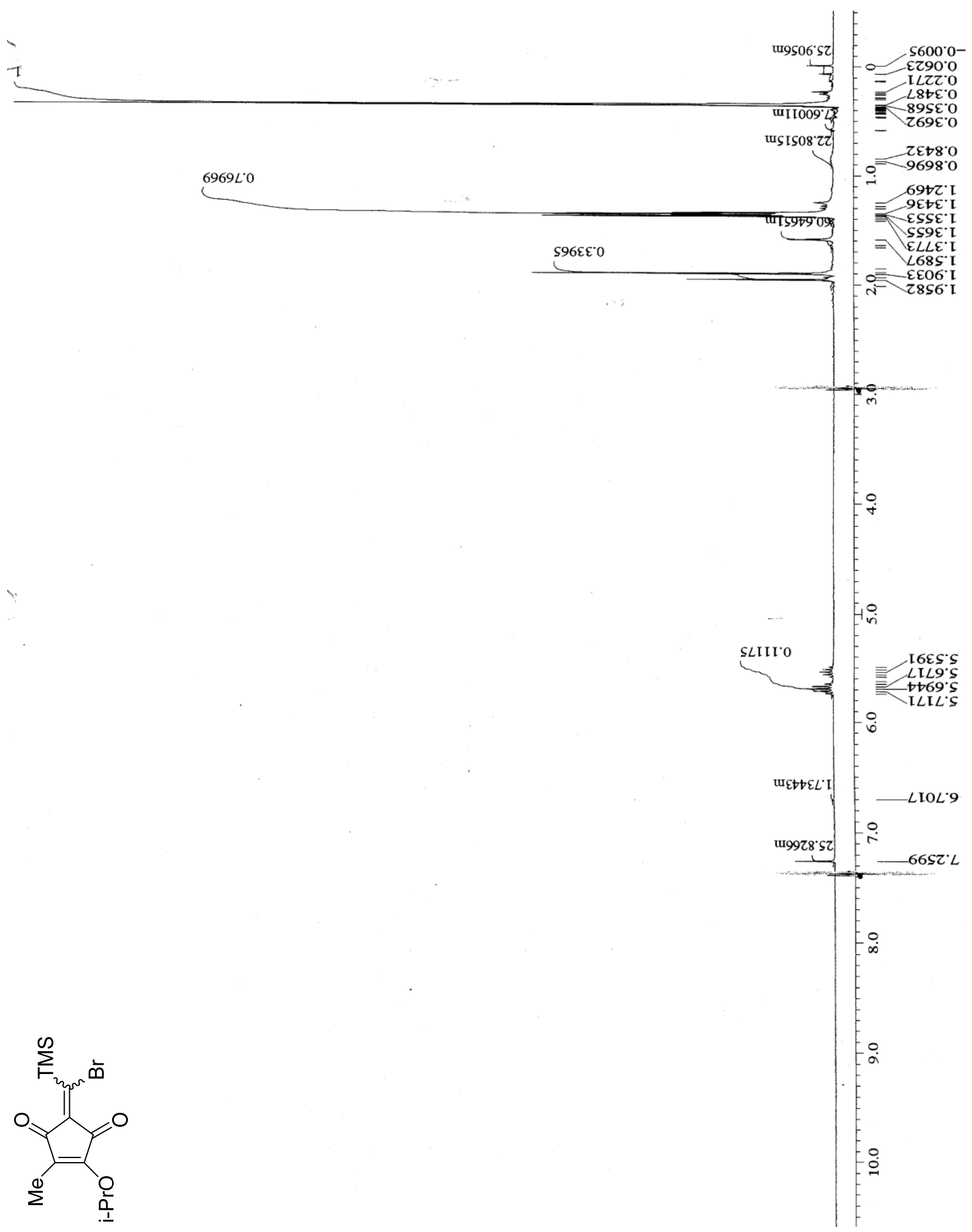

Figure 53: ${ }^{1} \mathrm{H}$ NMR of 2-(1-bromo-1-trimethylsilylmethylene)-4-(1-methylethoxy)-5-

methyl-4-cyclopentene-1,3-dione (94) 


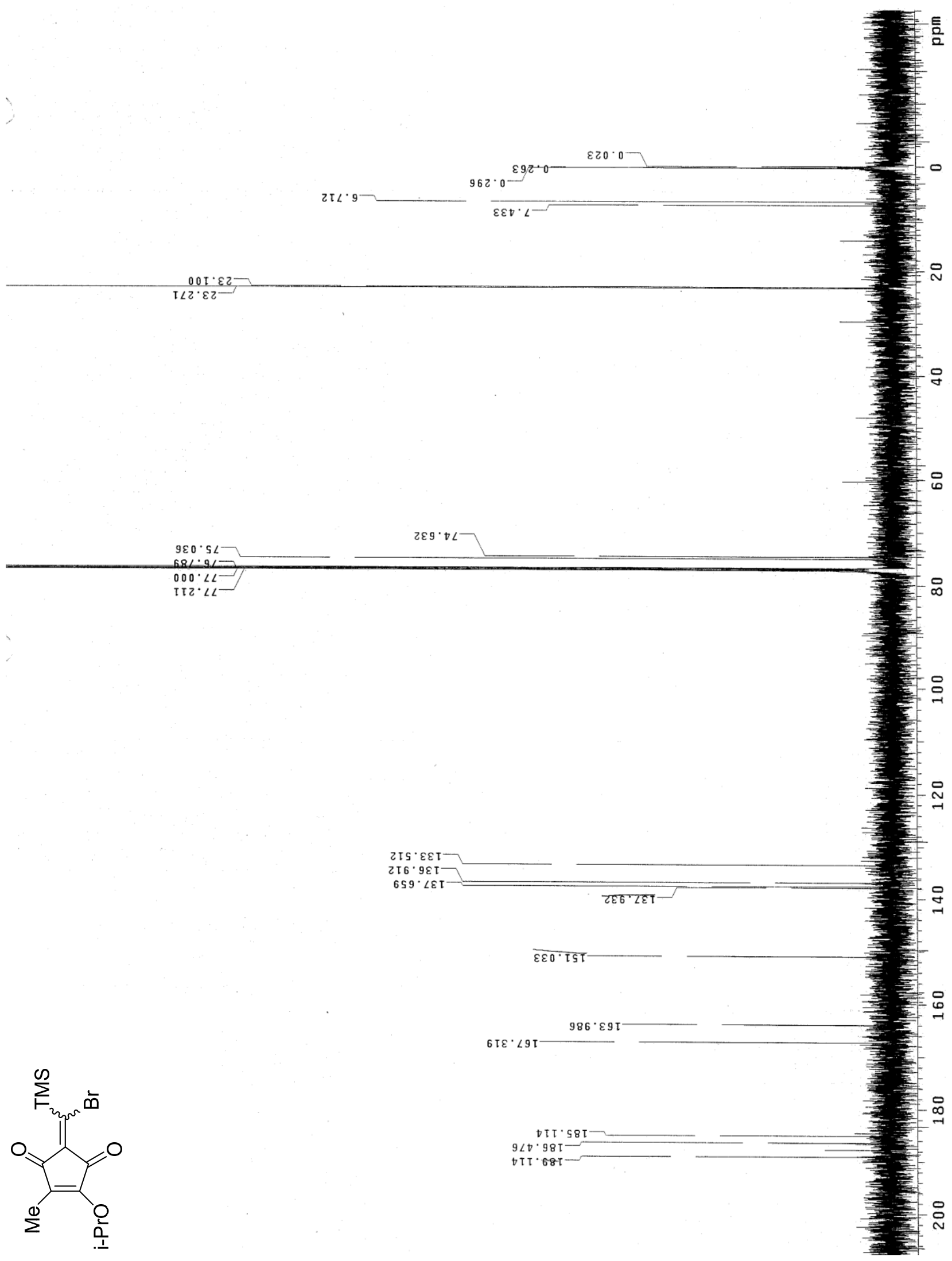

Figure 54: ${ }^{13} \mathrm{C}$ NMR of 2-(1-bromo-1-trimethylsilylmethylene)-4-(1-methylethoxy)-5methyl-4-cyclopentene-1,3-dione (94) 


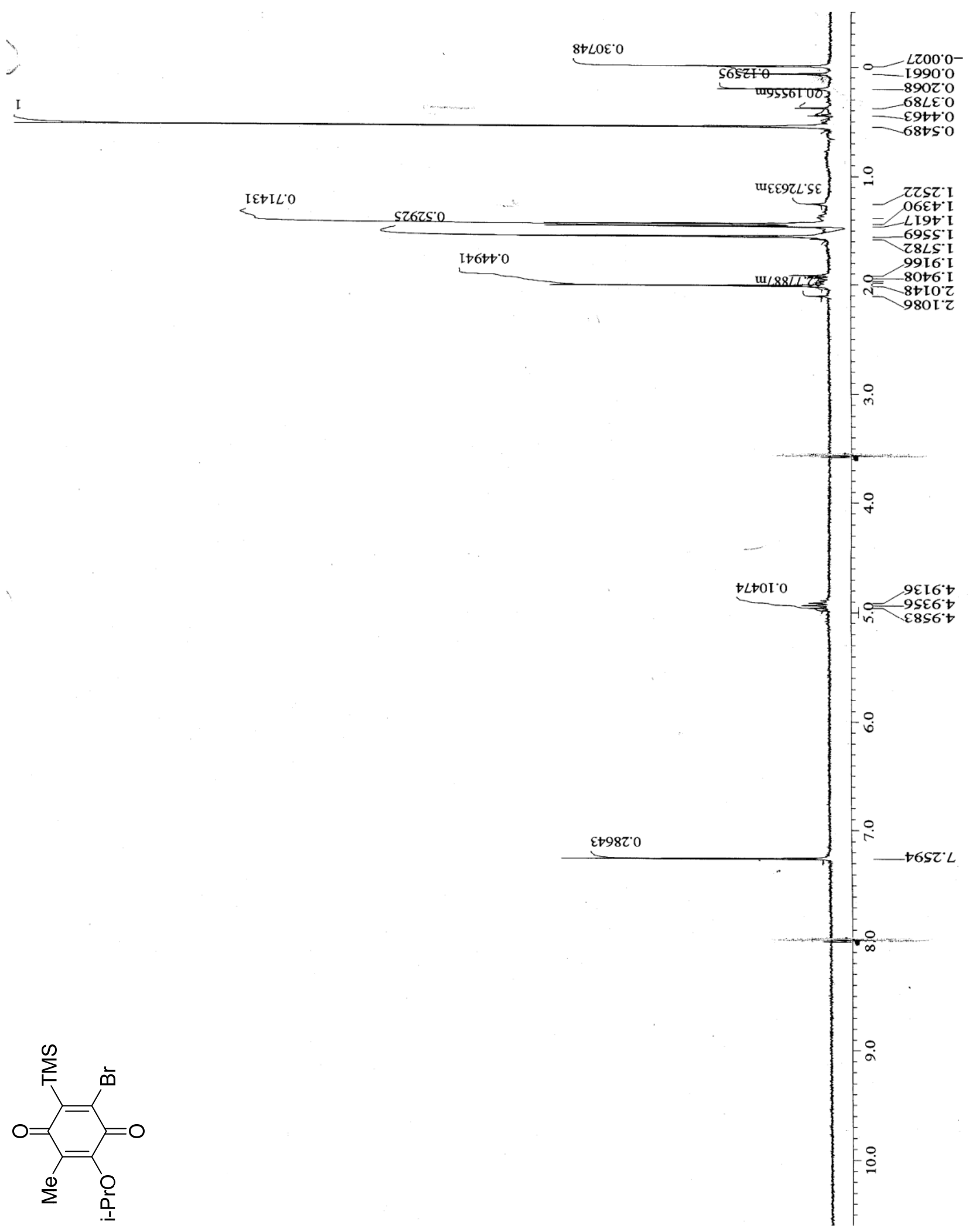

Figure 55: ${ }^{1} \mathrm{H}$ NMR of 6-bromo-5-trimethylsily-3-methyl-2-(1-methylethoxy)-2,5-

cyclohexadiene-1,4-dione (95) 


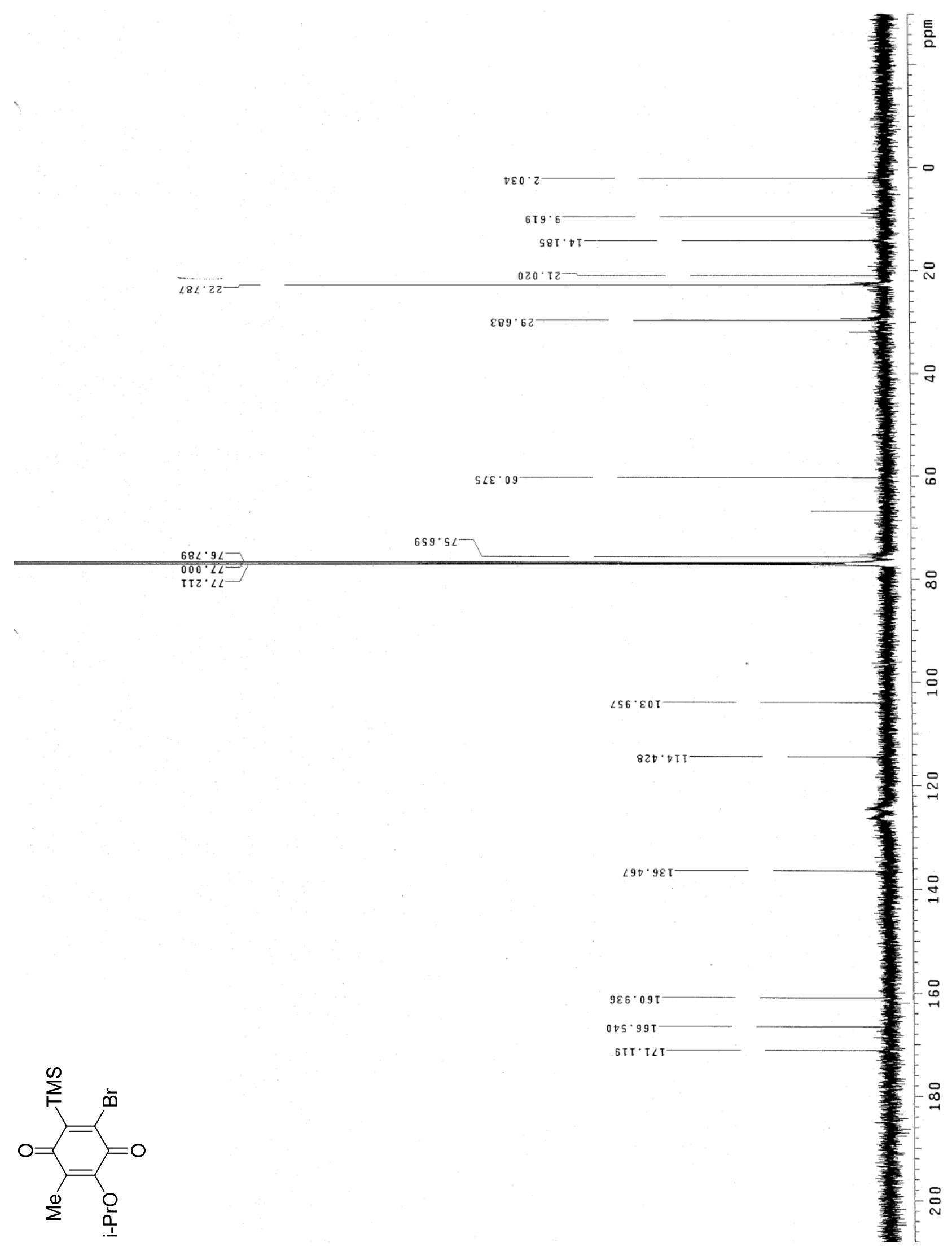

Figure 56: ${ }^{13} \mathrm{C}$ NMR of 6-bromo-5-trimethylsily-3-methyl-2-(1-methylethoxy)-2,5cyclohexadiene-1,4-dione (95) 


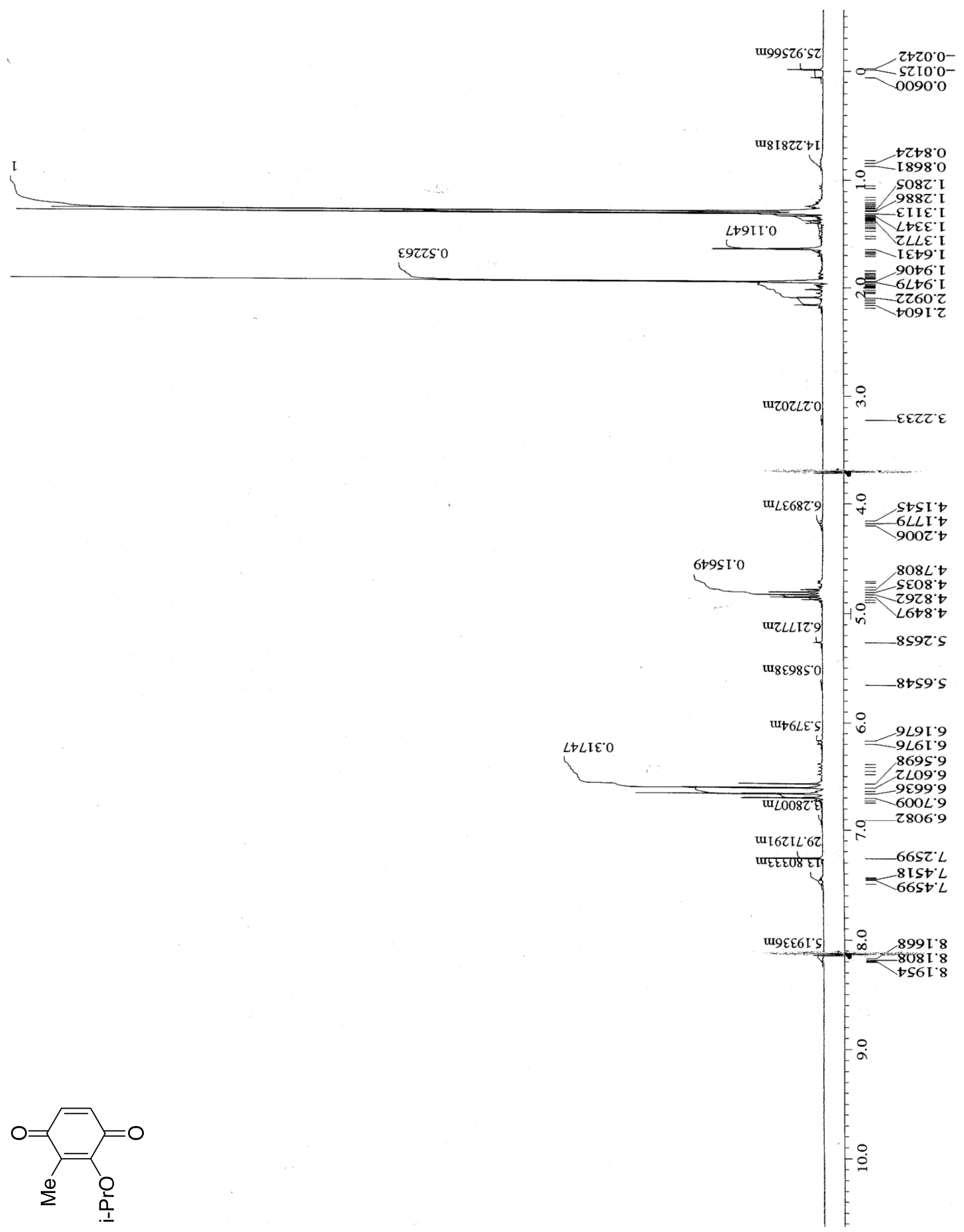

Figure 57: ${ }^{1} \mathrm{H}$ NMR of 3-methyl-2-(1-methylethoxy)-2,5-cyclohexadiene-1,4-dione (97) 


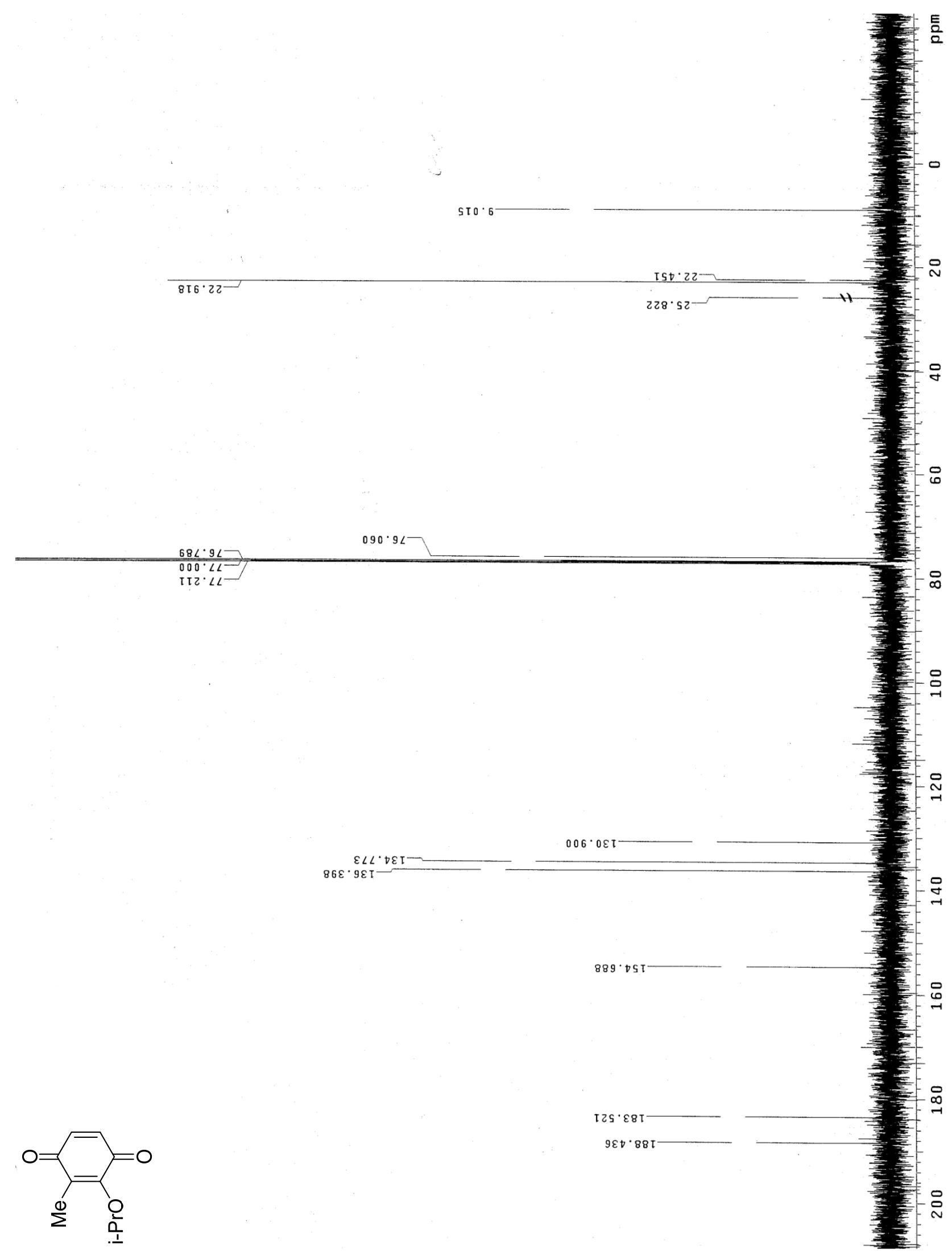

Figure 58: ${ }^{13} \mathrm{C}$ NMR of 3-methyl-2-(1-methylethoxy)-2,5-cyclohexadiene-1,4-dione (97) 


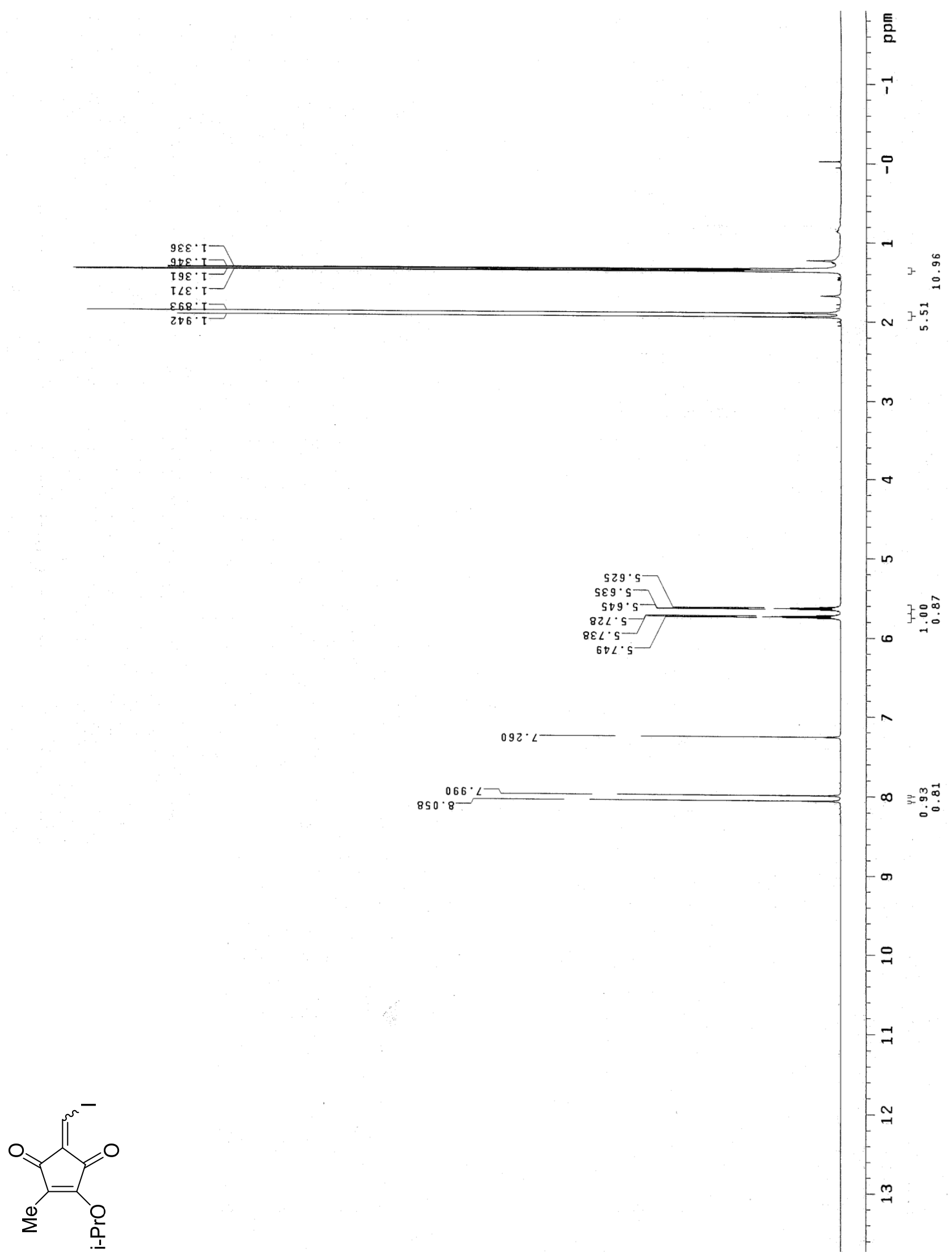

Figure 59: ${ }^{1} \mathrm{H}$ NMR of 2-(1-iodomethylene)-4-methyl-5-(1-methylethoxy)-4-cyclopentene- 


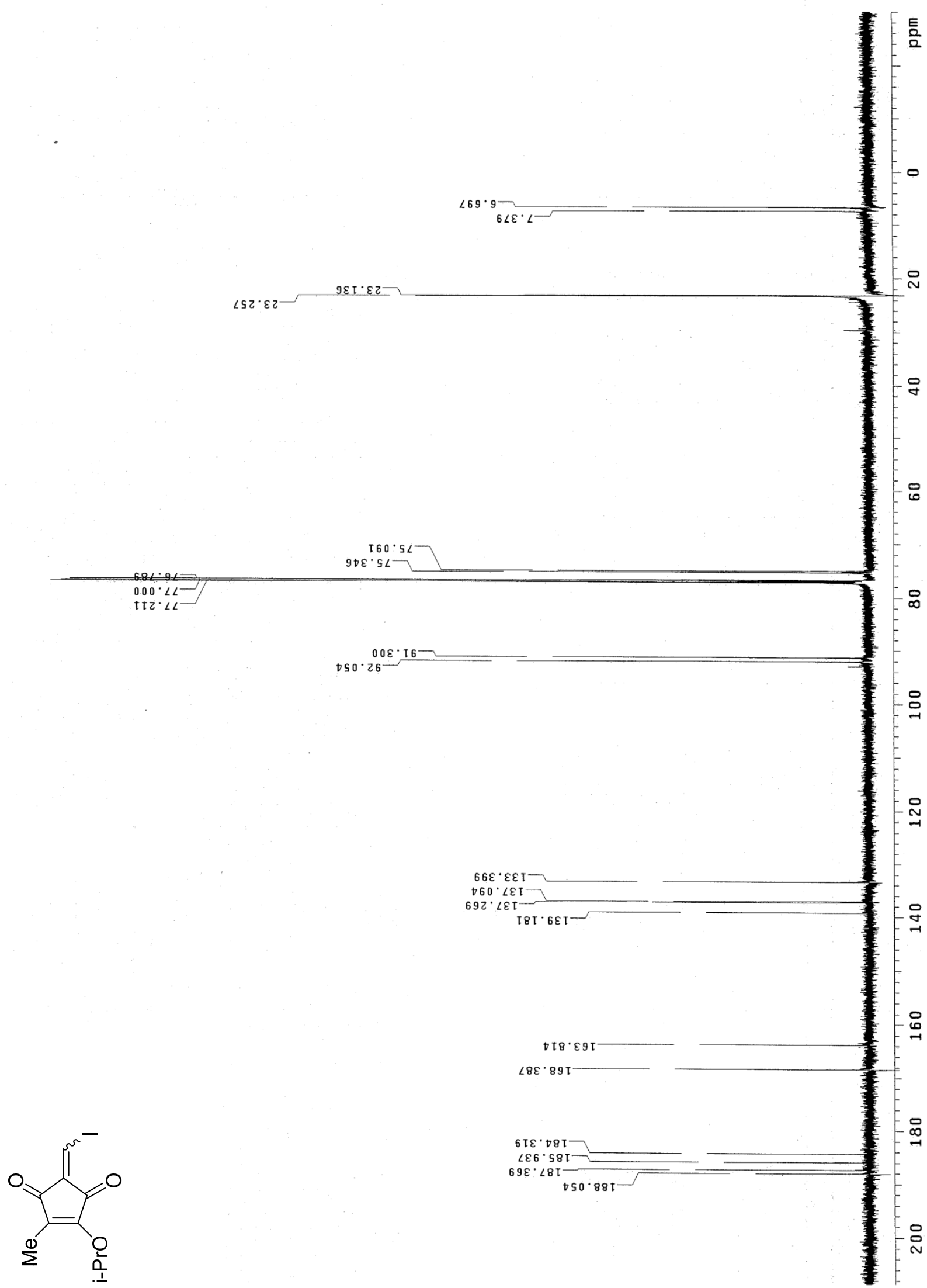

Figure 60: ${ }^{13} \mathrm{C}$ NMR of 2-(1-iodomethylene)-4-methyl-5-(1-methylethoxy)-4-cyclopentene- 


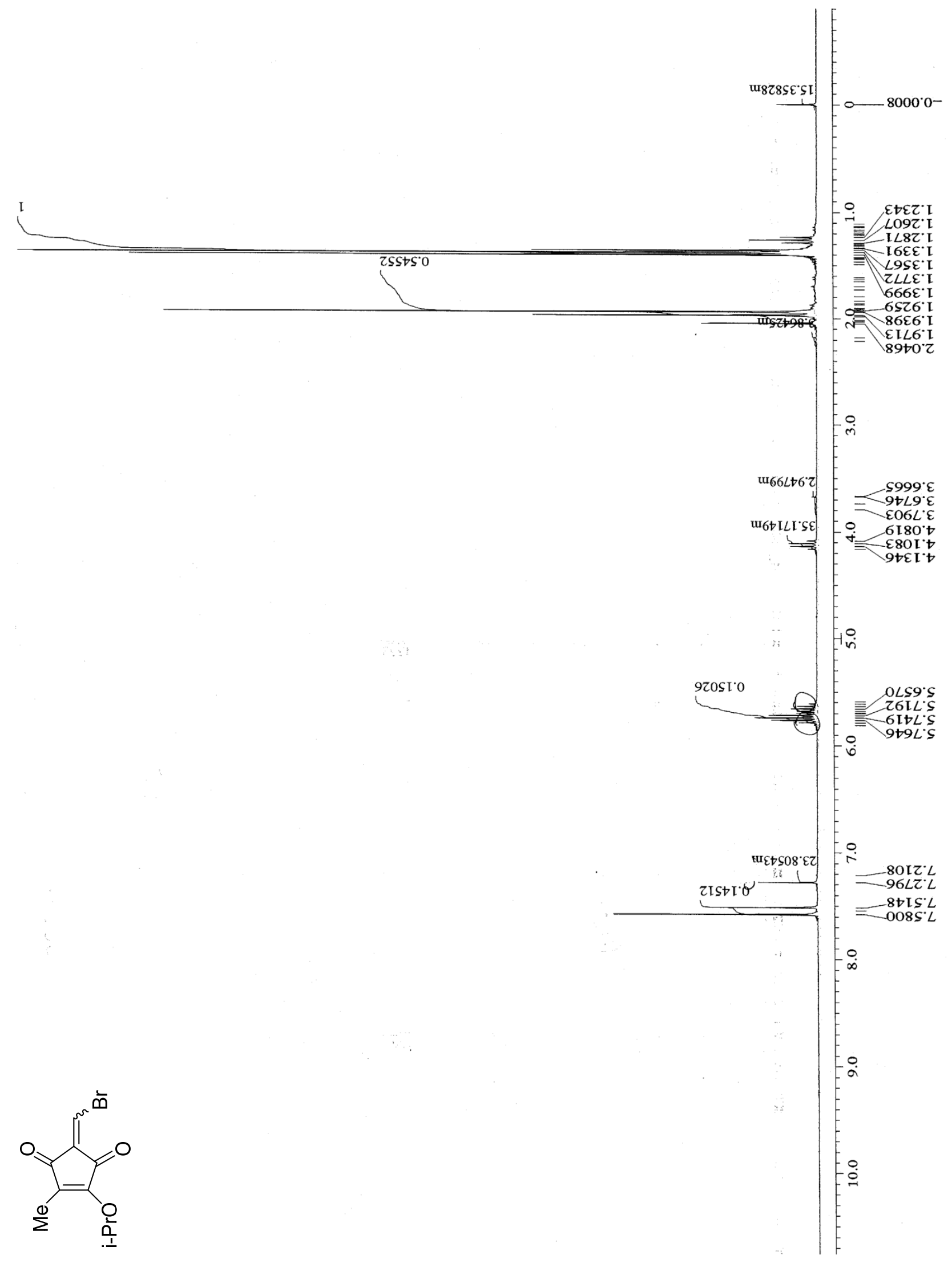

Figure 61: ${ }^{1} \mathrm{H}$ NMR of 2-(1-bromomethylene)-4-(1-methylethoxy)-5-methyl-4-cyclopentene- 


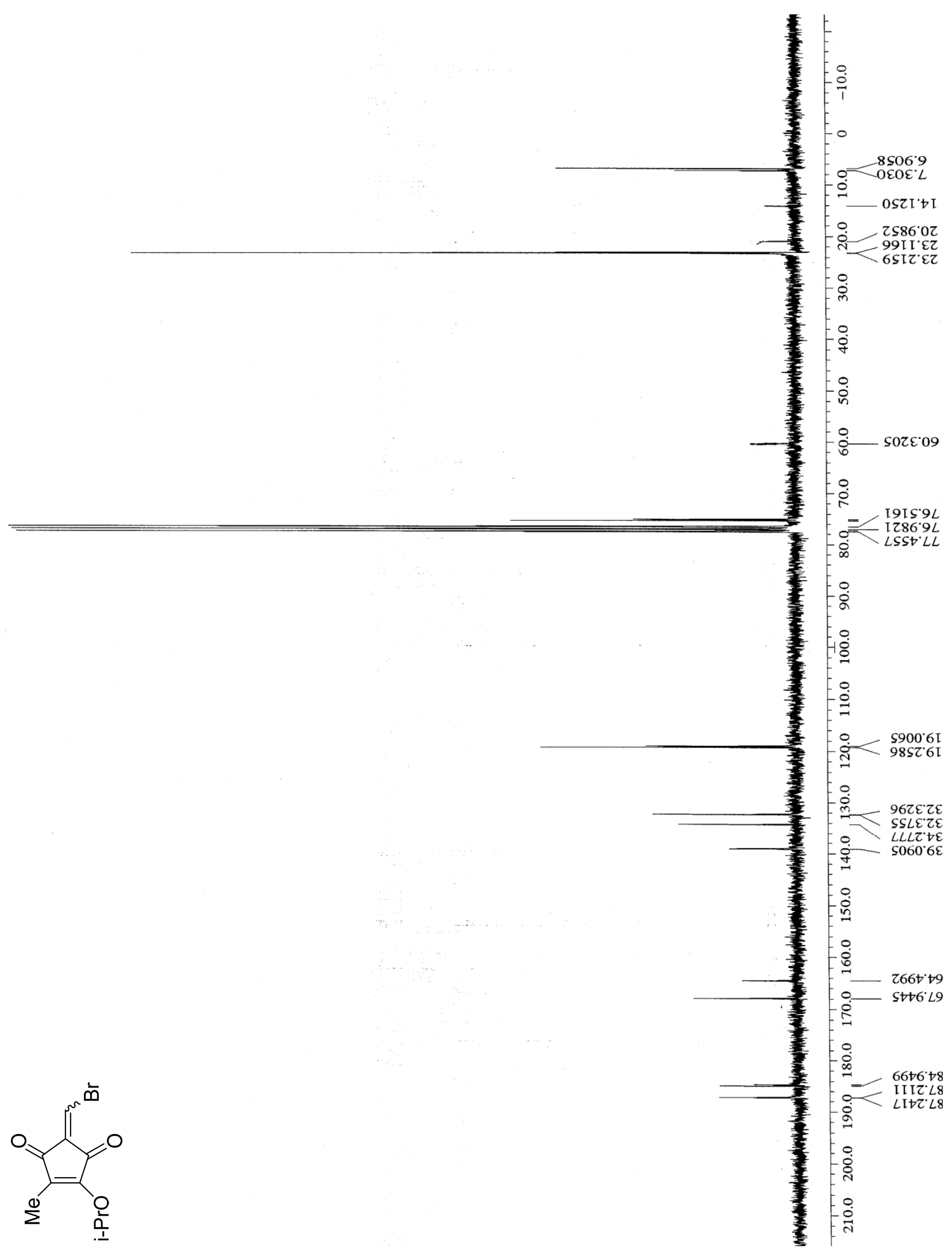

Figure 62: ${ }^{13} \mathrm{C}$ NMR of 2-(1-bromomethylene)-4-(1-methylethoxy)-5-methyl-4-

cyclopentene-1,3-dione (99) 


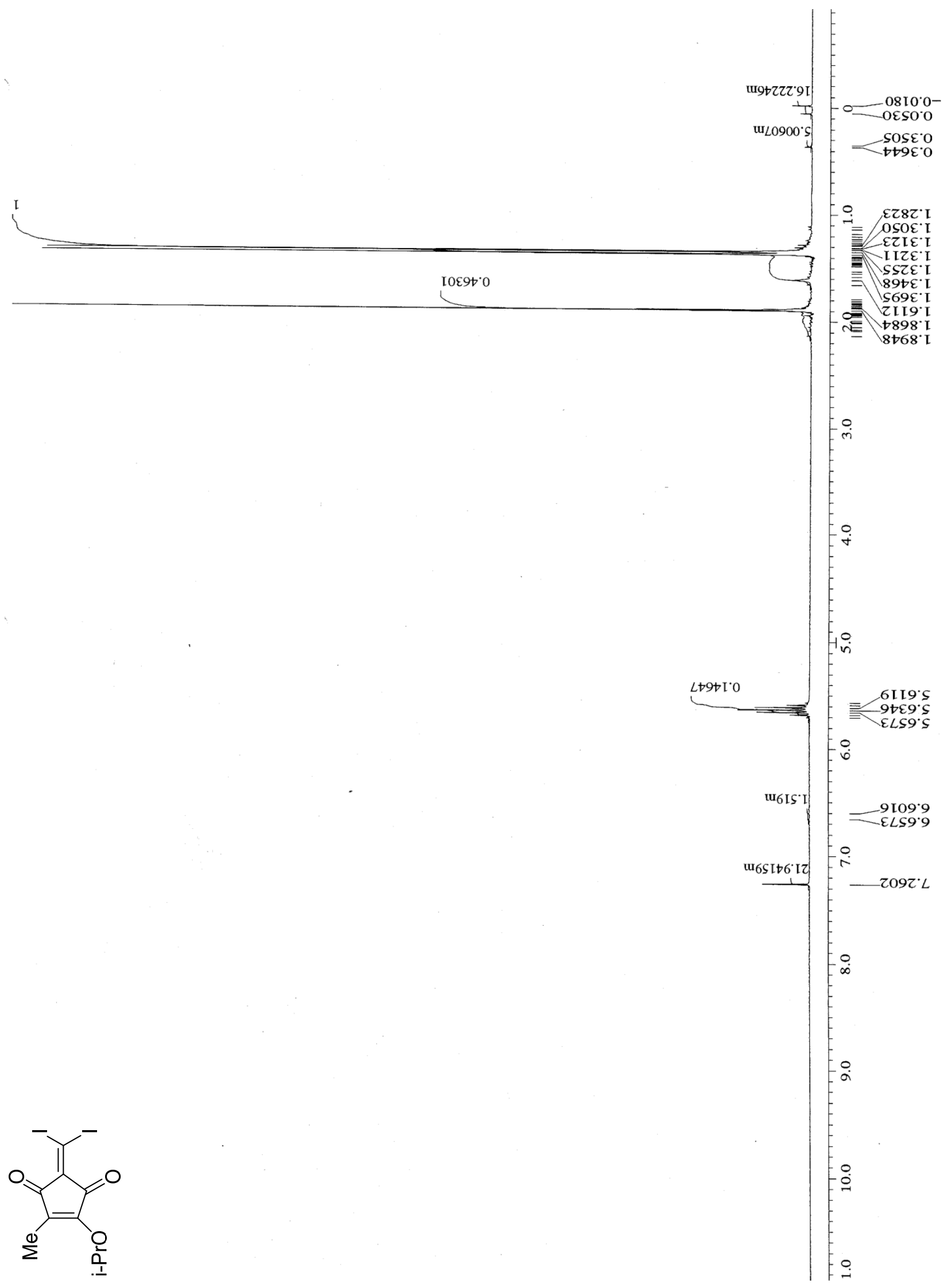

Figure 63: ${ }^{1} \mathrm{H}$ NMR of 2-(diiodomethylene)-4-(1-methylethoxy)-5-methyl-4-cyclopentene-

1,3-dione (101) 


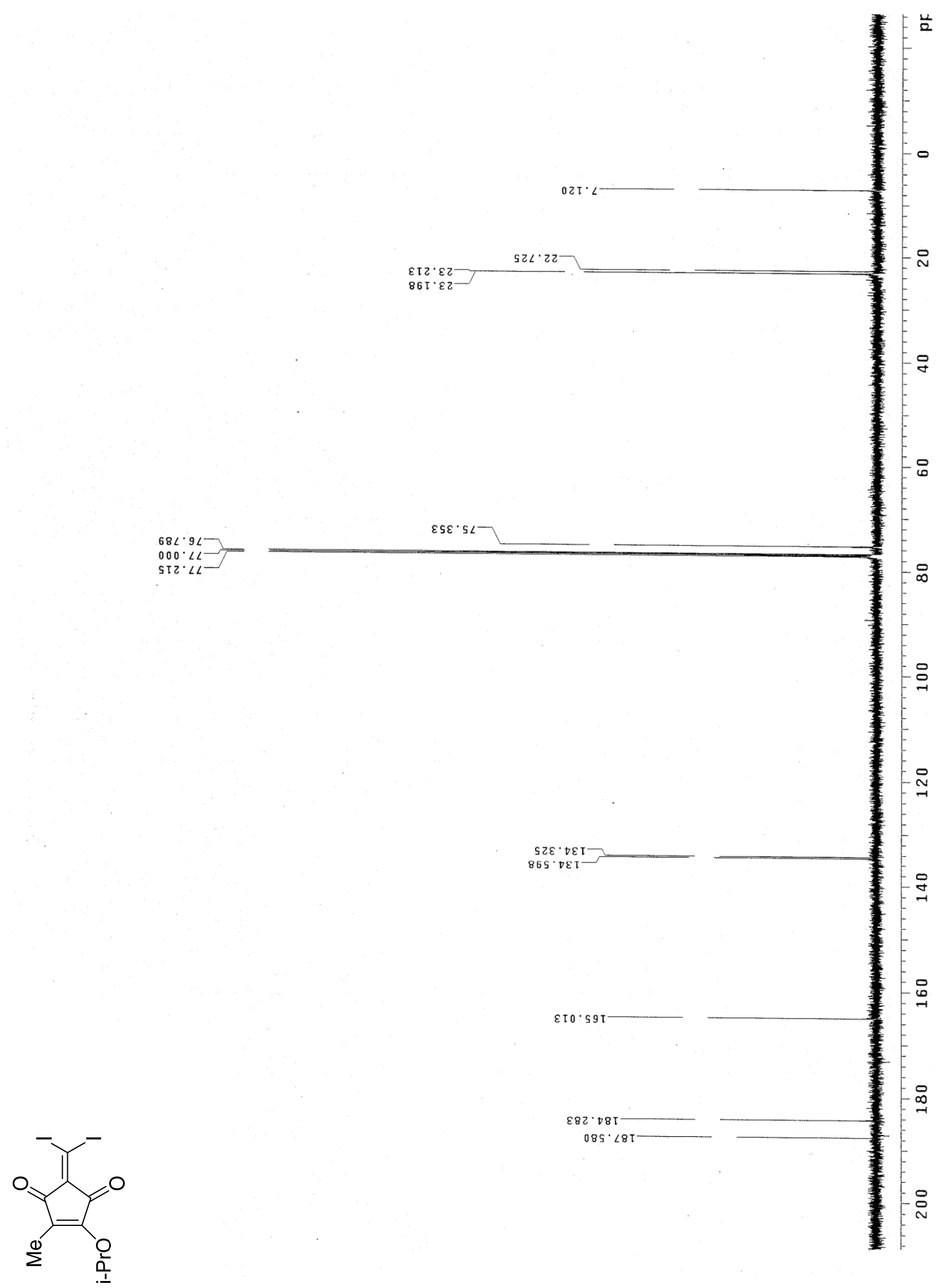

Figure $64:{ }^{13} \mathrm{C}$ NMR of 2-(diiodomethylene)-4-(1-methylethoxy)-5-methyl-4-cyclopentene-

1,3-dione (101) 


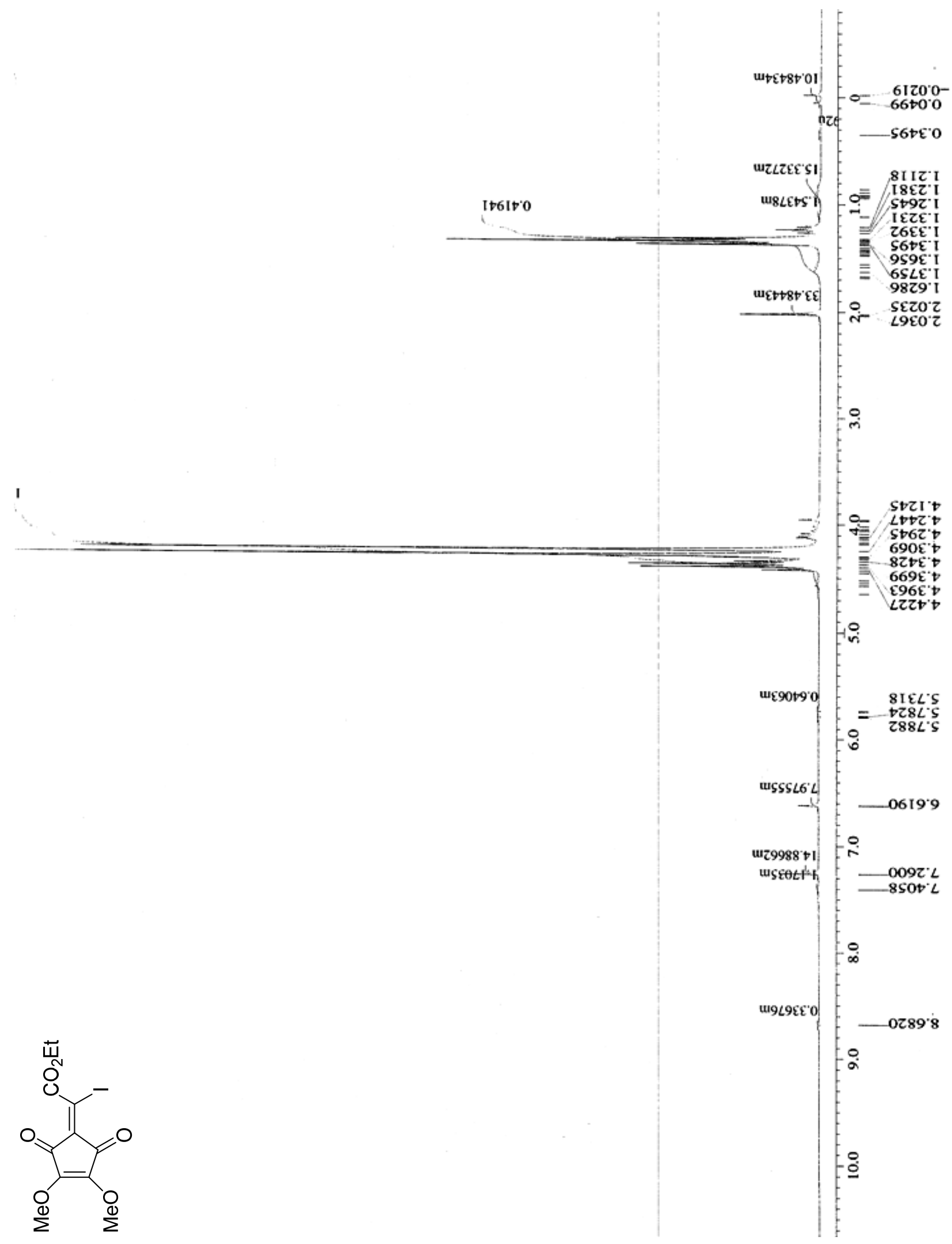

Figure 65: ${ }^{1} \mathrm{H}$ NMR of ethyl 2-(3,4-dimethoxy-2,5-dioxo-3-cyclopenten-1-ylene)-2-

iodoethanoate (104) 


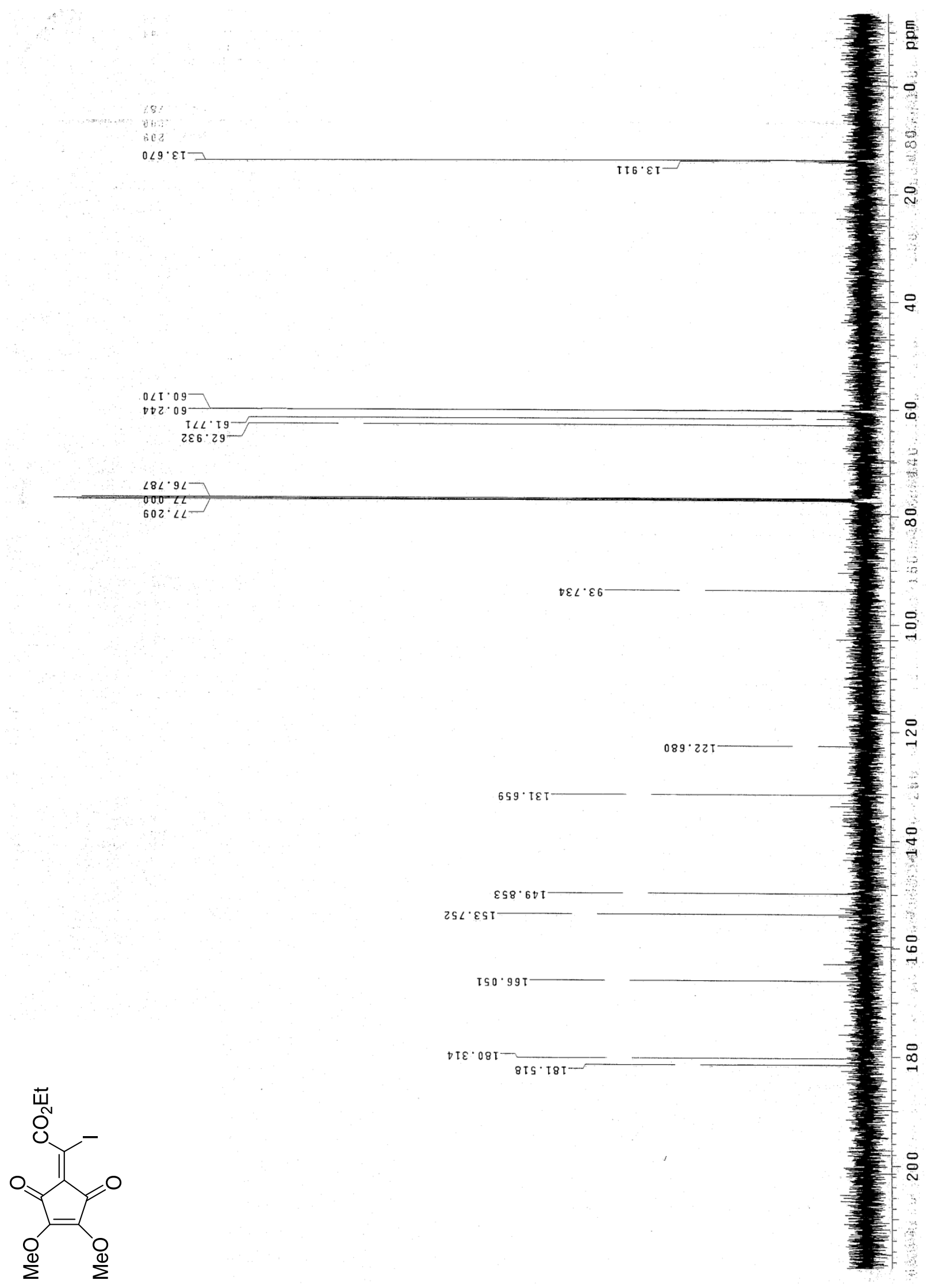

Figure 66: ${ }^{13} \mathrm{C}$ NMR of ethyl 2-(3,4-dimethoxy-2,5-dioxo-3-cyclopenten-1-ylene)-2iodoethanoate (104) 


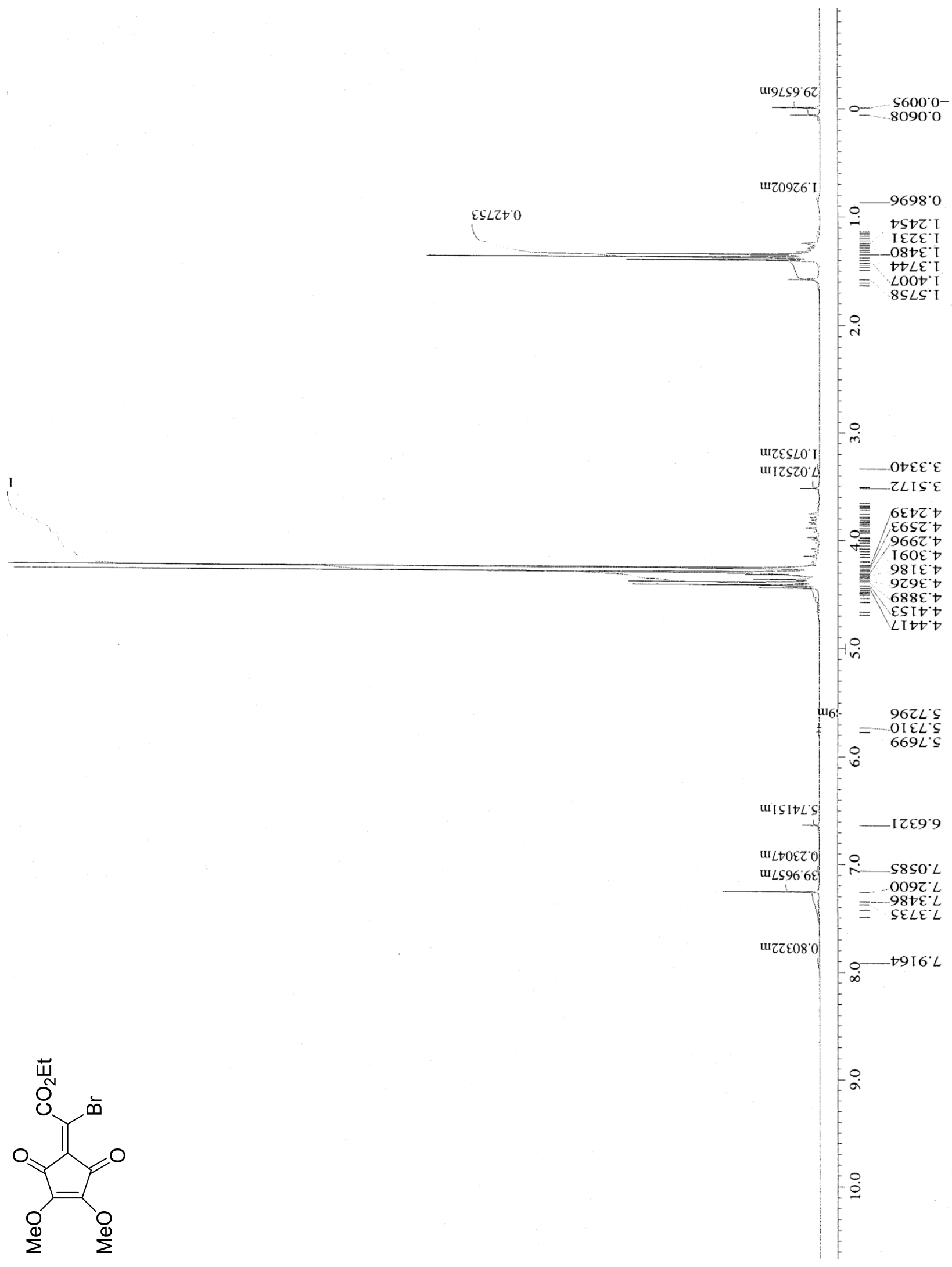

Figure 67: ${ }^{1} \mathrm{H}$ NMR of ethyl 2-(3,4-dimethoxy-2,5-dioxo-3-cyclopenten-1-ylene)-2-

bromoethanoate (105) 


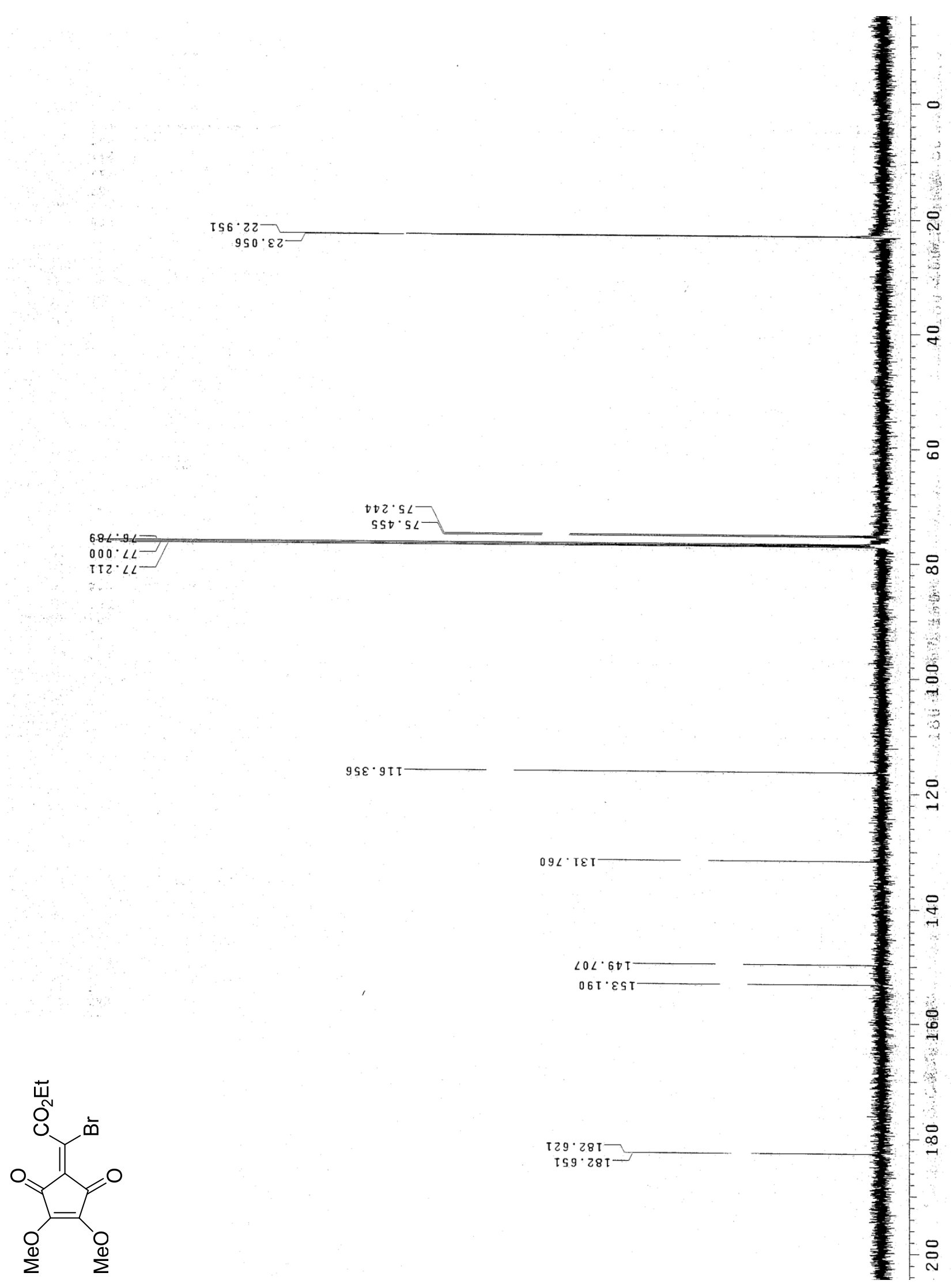

Figure 68: ${ }^{13} \mathrm{C}$ NMR of ethyl 2-(3,4-dimethoxy-2,5-dioxo-3-cyclopenten-1-ylene)-2-

bromoethanoate (105) 
${ }^{1} \mathrm{H}$ and ${ }^{13} \mathrm{C}$ for Chapter 2

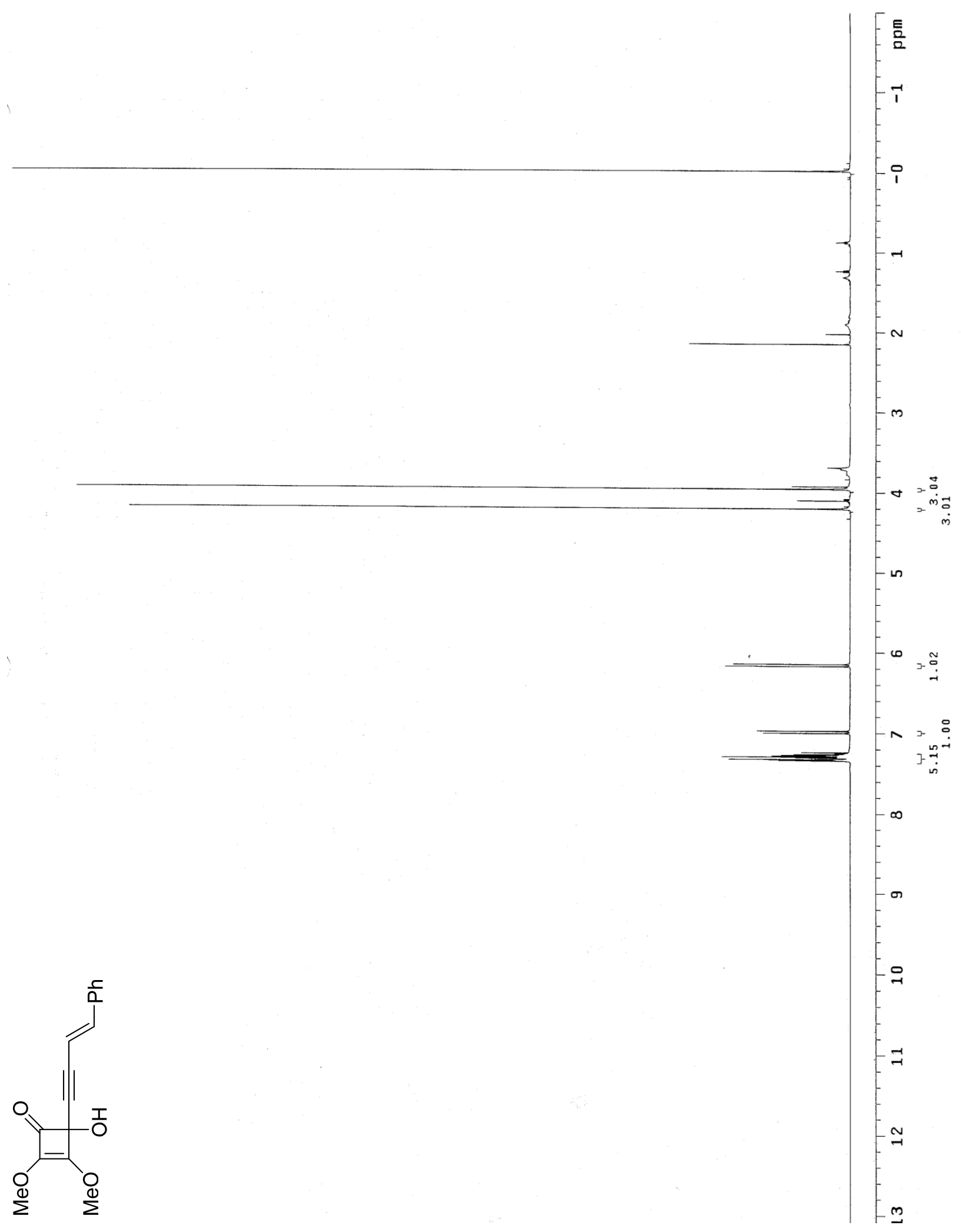

Figure 69: ${ }^{1} \mathrm{H}$ NMR of 2,3-dimethoxy-4-hydroxy-4-[(E)-4-phenyl-3-buten-1-yn-1-yl]-2-

cyclobuten-1-one (137) 


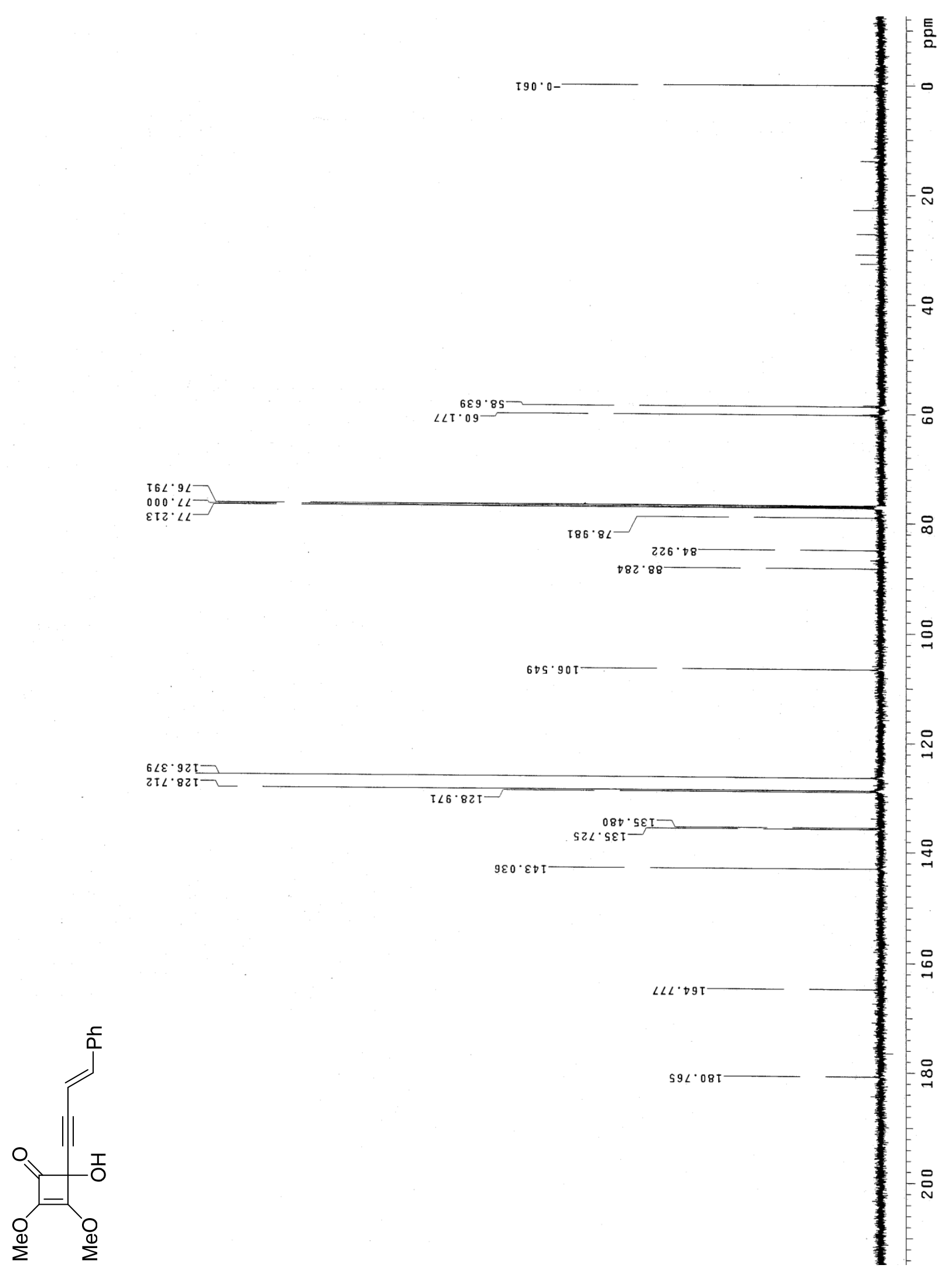

Figure 70: ${ }^{13} \mathrm{C}$ NMR of 2,3-dimethoxy-4-hydroxy-4-[(E)-4-phenyl-3-buten-1-yn-1-yl]-2-

cyclobuten-1-one (137) 


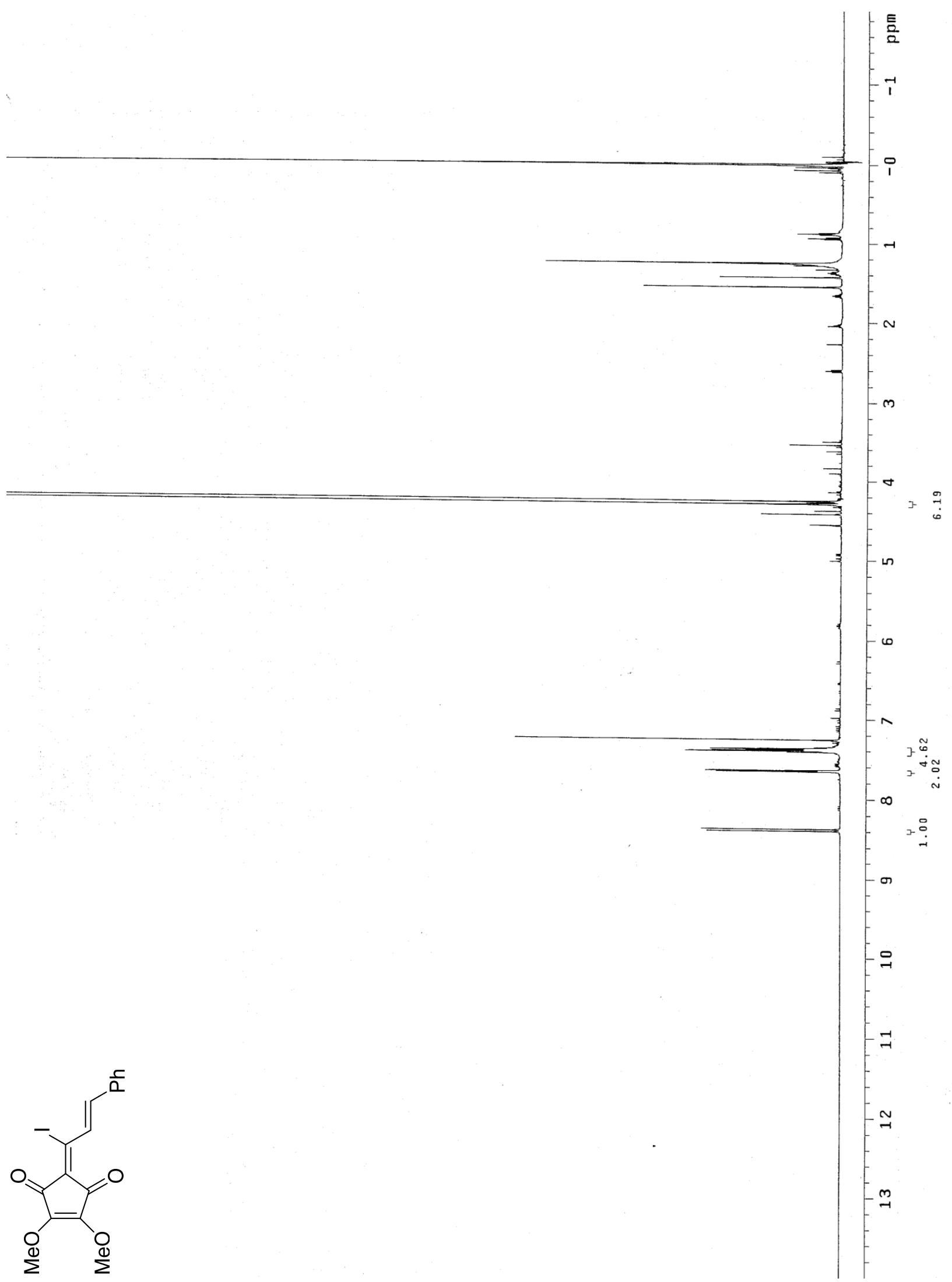

Figure 71: ${ }^{1} \mathrm{H}$ NMR of 4,5-dimethoxy-[(E)-2-(1-iodo-3-phenyl-2-propen-1-ylidene)]-4cyclopentene-1,3-dione (138) 


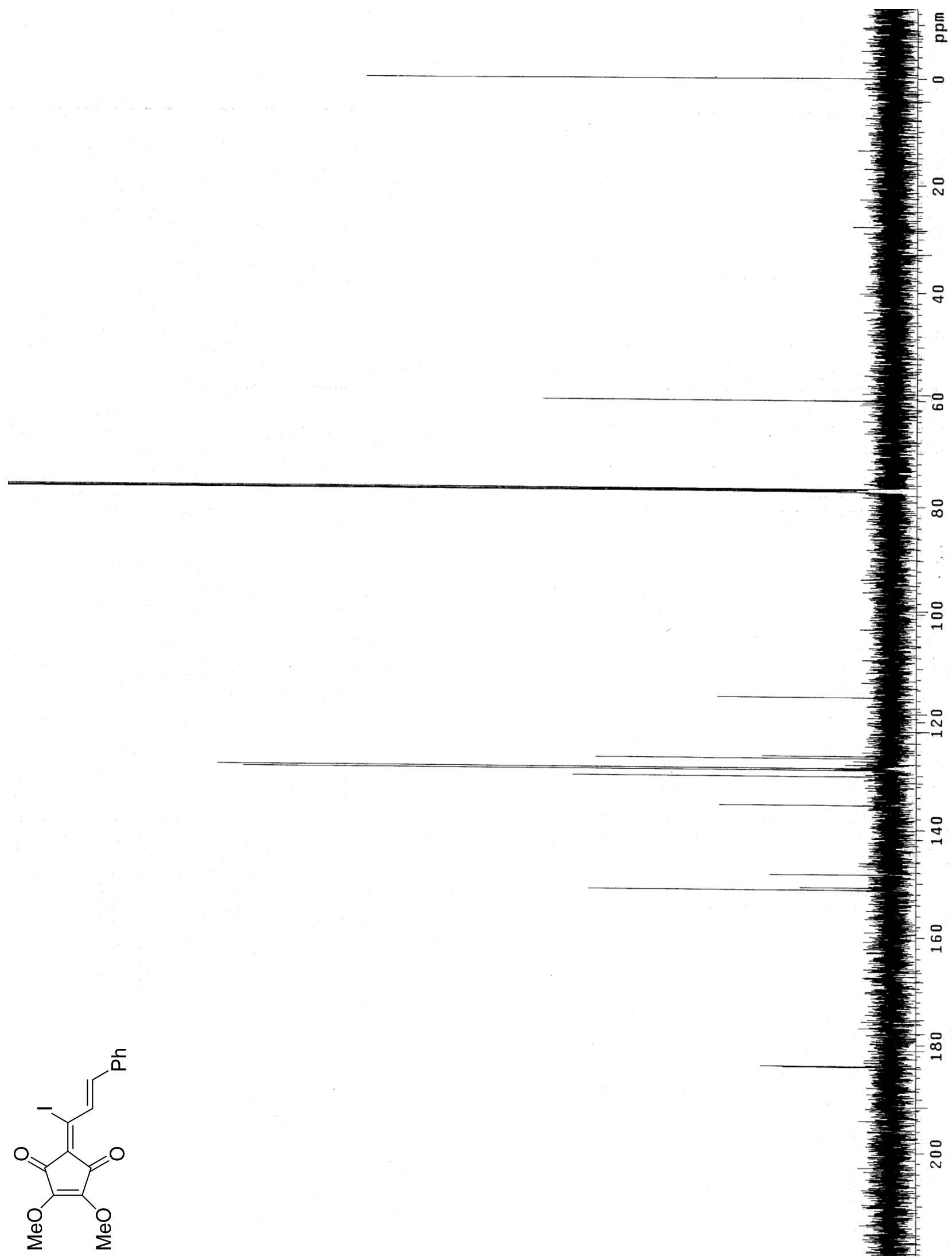

Figure 72: ${ }^{13} \mathrm{C}$ NMR of 4,5-dimethoxy-[(E)-2-(1-iodo-3-phenyl-2-propen-1-ylidene)]-4cyclopentene-1,3-dione (138) 


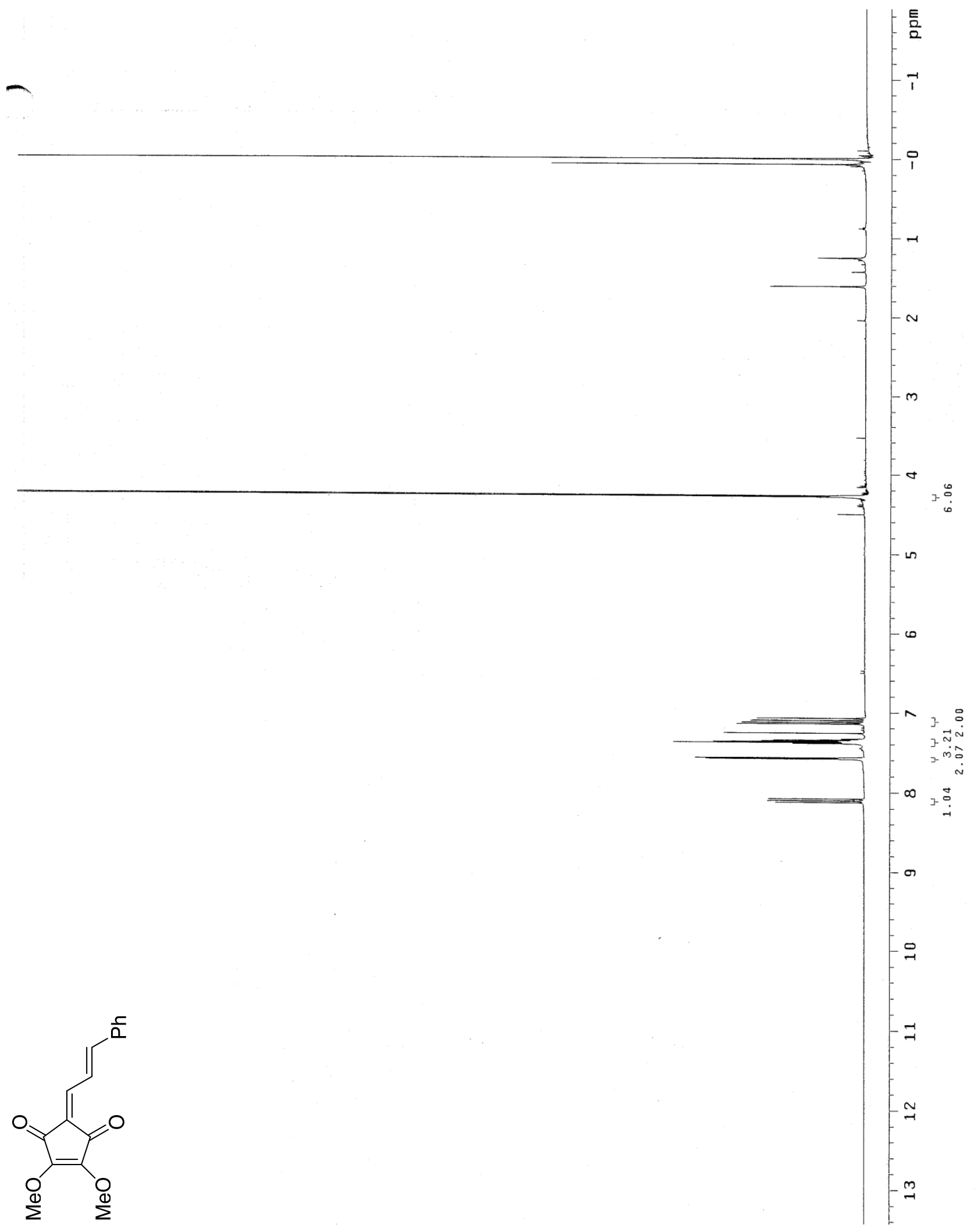

Figure 73: ${ }^{1} \mathrm{H}$ NMR of 4,5-dimethoxy-2-[(E)-3-phenyl-2-propen-1-ylidene]-4-

cyclopente-1,3-dione (139) 


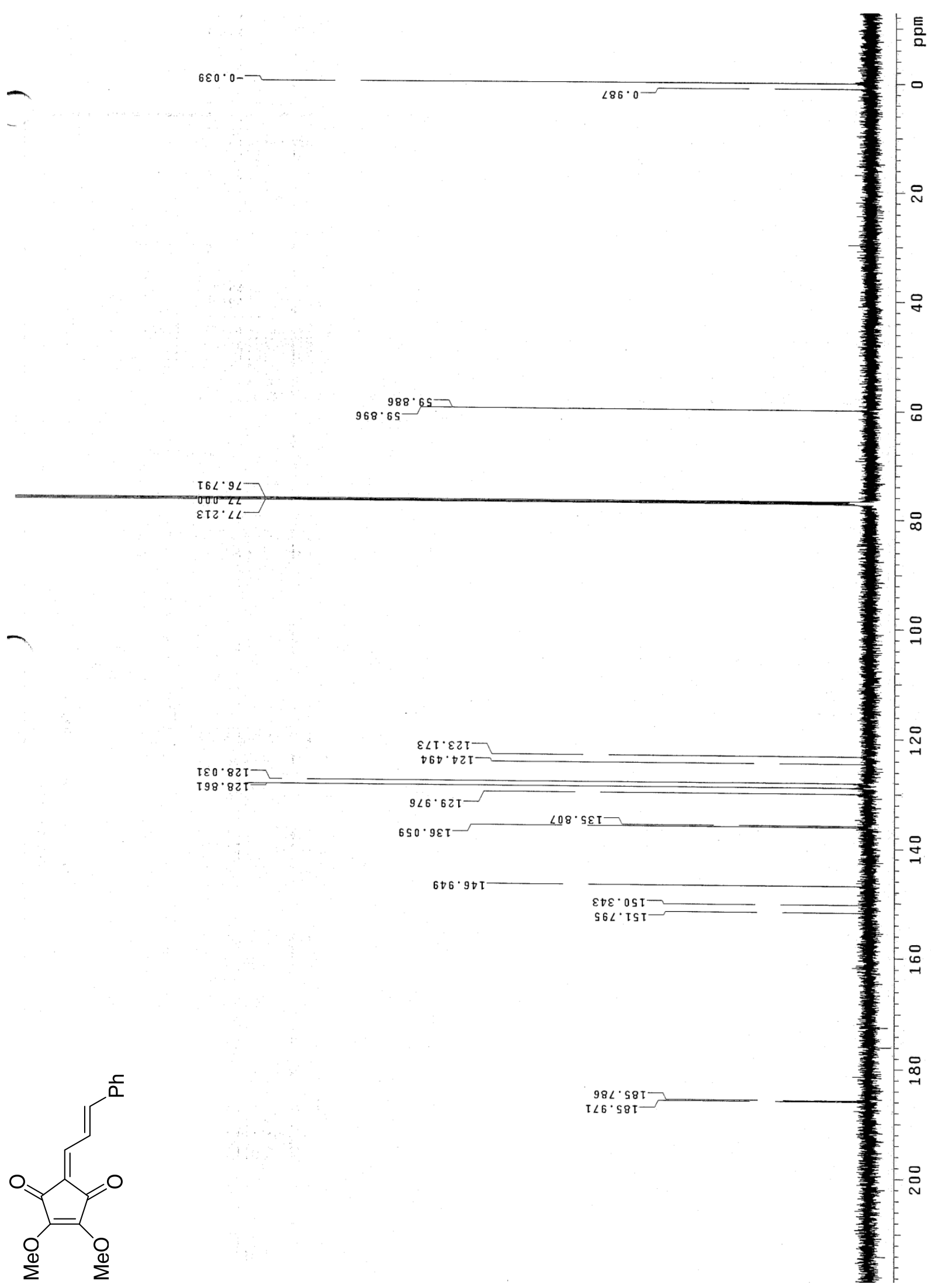

Figure 74: ${ }^{13} \mathrm{C}$ NMR of 4,5-dimethoxy-2-[(E)-3-phenyl-2-propen-1-ylidene]-4-

cyclopente-1,3-dione (139) 


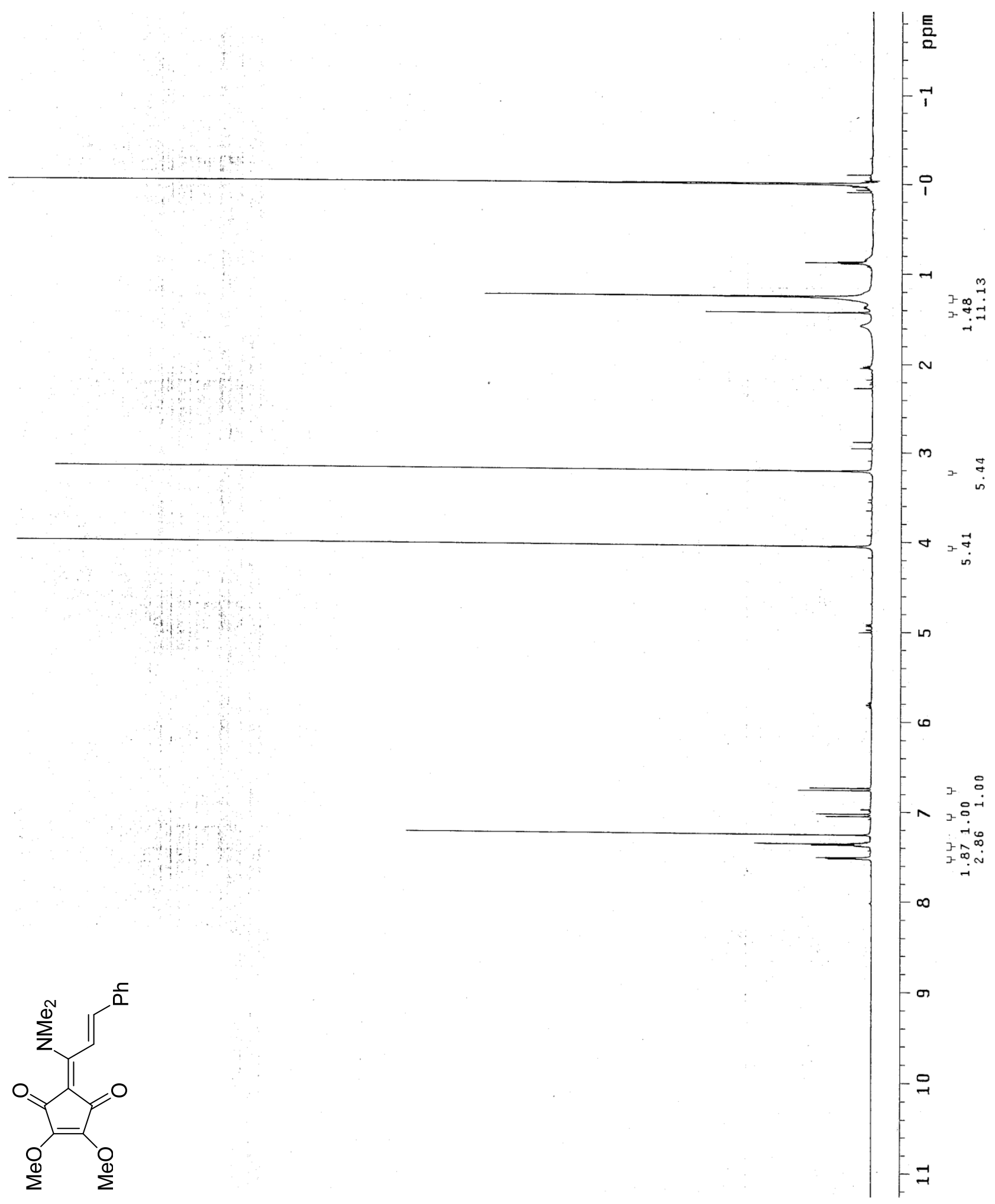

Figure 75: ${ }^{1} \mathrm{H}$ NMR of 4,5-dimethoxy-2-[(E)-1-(N,N-dimethylamino)-3-phenyl-2-propen-1ylidene]-4-cyclopente-1,3-dione (140) 


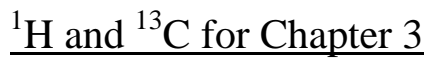

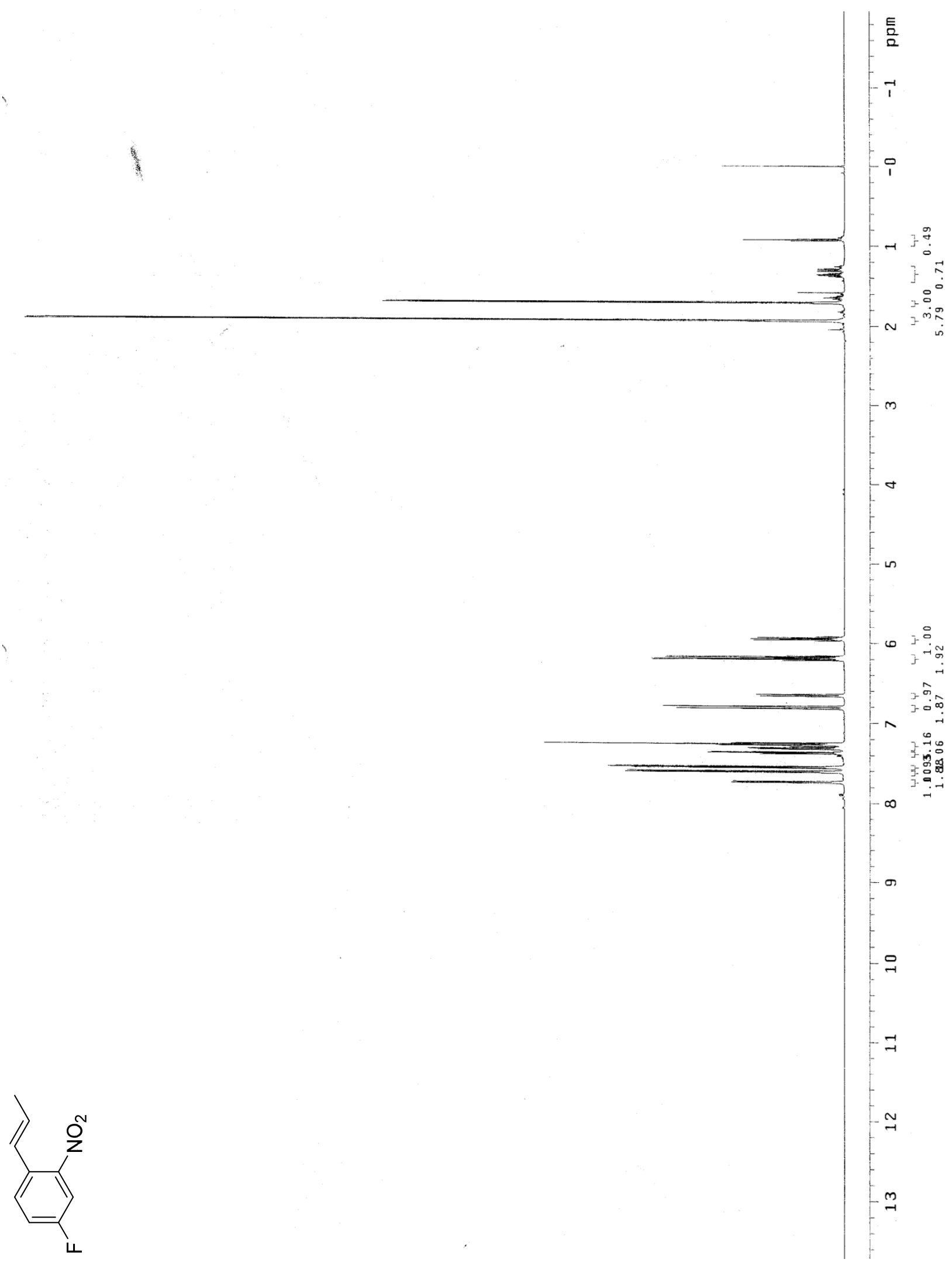

Figure 76: ${ }^{1} \mathrm{H}$ NMR of 4-fluoro-2-nitro-1-(1-propen-1-yl)benzene (233) 


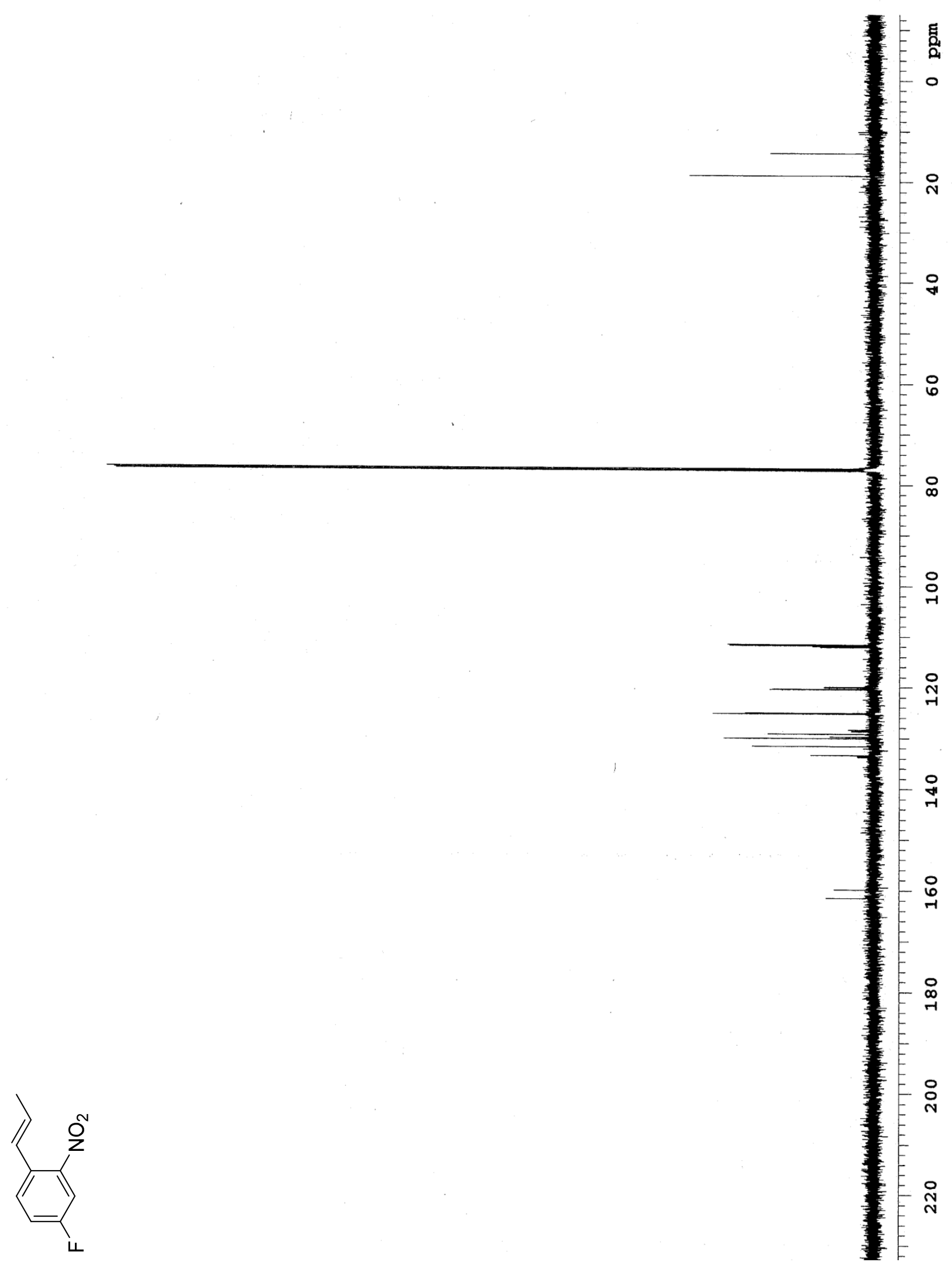

Figure 77: ${ }^{13} \mathrm{C}$ NMR of 4-fluoro-2-nitro-1-(1-propen-1-yl)benzene (233) 


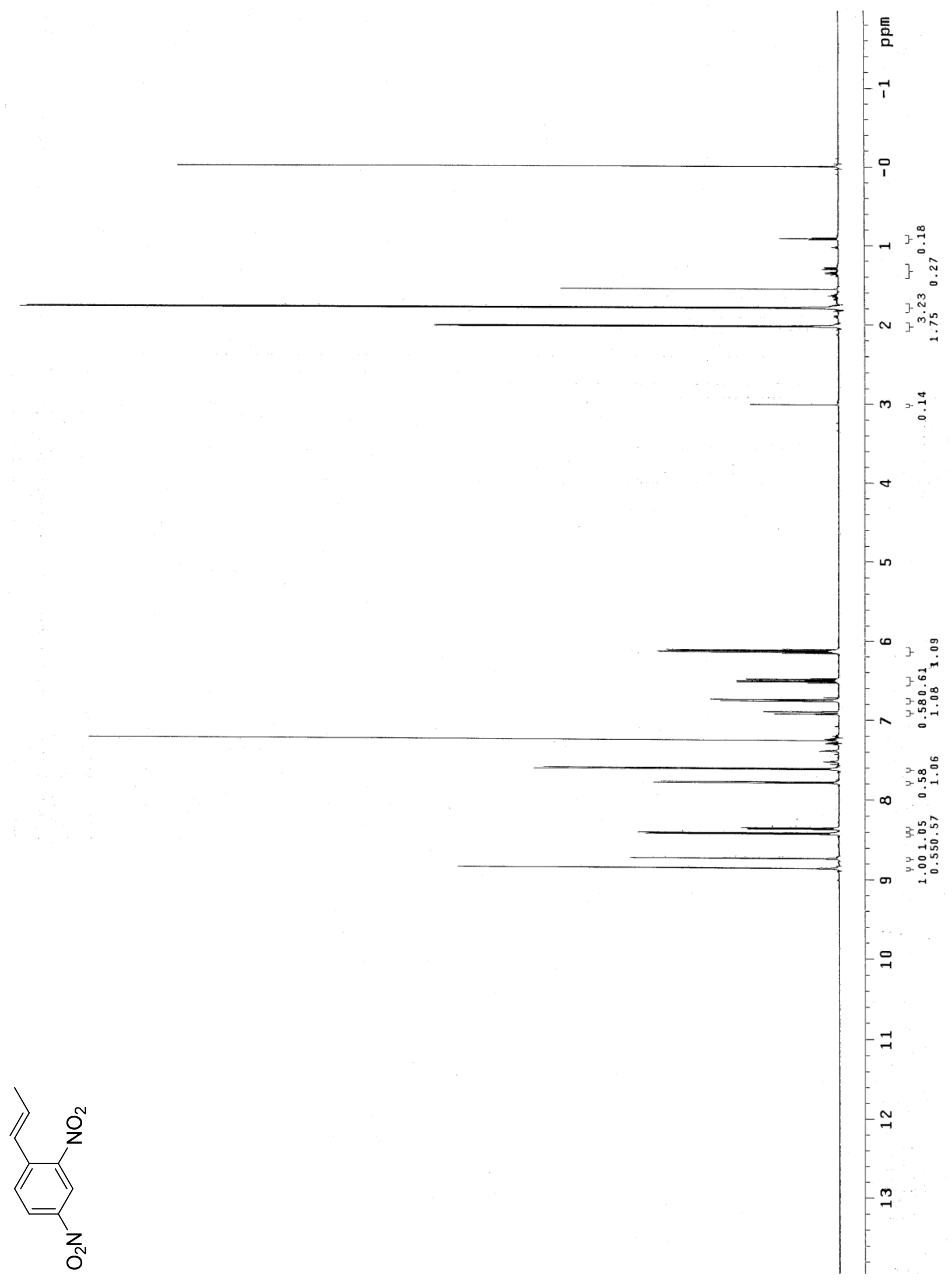

Figure 78: ${ }^{1} \mathrm{H}$ NMR of 2,4-dinitro-1-(1-propen-1-yl)benzene (234) 


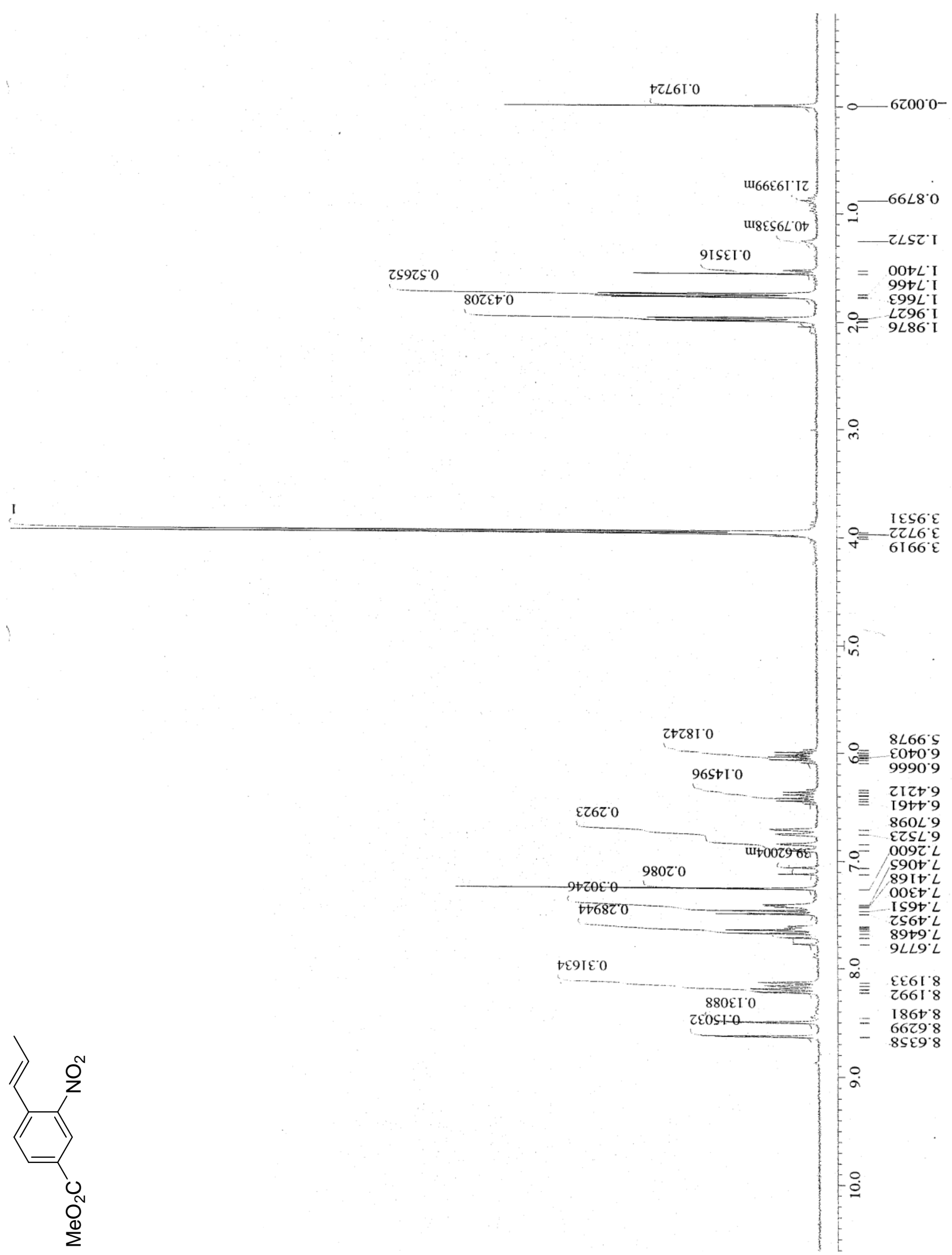

Figure 79: ${ }^{1} \mathrm{H}$ NMR of 4-carbomethoxy-2-nitro-1-(1-propen-1-yl)benzene (235) 


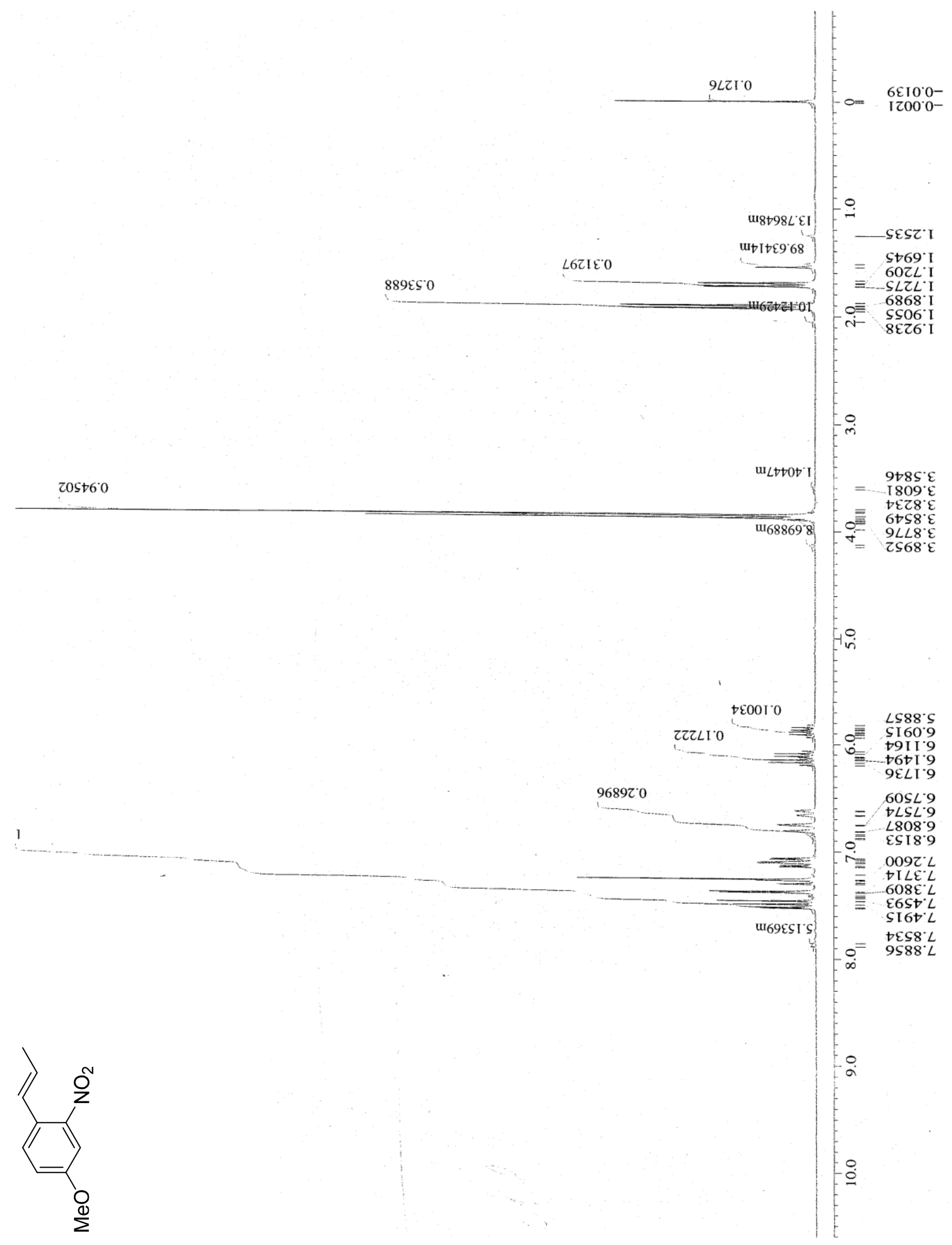

Figure 80: ${ }^{1} \mathrm{H}$ NMR of 4-methoxy-2-nitro-1-(1-propen-1-yl)benzene (236) 


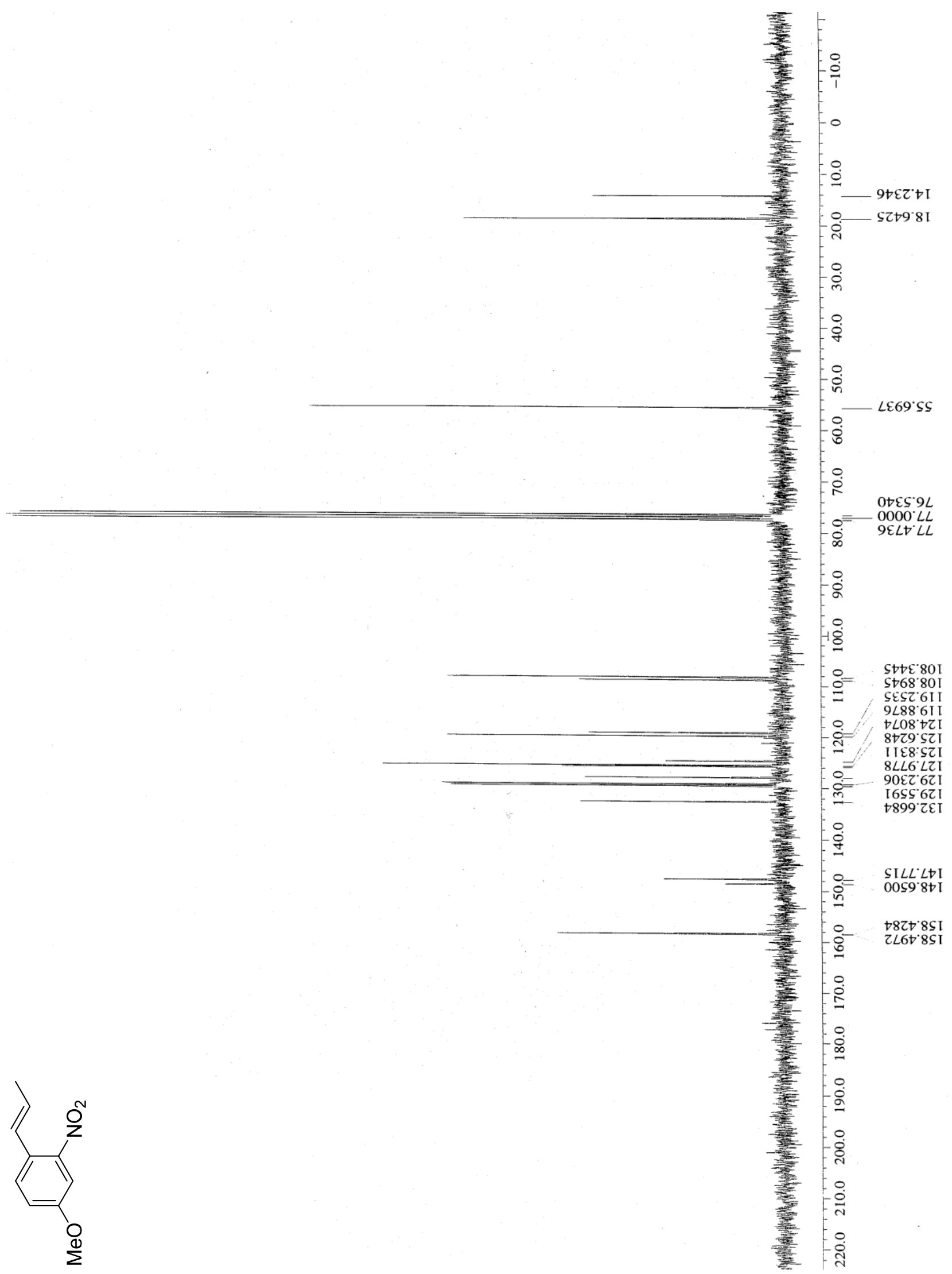

Figure 81: ${ }^{13} \mathrm{C}$ NMR of 4-methoxy-2-nitro-1-(1-propen-1-yl)benzene (236) 


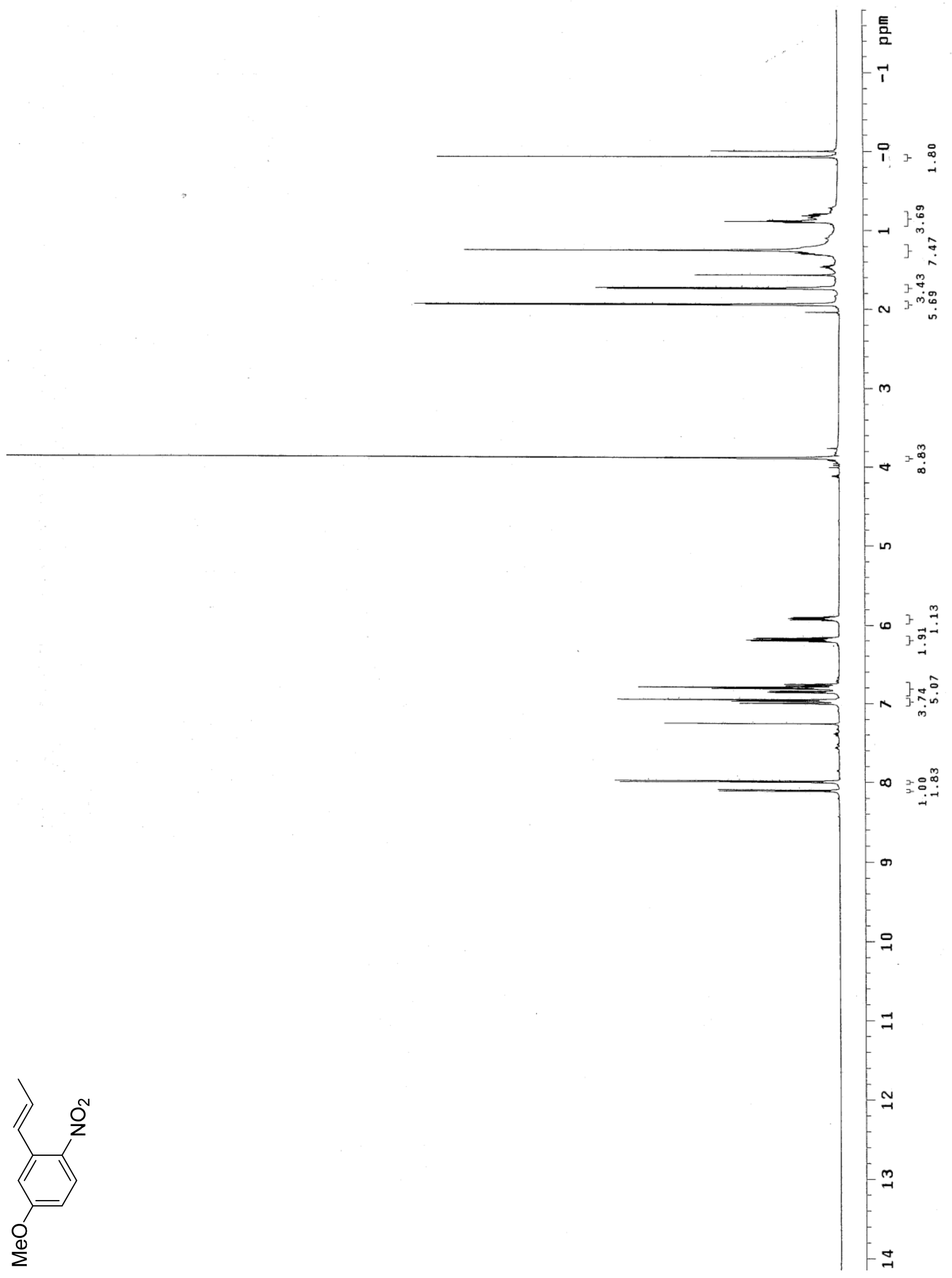

Figure 82: ${ }^{1} \mathrm{H}$ NMR of 5-methoxy-2-nitro-1-(1-propen-1-yl)-benzene (8) 


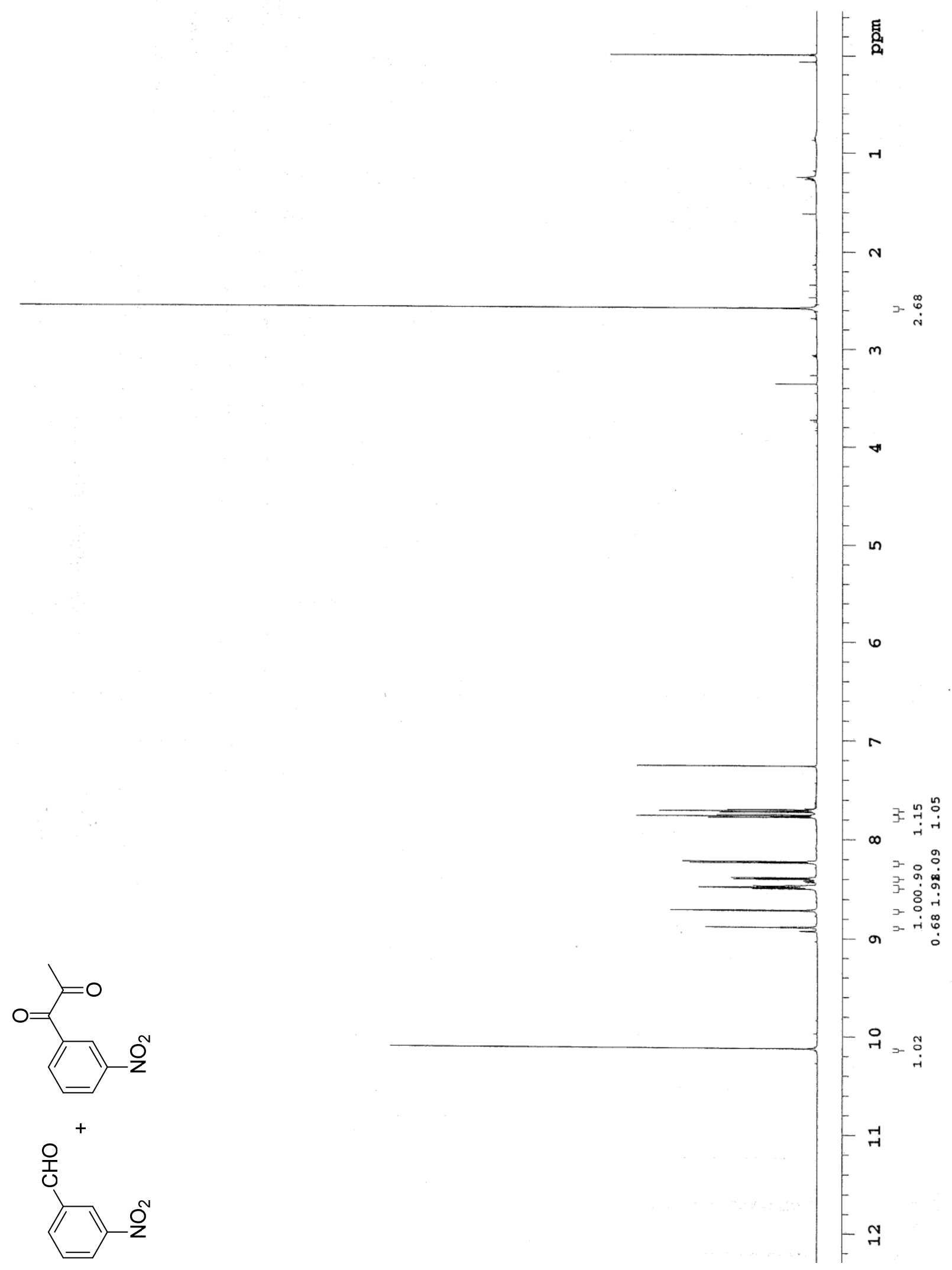

Figure 83: ${ }^{1} \mathrm{H}$ NMR of 3-nitrobenzaldehyde (250) and

1-(3-nitrophenyl)-1,2-propandione (251) 


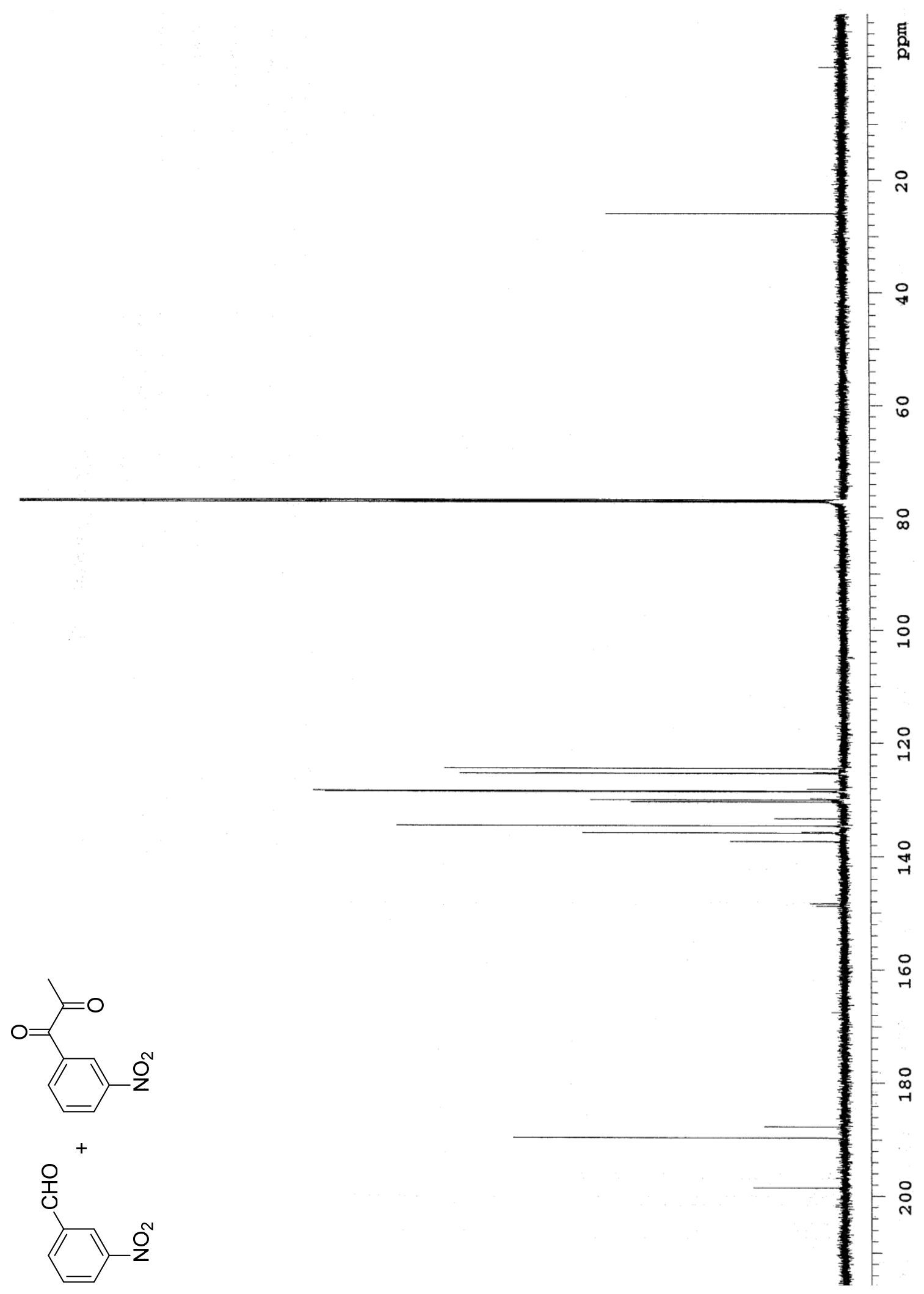

Figure $84:{ }^{13} \mathrm{C}$ NMR of 3-nitrobenzaldehyde (250) and

1-(3-nitrophenyl)-1,2-propandione (251) 


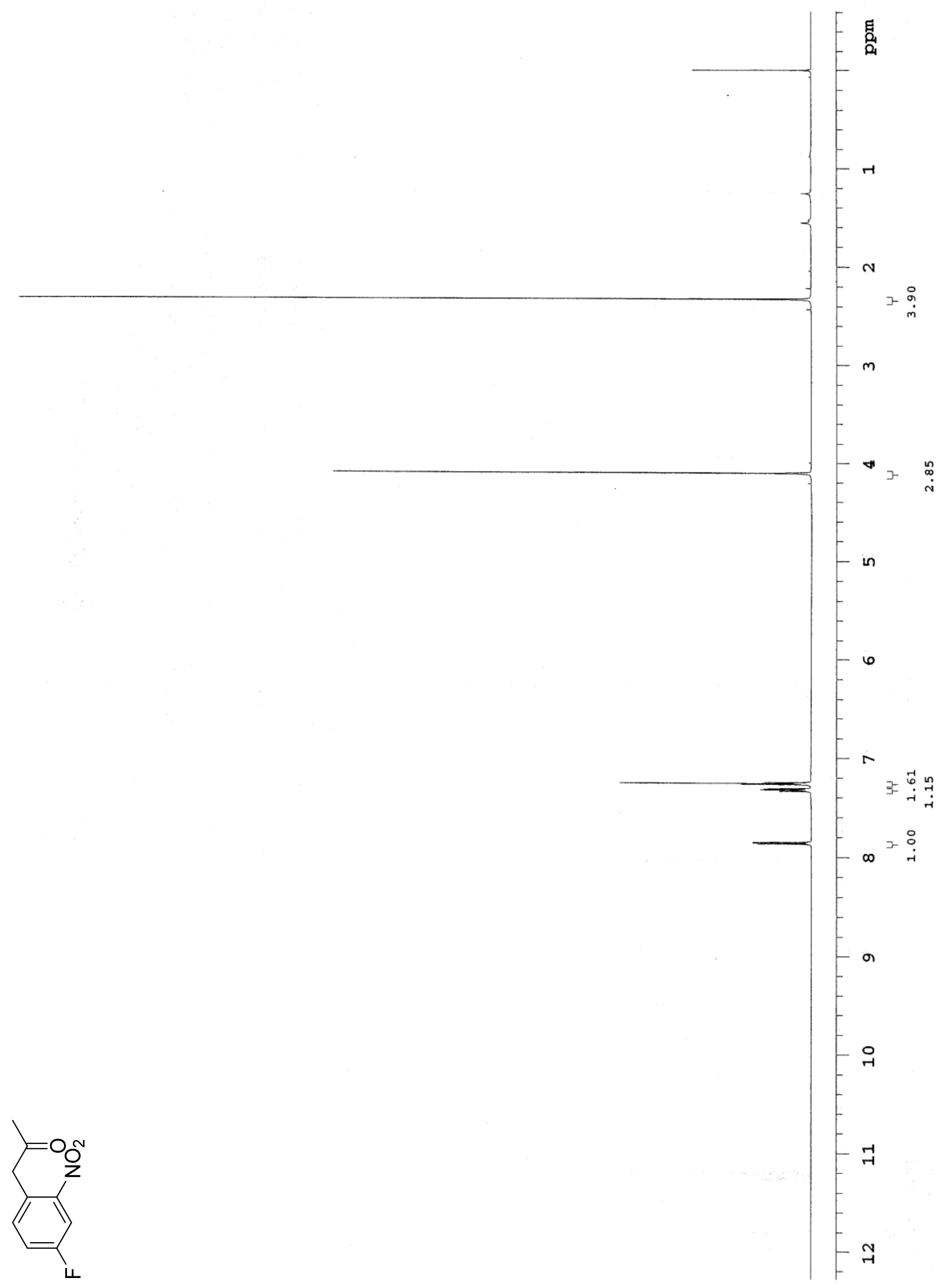

Figure 85: ${ }^{1} \mathrm{H}$ NMR of 1-(4-fluoro-2-nitrophenyl)-2-propanone (257) 


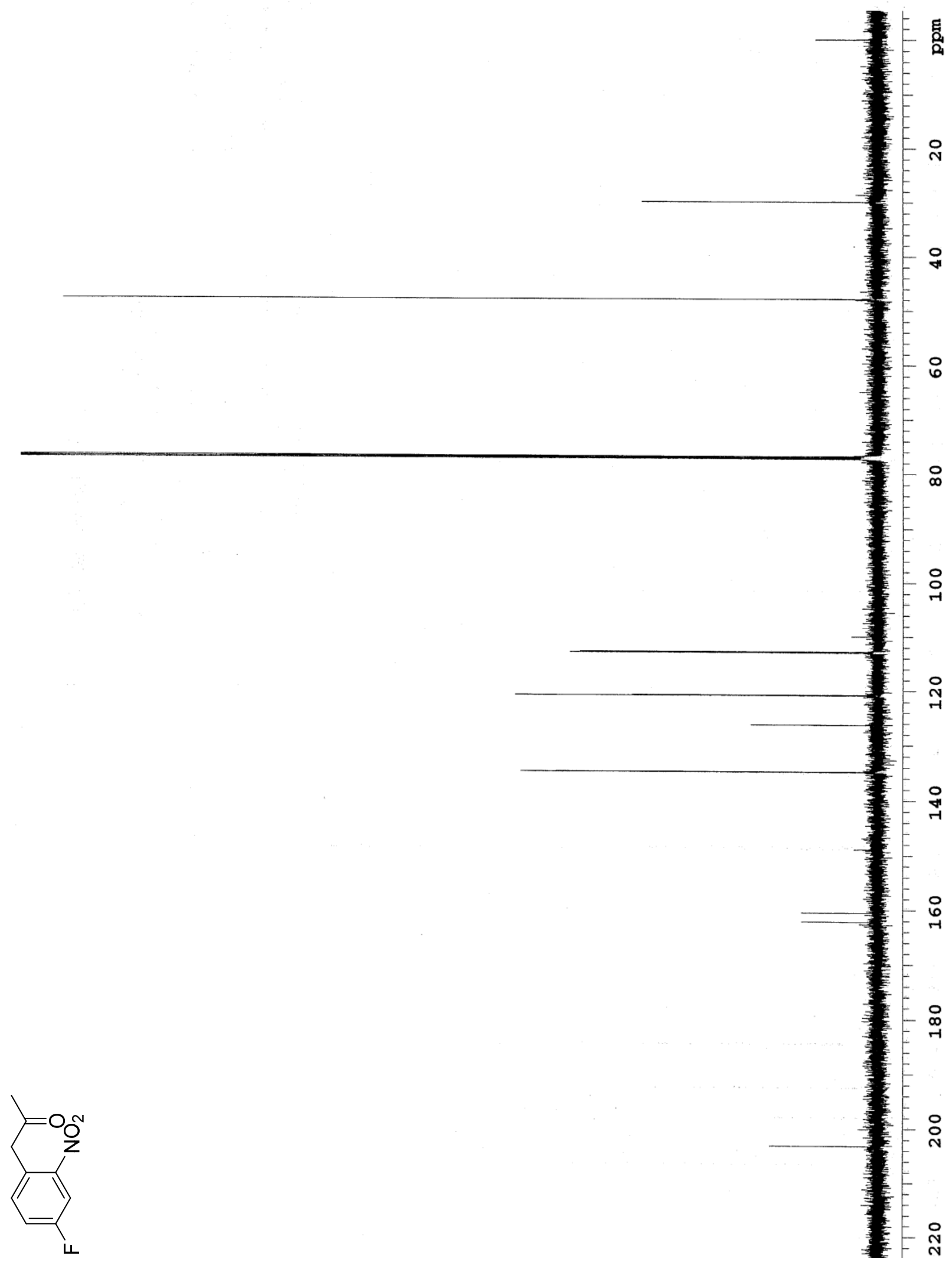

Figure 86: ${ }^{13} \mathrm{C}$ NMR of 1-(4-fluoro-2-nitrophenyl)-2-propanone (257) 


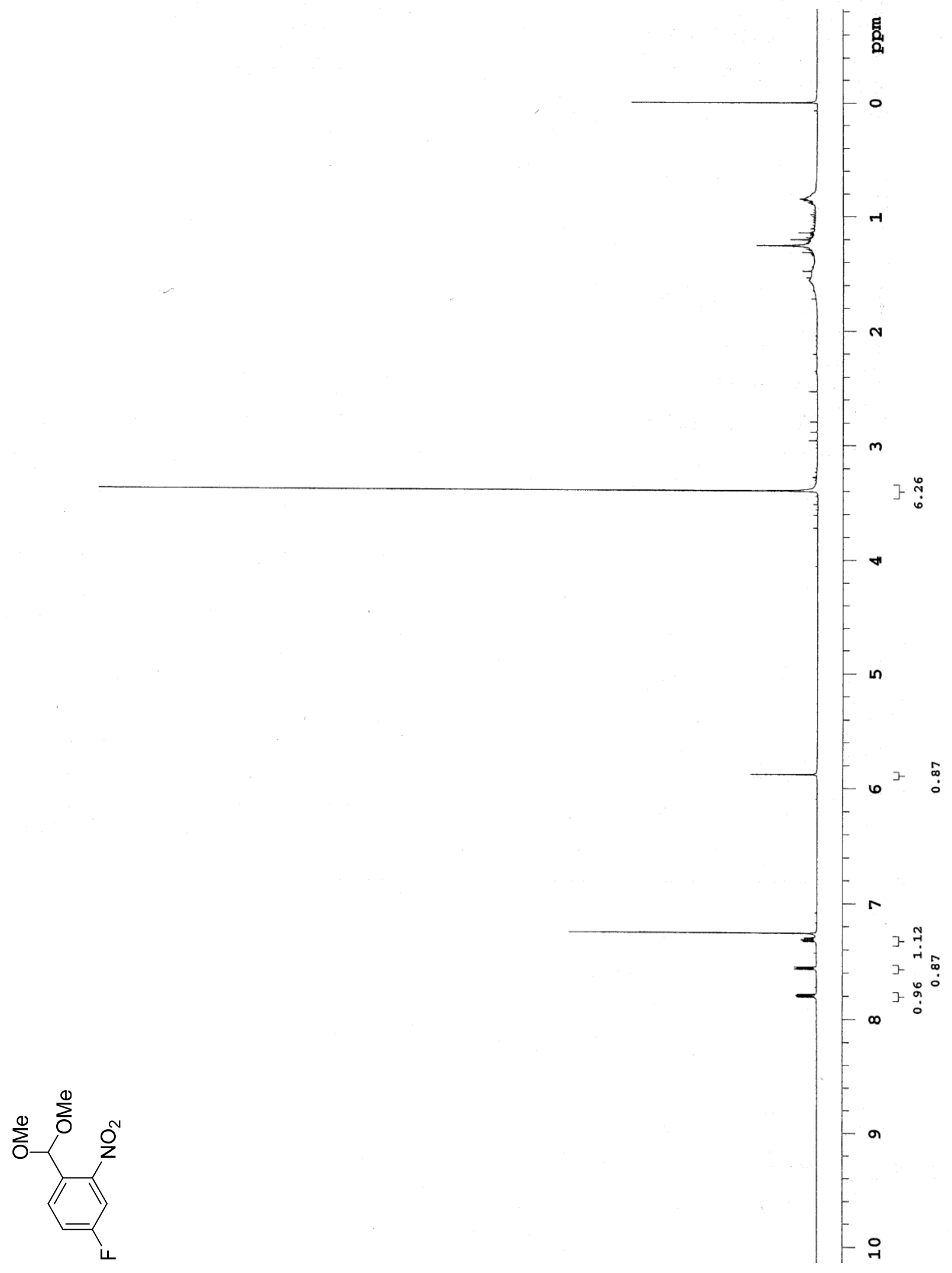

Figure 87: ${ }^{1} \mathrm{H}$ NMR of 4-fluoro-1-(1,1-dimethoxymethyl)-2-Nitrobenzene (258) 


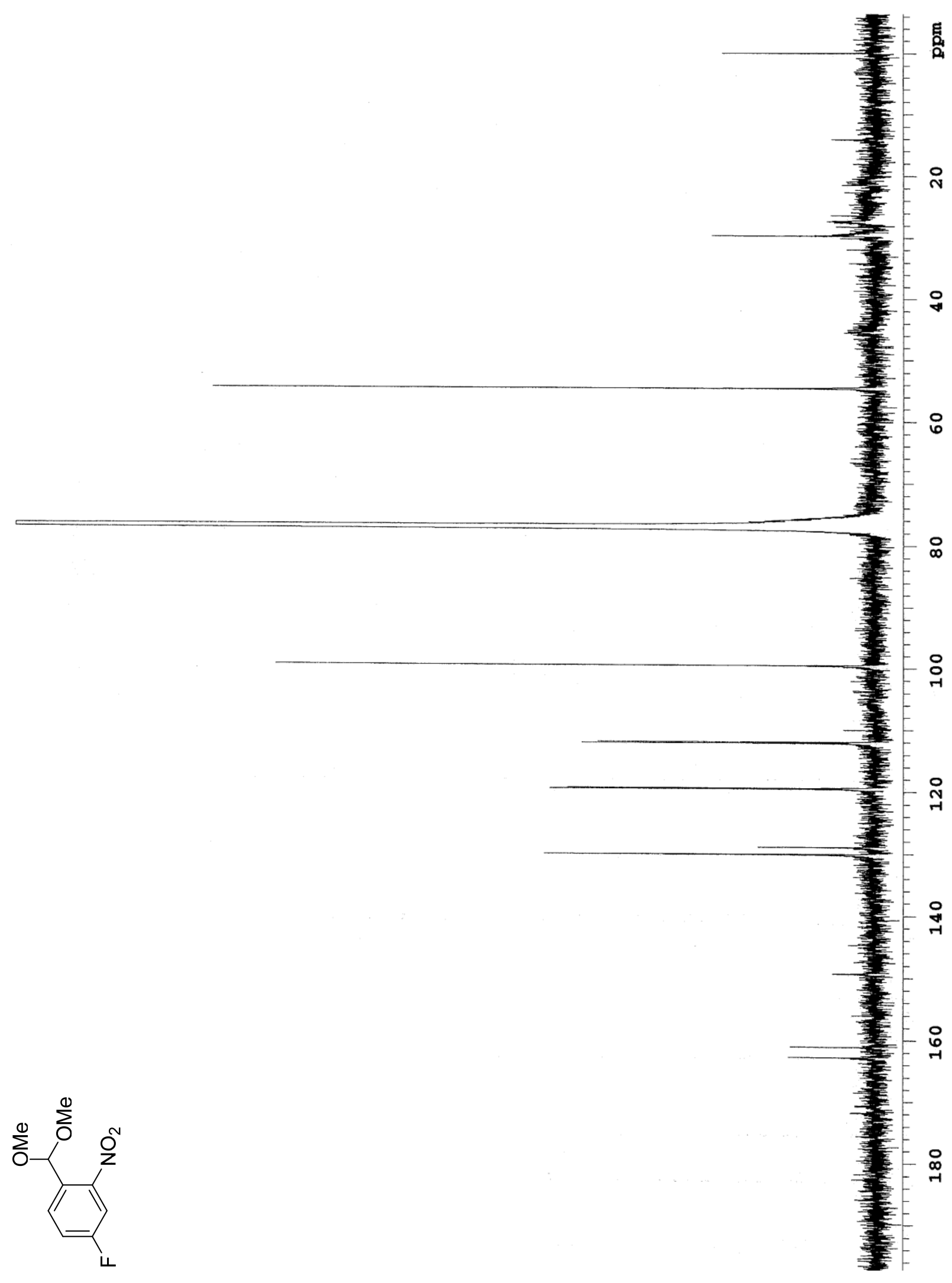

Figure 88: ${ }^{13} \mathrm{C}$ NMR of 4-fluoro-1-(1,1-dimethoxymethyl)-2-Nitrobenzene (258) 


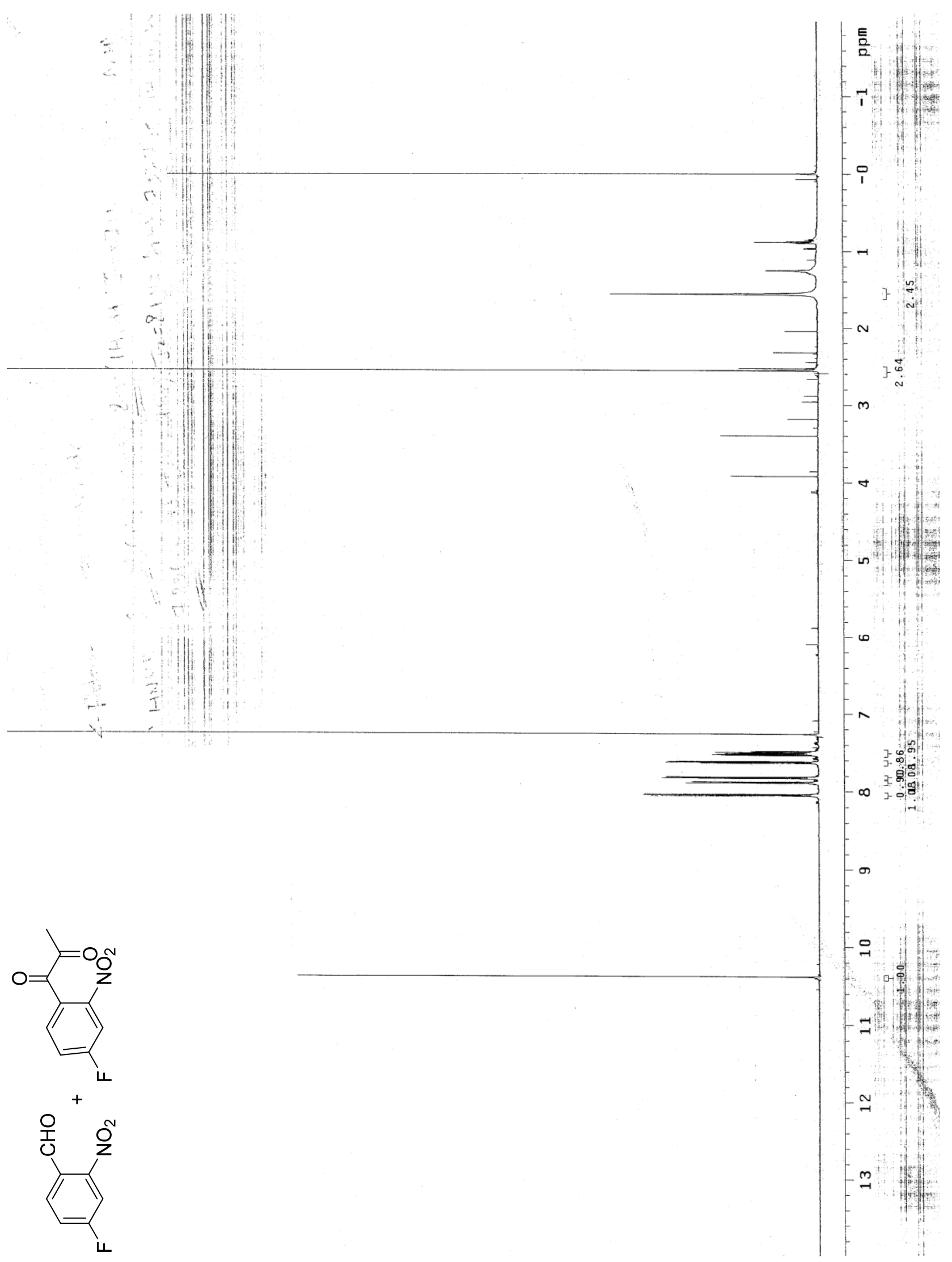

Figure 89: ${ }^{1} \mathrm{H}$ NMR of 4-fluoro-2-nitrobenzaldehyde (259) and 1-(4-fluoro-2-nitrophenyl)-1,2-propanedione (260) 


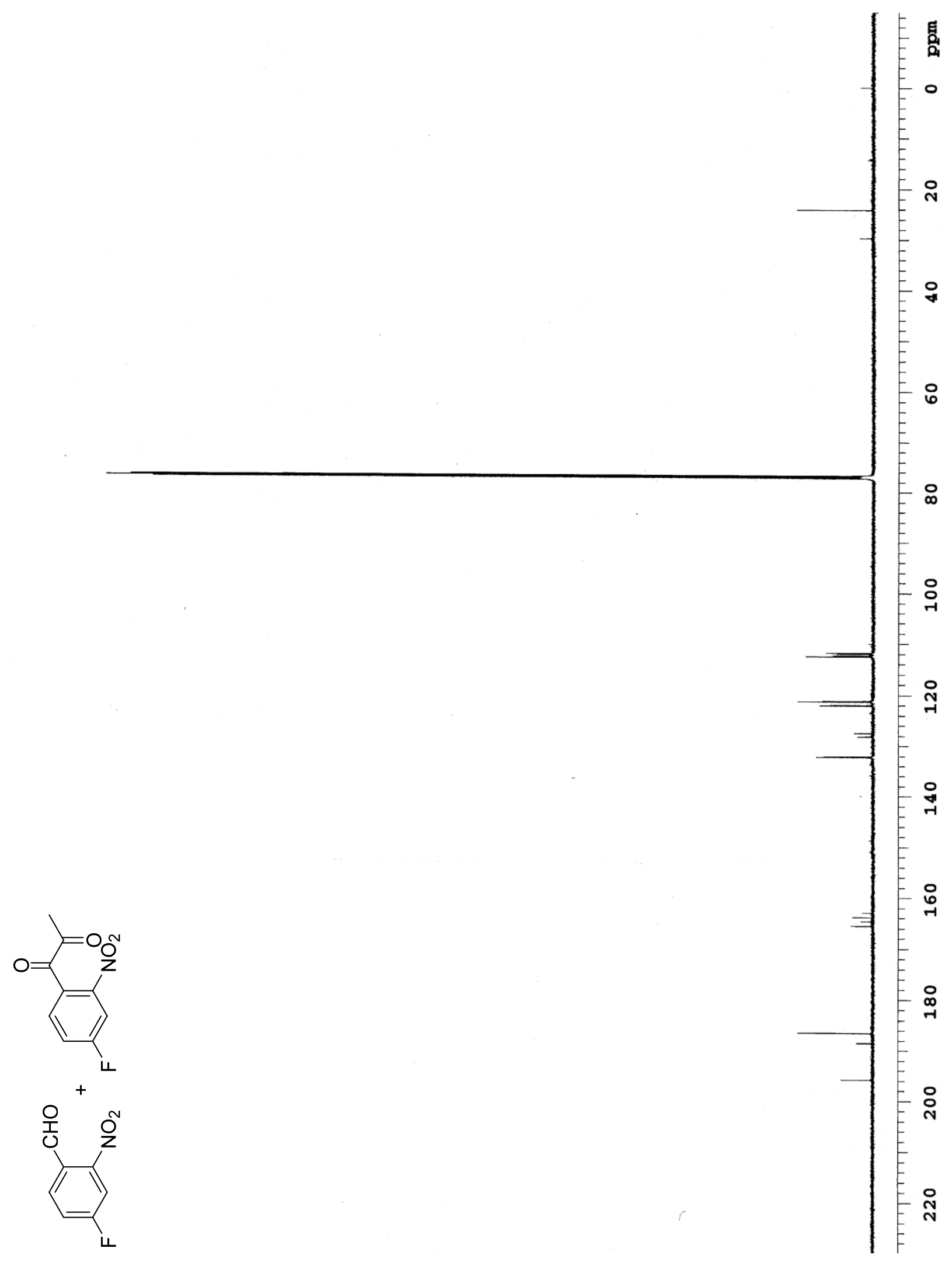

Figure 90: ${ }^{13} \mathrm{C}$ NMR of 4-fluoro-2-nitrobenzaldehyde (259) and

1-(4-fluoro-2-nitrophenyl)-1,2-propanedione (260) 


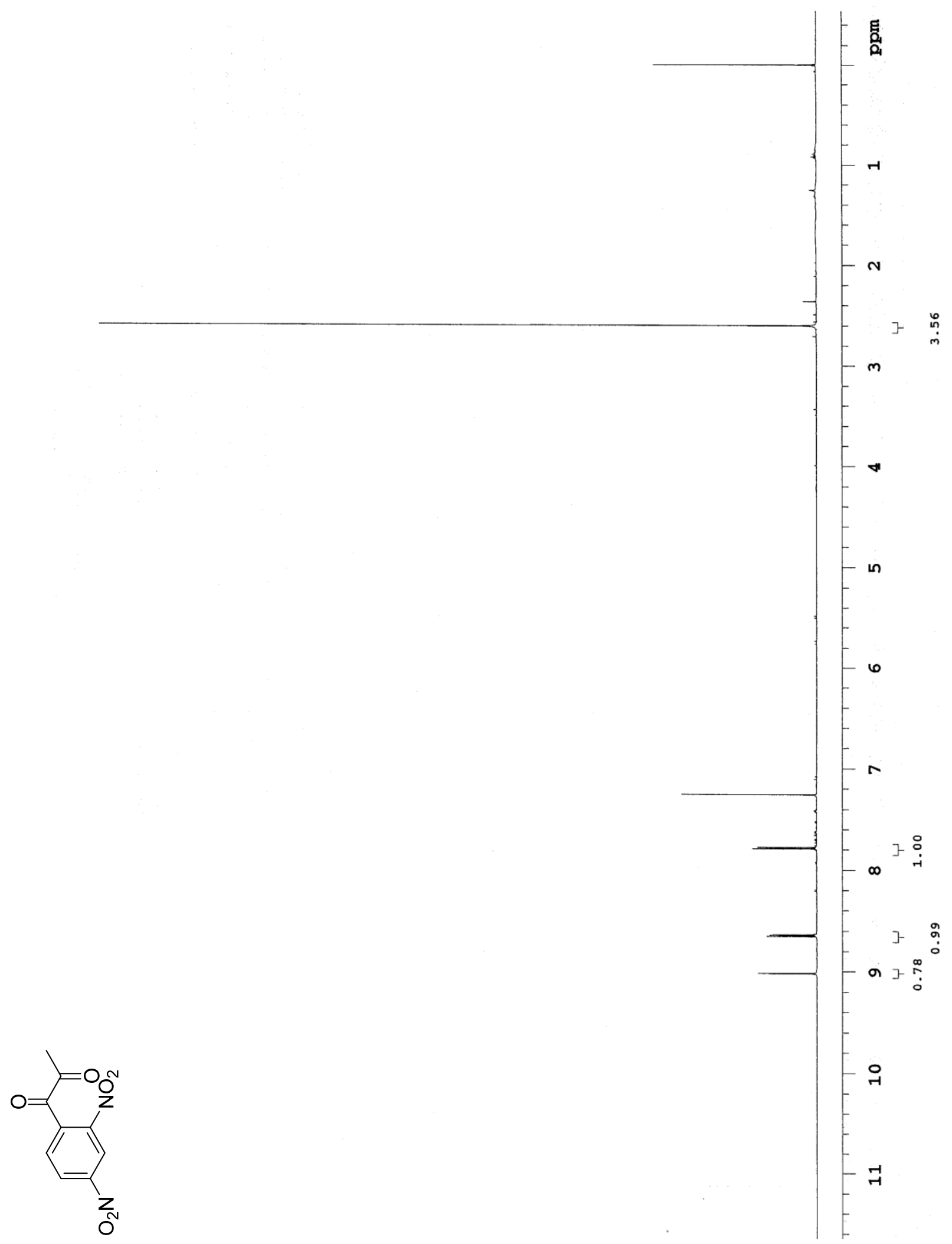

Figure 91: ${ }^{1} \mathrm{H}$ NMR of 4-fluoro-1-(1,1-dimethoxymethyl)-2-Nitrobenzene (263) 


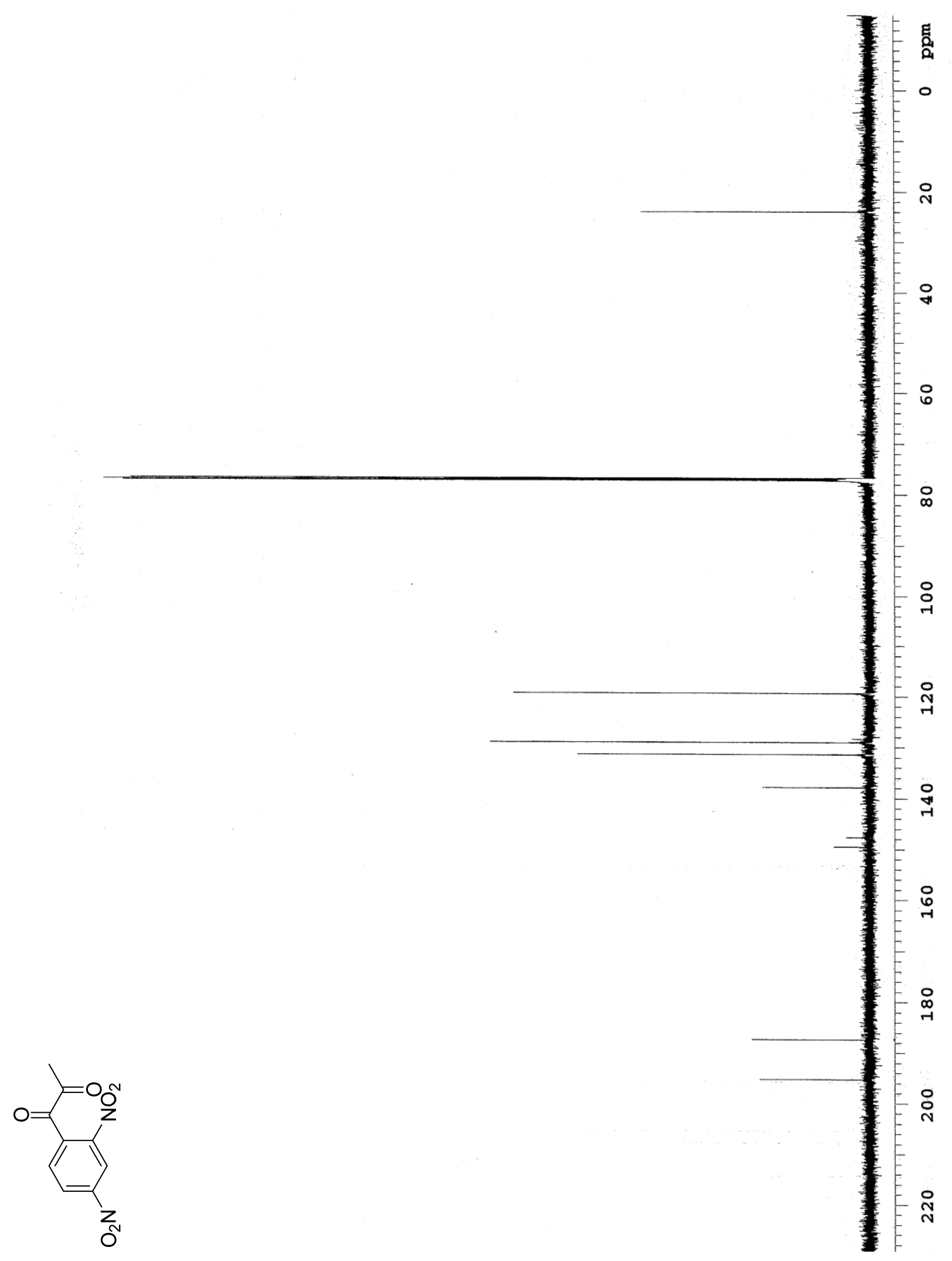

Figure 92: ${ }^{13} \mathrm{C}$ NMR of 4-fluoro-1-(1,1-dimethoxymethyl)-2-nitrobenzene (263) 


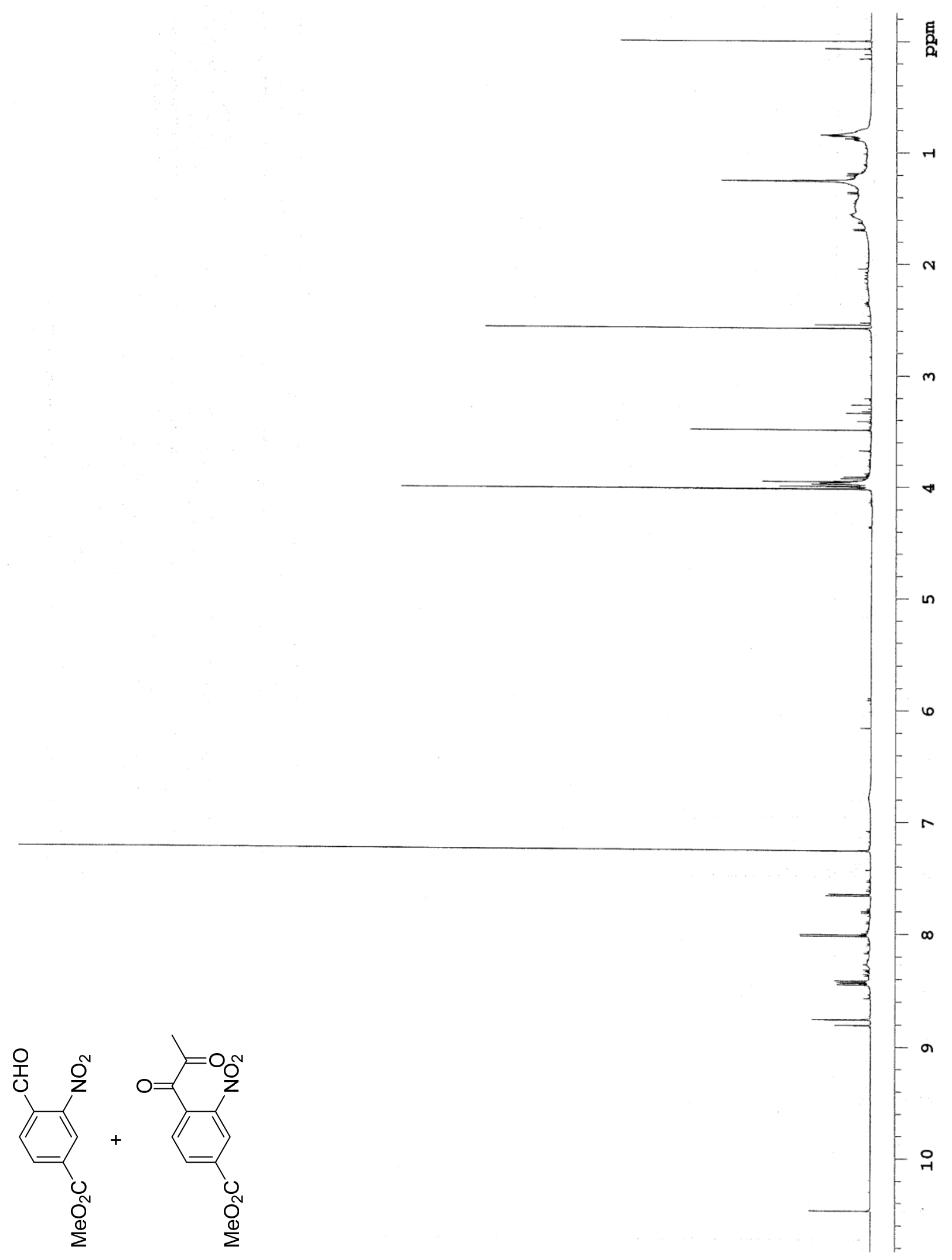

Figure 93: ${ }^{1} \mathrm{H}$ NMR of 4-carbomethoxy-2-nitrobenzaldehyde (266) and 1-(4-carbomethoxy-2-nitrophenyl)-1,2-propanedione (267) 


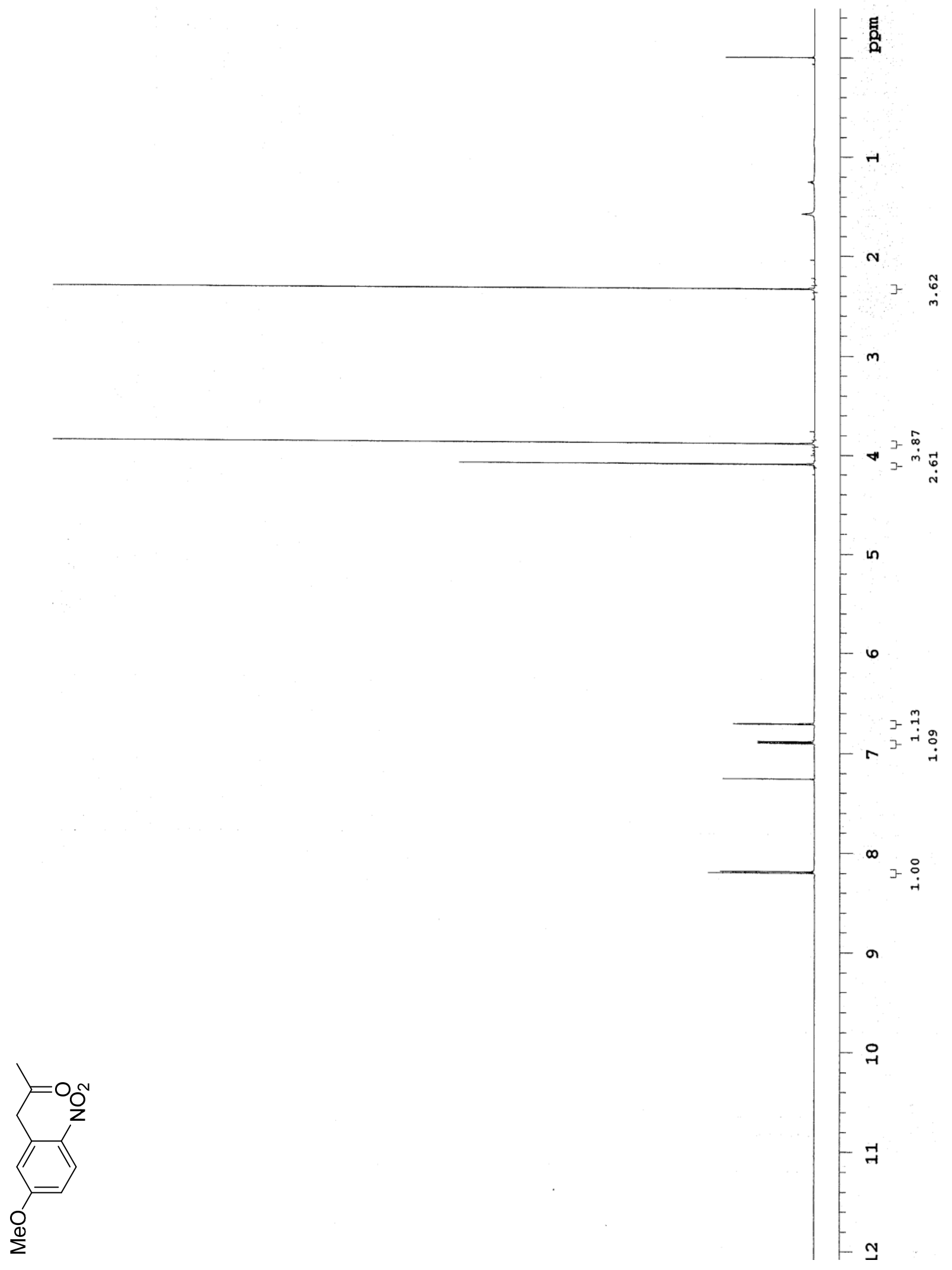

Figure 94: ${ }^{1} \mathrm{H}$ NMR of 1-(5-methoxy-2-nitrophenyl)-2-propanone (269) 


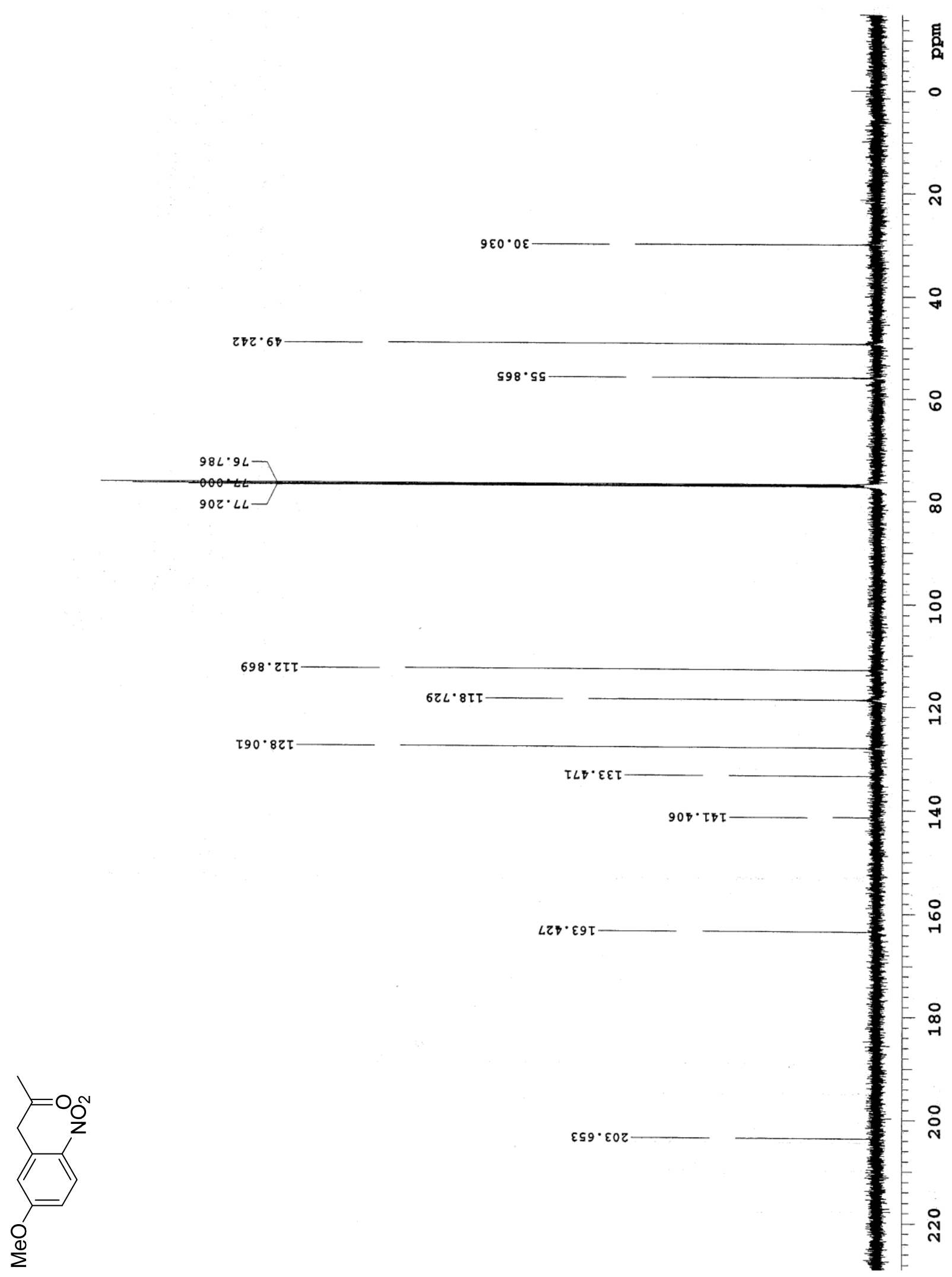

Figure 95: ${ }^{13} \mathrm{C}$ NMR of 1-(5-methoxy-2-nitrophenyl)-2-propanone (269) 


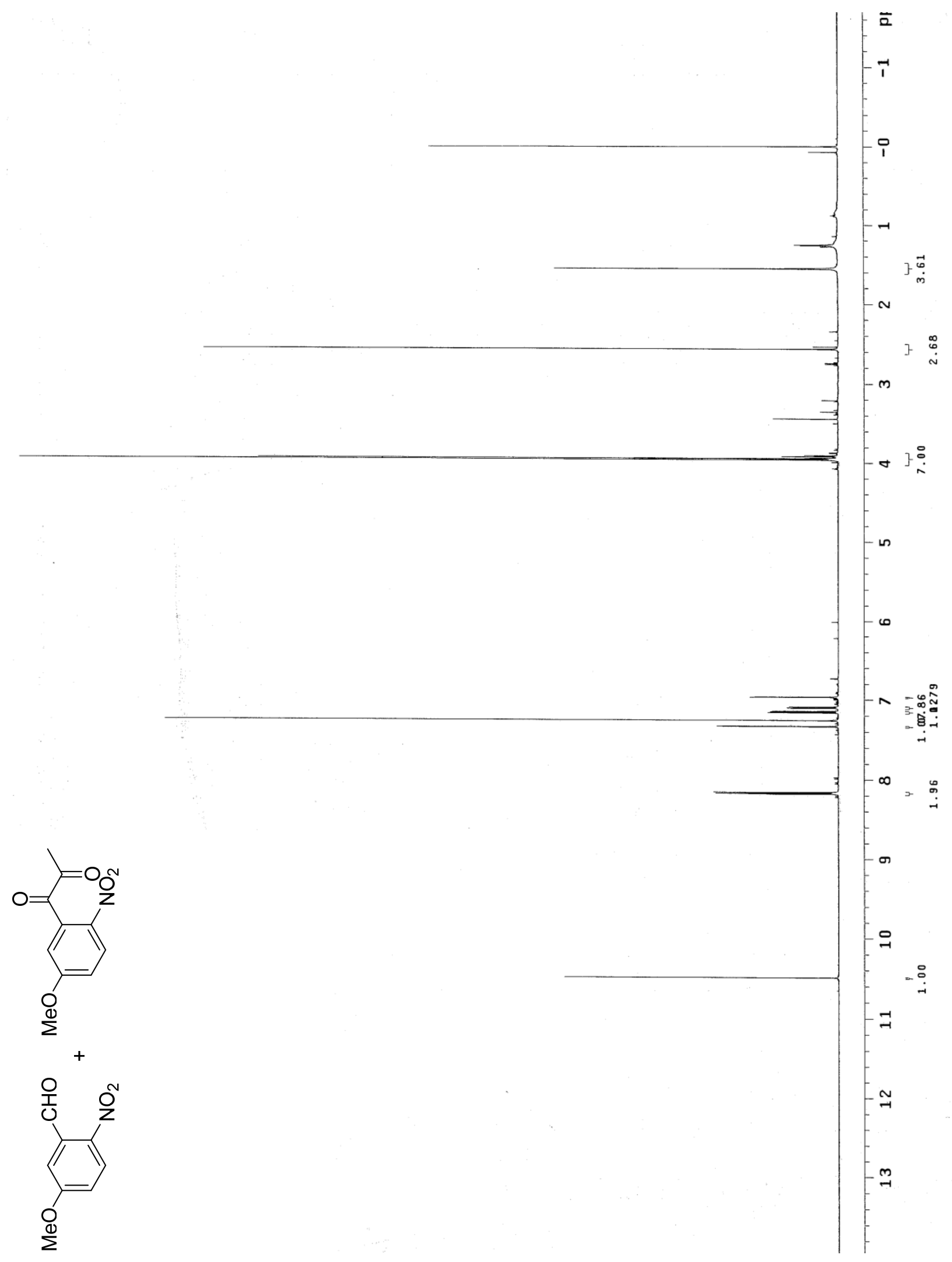

Figure 96: ${ }^{1} \mathrm{H}$ NMR of 5-methoxy-2-nitro-benzaldehyde (270) and

1-(5-methoxy-2-nitrophenyl)-1,2-propanedione (271) 


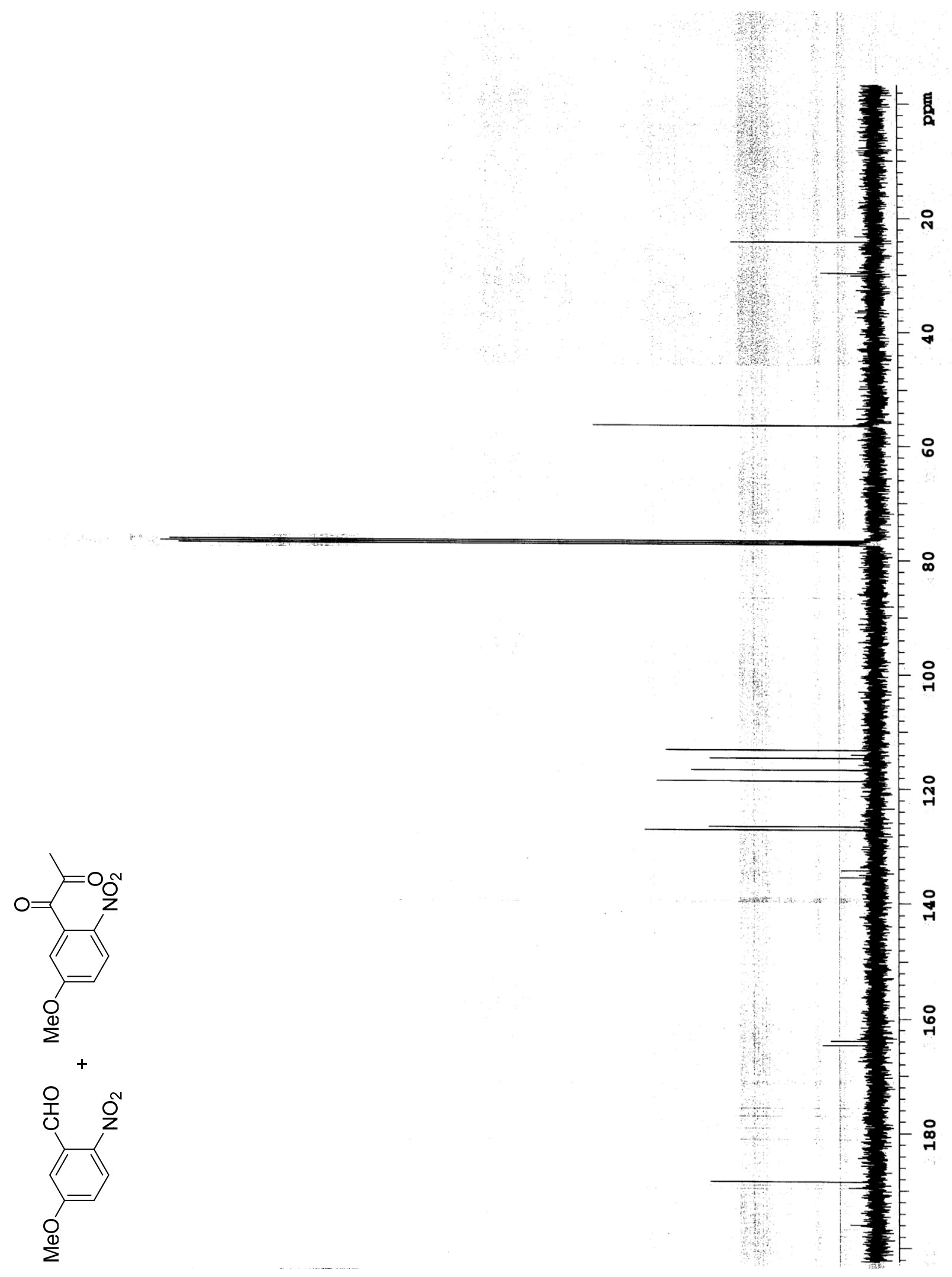

Figure 97: ${ }^{13} \mathrm{C}$ NMR of 5-methoxy-2-nitro-benzaldehyde (270) and

1-(5-methoxy-2-nitrophenyl)-1,2-propanedione (271) 


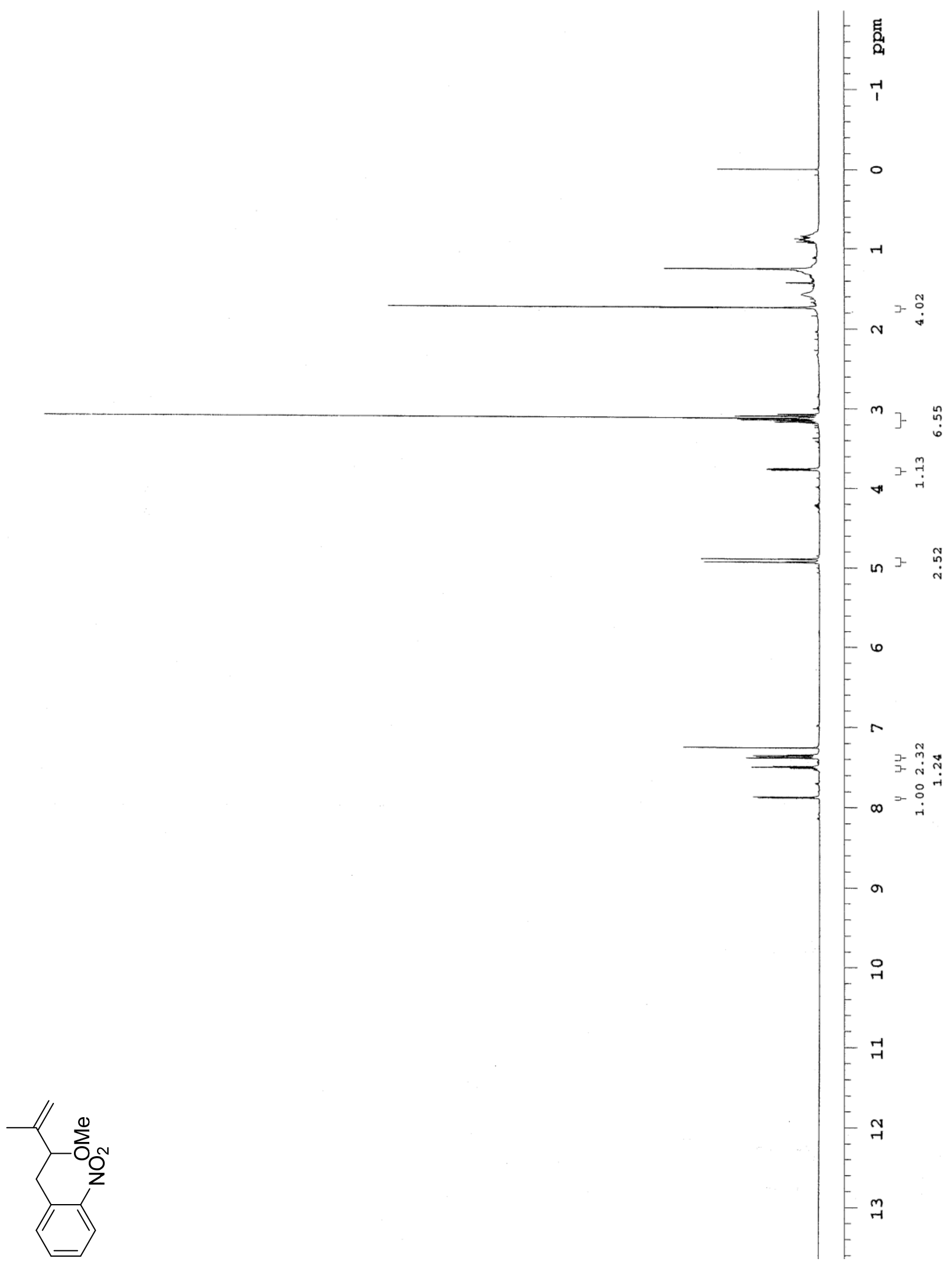

Figure 98: ${ }^{1} \mathrm{H}$ NMR of 4-(2-nitrophenyl)-3-methoxy-2-methyl-1-butene (277) 


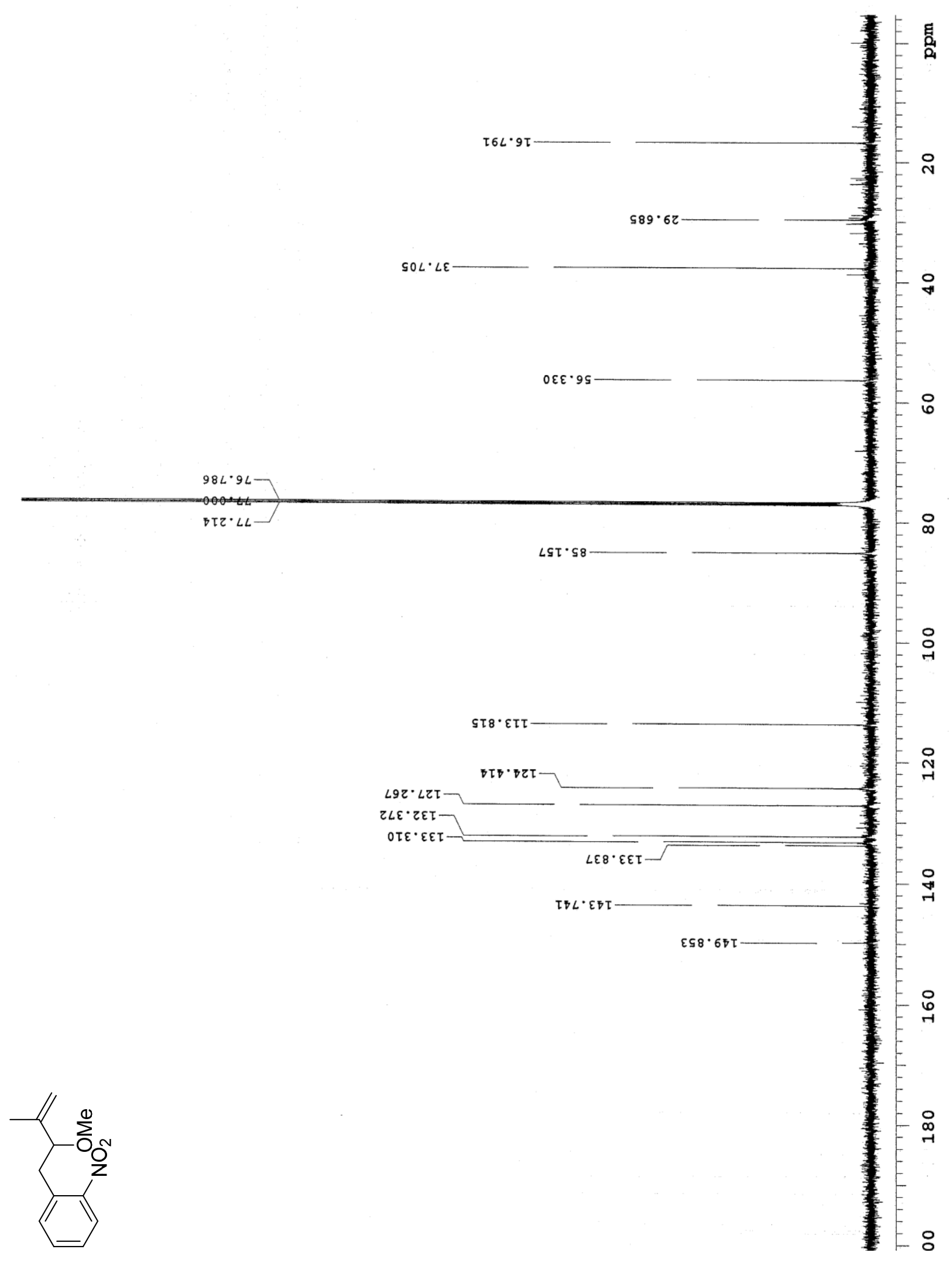

Figure 99: ${ }^{13} \mathrm{C}$ NMR of 4-(2-nitrophenyl)-3-methoxy-2-methyl-1-butene (277) 


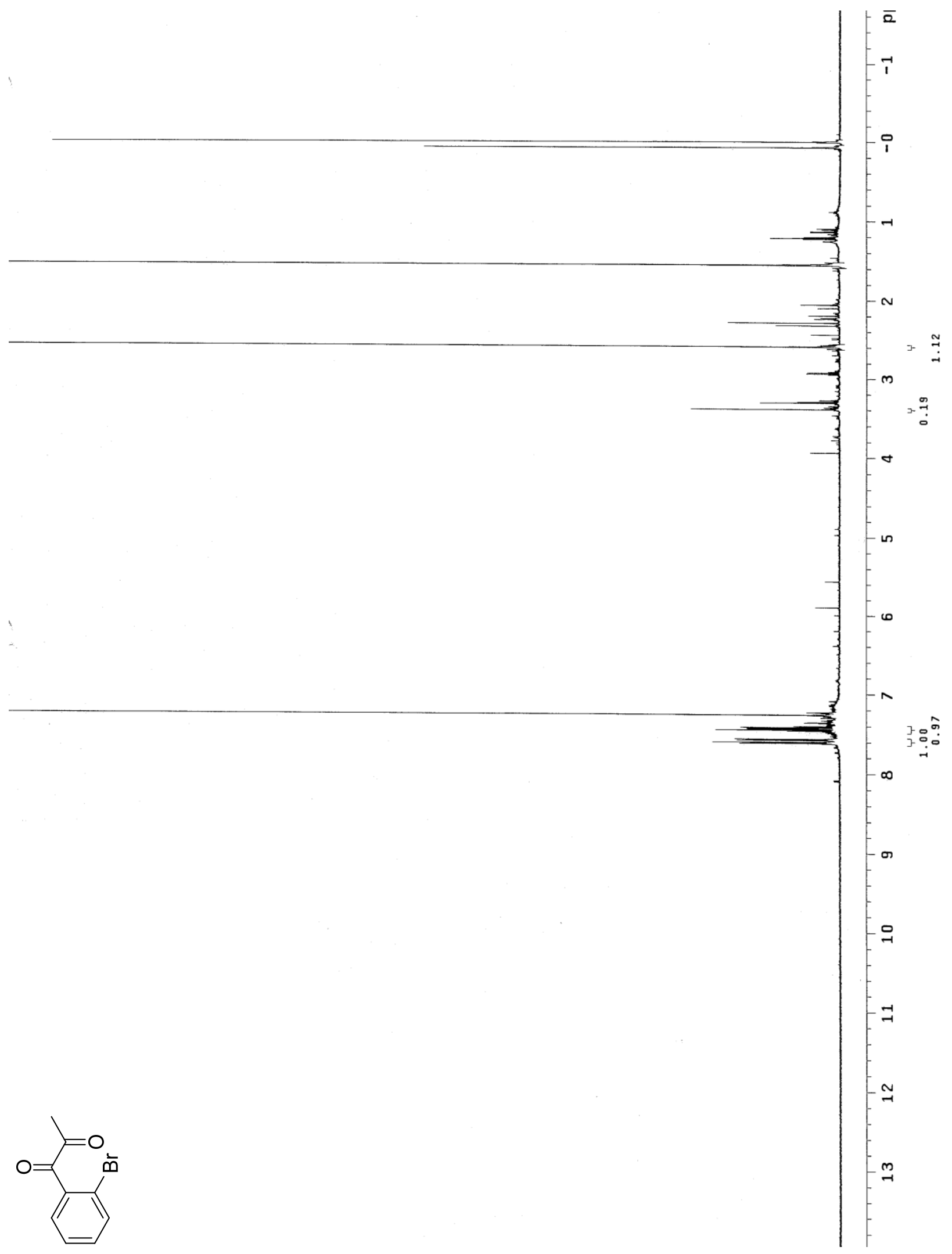

Figure 100: ${ }^{1} \mathrm{H}$ NMR of 1-(2-bromophenyl)-1,2-propanedione (282) 


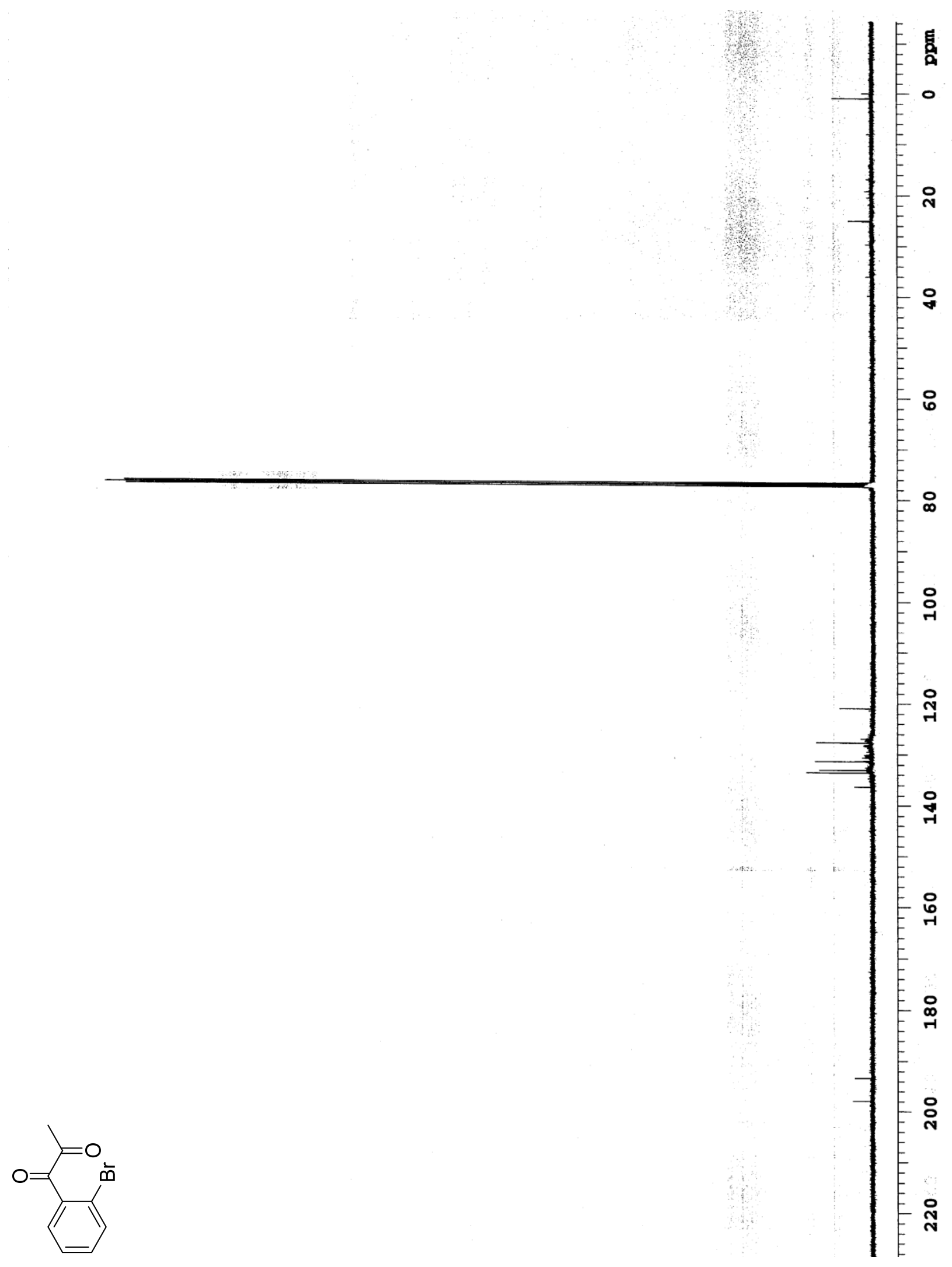

Figure 101: ${ }^{13} \mathrm{C}$ NMR of 1-(2-bromophenyl)-1,2-propanedione (282) 